\title{
DETERMINATION OF THE INITIATION AND PROPAGATION MECHANISM OF FIRESIDE CORROSION
}

\author{
by
}

\section{Bradley Scott Lutz}

B.S. in Materials Science and Engineering, Purdue University, 2009

M.S. in Materials Science and Engineering, University of Pittsburgh, 2012

Submitted to the Graduate Faculty of

The Swanson School of Engineering in partial fulfillment

of the requirements for the degree of

Ph.D. in Materials Science and Engineering

University of Pittsburgh 
UNIVERSITY OF PITTSBURGH

SWANSON SCHOOL OF ENGINEERING

This dissertation was presented

by

Bradley Scott Lutz

It was defended on

December 8, 2014

and approved by

B. Gleeson, Ph.D., Harry S. Tack Chair Professor and Chairman Department of Mechanical Engineering and Materials Science

J.K. Lee, Ph.D., Associate Professor

Department of Mechanical Engineering and Materials Science

G.R. Holcomb, Ph.D., Materials Research Engineer National Energy Technology Laboratory, Albany Oregon

Dissertation Co-Director: F.S. Pettit, Ph.D., Professor Emeritus Department of Mechanical Engineering and Materials Science

Dissertation Director: G.H. Meier, Ph.D., William Kepler Whiteford Professor Department of Mechanical Engineering and Materials Science 


\title{
DETERMINATION OF THE INITIATION AND PROPAGATION MECHANISM OF FIRESIDE CORROSION
}

\author{
Bradley Scott Lutz, Ph.D. \\ University of Pittsburgh, 2015
}

A variety of deposit compositions were examined in short-term laboratory tests with the aim of determining the corrosion mechanisms of fireside corrosion for a range of chromiaforming alloys in various combustion systems. The deposits formed in boilers are complex, and despite decades of study, the propagation mechanism of fireside corrosion is not well understood. Alkali iron trisulfates, which are stabilized by $\mathrm{SO}_{3}$ in the gas atmosphere, have been believed to be the major corrosive species for many years. The propagation mechanism for fireside corrosion was investigated using T92 (a typical ferritic boiler steel) and a model austenitic Fe-Ni-Cr alloy and synthetic coal ash deposits. The metal loss, corrosion product morphologies, and compositions were carefully characterized in order to define a propagation mechanism. The corrosive species responsible for degradation was a $\left(\mathrm{Na}, \mathrm{K}_{2} \mathrm{SO}_{4}-\mathrm{Fe}_{2}\left(\mathrm{SO}_{4}\right)_{3}\right.$ solution and not alkali iron trisulfates, which is contrary to what has been believed for decades. The formation of the liquid deposit is similar to Type II hot corrosion of gas turbine engines. The mechanism is a synergistic dissolution process similar to that which can occur for hot corrosion as well. Simultaneous basic and acidic dissolution of protective $\mathrm{Cr}_{2} \mathrm{O}_{3}$ and $\mathrm{Fe}_{2} \mathrm{O}_{3}$ disrupts protective oxide formation and locally produces negative solubility gradients at the oxide/salt interface. The dissolved $\mathrm{Fe}_{2} \mathrm{O}_{3}$ and $\mathrm{Cr}_{2} \mathrm{O}_{3}$ reprecipitate where there is lower solubility, creating the observed corrosion products. The effect of the deposit composition, gas atmosphere 
composition, alloy composition, temperature, and deposit thickness were examined with respect to the proposed fireside corrosion mechanism. These measurements were found to be consistent with the proposed mechanism based on synergistic fluxing. 
TABLE OF CONTENTS

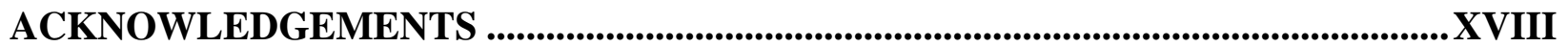

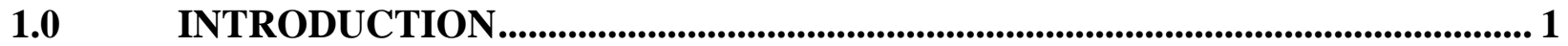

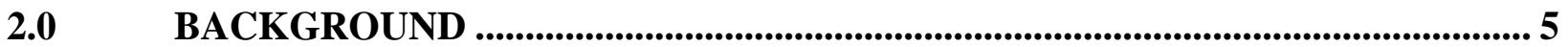

2.1 FORMATION OF DEPOSITS ON BOILER TUBES .......................................... 5

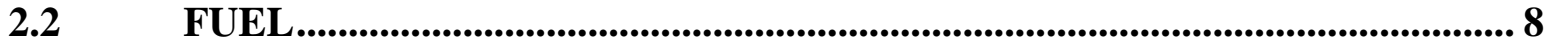

2.2.1 Coal Ash Composition ..................................................................................... 9

$2.3 \quad$ FIRESIDE CORROSION ................................................................................. 16

2.3.1 Sulfur and Sulfates...................................................................................... 18

2.3.1.1 Pyrosulfates....................................................................................................... 24

2.3.1.2 Alkali Iron Trisulfates .......................................................................... 25

2.3.2 Mechanism of Corrosion ................................................................................... 27

2.3.2.1 Gas-Phase Oxidation.................................................................................. 27

2.3.2.2 Liquid-Phase Corrosion ....................................................................... 30

2.3.3 Alloys for Use in Boilers ................................................................................ 38

2.3.3.1 Alumina Forming Austenitic (AFA) Stainless Steel Alloys.............. 42

2.3.4 Comparing Oxy-Fired to Air Fired Gas Environments .............................. 47

$2.4 \quad$ SODIUM SULFATE-INDUCED HOT CORROSION ................................... 52

2.4.1 Stages of Corrosion ................................................................................................. 53 
2.4.1.1 Initiation Stage ................................................................................................ 55

2.4.1.2 Propagation Stage ........................................................................................... 58

2.4.2 Type II Hot Corrosion ........................................................................................ 64

2.4.2.1 Gas-Phase Induced Acidic Fluxing........................................................... 64

2.4.3 Synergistic Dissolution............................................................................ 72

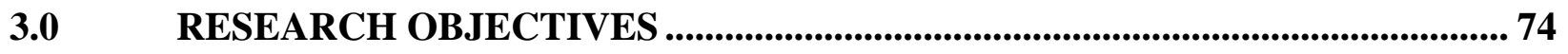

4.0 EXPERIMENTAL PROCEDURE ...................................................................... 78

4.1 MATERIALS PREPARATION_.................................................................. 78

4.2 TEST PROCEDURE ............................................................................................. 81

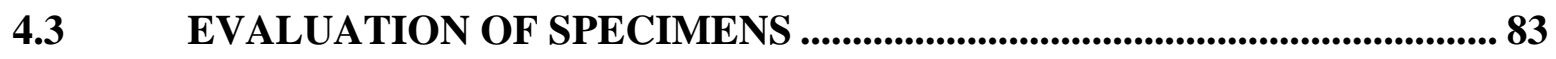

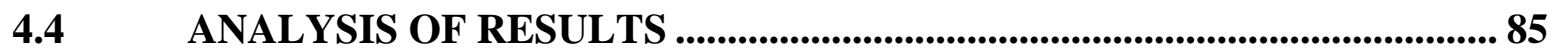

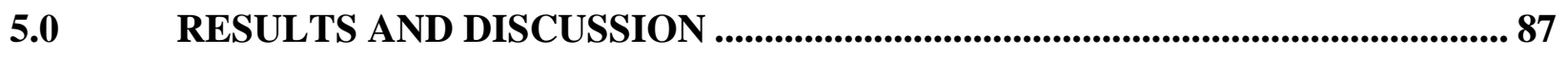

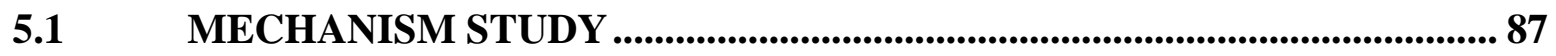

5.1.1 M1 Results ......................................................................................................... 87

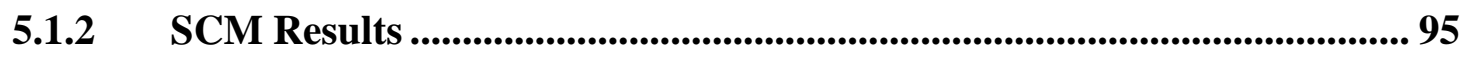

5.1.3 Proposed Fireside Corrosion Mechanism..................................................... 103

5.2 DEPOSIT COMPOSITION EFFECT.............................................................. 126

5.2.1 Alumina Additions ............................................................................................. 128

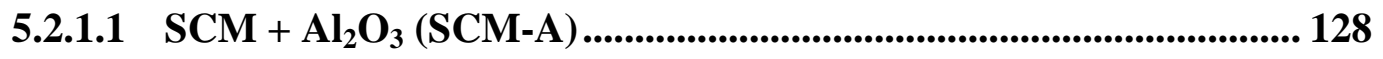

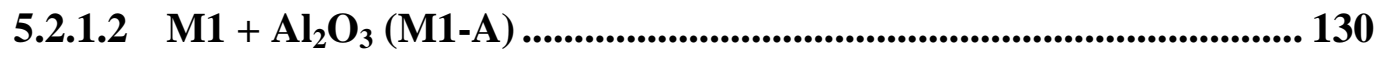

5.2.2 Calcia Additions ................................................................................................... 133

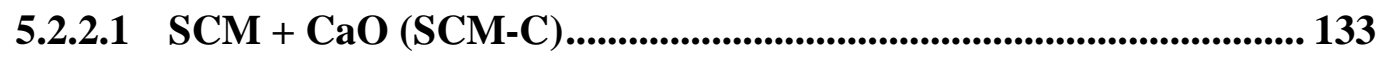

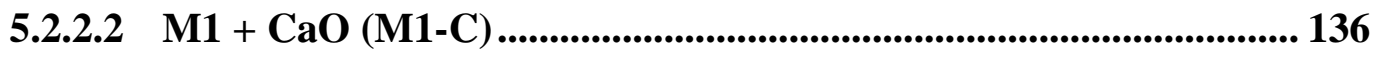


5.2.3 Silica Additions............................................................................................. 136

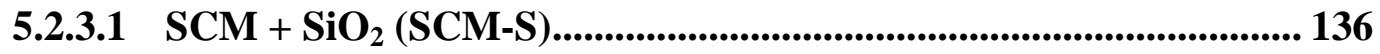

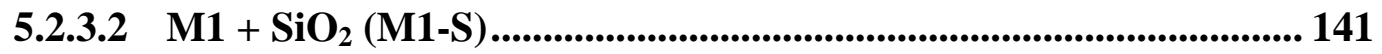

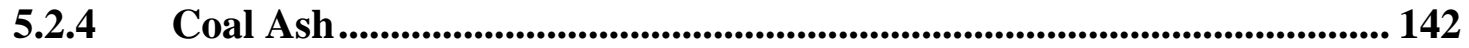

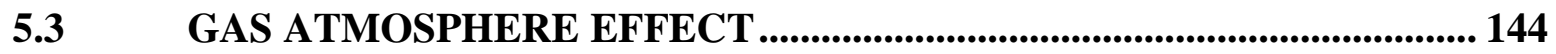

5.3.1 $\mathrm{SO}_{2}$ Concentration Effect ........................................................................... 144

5.4 ALLOY COMPOSITION EFFECT ................................................................ 150

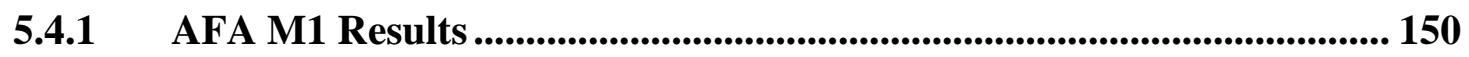

5.4.2 OC4 and OC8 SCM Results....................................................................... 154

5.4.3 OCS and OCT SCM Results..................................................................... 161

5.4.4 Effect of Slowly Changing Microstructure............................................... 170

$5.5 \quad$ TEMPERATURE EFFECT …........................................................................... 188

5.5.1 Effect of Deposit Composition on the Maximum Temperature ............ 192

5.5.2 Effect of Alloy Composition on the Maximum Temperature................. 194

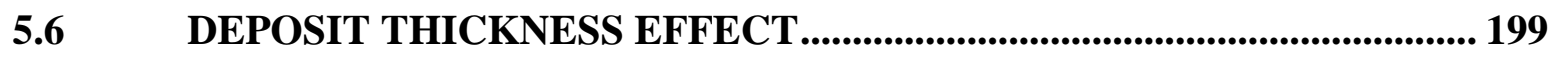

5.6.1 Powder-Crucible Method................................................................................... 200

5.6.2 Slurry Method ....................................................................................................... 204

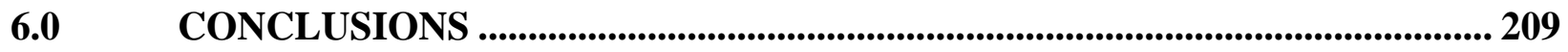

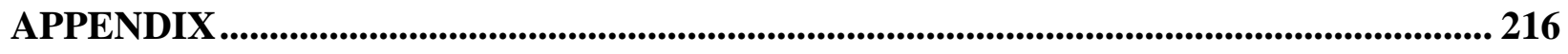

OXY-FUEL COMBUSTION ATMOSPHERE ................................................................. 216

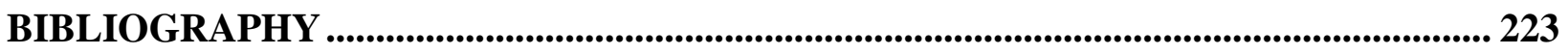




\section{LIST OF TABLES}

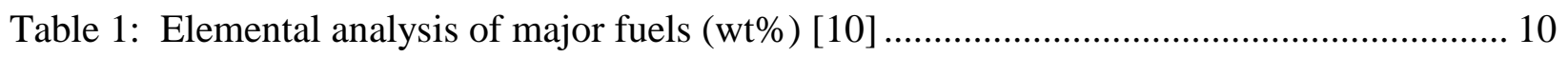

Table 2: Occurance of minerals in coal [14] ......................................................................... 12

Table 3: Composition of Typical Eastern U.S. Coals [17] ........................................................ 13

Table 4: Composition of Typical Western U.S. Coals [17] ........................................................... 13

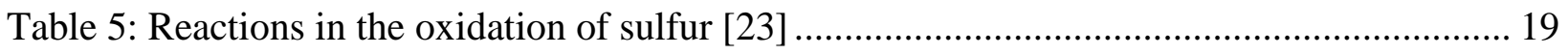

Table 6: Average Gas Concentrations Measured in Oxidizing Zone for Different Coals [28-29]22

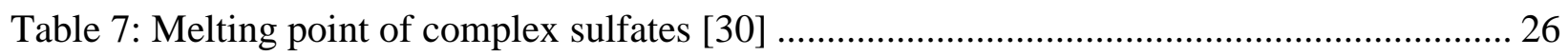

Table 8: Composition of AFA alloys used in this study (wt\%) .................................................. 47

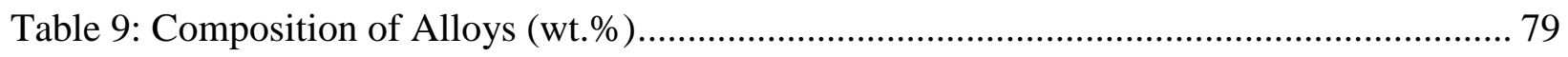

Table 10: Equilibrium $\mathrm{SO}_{3}$ partial pressures at experimental temperatures and gas atmospheres 82

Table 11: Minimum $\mathrm{Na}_{2} \mathrm{O}$ activities and maximum pso3 partial pressures for $\mathrm{SiO}_{2}$ dissolution [86] 139

Table 12: Volume Fraction (\%) of Laves Phase and NbC in OCS and OCT specimens before and

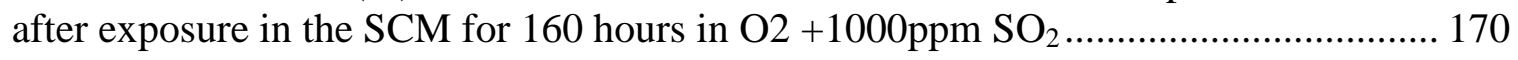

Table 13: OC8 Cr content and Cr activity change with temperature [87] ................................. 181 


\section{LIST OF FIGURES}

Figure 1: Schematic diagram of oxy-fuel combustion..................................................... 2

Figure 2: Rate of change of heat flux with accumulation of slag[7] ...................................... 6

Figure 3: Deposits and corrosion area for typical reheater tube[3] ....................................... 8

Figure 4: Calculated flue gas composition upon coal combustion[10].................................. 9

Figure 5: Mineral matter transformation mechanism [13] .................................................. 15

Figure 6: Calculated molar quantity of pure compounds of condensed phases in equilibrium with the flue gas upon combustion of $100 \mathrm{~g}$ of the coal shown in Table 1 [10] ...................... 16

Figure 7: Fireside corrosion regimes in coal-fired boilers [19] ........................................... 18

Figure 8: Formation of $\mathrm{SO}_{3}$ in thin stabilized flame of $\mathrm{H}_{2} \mathrm{~S}-\mathrm{O}_{2}-\mathrm{N}_{2}$ [25] ............................. 21

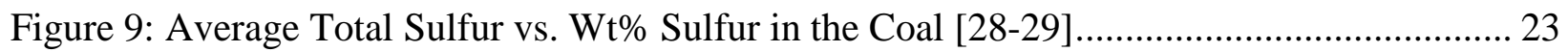

Figure 10: Melting points in the system $\mathrm{Na}_{2} \mathrm{SO}_{4}-\mathrm{SO}_{3}$ and $\mathrm{K}_{2} \mathrm{SO}_{4}-\mathrm{SO}_{3}$ [33] ........................... 24

Figure 11: The iron-oxygen phase diagram [35] .......................................................... 28

Figure 12: The general temperature distribution through a superheater tube, the oxide, and the

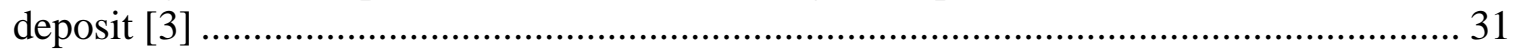

Figure 13: Mechanism of fireside corrosion of steel surfaces by removal of oxide film to form $\mathrm{K}_{3}$

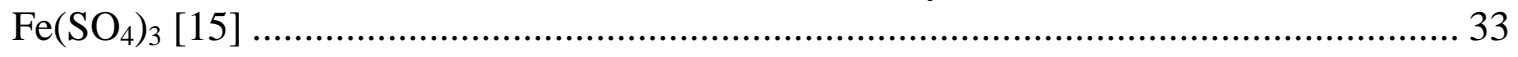

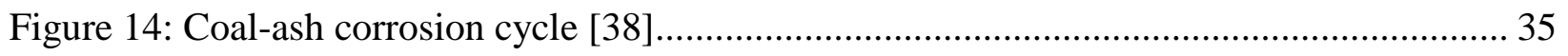

Figure 15: Oxidation kinetics of $\mathrm{Fe}-10 \mathrm{Al}$ Alloy exposed to $\mathrm{O}_{2}-0.5 \%\left(\mathrm{SO}_{2}+\mathrm{SO}_{3}\right)$ at $650^{\circ} \mathrm{C}$ : (a) $\mathrm{Na}_{2} \mathrm{SO}_{4}-\mathrm{K}_{2} \mathrm{SO}_{4}$, (b) $\mathrm{Na}_{2} \mathrm{SO}_{4}$ alone, and (c) $\mathrm{K}_{2} \mathrm{SO}_{4}$ alone [41] .................................... 37

Figure 16: $\mathrm{SO}_{3}$ levels required to stabilize eutectic melts: (a) $\mathrm{Na}_{2} \mathrm{SO}_{4}$-iron trisulfates and (b)

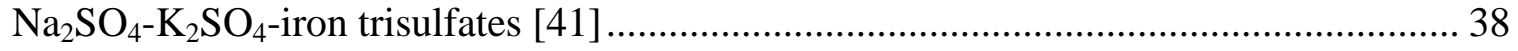


Figure 17: Evolution of ferritic steels for boilers [42]

Figure 18: Allowable stress for various classes of alloys [42] ………....................................... 41

Figure 19: Phase diagram for Fe-Cr-Al-20Ni-1Nb-1Mo-0.1C showing the limitations of additions of $\mathrm{Cr}$ and $\mathrm{Al}$ to avoid formation of bcc and sigma phases, predicted by thermodynamic calculation. [45] ...................................................................................... 43

Figure 20: Microstructure of typical $\gamma^{\prime}-\mathrm{Ni}_{3} \mathrm{Al}$ strengthened AFA alloy [51] ................................. 46

Figure 21: Isothermal mass change versus time for IN-738. The data consists of an initiation stage and a propagation stage with large weight changes (dashed line gives arbitrary end of initiation stage) [35] ................................................................................................ 54

Figure 22: Thermodynamic stability diagram for the Na-O-S system at constant temperature [35] 55

Figure 23: Isothermal stability diagram of the Cr-O-S System superimposed onto the $\mathrm{Na}_{2} \mathrm{SO}_{4}$ portion of the Na-S-O stability diagram for $\mathrm{T}=927^{\circ} \mathrm{C}[65]$............................................. 59

Figure 24: Measured oxide solubilities in $\mathrm{Na}_{2} \mathrm{SO}_{4}$ at $927^{\circ} \mathrm{C}$ and $1 \mathrm{~atm} \mathrm{O}_{2}[65] \ldots \ldots \ldots \ldots \ldots \ldots \ldots \ldots \ldots . . . . . . . . . . . .60$

Figure 25: Conditions in the $\mathrm{Na}_{2} \mathrm{SO}_{4}$ salt the satisfy the Rapp-Goto Criterion [73] ....................... 63

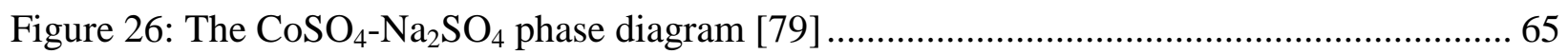

Figure 27: The $\mathrm{SO}_{3}$ partial pressure required to form various species [39].................................. 67

Figure 28: Solubility diagrams of $\mathrm{Fe}_{2} \mathrm{O}_{3}$ and $\mathrm{Cr}_{2} \mathrm{O}_{3}$ in fused $\mathrm{Na}_{2} \mathrm{SO}_{4}$ at $1200 \mathrm{~K}$ and 1 atm $\mathrm{O}_{2}$ [80] 73

Figure 29: Schematic of horizontal tube furnace apparatus for fireside corrosion tests................ 81

Figure 30: Modified quartz rod for crucible fireside corrosion tests ............................................ 82

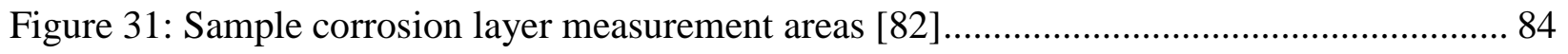

Figure 32: Macroscopic images of $\mathrm{T} 92$ and FeNiCr exposed at $700^{\circ} \mathrm{C}$ in $\mathrm{M} 1$ deposit in $\mathrm{O}_{2}+$

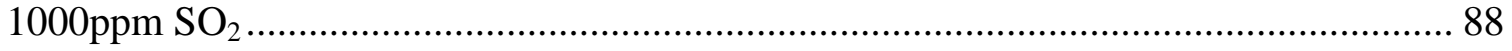

Figure 33: Kinetics of alloys exposed at $700^{\circ} \mathrm{C}$ with the $\mathrm{M} 1$ in $\mathrm{O}_{2}+1000 \mathrm{ppm}^{\mathrm{SO}} \mathrm{O}_{2}$.................. 89

Figure 34: Metal loss of FeNiCr and $\mathrm{T} 92$ exposed at $700^{\circ} \mathrm{C}$ with the $\mathrm{M} 1$ deposit in $\mathrm{O}_{2}+$

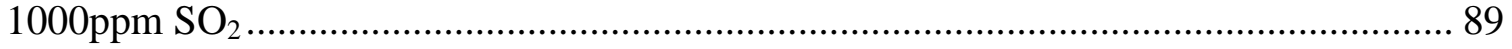


Figure 35: Cross-sectional micrographs of the non-deposit zone of T92 tested at $700^{\circ} \mathrm{C}$ with the M1 deposit in a crucible in $\mathrm{O}_{2}+1000 \mathrm{ppm} \mathrm{SO}_{2}$ for 20, 40, 80, and 160 hours 90

Figure 36: Cross-sectional micrographs of the thin-deposit zone of $\mathrm{T} 92$ tested at $700^{\circ} \mathrm{C}$ with the M1 deposit in a crucible in $\mathrm{O}_{2}+1000 \mathrm{ppm} \mathrm{SO}_{2}$ for 20, 40, 80, and 160 hours 91

Figure 37: Cross-sectional micrographs of the thick-deposit zone of T92 tested at $700^{\circ} \mathrm{C}$ with the $\mathrm{M} 1$ deposit in a crucible in $\mathrm{O}_{2}+1000 \mathrm{ppm} \mathrm{SO}_{2}$ for 20, 40, 80, and 160 hours 91

Figure 38: Cross-sectional micrographs of the no deposit zone of FeNiCr tested at $700^{\circ} \mathrm{C}$ with the $\mathrm{M} 1$ deposit in a crucible in $\mathrm{O}_{2}+1000$ ppm SO2 for 20, 40, 80, and 160 hours......... 92

Figure 39: Cross-sectional micrographs of the thin deposit zone of FeNiCr tested at $700^{\circ} \mathrm{C}$ with the $\mathrm{M} 1$ deposit in a crucible in $\mathrm{O}_{2}+1000 \mathrm{ppm} \mathrm{SO}_{2}$ for 20, 40, 80, and 160 hours ......... 93

Figure 40: Cross-sectional micrographs of the thick deposit zone of FeNiCr tested at $700^{\circ} \mathrm{C}$ with the $\mathrm{M} 1$ deposit in a crucible in $\mathrm{O}_{2}+1000 \mathrm{ppm} \mathrm{SO}_{2}$ for 20, 40, 80, and 160 hours ......... 93

Figure 41: Macroscopic images of T92 and FeNiCr exposed at $700^{\circ} \mathrm{C}$ with the standard corrosion mix powder in a crucible in $\mathrm{O}_{2}+1000 \mathrm{ppm} \mathrm{SO}_{2}$ for 20-160 hours 95

Figure 42: Kinetics of FeNiCr and T92 oxidized at $700^{\circ} \mathrm{C}$ in $\mathrm{O}_{2}+1000 \mathrm{ppm} \mathrm{SO}_{2}$ with the standard corrosion mix powder in a crucible............................................................ 95

Figure 43: Metal loss of FeNiCr and T92 oxidized at $70{ }^{\circ} \mathrm{C}$ in $\mathrm{O}_{2}+1000 \mathrm{ppm} \mathrm{SO}_{2}$ with the standard corrosion mix powder in a crucible (missing bars means minimal or no metal loss) 96

Figure 44: Cross-sectional micrographs of the non-deposit zone of T92 tested at $700^{\circ} \mathrm{C}$ with the standard corrosion mix powder in a crucible in $\mathrm{O}_{2}+1000 \mathrm{ppm} \mathrm{SO}_{2}$ for 20, 40, 80, and 160 hours. 97

Figure 45: Cross-sectional micrographs of the thin deposit zone of T92 tested at $700^{\circ} \mathrm{C}$ with the standard corrosion mix powder in a crucible in $\mathrm{O}_{2}+1000 \mathrm{ppm} \mathrm{SO}_{2}$ for 20,40, 80, and 160 hours 98

Figure 46: Cross-sectional micrographs of the thick deposit zone of $\mathrm{T} 92$ tested at $700^{\circ} \mathrm{C}$ with the standard corrosion mix powder in a crucible in $\mathrm{O}_{2}+1000 \mathrm{ppm} \mathrm{SO}_{2}$ for 20,40, 80, and 160 hours. 98

Figure 47: Surface SEM image of T92 showing corrosion boundary 99

Figure 48: Cross-sectional micrographs of the non-deposit zone of FeNiCr tested at $700^{\circ} \mathrm{C}$ with the standard corrosion mix powder in a crucible in $\mathrm{O}_{2}+1000 \mathrm{ppm} \mathrm{SO}$ for 20, 40, 80, and 160 hours. 100 
Figure 49: Cross-sectional micrographs of thin deposit zone of FeNiCr tested at $700^{\circ} \mathrm{C}$ with the standard corrosion mix powder in a crucible in $\mathrm{O}_{2}+1000 \mathrm{ppm} \mathrm{SO}_{2}$ for 20,40, 80, and 160 hours. 100

Figure 50: Cross-sectional micrographs of the thick deposit zone of FeNiCr tested at $700^{\circ} \mathrm{C}$ with the standard corrosion mix powder in a crucible in $\mathrm{O}_{2}+1000 \mathrm{ppm} \mathrm{SO}_{2}$ for 20,40, 80, and 160 hours. 101

Figure 51: Surface SEM image of FeNiCr showing corrosion boundary 102

Figure 52: X-ray diffraction scan of SCM powder exposed at $700^{\circ} \mathrm{C}$ in $\mathrm{O}_{2}+2500 \mathrm{ppm} \mathrm{SO}_{2} \ldots 103$

Figure 53: Comparison of T92 and FeNiCr exposed in the M1 and SCM deposits at $700^{\circ} \mathrm{C}$ in $\mathrm{O}_{2}$ +1000 ppm SO $\mathrm{SO}_{2}$ for 160 hours .......................................................................... 105

Figure 54: $\mathrm{K}_{2} \mathrm{SO}_{4}-\mathrm{Fe}_{2}\left(\mathrm{SO}_{4}\right)_{3}$ phase diagram [83] ...................................................... 106

Figure 55: Schematic of $\mathrm{SO}_{3}$ gradient at oxide/salt interface and $\mathrm{Fe}_{2} \mathrm{O}_{3}$ solubility curve for acidic fluxing. 108

Figure 56: Schematic of $\mathrm{SO}_{3}$ gradient at oxide/salt interface and $\mathrm{Cr}_{2} \mathrm{O}_{3}$ solubility curve for acidic fluxing. 109

Figure 57: Schematic and solubility curves demonstrating synergistic fluxing the repeating acidic and basic dissolution reactions. 111

Figure 58: Negative solubility gradients on the $\mathrm{Fe}_{2} \mathrm{O}_{3}$ and $\mathrm{Cr}_{2} \mathrm{O}_{3}$ solubility curves due to synergistic fluxing and schematic of reprecipitation process ................................... 112

Figure 59: Solubility of $\mathrm{Cr}_{2} \mathrm{O}_{3}$ in sulfate melts (top data at 963K) [84] ................................ 114

Figure 60: Schematic showing $\mathrm{SO}_{3}$ exchange reaction and migration through liquid salt......... 116

Figure 61: Macroscopic and microscopic SEM images of FeNiCr and T92 exposed at $700^{\circ} \mathrm{C}$ with $\mathrm{M} 1+30 \% \mathrm{Cr}_{2} \mathrm{O}_{3}$ powder deposit in $\mathrm{O}_{2}+1000 \mathrm{pppm} \mathrm{SO}_{2}$ for 160 hours. 119

Figure 62: Mass change and metal loss for T92 exposed at $700^{\circ} \mathrm{C}$ with the $\mathrm{M} 1$, SCM, and $\mathrm{M} 1+30 \% \mathrm{Cr}_{2} \mathrm{O}_{3}$ powder deposits in a crucible in $\mathrm{O}_{2}+1000 \mathrm{ppm} \mathrm{SO}_{2}$ for 160 hours .... 120

Figure 63: Mass change and metal loss for FeNiCr exposed at $700^{\circ} \mathrm{C}$ with the M1, SCM, and $\mathrm{M} 1+30 \% \mathrm{Cr}_{2} \mathrm{O}_{3}$ powder deposits in a crucible in $\mathrm{O}_{2}+1000 \mathrm{ppm} \mathrm{SO}_{2}$ for 160 hours ..... 120

Figure 64: Macroscopic and cross-sectional SEM images of Fe exposed at $700^{\circ} \mathrm{C}$ with the $\mathrm{M} 1$ powder deposit in $\mathrm{O}_{2}+1000 \mathrm{ppm} \mathrm{SO}_{2}$ for 160 hours 121 
Figure 65: Macroscopic and cross-sectional SEM images of Fe exposed at $700^{\circ} \mathrm{C}$ with the SCM powder deposit in $\mathrm{O}_{2}+1000 \mathrm{ppm} \mathrm{SO}_{2}$ for 160 hours

Figure 66: Metal loss of Fe exposed at $700^{\circ} \mathrm{C}$ with the $\mathrm{M} 1$ powder deposit in $\mathrm{O}_{2}+1000 \mathrm{ppm} \mathrm{SO}$ for 160 hours compared with the results of the T92 and FeNiCr alloys.....

Figure 67: Metal loss of Fe exposed at $700^{\circ} \mathrm{C}$ with the SCM powder deposit in $\mathrm{O}_{2}+1000$ ppm $\mathrm{SO}_{2}$ for 160 hours compared with the results of the T92 and FeNiCr alloys 123

Figure 68: Macroscopic and microscopic SEM images of CoCrAlY exposed at $700^{\circ} \mathrm{C}$ with the $\mathrm{M} 1$ and $\mathrm{M} 1+30 \% \mathrm{Co}_{3} \mathrm{O}_{4}$ deposits in $\mathrm{O}_{2}+1000 \mathrm{ppm} \mathrm{SO}_{2}$ for 160 hours 124

Figure 69: Metal loss of FeNiCr and T92 exposed in various deposits containing the SCM with oxide additions at $700^{\circ} \mathrm{C}$ in $\mathrm{O}_{2}+1000 \mathrm{ppm} \mathrm{SO}_{2}$ for 160 hours 127

Figure 70: Metal loss of FeNiCr and T92 exposed in various deposits containing M1 with oxide additions at $700^{\circ} \mathrm{C}$ in $\mathrm{O}_{2}+1000 \mathrm{ppm} \mathrm{SO}_{2}$ for 160 hours 127

Figure 71: Macroscopic images of T92 and FeNiCr exposed at $700^{\circ} \mathrm{C}$ with the SCM-A powder in $\mathrm{O}_{2}+1000 \mathrm{ppm} \mathrm{SO}_{2}$ for 160 hours 128

Figure 72: Cross-sectional micrographs of $\mathrm{T} 92$ and FeNiCr exposed at $700^{\circ} \mathrm{C}$ with the SCM-A powder deposit in $\mathrm{O}_{2}+1000$ ppm $\mathrm{SO}_{2}$ for 160 hours .

Figure 73: Macroscopic images of T92 and FeNiCr exposed at $700^{\circ} \mathrm{C}$ with the M1-A powder in $\mathrm{O}_{2}+1000 \mathrm{ppm} \mathrm{SO}_{2}$ for 160 hours 131

Figure 74: Cross-sectional micrographs of T92 and FeNiCr exposed at $700^{\circ} \mathrm{C}$ with the M1-A powder deposit in $\mathrm{O}_{2}+1000$ ppm $\mathrm{SO}_{2}$ for 160 hours 132

Figure 75: Macroscopic images of T92 and FeNiCr exposed at $700^{\circ} \mathrm{C}$ with SCM-C powder deposit in $\mathrm{O}_{2}+1000 \mathrm{ppm} \mathrm{SO}_{2}$ for 160 hours 133

Figure 76: Microscopic cross-sectional images of T92 and FeNiCr exposed at $700^{\circ} \mathrm{C}$ with SCM$\mathrm{C}$ powder in $\mathrm{O}_{2}+1000 \mathrm{ppm} \mathrm{SO}_{2}$ for 160 hours 134

Figure 77: Microscopic cross-sectional images of T92 and FeNiCr exposed at $700^{\circ} \mathrm{C}$ with M1-C powder in $\mathrm{O}_{2}+1000 \mathrm{ppm} \mathrm{SO}_{2}$ for 160 hours 135

Figure 78: Macroscopic images of T92 and FeNiCr exposed at $700^{\circ} \mathrm{C}$ with SCM-S powder in $\mathrm{O}_{2}$ $+1000 \mathrm{ppm} \mathrm{SO}_{2}$ for 160 hours 137

Figure 79: Microscopic cross-sectional images of T92 and FeNiCr exposed at $700^{\circ} \mathrm{C}$ with SCM$\mathrm{S}$ powder in $\mathrm{O}_{2}+1000$ ppm $\mathrm{SO}_{2}$ for 160 hours. 138

Figure 80: Solubility of $\mathrm{SiO}_{2}$ in sulfate melts [84] 140 
Figure 81: Microscopic cross-sectional images of T92 and FeNiCr exposed at $700^{\circ} \mathrm{C}$ with M1-S powder in $\mathrm{O}_{2}+1000 \mathrm{ppm} \mathrm{SO}_{2}$ for 160 hours ........................................................... 142

Figure 82: Macroscopic and microscopic SEM images of T92 and FeNiCr exposed at $700^{\circ} \mathrm{C}$ with the Deposit D powder in $\mathrm{O}_{2}+1000 \mathrm{ppm} \mathrm{SO}$ for 160 hours.......................................... 144

Figure 83: Metal loss of T92 and FeNiCr exposed at $700^{\circ} \mathrm{C}$ with the SCM powder deposit in crucibles as a function of the amount of $\mathrm{SO}_{2}$ in the gas atmosphere. 146

Figure 84: $\mathrm{SO}_{3}$ equilibrium partial pressures plotted on the solubility plot for $\mathrm{Fe}_{2} \mathrm{O}_{3}$ and $\mathrm{Cr}_{2} \mathrm{O}_{3}$ 147

Figure 85: Microstructure of batches FeNiCr alloy that came from an ingot and a plate (same

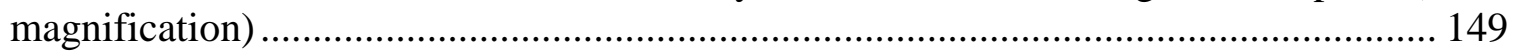

Figure 86: Macroscopic images of alloys exposed at $700^{\circ} \mathrm{C}$ in $\mathrm{M} 1$ deposit in $\mathrm{O}_{2}+1000 \mathrm{ppm}^{\mathrm{SO}_{2}}$ 151

Figure 87: Kinetics and Metal Loss of alloys exposed at $700^{\circ} \mathrm{C}$ in the $\mathrm{M} 1$ in $\mathrm{O}_{2}+1000 \mathrm{ppm} \mathrm{SO}_{2}$ 152

Figure 88: Macroscopic photographs and cross-sections of OC8 after fireside corrosion at $700^{\circ} \mathrm{C}$

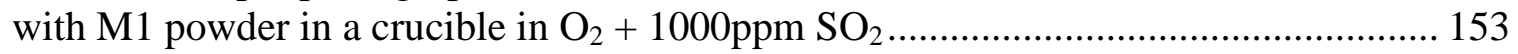

Figure 89: Macroscopic images of OC4 and OC8 exposed at $700^{\circ} \mathrm{C}$ with the standard corrosion

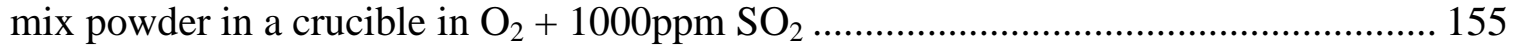

Figure 90: Weight change per area of fireside corrosion test of OC4 and OC8 alloys compared with chromia-forming alloys at $700^{\circ} \mathrm{C}$ with the SCM in a crucible in $\mathrm{O}_{2}+1000 \mathrm{ppm} \mathrm{SO}_{2}$ 156

Figure 91: Metal Loss of fireside corrosion test OC4 and OC8 alloys compared with chromiaforming alloys at $700^{\circ} \mathrm{C}$ with the SCM in a crucible in $\mathrm{O}_{2}+1000 \mathrm{ppm} \mathrm{SO}_{2} \ldots \ldots \ldots \ldots \ldots . . . . .157$

Figure 92: Microscopic cross-sectional images of OC4 exposed at $700^{\circ} \mathrm{C}$ with the standard

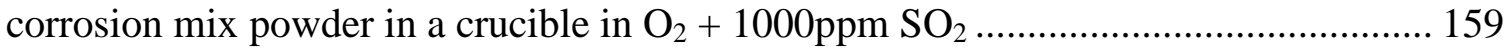

Figure 93: Fireside Corrosion of OC4 at $700^{\circ} \mathrm{C}$ with the standard corrosion mix powder in a crucible in $\mathrm{O}_{2}+1000 \mathrm{ppm} \mathrm{SO}_{2}$ for 20 hours 159

Figure 94: Microscopic cross-sectional images of OC8 exposed at $700^{\circ} \mathrm{C}$ with the standard corrosion mix powder in a crucible in $\mathrm{O}_{2}+1000 \mathrm{ppm} \mathrm{SO}_{2}$ 161

Figure 95: Macroscopic Results of OCS exposed at $700^{\circ} \mathrm{C}$ with the SCM powder in a crucible in $\mathrm{O}_{2}+1000 \mathrm{ppm} \mathrm{SO}_{2}$ (Volume fraction of Laves phase and $\mathrm{NbC}$ shown in red). 162 
Figure 96: Macroscopic Results of OCT exposed at $700^{\circ} \mathrm{C}$ with the SCM powder in a crucible in $\mathrm{O}_{2}+1000 \mathrm{ppm} \mathrm{SO} \mathrm{SO}_{2}$ (Volume fraction of Laves phase and $\mathrm{NbC}$ shown in red). 163

Figure 97: Fireside corrosion of OCS at $700^{\circ} \mathrm{C}$ with the standard corrosion mix powder in a crucible in $\mathrm{O}_{2}+1000 \mathrm{ppm} \mathrm{SO}_{2}$ 164

Figure 98: Fireside corrosion of OCT at $700^{\circ} \mathrm{C}$ with the standard corrosion mix powder in a crucible in $\mathrm{O}_{2}+1000 \mathrm{ppm} \mathrm{SO}_{2}$ 165

Figure 99: Microstructure of OCT Alloy Displaying Laves Phase and Nb-Carbides ................. 166

Figure 100: Calculated volume fraction of Laves Phase and MC in tested specimens 167

Figure 101: Predicted phases of OCS as a function of temperature [87].................................... 169

Figure 102: Predicted phases of OCT as a function of temperature [87] .................................... 169

Figure 103: Microstructure of OCS as processed and aged at $700^{\circ} \mathrm{C}$ for 2350 hours ................ 172

Figure 104: OCS Aged 2350 hours at $700^{\circ} \mathrm{C}$ then exposed at $700^{\circ} \mathrm{C}$ with the SCM powder deposit in $\mathrm{O}_{2}+1000 \mathrm{ppm} \mathrm{SO}_{2}$ for 160 hours .............................................................. 173

Figure 105: OCT Aged 2350 hours at $700^{\circ} \mathrm{C}$ then exposed at $700^{\circ} \mathrm{C}$ with the SCM powder deposit in $\mathrm{O}_{2}+1000 \mathrm{ppm} \mathrm{SO}_{2}$ for 160 hours ............................................................... 173

Figure 106: Predicted phases of OC8 as a function of temperature [87] .................................... 175

Figure 107: Microstructure of OC8 as processed ................................................................. 176

Figure 108: OC8 aged 2350 hours microstructure............................................................... 177

Figure 109: Etched microstructure of OC8 aged 2350 hours at $700^{\circ} \mathrm{C}$ displaying sigma phase formation at the grain boundaries ..................................................................................... 178

Figure 110: OC8 aged 2350 hours at $700^{\circ} \mathrm{C}$ exposed at $700^{\circ} \mathrm{C}$ with the SCM powder deposit in $\mathrm{O}_{2}+1000 \mathrm{ppm} \mathrm{SO}_{2}$ for 160 hours ........................................................................ 179

Figure 111: OC8 composition change with temperature [87] .................................................... 180

Figure 112: OC8 as-processed microstructure (a.) compared with 7000 hour creep at $650^{\circ} \mathrm{C}$

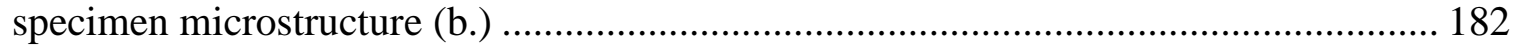

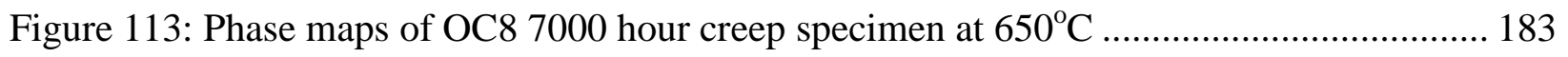

Figure 114: OC8 7000 hour creep specimens exposed at $700^{\circ} \mathrm{C}$ with the SCM in $\mathrm{O}_{2}+1000 \mathrm{ppm}$

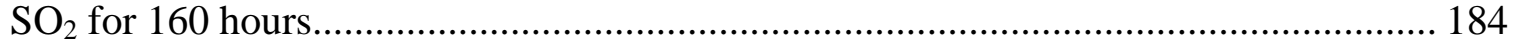


Figure 115: As-processed and OCS 5000 hour creep specimen microstructures 185

Figure 116: OCS 5000 hour and OCT 5500 hour creep specimens exposed at $700^{\circ} \mathrm{C}$ with the SCM powder deposit in $\mathrm{O}_{2}+1000 \mathrm{ppm} \mathrm{SO}_{2}$ for $160 \mathrm{hr}$ 186

Figure 117: Macroscopic images of T92 and FeNiCr exposed at $650^{\circ} \mathrm{C}, 700^{\circ} \mathrm{C}$, and $750^{\circ} \mathrm{C}$ with the SCM powder in $\mathrm{O}_{2}+1000 \mathrm{ppm} \mathrm{SO}_{2}$ for 160 hours 190

Figure 118: Weight change and metal loss plots of $\mathrm{T} 92$ and $\mathrm{FeNiCr}$ exposed at $650^{\circ} \mathrm{C}, 700^{\circ} \mathrm{C}$, and $750^{\circ} \mathrm{C}$ with the SCM powder in $\mathrm{O}_{2}+1000 \mathrm{ppm} \mathrm{SO}_{2}$ for 160 hours 190

Figure 119: Mass Change and metal loss of T92 exposed at 650,700 , and $750^{\circ} \mathrm{C}$ with the SCM, SCM-A, SCM-S, and SCM-C powder deposits in $\mathrm{O}_{2}+1000 \mathrm{ppm} \mathrm{SO}_{2}$ for 160 hours... 192

Figure 120: Mass Change and metal loss of FeNiCr exposed at 650,700 , and $750^{\circ} \mathrm{C}$ with the SCM, SCM-A, SCM-S, and SCM-C powder deposits in $\mathrm{O}_{2}+1000 \mathrm{ppm} \mathrm{SO}_{2}$ for 160 hours 193

Figure 121: Macroscopic images of AFA alloys compared with Cr-forming alloys tested at various temperatures with the SCM powder in $\mathrm{O}_{2}+1000 \mathrm{ppm} \mathrm{SO}_{2}$ for 160 hours 195

Figure 122: Mass Change of AFA alloys compared with Cr-forming alloys tested at various temperatures with the SCM powder in $\mathrm{O}_{2}+1000 \mathrm{ppm} \mathrm{SO}_{2}$ for 160 hours. 196

Figure 123: Metal loss of AFA alloys compared with Cr-forming alloys tested at various temperatures with the SCM powder in $\mathrm{O}_{2}+1000 \mathrm{ppm} \mathrm{SO}_{2}$ for 160 hours 196

Figure 124: Cross-sectional microscopic images of OC4 and OC8 exposed at $650^{\circ} \mathrm{C}$ and $750^{\circ} \mathrm{C}$ with the SCM powder deposit in $\mathrm{O}_{2}+1000$ ppm $\mathrm{SO}_{2}$ for 160 hours

Figure 125: OC8 7000 hour creep specimen exposed at $750^{\circ} \mathrm{C}$ with the SCM powder deposit in $\mathrm{O}_{2}+1000 \mathrm{ppm} \mathrm{SO}_{2}$ for 160 hours 199

Figure 126: Schematic of the three deposit zones able to be analyzed when using the powdercrucible method (the red area denotes the region covered in the deposit). 200

Figure 127: OCS exposed at $700^{\circ} \mathrm{C}$ with the SCM using the powder-crucible method in $\mathrm{O}_{2}+$ 1000ppm $\mathrm{SO}_{2}$ for 80 hours 201

Figure 128: OCS exposed at $700^{\circ} \mathrm{C}$ with the SCM using the powder-crucible method in $\mathrm{O}_{2}+$ $1000 \mathrm{ppm} \mathrm{SO}_{2}$ for 160 hours 201

Figure 129: Metal loss with respect to position on the specimen of T92 exposed at $700^{\circ} \mathrm{C}$ with the SCM powder deposit in $\mathrm{O}_{2}+1000 \mathrm{ppm} \mathrm{SO}_{2}$. (Zero distance into specimen marks the position where the specimen is completely buried in the deposit) 202 
Figure 130: Metal loss with respect to position on the specimen of FeNiCr exposed at $700^{\circ} \mathrm{C}$ with the SCM powder deposit in $\mathrm{O}_{2}+1000 \mathrm{ppm} \mathrm{SO}_{2}$. (Zero distance into specimen marks the position where the specimen is completely buried in the deposit) 203

Figure 131: Metal loss of T92 and FeNiCr deposited with varying thicknesses of SCM and M1 slurries exposed at $700^{\circ} \mathrm{C}$ in $\mathrm{O}_{2}+1000 \mathrm{ppm} \mathrm{SO}_{2}$ for 160 hours compared with the powder deposit 205

Figure 132: T92 coated with $10 \mathrm{mg} / \mathrm{cm}^{2}$ of various deposit slurries and exposed at $700^{\circ} \mathrm{C}$ in $\mathrm{O}_{2}+$ 1000ppm $\mathrm{SO}_{2}$ for 160 hours 207

Figure 133: FeNiCr coated with $10 \mathrm{mg} / \mathrm{cm}^{2}$ of various deposit slurries and exposed at $700^{\circ} \mathrm{C}$ in $\mathrm{O}_{2}+1000 \mathrm{ppm} \mathrm{SO}_{2}$ for 160 hours 207

Figure 134: Macroscopic and microscopic images of T92 exposed at $700^{\circ} \mathrm{C}$ in the SCM powder deposit for 20 hours in $60 \% \mathrm{CO}_{2}-25 \% \mathrm{H}_{2} \mathrm{O}-3 \% \mathrm{O}_{2}-0.5 \% \mathrm{SO}_{2}$ 217

Figure 135: Macroscopic and microscopic images of FeNiCr exposed at $700^{\circ} \mathrm{C}$ in the SCM powder deposit for 20 hours in $60 \% \mathrm{CO}_{2}-25 \% \mathrm{H}_{2} \mathrm{O}-3 \% \mathrm{O}_{2}-0.5 \% \mathrm{SO}_{2}$ 218

Figure 136: Macroscopic images of FeNiCr and T92 exposed at $700^{\circ} \mathrm{C}$ with the SCM in powder deposit for 40 and 160 hours in $60 \% \mathrm{CO}_{2}-25 \% \mathrm{H}_{2} \mathrm{O}-3 \% \mathrm{O}_{2}-0.5 \% \mathrm{SO}_{2}$ 219

Figure 137: Macroscopic and microscopic images of $\mathrm{T} 92$ and FeNiCr exposed at $700^{\circ} \mathrm{C}$ with the SCM powder deposit in $\mathrm{O}_{2}+2500 \mathrm{ppm} \mathrm{SO}_{2}$ for 40, 80, and 160 hours 220 


\section{ACKNOWLEDGEMENTS}

I would like to thank my research advisor Professor Gerald H. Meier for the guidance and wisdom given to me not only on the work for this thesis but in my all of my academic and research efforts. He creates a work atmosphere that is both pleasant and exciting to work in. I also owe a lot of gratitude to my colleagues Michael Task, Michael Helminiak, Meltem Yanar, Ed Magee, Keeyoung Jung, Nan Mu, Juan Manuel Alvarado Orozco, Thomas Gheno, and Nate Bohna for their experience and knowledge given to me in working in the laboratory. Without them this would not have been possible. I would also like to thank my committee members, Professors Federick S. Petit, Brian Gleeson, J.K. Lee, as well as Dr. Gordon Holcomb at NETL Albany for sharing their knowledge and expertise with me.

I would like to thank my family for all of the support and guidance they have given me over the years with all of my life choices. Thank you for all of your help. I could not have done this without you and I will never forget that. I love you all!

On a personal note, I would like to thank Christina for her constant words of encouragement and well wishes while working on this project. You always put a smile on my face even when things weren't working out. Thank you for some of the happiest times of my life. I will always love you!

This project was funded by the National Energy Technology Laboratory under URS Corps. Task Release 168. 


\subsection{INTRODUCTION}

The growing population requires increasing amounts of electricity from sources that will have a reduced environmental impact. The worldwide energy demand will increase by approximately $40 \%$ by 2030 , and coal combustion is believed to account for $30 \%$ of the future worldwide energy production.[1] Coal is plentiful and available at low cost, but traditional methods of coal combustion lead to high pollutant and $\mathrm{CO}_{2}$ emissions. Global warming is becoming a bigger problem every day with the emission of greenhouse gasses, and therefore power plants in the United States are under increasing pressure to improve thermal efficiency in order to provide abundant and affordable electricity while reducing gas emissions. Advanced coal combustion designs will provide this. Older power plants from the 70's and 80's need to be either replaced with the new advanced combustion technology power plants, or with their retrofit. Some of the advanced combustion technologies include using renewable fuels, such as biomass, and carbon capture storage (CCS), such as oxy-fuel combustion. The research discussed is determining the initiation and propagation mechanisms for fireside corrosion in oxy-fuel combustion systems as well as for materials development using alumina-forming austenitic stainless steels for superheater and reheater tubes.

Oxy-fuel firing is one of three ways in which CCS can be accomplished. The other two ways are post-combustion capture, where the $\mathrm{CO}_{2}$ is removed from the flue gas after combustion, and pre-combustion capture, where the $\mathrm{CO}_{2}$ is removed from the fuel before combustion. Oxy- 
fuel firing is carrying out the combustion in an environment consisting of recirculated flue gases containing primarily $\mathrm{CO}_{2}$, steam and pure oxygen instead of air in order to create a flue gas with minimal amounts of $\mathrm{N}_{2}$. A schematic diagram of the oxy-fuel process is shown below in Figure

1.

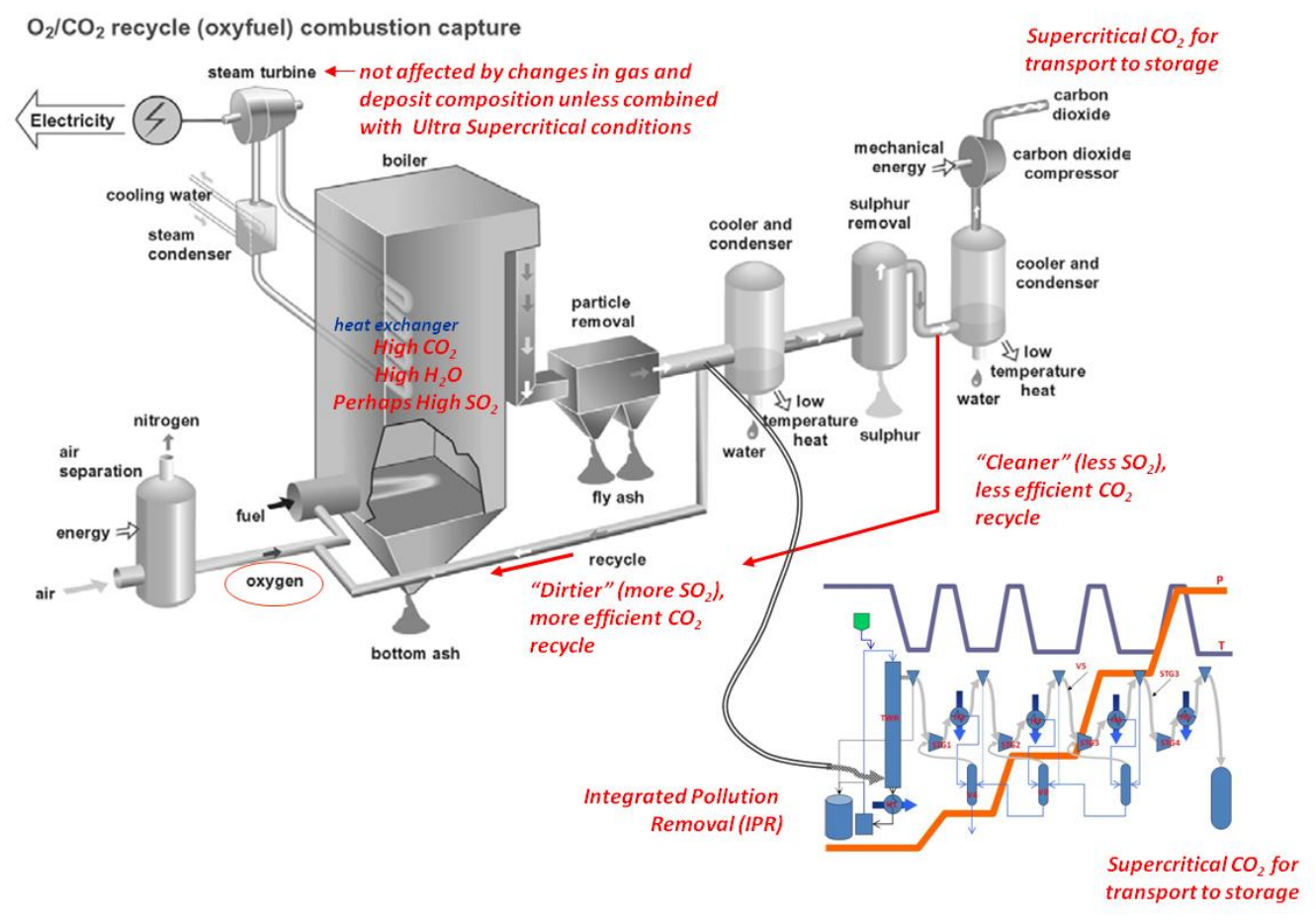

Figure 1: Schematic diagram of oxy-fuel combustion

Oxy-fuel combustion produces flue gases containing approximately $60 \% \mathrm{CO}_{2}-30 \% \mathrm{H}_{2} \mathrm{O}-$ $4 \% \mathrm{O}_{2}-5 \% \mathrm{~N}_{2}$, whereas traditional air-fired combustion produces flue gases containing $74 \% \mathrm{~N}_{2}-$ $12 \% \mathrm{CO}_{2}-9 \% \mathrm{H}_{2} \mathrm{O}-4 \% \mathrm{O}_{2}$.[2] The flue gases in oxy-fuel systems are able to be recycled through the fuel burners leading to decreased $\mathrm{CO}_{2}$ emissions. However, with the reduced amounts of nitrogen, the products of the oxy-fuel combustion process have increased amounts of $\mathrm{CO}_{2}$, steam and corrosive gases, such as $\mathrm{SO}_{2}$ that can cause significant corrosion in superheater and reheater 
tubes when compared to air-fired combustion. Burning biomass as fuel or oxy-fuel combustion will increase corrosion due to increased corrosive gas products and ash deposits from the coal/biomass. $\mathrm{SO}_{2}$ in the flue gas and ash deposits from the fuel cause severe corrosion in the superheater and reheater tubes of coal fired boilers where the temperature is the highest. This form of corrosion is called fireside corrosion, and is caused by the formation of liquid deposits on the surface of superheater and reheater tubes.

Because the oxy-fuel combustion system operates in two parts, the plant efficiency decreases. One way to overcome the efficiency loss of using oxy-fuel combustion is to increase the steam temperatures and pressures to ultra-supercritical conditions. The efficiency of a coalfired power plant is related to the steam temperature and pressure. This is the Carnot efficiency. Higher efficiency requires higher temperatures and materials which can withstand the higher temperatures than current coal-fired power plants. Ultra-supercritical steam conditions are the result of increasing temperature and pressure. The critical point for the water/steam system is 22.1MPa at $374^{\circ} \mathrm{C}$. Operating at higher temperatures and pressures produces supercritical and even higher produces ultra-supercritical steam conditions. At these high temperatures and pressures, water does not form a two-phase steam/water mixture during boiling. The system forms a single phase going from water directly into steam.[3] The goal is to move from supercritical conditions of $16.5-24 \mathrm{MPa}$ and $540^{\circ} \mathrm{C}$ to ultra-supercritical conditions of $35 \mathrm{MPa}$ and $760^{\circ} \mathrm{C}$. The higher steam temperatures and pressures will significantly increase efficiency while decreasing fuel usage and $\mathrm{CO}_{2}$ emissions. Compared to normal pulverized coal (PC) power plants which operate at 35\% efficiency, ultra-supercritical steam conditions can potentially increase efficiency to more than $47 \%$, while reducing carbon dioxide emissions by $30 \%$.[4] The current materials used in supercritical conditions do not have the high temperature strength and 
corrosion resistance to be operated in ultra-supercritical conditions. The technology needed to reach the ultra-supercritical goals is developing stronger and more oxidation resistant high temperature materials. Ferritic and austenitic stainless steels are currently used in energy production environments due to their combination of creep and oxidation resistance at a relatively low cost. These types of alloys typically rely on a chromia scale for protection. The presence of higher temperature steam, sulfur and carbon species atmospheres that will be encountered will provide durability issues regarding high temperature oxidation and corrosion for these alloys. Nickel based alloys offer better protection, however they are far more expensive. The development of alumina-forming austenitic stainless steels offers a potential solution to maintain oxidation and corrosion resistance in these atmospheres without significantly increasing the alloy cost. Alumina grows at a slower rate than chromia, is more thermodynamically stable with oxygen, and allows for a higher degree of protection in the presence of many oxidizing species.[5] 


\subsection{BACKGROUND}

\subsection{FORMATION OF DEPOSITS ON BOILER TUBES}

Corrosion of the wall tubes of coal-fired boilers is caused by ash deposits that form a slag layer with high alkali and $\mathrm{SO}_{3}$ contents and high solubility in water. The ash deposits on wall tubes prevent heat transfer, and lead to corrosion of the tube. Reid and Cohen[6] examined the influence of slag thickness on wall tubes. They showed that there is a stationary layer of slag next to the tube and a moving layer of slag at higher temperature. These layers are based on the temperature and composition of the slag. The more fluid a slag layer is, the more heat it will conduct to the tubes. The heat transfer through the slag increases linearly with slag surface temperature. The heat flux will vary around the tube, and it will be the smallest where the deposit is the thickest. Ely and Schueler[7] examined the influence of slag thickness on the heat transfer through the wall tubes. The heat flux was found to decrease as the slag becomes thicker with increasing time. This can be seen below in Figure 2. 


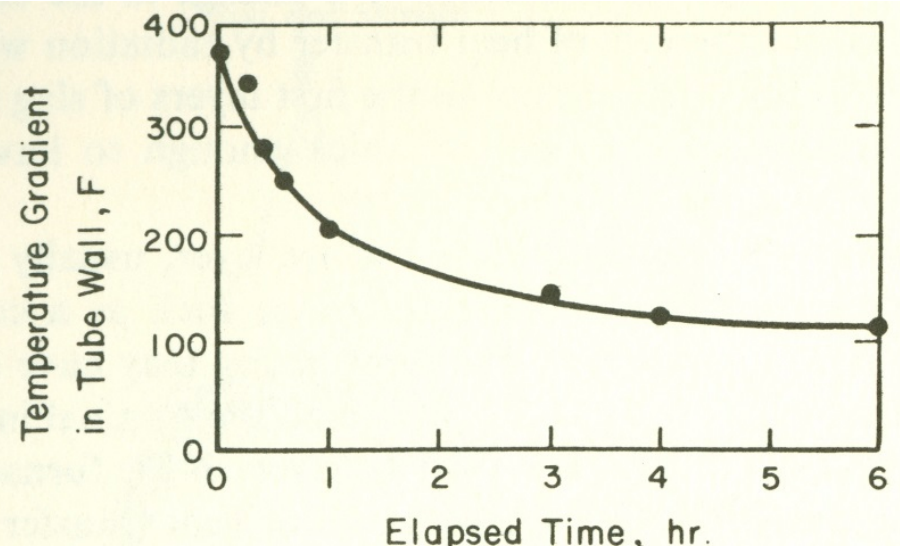

Figure 2: Rate of change of heat flux with accumulation of slag[7]

The corrosion of superheater tubes from ash deposits is dependent on the operating steam temperatures. The steam temperature in boilers is increasing for increased efficiency in power production, but corrosion becomes a great problem at higher temperatures. The corrosion kinetics follow a bell-shaped curve with the largest amount of corrosion occurring in a temperature range of $650-750^{\circ} \mathrm{C}$. In this temperature range, the deposits become molten and corrode the metal. At lower temperatures, the deposits are solid and for the most part are not reactive. At higher temperatures, the deposits will become molten, however there is not enough $\mathrm{SO}_{3}$ produced to cause the formation of highly corrosive alkali iron trisulfates. This will be explained in later sections. Trisulfates decompose in the absence of sufficient $\mathrm{SO}_{3}$. At these high temperatures, a slag of alkali sulfates will form, which can still cause corrosion of the boiler hardware. Species other than alkali iron trisulfates may become liquid and cause severe corrosion at higher temperatures as well. 
The build-up of ash deposits on boiler tubes was examined by Bishop[8]. He proposed the following possible causes of deposit build-up:

- Alkali metal salts in the vapor phase condense on the tubes to form a sticky layer, which collects impacting particles of fly ash.

- The initial deposit consists of fly ash; the insulating effect of this ash results in the outer layers of the deposit becoming hotter than the inside, and this temperature gradient allows partial decomposition of sulfates in the hotter parts, with the $\mathrm{SO}_{3}$ so formed diffusing toward the cooler surface. An inner dense alkali sulfate-rich layer forms.

- Alkali metal or alkaline-earth oxides are deposited on the surface, and are then converted to low-melting point sulfates and pyrosulfates by reaction with $\mathrm{SO}_{3}$ in the bulk gas phase.

- Alkali chloride vapors from high-chlorine coals condense on the tubes and are converted to sulfates.

- Silicon compounds are evolved as vapors from silicate materials during combustion, and are then deposited as fine aerosol particles on the surface and are rapidly oxidized to silica.

- Molten ash particles in the hot gas stream impact on the cold metal surface and freeze in place.

Generally, a white deposit will form first on the surface of the tube. This is mostly sodium sulfate. An ash deposit then forms. The deposit on a corroding tube is shown below in Figure 3. The amount of corrosion will be determined by the $\mathrm{SO}_{3}$ partial pressure near the alkali sulfates and the temperature. 


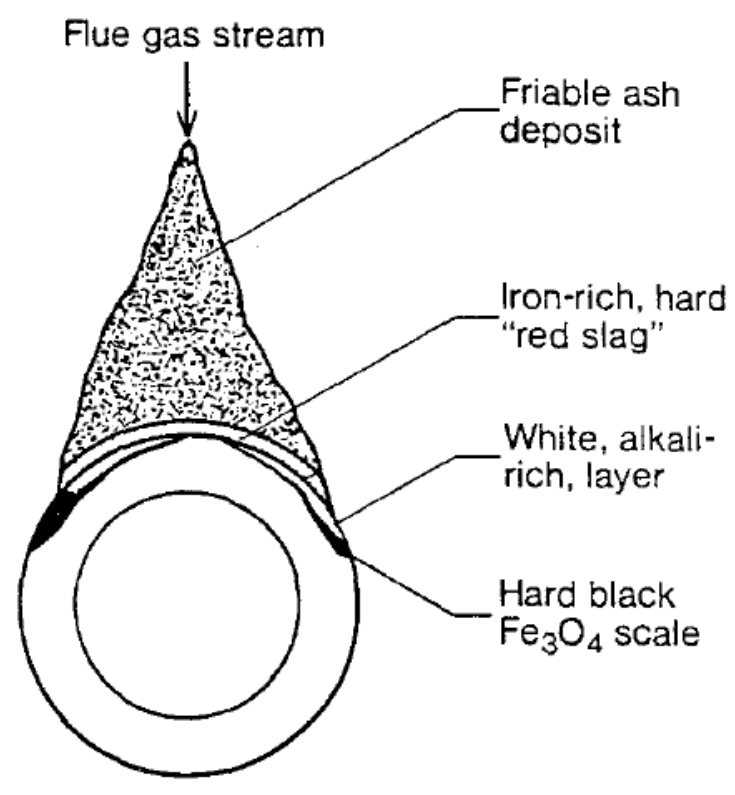

Figure 3: Deposits and corrosion area for typical reheater tube[3]

\subsection{FUEL}

There are many different kinds of fuels that can be used in power generation systems. These fuels can be compared based on fuel storage, preparation and handling, combustion behavior, and fuel compositions that can cause corrosion issues. The types of fuels can range from solid fuels such as coal, biomass, and waste to gaseous fuels. Co-firing of different types of fuel is also possible.[9] The research which has been conducted is focused on the deposits and corrosion caused from coal-fired boilers and power systems. Other types of fuels can lead to corrosion from different deposits and mechanisms. 


\subsubsection{Coal Ash Composition}

When coal is burned, coal ash is put into the gas stream and becomes a major part of the deposits on superheater tubes. The typical composition of the flue gas in burning coal at temperatures between $400-1200^{\circ} \mathrm{C}$ is shown below in Figure 4. The main difference in flue gas composition between coal and other types of fuels is the $\mathrm{SO}_{2} / \mathrm{SO}_{3}$ content, which is increased due to higher amounts of sulfur in coal. $\mathrm{SO}_{2}$ is dominant at temperatures greater than $700^{\circ} \mathrm{C}$, while $\mathrm{SO}_{3}$ becomes dominant at lower temperatures. The maximum amount of corrosion occurs at the highest temperature in which sufficient $\mathrm{SO}_{3}$ is present in the atmosphere $\left(650-750^{\circ} \mathrm{C}\right)$. $\mathrm{The}_{2}$ and $\mathrm{SO}_{3}$ curves in Figure 4 form the earlier described bell-shaped curve.

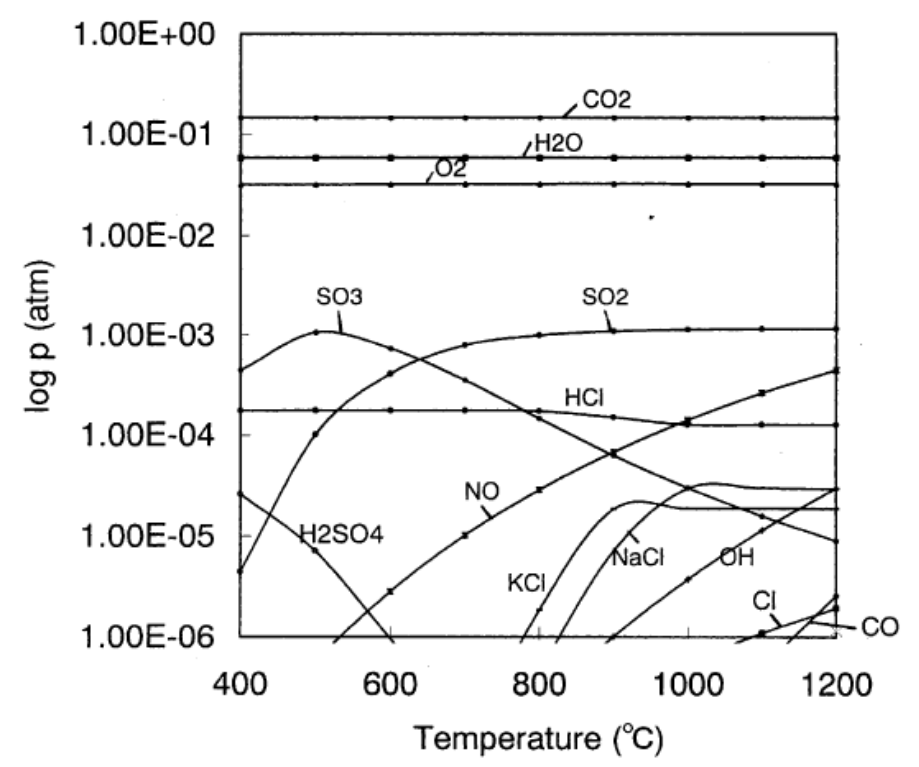

Figure 4: Calculated flue gas composition upon coal combustion[10] 
Differences in fuel composition can affect the formation of deposits on the superheater tubes. Table 1 below shows a typical elemental composition of coal compared with other kinds of fuels used in power generation systems.

Table 1: Elemental analysis of major fuels (wt\%) [10]

\begin{tabular}{lllllll}
\hline Element & MSW & Coal & Black liquor $^{\mathrm{a}}$ & Oil $^{\mathrm{b}}$ & Orimulsion $^{\mathrm{b}}$ & LNG $^{\mathrm{b}}$ \\
\hline Ultimate & & & & & & \\
$\mathrm{C}$ & 22 & 76.2 & 28.4 & 85 & 60.1 & 76.5 \\
$\mathrm{H}$ & 8.7 & 5.13 & 5.2 & 12 & 10.1 & 23.5 \\
$\mathrm{O}$ & 60.4 & 6.15 & 44.3 & 0.4 & 26.4 & - \\
$\mathrm{N}$ & 0.3 & 1.63 & - & 0.2 & 0.35 & - \\
$\mathrm{S}$ & 0.02 & 1.73 & 2.7 & 2.35 & 2.85 & - \\
$\mathrm{Cl}$ & 0.4 & 0.275 & 3.0 & - & - & - \\
ash & 8.18 & 8.89 & - & 0.05 & 0.2 & - \\
$\mathrm{Metals}$ & & & & & & \\
$\mathrm{Fe}$ & 0.2 & 1.1 & - & - & - & - \\
$\mathrm{Ca}$ & 0.9 & 0.1 & - & - & - & - \\
$\mathrm{Mg}$ & 0.1 & 0.04 & - & - & $370^{\mathrm{c}}$ & - \\
$\mathrm{V}$ & - & - & - & $100^{\mathrm{c}}$ & $310^{\mathrm{c}}$ & - \\
$\mathrm{Na}$ & $600^{\mathrm{c}}$ & $311^{\mathrm{c}}$ & 13.0 & $50^{\mathrm{c}}$ & $30^{\mathrm{c}}$ & - \\
$\mathrm{K}$ & $400^{\mathrm{c}}$ & $325^{\mathrm{c}}$ & 3.4 & $50^{\mathrm{c}}$ & - & - \\
$\mathrm{Zn}$ & $70^{\mathrm{c}}$ & - & - & - & - & - \\
$\mathrm{Pb}$ & $10^{\mathrm{c}}$ & - & - & - & - & - \\
$\mathrm{Heat} \mathrm{value}$ & 2440 & 7509 & 3700 & 10400 & 7242 & 13000 \\
(kcal/kg) & & & & & & \\
\hline
\end{tabular}

The major difference between coal and other types of fuel is the sulfur content. The greater the amount of sulfur there is in the coal, the more corrosion will occur. Coal can be generally described as high sulfur and high chlorine fuel. The iron content in the coal can also play a large part in the behavior of ashes. When in a completely oxidized form, iron oxide can raise the fusion temperature of the ash, but when it is in a less oxidized form, the fusion temperature will decrease. The ash viscosity will also increase with increasing ferrite content.[11] 
It is the inorganic matter in fuels that is the cause of corrosion of boiler tubes. The amount of mineral matter in coal varies, but there is almost always enough to cause significant problems. The mineral matter occurs in coal as either discrete mineral grains or as minerals that range in size between several microns to 100 microns.[12] Removal of the ash from fuels would solve the deposit-induced corrosion problem, but this is not economically feasible. The inorganic mineral matter in coal can be categorized as inherent mineral matter or extraneous mineral matter. Inherent mineral matter is inorganic materials that were part of the original plant substances that turned into coal. Some examples of this type of mineral matter are compounds of iron, magnesium, calcium, phosphorous, potassium, and sulfur. Inherent mineral matter constitutes very little of the inorganic matter in the ash in coals. Extraneous mineral matter is inorganic materials that were added to the original substances during the process of becoming coal. This is the predominant contributor to the inorganic matter in the ash in coals. Extraneous mineral matter is roughly 4-7 microns in size.[13] Table 2 lists the common minerals found in coal in order of their abundance.[15] The main metallic elements are aluminum, silicon, iron, calcium, magnesium, titanium, sodium, and potassium. There are four main groups into which the minerals may be grouped. These are clay minerals, sulfates and sulfides, carbonates, and quartz.[16] The composition of coal ash can change based on from where the coal comes. In the United States, the coals are labeled based on their inorganic constituents as “Eastern” or "Western" coals. Western coals are typically described as those for which the $\mathrm{CaO}+\mathrm{MgO}$ content exceeds the $\mathrm{Fe}_{2} \mathrm{O}_{3}$ content of the ash, while the reverse is true for Eastern coals. The inorganic materials in Eastern coals are bituminous and are predominantly in the form of discrete mineral 
particles. Clay minerals such as kaolin or illite are dominant, as well as quartz and pyrite.

Typcial Eastern coal compositions are shown in Table 3. Western coals are usually lignites or subbituminous, and typical compositions are shown in Table 4.

Table 2: Occurance of minerals in coal [14]

\begin{tabular}{|c|c|}
\hline Mineral & Formula \\
\hline Shale group & $\left(\mathrm{K}, \mathrm{Na}, \mathrm{H}_{3} \mathrm{O}_{3}, \mathrm{Ca}\right)_{2}(\mathrm{Al}, \mathrm{Mg}, \mathrm{Fe}, \mathrm{Ti})_{4}(\mathrm{Al}, \mathrm{Si})_{8} \mathrm{O}_{20}(\mathrm{OH}, \mathrm{F})_{4}$ \\
\hline Clay group & $\mathrm{Al}_{2} \mathrm{O}_{3} \cdot 2 \mathrm{SiO}_{2} \cdot x \mathrm{H}_{2} \mathrm{O}$ \\
\hline (Kaolinite) & $\mathrm{Al}_{2} \mathrm{O}_{3} \cdot 2 \mathrm{SiO}_{2} \cdot 2 \mathrm{H}_{2} \mathrm{O}$ \\
\hline Sulfur group & $\mathrm{FeS}_{2}, \mathrm{FeSO}_{4}, \mathrm{Na}_{2} \mathrm{SO}_{4}$ \\
\hline Carbonate group & $\mathrm{CaCO}_{3}, \mathrm{CaCO}_{3} \cdot \mathrm{MgCO}_{3}$ \\
\hline \multicolumn{2}{|c|}{ Associated minerals } \\
\hline Quartz & $\mathrm{SiO}_{2}$ \\
\hline Feldspar & $(\mathrm{K}, \mathrm{Na})_{2} \mathrm{O} \cdot \mathrm{Al}_{2} \mathrm{O}_{3} \cdot 6 \mathrm{SiO}_{2}$ \\
\hline Garnet & $3 \mathrm{CaO} \cdot \mathrm{Al}_{2} \mathrm{O}_{3} \cdot 3 \mathrm{SiO}_{2}$ \\
\hline Hornblende & $\mathrm{CaO} \cdot 3 \mathrm{FeO} \cdot 4 \mathrm{SiO}_{2}$ \\
\hline Gypsum & $\mathrm{CaSO}_{4} \cdot 2 \mathrm{H}_{2} \mathrm{O}$ \\
\hline Apatite & $9 \mathrm{CaO} \cdot 3 \mathrm{P}_{2} \mathrm{O}_{5} \cdot \mathrm{CaF}_{2}$ \\
\hline Zircon & $\mathrm{ZrSiO}_{4}$ \\
\hline Epidote & $4 \mathrm{CaO} \cdot 3 \mathrm{Al}_{2} \mathrm{O}_{3} \cdot 6 \mathrm{SiO}_{2} \cdot \mathrm{H}_{2} \mathrm{O}$ \\
\hline Biotite & $\mathrm{K}{ }_{2} \mathrm{O} \cdot \mathrm{MgO} \cdot \mathrm{Al}_{2} \mathrm{O}_{3} \cdot 3 \mathrm{SiO}_{2} \cdot \mathrm{H}_{2} \mathrm{O}$ \\
\hline Augite & $\mathrm{CaO} \cdot \mathrm{MgO} \cdot 2 \mathrm{SiO}_{2}$ \\
\hline Prochlorite & $2 \mathrm{FeO} \cdot 2 \mathrm{MgO} \cdot \mathrm{Al}_{2} \mathrm{O}_{3} \cdot 2 \mathrm{SiO}_{2} \cdot 2 \mathrm{H}_{2} \mathrm{O}$ \\
\hline Diaspore & $\mathrm{Al}_{2} \mathrm{O}_{3} \cdot \mathrm{H}_{2} \mathrm{O}$ \\
\hline Lepidocrocite & $\mathrm{Fe}_{2} \mathrm{O}_{3} \cdot \mathrm{H}_{2} \mathrm{O}$ \\
\hline Magnetite & $\mathrm{Fe}_{3} \mathrm{O}_{4}$ \\
\hline Kyanite & $\mathrm{Al}_{2} \mathrm{O}_{3} \cdot \mathrm{SiO}_{2}$ \\
\hline Staurolite & $2 \mathrm{FeO} \cdot 5 \mathrm{Al}_{2} \mathrm{O}_{3} \cdot 4 \mathrm{SiO}_{2} \cdot \mathrm{H}_{2} \mathrm{O}$ \\
\hline Topaz & $(\mathrm{Al}, \mathrm{F})_{2} \mathrm{SiO}_{4}$ \\
\hline Tourmaline & $\mathrm{MgAl}_{3}(\mathrm{BOH})_{2} \mathrm{Si}_{4} \mathrm{O}_{1}$ \\
\hline Hematite & $\begin{array}{cc}\mathrm{Fe}_{2} \mathrm{O}_{3} \\
\end{array}$ \\
\hline Penninite & $5 \mathrm{MgO} \cdot \mathrm{Al}_{2} \mathrm{O}_{3} \cdot 3 \mathrm{SiO}_{2} \cdot 2 \mathrm{H}_{2} \mathrm{O}$ \\
\hline
\end{tabular}


Table 3: Composition of Typical Eastern U.S. Coals [17]

\section{Inorganic Constituents of Eastern Coals}

\begin{tabular}{lcr}
\multicolumn{2}{c}{ Mineral } & Distribution \\
\hline Mineral & Range & Typical \\
\cline { 3 - 3 } Quartz & $5-44$ & 18 \\
Kaolinite & $9-60$ & 32 \\
Illite & $2-29$ & 14 \\
Chlorite & $0-15$ & 2 \\
Mixed Silicates & $5-31$ & 17 \\
Pyrite & $1-27$ & 8 \\
Calcite & $0-14$ & 3 \\
Siderite/Ankerite & $0-11$ & 2 \\
Other Minerals & $0-12$ & 4
\end{tabular}

\begin{tabular}{|c|c|}
\hline$\frac{\text { Typical }}{\text { Species }}$ & $\frac{\text { Ash Chemistry }}{\text { Weight }}$ \\
\hline $\mathrm{SiO}_{2}$ & 54 \\
\hline $\mathrm{Al}_{2} \mathrm{O}_{3}$ & 29 \\
\hline $\mathrm{Fe}_{2} \mathrm{O}_{3}$ & 8 \\
\hline $\mathrm{CaO}$ & 2 \\
\hline $\mathrm{MgO}$ & 1 \\
\hline $\mathrm{K}_{2} \mathrm{O}$ & 2 \\
\hline $\mathrm{Na}_{2} \mathrm{O}$ & 1 \\
\hline $\mathrm{TiO}_{2}$ & 1 \\
\hline $\mathrm{P}_{2} \mathrm{O}_{5}$ & 0.2 \\
\hline $\mathrm{So}_{3}$ & 2 \\
\hline
\end{tabular}

Table 4: Composition of Typical Western U.S. Coals [17]

Inorganic Constituents of Western Coals

\begin{tabular}{|c|c|c|}
\hline Mineral & Range & Typical \\
\hline Ouartz & $7-22$ & 15 \\
\hline Kaolinite & $13-45$ & 30 \\
\hline Illite & $0-12$ & 2 \\
\hline Mixed Silicates & $0-22$ & 8 \\
\hline Pyrite & $1-26$ & 7 \\
\hline Fe Sulfates & $0-5$ & 1 \\
\hline Fe-rich* & $0-14$ & 2 \\
\hline $\mathrm{Ca}-\mathrm{rich}{ }^{\star \star}$ & $7-49$ & 25 \\
\hline Other minerals $s^{\star \star \star}$ & $1-10$ & 7 \\
\hline
\end{tabular}

\begin{tabular}{cc} 
Typical & Ash Chemistry \\
\hline Species & Weight \\
\hline $\mathrm{SiO}_{2}$ & 30 \\
$\mathrm{Al}_{2} \mathrm{O}_{3}$ & 15 \\
$\mathrm{Fe}_{2} \mathrm{O}_{3}$ & 10 \\
$\mathrm{CaO}$ & 20 \\
$\mathrm{MgO}$ & 8 \\
$\mathrm{~K} \mathrm{O}_{2} \mathrm{O}$ & 0.7 \\
$\mathrm{NaO}$ & 0.6 \\
$\mathrm{TiO}_{2}$ & 0.7 \\
$\mathrm{P}_{2} \mathrm{O}_{5}$ & 0.4 \\
$\mathrm{SO}_{3}$ & 15
\end{tabular}

The deposits on superheater parts can be classified into three types: sintered and fused, alkali matrix, and phosphatic. Sintered and fused deposits are coal ash particles consisting of 
silicates, alumina, iron oxide, lime, magnesia, and alkalis that are carried by the flue gas and deposited on the surface of boiler tubes. Alkali matrix deposits contain large amounts of alkali sulfates. Phosphatic deposits rarely occur in coal-fired boilers. The most troublesome deposit is sintered fly ash. Fly ash can form thick layers on superheater and reheater materials and can reduce heat transfer to the tube, plug gas passages, and provide the environment in which complex sulfates form and cause corrosion. The sintered deposits will form a layered structure, which is enhanced by the porosity of the sintered deposit and the temperature gradient.[11] The sintering characteristics of coal ash are very unpredictable, and are not well understood. The effect of the fly ash deposit particle size is very important. Smith[18] showed that the sintering temperature decreased as the particle size decreased.

The inorganic mineral matter in coals turns to ash or slag when heated. The mechanism of the process of transformation of mineral matter into ash in coal combustion chambers is shown below in Figure 5. It is a very complicated process, because it is determined by the composition of the original mineral matter, its size and distribution within the coal, the heating rate, the mixing of the inorganic matter during combustion, the maximum temperature reached, time, and turbulence in the gas stream. 


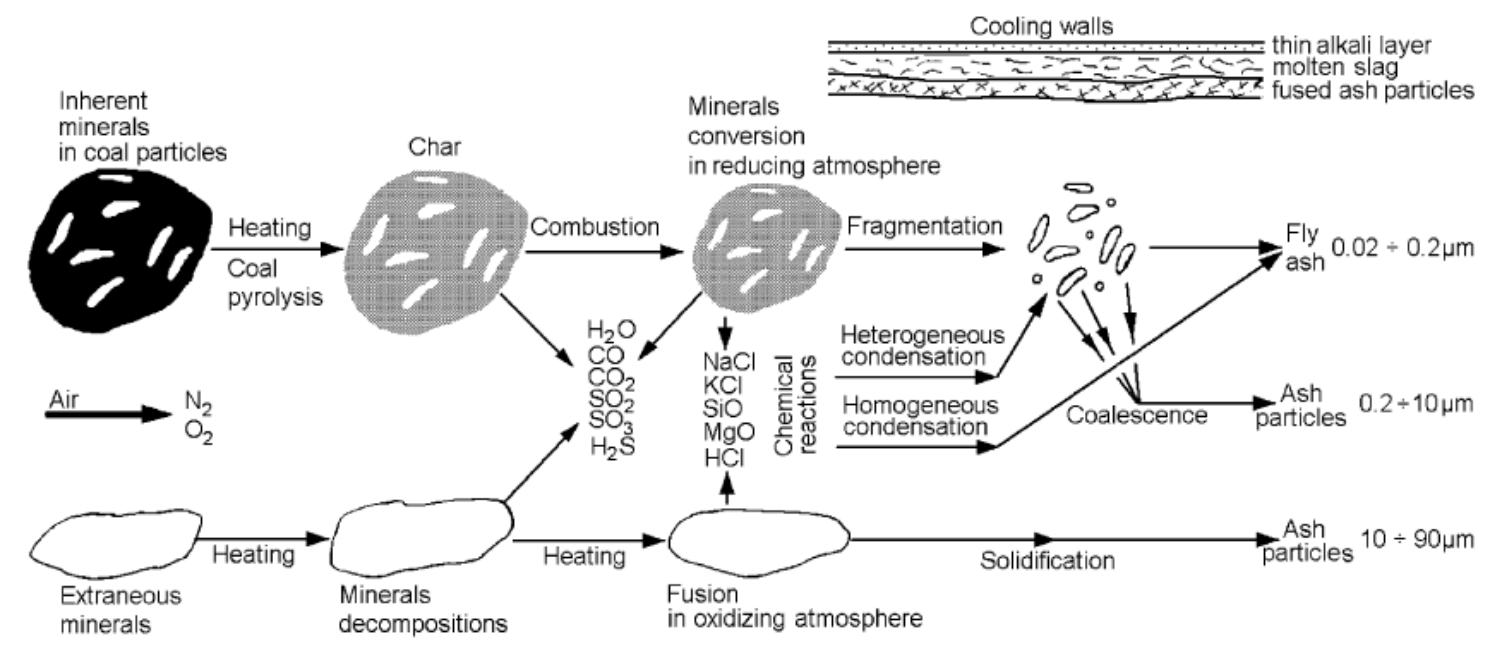

Figure 5: Mineral matter transformation mechanism [13]

An example of some of the many reactions that occur is when sulfides, kyanites, and marcasite begin to decompose at $300^{\circ} \mathrm{C}$. Under oxidizing conditions, the evolved sulfur is burnt to $\mathrm{SO}_{2}$, while some may be emitted as $\mathrm{H}_{2} \mathrm{~S}$ in the flue gas. In an oxidizing atmosphere, magnesium and calcium oxides will react with $\mathrm{SO}_{2}$ to form sulfates, which do not decompose until $1000^{\circ} \mathrm{C}$.[11] The sulfur in coal is stabilized by the formation of these calcium and magnesium sulfates, while the remaining sulfur will be oxidized to $\mathrm{SO}_{2} / \mathrm{SO}_{3}$. Even though coal may have large amounts of chlorine, $\mathrm{NaCl}$ and $\mathrm{KCl}$ salts are not able to deposit on the surface. This is because there are high amounts of $\mathrm{SO}_{2} / \mathrm{SO}_{3}$ in the flue gas, so the chlorides react with $\mathrm{SO}_{2}, \mathrm{O}_{2}$, and $\mathrm{H}_{2} \mathrm{O}$ to form sodium and potassium sulfates according to the following reactions[10],

$$
\begin{aligned}
& 2 \mathrm{NaCl}_{(\mathrm{s})}+\mathrm{SO}_{2(\mathrm{~g})}+1 / 2 \mathrm{O}_{2(\mathrm{~g})}+\mathrm{H}_{2} \mathrm{O}_{(\mathrm{g})}=\mathrm{Na}_{2} \mathrm{SO}_{4(\mathrm{~s})}+2 \mathrm{HCl}_{(\mathrm{g})} \\
& 2 \mathrm{KCl}_{(\mathrm{s})}+\mathrm{SO}_{2(\mathrm{~g})}+1 / 2 \mathrm{O}_{2(\mathrm{~g})}+\mathrm{H}_{2} \mathrm{O}_{(\mathrm{g})}=\mathrm{K}_{2} \mathrm{SO}_{4(\mathrm{~s})}+2 \mathrm{HCl}_{(\mathrm{g})}
\end{aligned}
$$

Figure 6 below shows the condensed compounds in equilibrium with the flue gas that form when coal is heated. $\mathrm{Na}_{2} \mathrm{SO}_{4}$ and $\mathrm{K}_{2} \mathrm{SO}_{4}$ become thermodynamically stable at temperatures below $900^{\circ} \mathrm{C}$ and $800^{\circ} \mathrm{C}$ respectively. $\mathrm{Na}_{2} \mathrm{SO}_{4}$ and $\mathrm{K}_{2} \mathrm{SO}_{4}$ are condensed from vapor in the surrounding 
flue gas. The corrosion of boiler tubes is thought to be from liquid phase alkali iron trisulfates. These can only form from $\mathrm{Na}_{2} \mathrm{SO}_{4}, \mathrm{~K}_{2} \mathrm{SO}_{4}$ and $\mathrm{Fe}_{2} \mathrm{O}_{3} \cdot[10]$

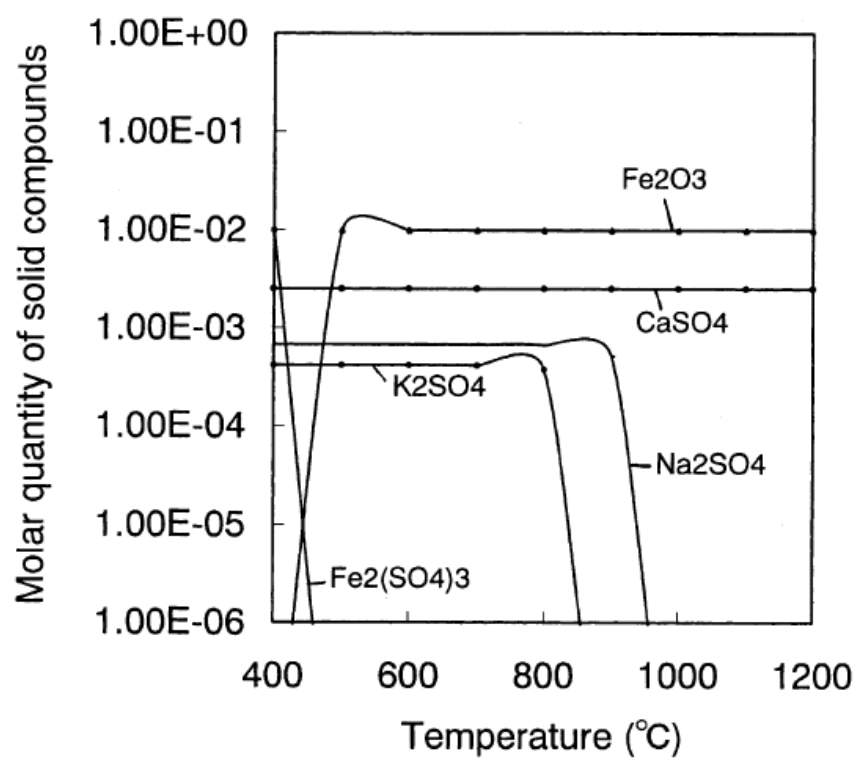

Figure 6: Calculated molar quantity of pure compounds of condensed phases in equilibrium with the flue gas upon combustion of $100 \mathrm{~g}$ of the coal shown in Table 1 [10]

\subsection{FIRESIDE CORROSION}

Corrosion from combustion gases can occur in many ways in boilers. Fireside corrosion is an accelerated form of corrosion induced from the melting of impurities in coal such as potassium, sodium, sulfur, and chlorine. It occurs by gas phase oxidation along with melted deposits that produce liquid-phase corrosion. Fireside corrosion can result in general mass loss or by the formation of cracks that then allow failure by mechanical mechanisms such as fatigue.[3] The temperature range of interest for boilers is between 650 and $750^{\circ} \mathrm{C}$, and along with the deposits, this will determine what type of corrosion will occur. The temperature regimes and corrosion 
materials are shown below in Figure 7. At the temperature range of interest, alkali iron trisulfates are believed to be the main contributor to fireside corrosion. The formation of liquid alkali iron trisulfates on the surface of boiler tubes beneath an ash deposit will cause significant corrosion. Alkali sulfate deposits will lead to rapid metal wastage especially when high sulfur coals are burned. The amount of corrosion will increase with increasing concentrations of $\mathrm{SO}_{2}$ and alkali sulfates. The temperature that corresponds to the maximum metal loss follows a bell curve with a maximum between $650-750^{\circ} \mathrm{C}$. The curve can be shifted based on alloy composition, $\mathrm{SO}_{2}$ level and alkali content. Alloys with lower corrosion resistance will usually have larger metal loss at lower temperatures than those with high corrosion resistance. Corrosion can be decreased by using materials with good oxidation resistance at the temperature range of interest. Gas phase oxidation is not typically a problem as long as alloys are chosen that have adequate oxidation and spallation resistance. Liquid-phase corrosion results in rapid attack even on stainless steels. Alloys with high chromium contents above 22wt\% show corrosion resistance. Chromium is the most beneficial alloying element for corrosion resistance. Pitting is the main result of fireside corrosion.[4,19-20] 


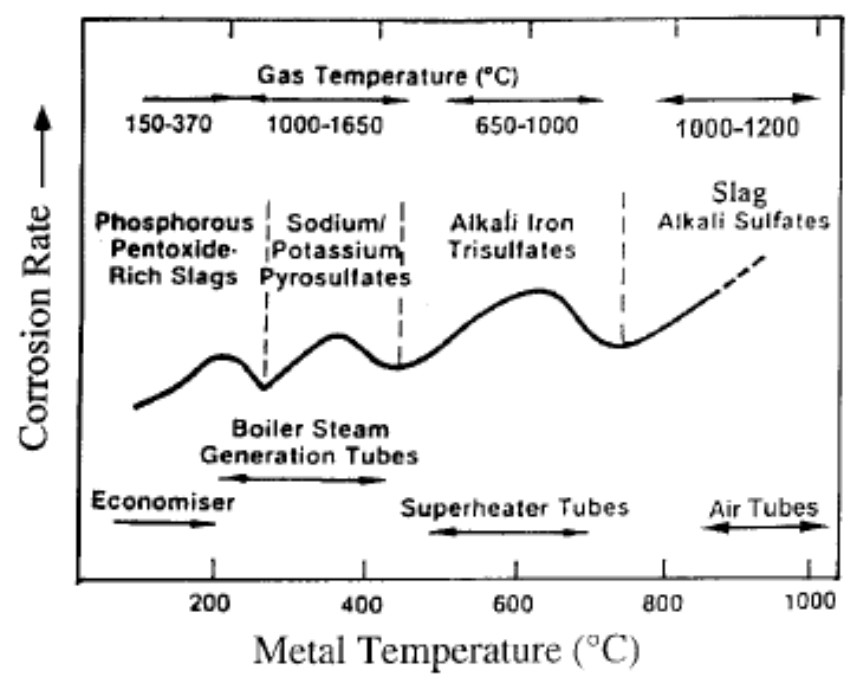

Figure 7: Fireside corrosion regimes in coal-fired boilers [19]

\subsubsection{Sulfur and Sulfates}

There are four main elements in fuels that are the major causes of corrosion. These are sulfur, vanadium, and the alkalis sodium and potassium. Sulfur is the most serious of these four. Vanadium occurs only in fuel oils. Sodium and potassium are present in coal, while sulfur is present in coal and fuel oils. The compounds of sulfur with iron, oxygen, and the alkalis cause the most corrosion and accumulation of deposits. Sulfur can cause high temperature corrosion from complex sulfates, or it can cause low temperature corrosion by $\mathrm{SO}_{3}$ reacting with deposits on the surface of metals (acidic fluxing).[21-22]

The amount of sulfur in coals can vary. The normal variation is $1-4 \%$. Sulfur occurs in coal in three forms: pyrites $\left(\mathrm{FeS}_{2}\right)$, organic sulfur in the coal itself, and sulfates. Pyritic sulfur is found in all coals, most likely as bands in the coal bed. Pyrites make up about half of the sulfur found in coals, and an effective way of removing it from the coal has not been found without suffering significant coal losses or significant costs. Organic sulfur is part of the complex 
mixture of molecules that make up coal, along with carbon, hydrogen, oxygen and nitrogen. Organic sulfur is uniformly distributed within the coal. After pyrites, half of the remaining sulfur in coal is organic sulfur. Organic sulfur can only be removed by combustion. Sulfate occurs as iron sulfate, but the amount of sulfate sulfur is so low that it plays little role in the many problems that sulfur can cause.[15]

Sulfur is highly reactive, especially with oxygen. $\mathrm{SO}_{2}$ and $\mathrm{SO}_{3}$ are in the products of combustion where they react to form sulfites, sulfates, and more complex trisulfates that cause corrosion. The total reaction for the formation of $\mathrm{SO}_{2}$ is given by[11],

$$
\mathrm{H}_{2} \mathrm{~S}+3 / 2 \mathrm{O}_{2}=\mathrm{H}_{2} \mathrm{O}+\mathrm{SO}_{2}
$$

The reaction of sulfur and oxygen occurs in many steps, and many of the intermediate steps in the oxidation of sulfur are unstable and do not last very long, but they all may influence the amount of reactants formed and the rate of reaction. A list of the reactions involved with the oxidation of sulfur is given below in Table 5 .

Table 5: Reactions in the oxidation of sulfur [23]

\begin{tabular}{|c|c|}
\hline $\mathrm{H}_{2} \mathrm{~S} \rightarrow \mathrm{SH}+\mathrm{H}-91 \mathrm{kcal}$ & (1) \\
\hline $\mathrm{H}+\mathrm{H}_{2} \mathrm{~S} \rightleftarrows \mathrm{SH}+\mathrm{H}_{2}+19 \mathrm{kcal}$ & \\
\hline $\mathrm{SH}+\mathrm{O}_{2} \rightleftarrows \mathrm{SO}+\mathrm{OH}+16 \mathrm{kcal}$ & $(3$ \\
\hline $\mathrm{OH}+\mathrm{H}_{2} \mathrm{~S} \rightleftarrows \mathrm{H}_{2} \mathrm{O}+\mathrm{SH}+22 \mathrm{kcal}$ & (4) \\
\hline $\mathrm{SO}+\mathrm{O}_{2} \rightleftarrows \mathrm{SO}_{2}+\mathrm{O}+18 \mathrm{kcal}$ & $(5$ \\
\hline$+\mathrm{H}_{2} \mathrm{~S} \rightleftarrows \mathrm{OH}+\mathrm{SH}+19 \mathrm{kcal}$ & 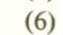 \\
\hline $\mathrm{O}+\mathrm{O} \rightarrow \mathrm{SO}_{2}{ }^{*} \rightarrow \mathrm{SO}_{2}+h v$ & \\
\hline $\mathrm{SO}+\mathrm{SO} \rightleftarrows \mathrm{S}_{2} \mathrm{O}_{2}+49 \mathrm{kcal}$ & $(8$ \\
\hline $\mathrm{SH}+\mathrm{SH} \rightleftarrows \mathrm{H}_{2}+\mathrm{S}_{2}+26 \mathrm{kcal}$ & \\
\hline $4 \mathrm{~S}_{2} \rightleftarrows \mathrm{S}_{8}$ & (10) \\
\hline $\mathrm{SH}+\mathrm{OH} \rightleftarrows \mathrm{H}_{2} \mathrm{O}+\mathrm{S}+27 \mathrm{kcal}$ & (11) \\
\hline $\mathrm{S}+\mathrm{O} \rightleftarrows \mathrm{SO}$ & (12) \\
\hline $\mathrm{S}+\mathrm{S} \rightleftarrows \mathrm{S}_{2}$ & (13) \\
\hline $\mathrm{H}+\mathrm{O}_{2} \rightleftarrows \mathrm{OH}+\mathrm{O}-16 \mathrm{kcal}$ & (14) \\
\hline $\mathrm{O}+\mathrm{H}_{2} \rightleftarrows \mathrm{OH}+\mathrm{H}-2 \mathrm{kcal}$ & (15) \\
\hline $\mathrm{OH}+\mathrm{H}_{2} \rightleftarrows \mathrm{H}_{2} \mathrm{O}+\mathrm{H}+15 \mathrm{kcal}$ & (16) \\
\hline $\mathrm{SO}_{2}+\mathrm{O}+\mathrm{M} \rightleftarrows \mathrm{SO}_{3}+\mathrm{M}+82 \mathrm{kcal}$ & (17) \\
\hline $\mathrm{SO}+\mathrm{O}_{2}+\mathrm{M} \rightleftarrows \mathrm{SO}_{3}+\mathrm{M}+93 \mathrm{kcal}$ & (18) \\
\hline $\mathrm{SO}_{3}+\mathrm{H}_{2} \rightleftarrows \mathrm{SO}_{2}+\mathrm{H}_{2} \mathrm{O}+38 \mathrm{kcal}$ & (19 \\
\hline
\end{tabular}


It does not matter which form of sulfur is present in the fuel. Combustion will convert it into $\mathrm{SO}_{2}$. The primary formation of $\mathrm{SO}_{2}$ is by the oxidation of $\mathrm{SO}$. The oxidation of pyrites can also form $\mathrm{SO}_{2}$. Levy and Merryman [23] studied the formation of sulfur dioxide in combustion reactions in $\mathrm{H}_{2} \mathrm{~S}$ flames, and determined that the oxidation of $\mathrm{SO}$ is the major cause of $\mathrm{SO}_{2}$ formation.

Sulfur trioxide in boiler furnaces and gas turbines can come from reactions within the flames, oxidation of $\mathrm{SO}_{2}$, and dissociation of complex sulfates. As was mentioned earlier, the sulfate content in fuels is so small, that it cannot contribute significant amounts of $\mathrm{SO}_{3}$ to the flue gas. The main source of $\mathrm{SO}_{3}$ in the flue gas is by the oxidation of $\mathrm{SO}_{2}$. The amount of $\mathrm{SO}_{2}$ will determine the amount of $\mathrm{SO}_{3}$ that can form. In boiler furnaces, roughly $1 \%$ of the $\mathrm{SO}_{2}$ is converted to $\mathrm{SO}_{3}$. There are two reactions which can produce $\mathrm{SO}_{3} \cdot[15]$

$$
\begin{aligned}
& \mathrm{SO}_{2}+1 / 2 \mathrm{O}_{2}=\mathrm{SO}_{3} \\
& \mathrm{SO}_{2}+\mathrm{O}=\mathrm{SO}_{3}
\end{aligned}
$$

The oxidation of $\mathrm{SO}_{2}$ with molecular oxygen only occurs in the presence of a catalyst. Dooley and Whittingham[24] found that the production of $\mathrm{SO}_{3}$ occurs by the reaction of $\mathrm{SO}_{2}$ with oxygen atoms, because there is a large concentration of atomic oxygen present in the combustion flames. Levy and Merryman [23] confirmed this by studying the microstructure of $\mathrm{H}_{2} \mathrm{~S}$ flames. The maximum amount of $\mathrm{SO}_{3}$ created was found about one flame thickness downstream of the flame, and remained constant even at further distances from the flame. This can be seen in Figure 8 below. This proves that reaction 4 above is not responsible for the formation of $\mathrm{SO}_{3}$, because large amounts of $\mathrm{O}_{2}$ and $\mathrm{SO}_{2}$ are present downstream of the flame, but the $\mathrm{SO}_{3}$ level reaches a maximum and then remains constant. If reaction 4 were responsible, the $\mathrm{SO}_{3}$ content would continue to rise. 


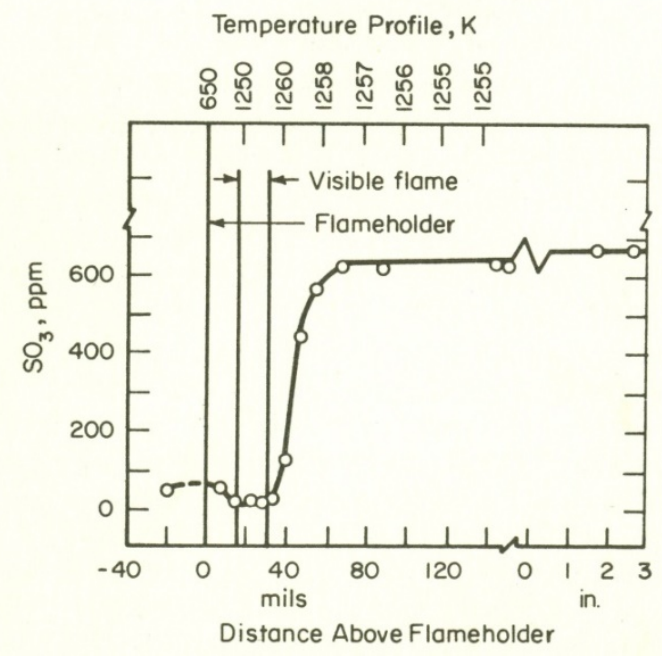

Figure 8: Formation of $\mathrm{SO}_{3}$ in thin stabilized flame of $\mathrm{H}_{2} \mathrm{~S}-\mathrm{O}_{2}-\mathrm{N}_{2}$ [25]

Levy and Merryman[23] also calculated the rate constants for the formation of $\mathrm{SO}_{3}$ from two flames, and found that the same amount of $\mathrm{SO}_{3}$ was created as in boiler furnaces. This shows that the conditions in a boiler furnace or gas turbine will not affect flame-produced $\mathrm{SO}_{3}$. The amount of $\mathrm{SO}_{3}$ that can be formed from $\mathrm{SO}_{2}$ depends on the temperature and the amount of the material exposed to the temperature. Lower temperatures will produce higher levels of $\mathrm{SO}_{3}$. At temperatures $426^{\circ} \mathrm{C}$ and below, $\mathrm{SO}_{3}$ will dominate the gas, but at temperatures $1093^{\circ} \mathrm{C}$ and above, $\mathrm{SO}_{2}$ will be the major component in the gas.[11] The partial pressure of oxygen will affect the equilibrium values of $\mathrm{SO}_{3}$. The more oxygen there is in the system, the higher amount of $\mathrm{SO}_{3}$ that can be created, but even very small amounts of oxygen are capable of oxidizing $\mathrm{SO}_{2}$ to $\mathrm{SO}_{3}$ in equilibrium. It is unusual for equilibrium to actually be reached in actual boiler furnaces however. The reason is the reactions do not have enough time to occur. The flue gas is cooled too quickly for equilibrium to be obtained.[15] When equilibrium levels of $\mathrm{SO}_{3}$ are approached, there is usually a catalyst involved. There can be homogeneous and heterogeneous 
catalysts. In boiler furnaces and gas turbines, homogeneous catalysis is not a significant factor in the formation of $\mathrm{SO}_{3}$. Platinum is a heterogeneous catalyst that can accelerate the oxidation of $\mathrm{SO}_{2}$ by $\mathrm{O}_{2}$. Vanadium and iron oxides, specifically $\mathrm{Fe}_{2} \mathrm{O}_{3}$, are also good catalysts and are less expensive. Harlow[26] was the first to find that $\mathrm{Fe}_{2} \mathrm{O}_{3}$ could be used as a catalyst for the oxidation of $\mathrm{SO}_{2}$ by $\mathrm{O}_{2}$. He found that the maximum amount of $\mathrm{SO}_{3}$ formed was in a specific temperature range (bell shaped curve), and the amount formed was not only dependent on the temperature, but also the amount of surface exposed. The formation of $\mathrm{SO}_{3}$ in the presence of $\mathrm{CO}_{2}$-containing (oxy-fuel combustion) and $\mathrm{N}_{2}$-containing (air fired combustion) atmospheres was compared.[27] Depending on the conditions, a $\mathrm{CO}_{2}$ atmosphere can increase or decrease $\mathrm{SO}_{3}$ formation, however it is difficult to determine what will occur in an oxy-fuel power plant. Increasing $\mathrm{H}_{2} \mathrm{O}$ contents have also been shown to increase $\mathrm{SO}_{3}$ formation.[27] The average gas concentrations measured in the oxidizing zone for different types of coals was conducted from a heavily instrumented pilot scale combustion facility. The concentrations can be seen in Table 6 . The total sulfur in the gas was linear with the amount of sulfur in the coal, which can be seen in Figure 9.[28-29]

Table 6: Average Gas Concentrations Measured in Oxidizing Zone for Different Coals [28-29]

\begin{tabular}{|c|c|c|c|c|c|c|}
\hline Coal & $\mathbf{C O}(\mathbf{p p m})$ & $\begin{array}{c}\mathrm{H}_{2} \mathrm{~S} \\
(\mathbf{p p m})\end{array}$ & $\begin{array}{c}\mathrm{SO}_{2} \\
(\mathbf{p p m})\end{array}$ & $\begin{array}{c}\mathrm{SO}_{3} \\
(\mathbf{p p m})\end{array}$ & $\mathbf{O}_{2}(\%)$ & $\mathbf{S O}_{3} / \mathrm{SO}_{2}$ Ratio \\
\hline PRB & 30 & 13 & 154 & 8 & 2.58 & 0.05 \\
\hline Beulah Zap & 22 & 202 & 556 & 10 & 3.00 & 0.02 \\
\hline Indiana & 543 & -9 & 854 & 26 & 3.50 & 0.03 \\
\hline Illinois \#6 & 478 & -14 & 2065 & 45 & 2.84 & 0.02 \\
\hline Gatling & 179 & -5 & 2983 & 68 & 3.28 & 0.02 \\
\hline
\end{tabular}




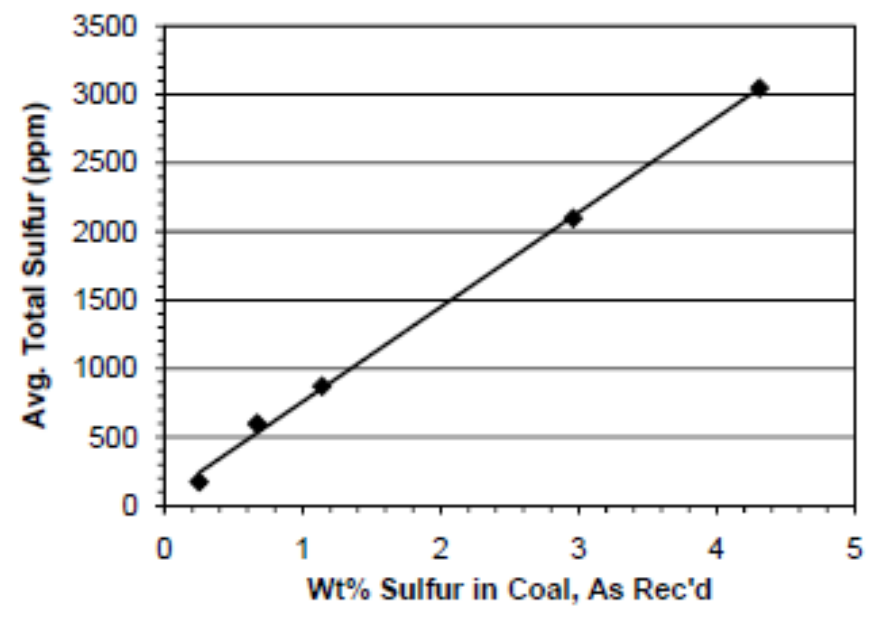

Figure 9: Average Total Sulfur vs. Wt\% Sulfur in the Coal [28-29]

Deposits of $\mathrm{K}_{2} \mathrm{SO}_{4}, \mathrm{Na}_{2} \mathrm{SO}_{4}$, and $\mathrm{Fe}_{2} \mathrm{O}_{3}$ in a 1.5:1.5:1.0 molar ratio exposed at 1100F $\left(593^{\circ} \mathrm{C}\right)$ produced alkali iron trisulfates. This deposit mixture is known from Cain and Nelson[30] as the "standard corrosion mix". Since 250ppm $\mathrm{SO}_{3}$ is necessary to produce trisulfates at this temperature[31], catalysis must be responsible, because there was no $\mathrm{SO}_{3}$ in the flue gas. $\mathrm{Fe}_{2} \mathrm{O}_{3}$ has been shown to be an excellent surface catalyst. Tests from Levy and Merryman[32] have shown that any ferritic alloy with $\mathrm{Fe}_{2} \mathrm{O}_{3}$ on the surface will aide in the oxidation of $\mathrm{SO}_{2}$, while $\mathrm{Fe}_{3} \mathrm{O}_{4}$ is an ineffective catalyst. A catalyst can be deactivated with additives from Group VA and Group VIA on the periodic table, specifically antimony or arsenic. Arsenic will deactivate platinum, so that it can no longer oxidize $\mathrm{SO}_{2}$ to $\mathrm{SO}_{3}$. Small amounts of $\mathrm{Sb}_{2} \mathrm{O}_{3}$ were shown to drastically decrease the formation of $\mathrm{SO}_{3}$ in the standard corrosion mix.[15] The deactivating materials are highly toxic substances however, and having these materials in the flue gas would not be tolerated. 


\subsubsection{Pyrosulfates}

Low-melting substances forming liquid films on the surfaces of boiler and gas turbine materials cause corrosion, and sulfates are the main cause of this. Alkali pyrosulfates such as $\mathrm{K}_{2} \mathrm{SO}_{7}$ and $\mathrm{Na}_{2} \mathrm{SO}_{7}$ were thought to be one of the main sulfates that cause corrosion. These substances have low melting points of $754^{\circ} \mathrm{F}\left(401^{\circ} \mathrm{C}\right.$ ) for $\mathrm{Na}_{2} \mathrm{SO}_{7}$ and $570^{\circ} \mathrm{F}\left(299^{\circ} \mathrm{C}\right)$ for $\mathrm{K}_{2} \mathrm{SO}_{7}$ and high chemical activity. Studies by Reid showed that the level of $\mathrm{SO}_{3}$ necessary to form the alkali pyrosulfates is not reached at the temperatures used in boilers and gas turbines.[15] Coats, Dear, and Penfold[33] examined the partial pressure of $\mathrm{SO}_{3}$ with the temperature of alkali pyrosulfates. They found that the amount of $\mathrm{SO}_{3}$ needed to produce pyrosulfates at the operating temperatures of boilers was higher than what is possible to be formed. At lower temperatures, the $\mathrm{SO}_{3}$ content is high enough to produce pyrosulfates. This can be seen in Figure 10 . If the temperature is low and the $\mathrm{SO}_{3}$ content is high enough, corrosion from pyrosulfates can occur.

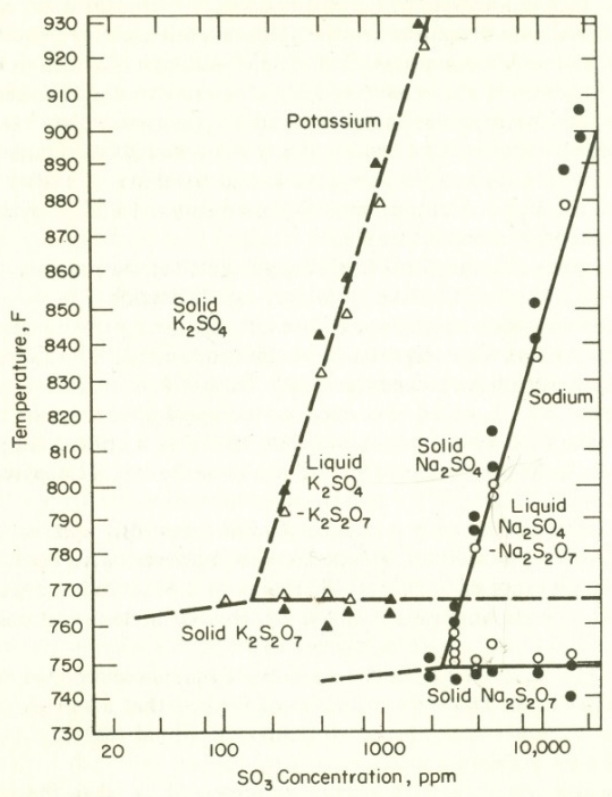

Figure 10: Melting points in the system $\mathrm{Na}_{2} \mathrm{SO}_{4}-\mathrm{SO}_{3}$ and $\mathrm{K}_{2} \mathrm{SO}_{4}-\mathrm{SO}_{3}$ [33] 
The high concentrations of $\mathrm{SO}_{3}$ needed come from the catalytic oxidation of $\mathrm{SO}_{2}$ on the surfaces, which can create much higher $\mathrm{SO}_{3}$ content than the bulk gas. The mechanism involves the formation of alkalis on the surface followed by a conversion to $\mathrm{K}_{2} \mathrm{SO}_{4}$ and $\mathrm{Na}_{2} \mathrm{SO}_{4}$. The formation of pyrosulfates is caused by the reaction of sulfates with $\mathrm{SO}_{3}$, and their reaction with oxides grown on the surface is shown by the following reactions[11],

$$
\begin{aligned}
& 3 \mathrm{Na}_{2} \mathrm{~S}_{2} \mathrm{O}_{7}+\mathrm{Fe}_{2} \mathrm{O}_{3}=3 \mathrm{Na}_{2} \mathrm{SO}_{4}+\mathrm{Fe}_{2}\left(\mathrm{SO}_{4}\right)_{3} \\
& 4 \mathrm{Na}_{2} \mathrm{~S}_{2} \mathrm{O}_{7}+\mathrm{Fe}_{3} \mathrm{O}_{4}=4 \mathrm{Na}_{2} \mathrm{SO}_{4}+\mathrm{FeSO}_{4}+\mathrm{Fe}_{2}\left(\mathrm{SO}_{4}\right)_{3}
\end{aligned}
$$

Further oxidation then occurs to replace the oxide scale leading to metal loss according to the reaction[11],

$$
3 \mathrm{Fe}+2 \mathrm{O}_{2}=\mathrm{Fe}_{3} \mathrm{O}_{4}
$$

\subsubsection{Alkali Iron Trisulfates}

Most of the alloys used as boiler tubes are iron-based alloys, and the mobility of iron from the metal substrate to the oxide/gas interface is fairly rapid, therefore considerable research has been done on the formation of alkali iron trisulfates and their role in the corrosion of boiler tubes.[19] Alkali iron trisulfates are the most probable cause of liquid phase corrosion, because their melting points are in the range of superheater metal temperatures, they have been found in the areas where corrosion has occurred, and they are highly reactive materials. The melting points of some alkali trisulfates are shown in Table 7. 
Table 7: Melting point of complex sulfates [30]

\begin{tabular}{lr}
\hline Compound & Melting Point, F \\
\hline $\mathrm{K}_{3} \mathrm{Fe}\left(\mathrm{SO}_{4}\right)_{3}$ & $1145\left(618^{\circ} \mathrm{C}\right)$ \\
$\mathrm{K}_{3} \mathrm{Al}\left(\mathrm{SO}_{4}\right)_{3}$ & $1210\left(654^{\circ} \mathrm{C}\right)$ \\
$\mathrm{KFe}\left(\mathrm{SO}_{4}\right)_{2}$ & $1281^{\circ}\left(694^{\circ} \mathrm{C}\right)$ \\
$\mathrm{Na}_{3} \mathrm{Fe}\left(\mathrm{SO}_{4}\right)_{3}$ & $1155\left(624^{\circ} \mathrm{C}\right)$ \\
$\mathrm{Na}_{3} \mathrm{Al}\left(\mathrm{SO}_{4}\right)_{3}$ & $1195\left(646^{\circ} \mathrm{C}\right)$ \\
$\mathrm{NaFe}\left(\mathrm{SO}_{4}\right)_{2}$ & $1274^{\circ}\left(690^{\circ} \mathrm{C}\right)$ \\
\hline
\end{tabular}

${ }^{\text {a }}$ In high $\mathrm{SO}_{3}$ atmosphere

Alkali iron trisulfates can form from reactions with iron oxides and $\mathrm{SO}_{3}$ in the gas, leading to further iron oxidation and metal loss[11],

$$
\begin{aligned}
& 3 \mathrm{~K}_{2} \mathrm{SO}_{4}+\mathrm{Fe}_{2} \mathrm{O}_{3}+3 \mathrm{SO}_{3}=2 \mathrm{~K}_{3} \mathrm{Fe}\left(\mathrm{SO}_{4}\right)_{3} \\
& 4 \mathrm{Fe}+3 \mathrm{O}_{2}=2 \mathrm{Fe}_{2} \mathrm{O}_{3}
\end{aligned}
$$

The iron oxides in these reactions can come from the oxide scale grown on the metal surface or from the ash deposits formed on the surface. $\mathrm{Na}_{3} \mathrm{Fe}\left(\mathrm{SO}_{4}\right)_{3}$ forms from a similar reaction, and these reactions become the basis for determining the standard corrosion mix.[15] At $1100^{\circ} \mathrm{F}$ $\left(593^{\circ} \mathrm{C}\right)$, alkali iron trisulfates formed when the $\mathrm{SO}_{3}$ level was above $250 \mathrm{ppm}$. The amount of $\mathrm{SO}_{3}$ present in the flue gas is a major factor on the formation of alkali iron trisulfates.[31] The trisulfates will decompose when heated in $\mathrm{SO}_{3}$-free atmospheres. The maximum amount of corrosion was found when deposits contain equimolar ratios of potassium and sodium sulfate at high temperatures. The ratio changes with temperature, and this shows that the rate of corrosion is dependent on the melting point. Large amounts of clay minerals such as kaolinite $\left(\mathrm{Al}_{2} \mathrm{O}_{3} \cdot 2 \mathrm{SiO}_{2} \cdot 2 \mathrm{H}_{2} \mathrm{O}\right)$ will dilute the sodium and potassium in the deposit and result in less corrosion.[2] Calcium and magnesium in coal ash may also inhibit the formation of alkali iron trisulfates, because they will preferentially form relatively harmless compounds such as 
$\mathrm{K}_{2} \mathrm{SO}_{4} \cdot 2 \mathrm{CaSO}_{4}$. This will be discussed in more detail in future sections. The reaction of $\mathrm{SO}_{3}$ directly with the superheater metal surfaces is not a significant source for corrosion.[15]

\subsubsection{Mechanism of Corrosion}

Metal loss in boilers and gas turbines can occur by gas-phase oxidation or by removal of the protective scale on metals through chemical reaction with a deposit. It is not certain which of these processes is the cause of fireside corrosion, but it is known that a liquid-phase deposit is needed for corrosion to occur at a significant rate. It may also be a case of many of these processes acting simultaneously. The formation of molten alkali iron trisulfates on superheater and reheater tube surfaces is thought to be the main cause of fireside corrosion, however it is undetermined if they are a corrosion product. The corrosion of boiler metals is hard to replicate in a laboratory, because there are variations in the fuel and the environment is constantly changing. Some of the non-replicable environmental problems are that the actual composition of deposits formed on tubes is more complex than simulated deposits, the $\mathrm{SO}_{3}$ content is variable, large temperature gradients occur, the ash and flue gas move at varying velocities, the composition of deposits will change with time, and fly-ash erosion can remove oxide scales exposing base metal; however it is believed that the research performed for this project is valid for studying the fireside corrosion of boiler materials.[34]

\subsubsection{Gas-Phase Oxidation}

Exposure of metal surfaces to the hot flue gas atmosphere creates an oxide film on the surface. The alloys used for boiler tubes are typically ferritic steels and stainless steels that form a protective and adherent oxide scale on the surface. The oxidation of metals produces scales 
that can grow at linear, parabolic, logarithmic, or cubic rates. The rate is determined by the diffusion of components through the oxide layer and the reactions at the metal/oxide and oxide/gas interfaces. The parabolic rate law is the most common, and the one that describes the growth rate of oxide scales for alloys used in boilers and gas turbines. The parabolic rate law is given by the equation shown below[35],

$$
x^{2}=2 k t
$$

where $\mathrm{x}$ is the oxide thickness, $\mathrm{k}$ is the rate constant, and $\mathrm{t}$ is time. Following this equation, the rate at which the oxide scale grows will decrease with time until it reaches a rate that is so small that it can be ignored. If the scale becomes too thick and breaks off, the metal will oxidize further at a high rate producing more metal loss. Most boiler metals are steels, and are therefore Fe-based. Unalloyed iron forms a multi-layered, fast-growing, non-protective scale that is dependent on the oxidation temperature. This can be seen from the iron-oxygen phase diagram shown below in Figure 11.

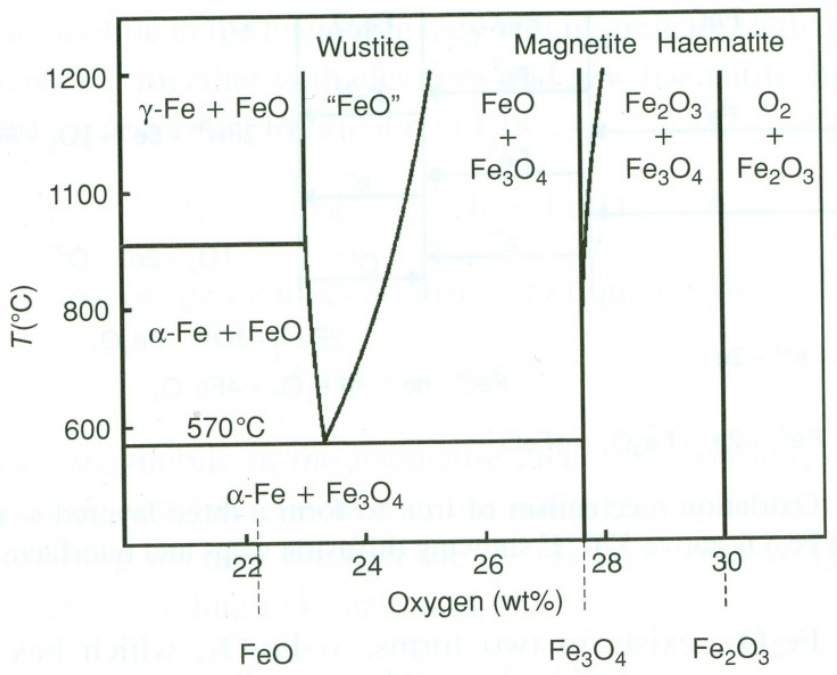

Figure 11: The iron-oxygen phase diagram [35] 
At temperatures above $570^{\circ} \mathrm{C}$, iron will form an oxide scale consisting of $\mathrm{FeO}, \mathrm{Fe}_{3} \mathrm{O}_{4}$, and $\mathrm{Fe}_{2} \mathrm{O}_{3}$ in order from the metal surface and in order of scale thickness. The relative thicknesses of the layers are given by the ratio, $\mathrm{FeO}: \mathrm{Fe}_{3} \mathrm{O}_{4}: \mathrm{Fe}_{2} \mathrm{O}_{3}$ roughly 95:4:1.[35] $\mathrm{FeO}$ does not form below this temperature. Most metals used for boiler or gas turbine hardware are stainless steels or nickel based alloys. These alloys usually have significant amounts of chromium in them in order to develop a slowly-growing protective layer of chromium oxide $\left(\mathrm{Cr}_{2} \mathrm{O}_{3}\right)$ on the surface. This is known as selective oxidation. There is a critical amount of chromium needed in an alloy in order to form this external protective scale. If the critical amount of chromium is not met, then a non-protective internal oxide scale will form. The critical amount for the transition from internal to external oxidation can be determined from equation 12[35], where $\mathrm{N}^{\mathrm{O}}$ Cr is the critical amount of chromium needed to form protective oxide layer, $v$ is the stoichiometric constant, $\mathrm{g}^{*}$ is a material constant, $\mathrm{N}_{\mathrm{O}}{ }^{(\mathrm{s})}$ is the oxygen solubility in the metal, $\mathrm{D}_{\mathrm{O}}$ is the oxygen diffusion coefficient through the metal, $\mathrm{V}_{\mathrm{m}}$ is the volume of the metal, $\tilde{\mathrm{D}}_{\mathrm{FeCr}}$ is the chromium diffusion coefficient through the metal, and $\mathrm{V}_{\mathrm{ox}}$ is the volume of oxide.

$$
N_{C r}^{o}>\left[\left(\frac{\pi g^{*}}{2 v}\right) \frac{N_{O}^{(s)} D_{O} V_{m}}{D_{C r} V_{O x}}\right]^{1 / 2}
$$

The amount of chromium needed can be influenced by all of the parameters in the equation given above. Conditions that decrease the inward flux of oxygen, such as lowering the partial pressure of oxygen, or conditions that increase the outward flux of chromium, such as cold working the alloy, will decrease the amount of chromium needed in order to produce an external protective scale. 
There is also a critical amount of chromium needed in order to maintain the external protective oxide scale. This is given by the equation shown below[35], where $k_{p}$ is the reaction rate constant.

$$
N_{C r}^{o}=\left(\frac{V_{m}}{32 v}\right)\left(\frac{\pi k_{p}}{\bar{D}_{F e C r}}\right)^{1 / 2}
$$

Most stainless steels used in high temperature applications are designed with chromium contents in excess of $20 \%$ in order to meet these requirements. Even with high chromium levels, iron ions will eventually diffuse through the chromia scale and a non-protective iron oxide layer will form. Austenitic stainless steels also contain large amounts of austenite stabilizing Ni, and are highly corrosion resistant materials. Nickel also enhances ductility and hardness. In any metal alloy that forms a protective oxide layer on the surface, transient oxides of the base element can form before the protective oxide layer. This can increase the amount of alloying element such as chromium needed to form the protective external scale. The extent of the transient oxides is decreased by the factors that promote selective oxidation, such as higher chromium contents, reduced oxygen pressures, and cold working. Any rupture of the protective chromia scale will expose a lower chromium content alloy and return it to its transient state, causing more metal loss.[35] Typically gas-phase oxidation in boiler atmospheres does not lead to significant metal loss in boiler tubes unless chlorides or low-melting oxides remove the usually protective oxide scales.

\subsubsection{Liquid-Phase Corrosion}

The presence of liquid is usually necessary in order for significant corrosion to occur. This is because chemical reactions are faster whenever liquids are present, liquids more effectively insulate the alloy from the gas, and because liquids provide an electrolyte for 
electrochemical attack. Different areas of the metal will act as cathodes and anodes. With a highly ionized melt, electrons will transfer from anode to cathode, so that anodic iron will oxidize.[15] The oxidation rate depends on the concentration of dissolved metal, the amount of oxygen and sulfur oxides in the melt, and the presence of other substances. A voltametric analysis of molten alkali sulfates showed that the degree of corrosion of iron will depend on the amount of $\mathrm{SO}_{3}$ in the molten sulfate on the surface of the metal.[36] The $\mathrm{SO}_{3}$ concentration in the molten sulfate is the equilibrium concentration at that temperature, and deposits of varying thickness will cause different $\mathrm{SO}_{3}$ concentrations at the metal surface, setting up a corrosion potential gradient. Figure 12 shows the temperature distribution through a superheater tube under typical operating conditions.

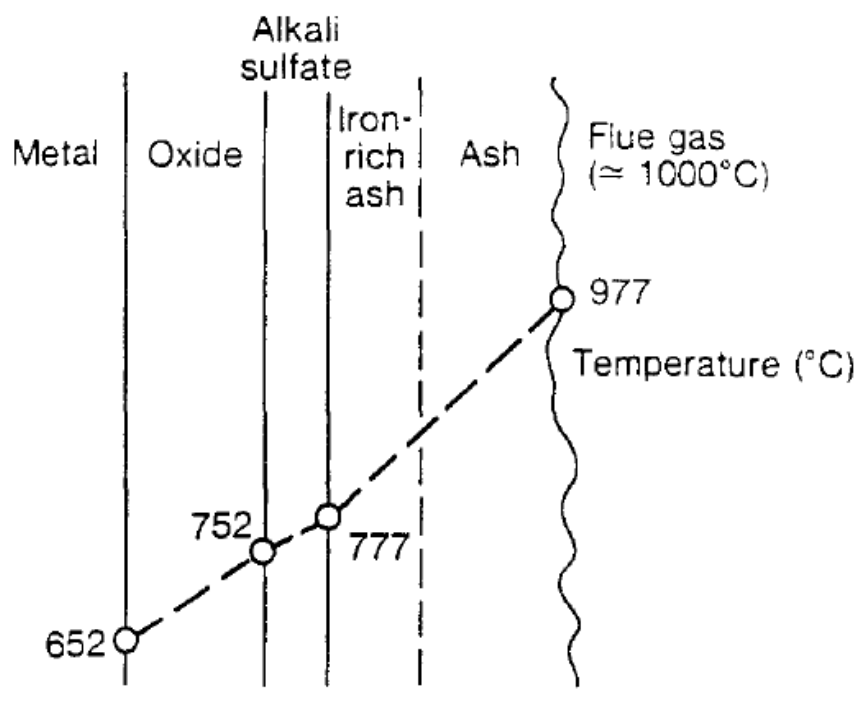

Figure 12: The general temperature distribution through a superheater tube, the oxide, and the deposit [3]

The heat flux will be the least in the areas where the ash is the thickest, and there will be the least amount of metal loss where the deposit is the thickest, directly in front of the flue gas stream. As 
mentioned before, if the temperature is low and there are high amounts of $\mathrm{SO}_{3}$, then pyrosulfates can cause corrosion. The temperature regimes in the present study were not in this range. The corrosion being analyzed was in the temperature range where alkali iron trisulfate is thought to be the main cause.

Alkali iron trisulfates such as $\mathrm{Na}_{3} \mathrm{Fe}\left(\mathrm{SO}_{4}\right)_{3}$ and $\mathrm{K}_{3} \mathrm{Fe}\left(\mathrm{SO}_{4}\right)_{3}$ are believed to be the main causes of corrosion in superheater and reheater tubes in boilers, and they have always been found in the areas where corrosion is occurring. It has been determined that metal wastage can occur due to the chemical reaction of iron oxide scales with alkali sulfates in the flame in the presence of sufficient amounts of $\mathrm{SO}_{3}$. The continuous reoxidation of the base iron alloy along with significant internal corrosion pits establishes the metal loss. The chemical reaction products between the iron oxide scale and the alkali sulfates are the alkali iron trisulfates $\mathrm{Na}_{3} \mathrm{Fe}\left(\mathrm{SO}_{4}\right)_{3}$ and $\mathrm{K}_{3} \mathrm{Fe}\left(\mathrm{SO}_{4}\right)_{3}$. The chemical reaction can be expressed by the following equations[15],

$$
\begin{aligned}
& 2 \mathrm{Fe}_{3} \mathrm{O}_{4}+9 \mathrm{~K}_{2} \mathrm{SO}_{4}+9 \mathrm{SO}_{3}+1 / 2 \mathrm{O}_{2}=6 \mathrm{~K}_{3} \mathrm{Fe}\left(\mathrm{SO}_{4}\right)_{3} \\
& \mathrm{Fe}_{2} \mathrm{O}_{3}+3 \mathrm{~K}_{2} \mathrm{SO}_{4}+3 \mathrm{SO}_{3}=2 \mathrm{~K}_{3} \mathrm{Fe}\left(\mathrm{SO}_{4}\right)_{3} \\
& 3 \mathrm{Fe}+2 \mathrm{O}_{2}=\mathrm{Fe}_{3} \mathrm{O}_{4} \\
& 4 \mathrm{Fe}+3 \mathrm{O}_{2}=2 \mathrm{Fe}_{2} \mathrm{O}_{3}
\end{aligned}
$$

There are a series of steps in which the corrosion of the metal occurs according to a mechanism proposed by Reid[15] assuming a high enough $\mathrm{SO}_{3}$ content. The steps can be seen in Figure 13 and are as follows: 


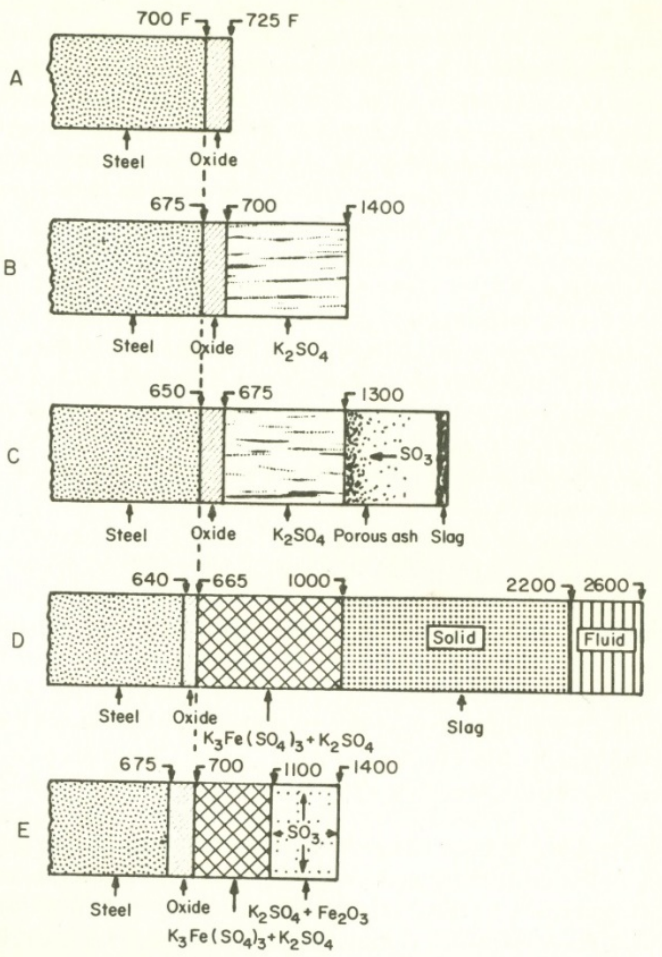

Figure 13: Mechanism of fireside corrosion of steel surfaces by removal of oxide film to form $\mathrm{K}_{3} \mathrm{Fe}\left(\mathrm{SO}_{4}\right)_{3}[15]$

A. An iron oxide scale grows on the surface of the metal tube.

B. Alkali sulfates such as $\mathrm{K}_{2} \mathrm{SO}_{4}$ that form from alkalis in the coal and the fuel ash and sulfur oxides in the atmosphere are deposited on the oxide scale.

C. The outer surface of the alkali sulfate layer becomes sticky due to an increasing temperature gradient, and this causes particles of fly ash to become captured on the surface. The temperature in the captured fly ash increases to the point that $\mathrm{SO}_{3}$ is released by thermal dissociation of the sulfur compounds in the ash. The released $\mathrm{SO}_{3}$ migrates towards the cooler base metal surface, and a layer of slag forms on the outer surface. 
D. More ash is collected reaching a steady-state thickness. The temperature decreases in the alkali sulfate layer, which causes a reaction with the oxide scale and $\mathrm{SO}_{3}$ occurs to form alkali iron trisulfates. This removes the oxide scale, which causes the base metal to reoxidize further causing metal wastage.

E. Deslagging then occurs exposing the alkali iron trisulfate layer to temperatures high enough to dissociate it releasing $\mathrm{SO}_{3}$. Part of this released $\mathrm{SO}_{3}$ moves toward the cooler part of the deposit, where it reacts with $\mathrm{K}_{2} \mathrm{SO}_{4}$ present and the oxide scale to form more alkali iron trisulfates. This leads to further oxidation of the scale and more metal loss.

This cycle can repeat indefinitely because there is no loss of alkalis except for the small amount lost due to deslagging. More alkalis can also be deposited from the flue gas after each deslagging event. The high $\mathrm{SO}_{3}$ content needed for this reaction can come from the gas atmosphere and the catalytic oxidation of $\mathrm{SO}_{2}$ with $\mathrm{Fe}_{2} \mathrm{O}_{3}$ as discussed earlier. The adherence of the ash deposits on the oxide scale is dependent on the characteristics of the oxide and the deposit. Because there is not a large difference in thermal expansion coefficients[37], the deposits on steel boiler tubes are very adherent and can become very difficult to remove. The deposits have been shown to peel off easily from austenitic stainless steels when cooled.[11] $\mathrm{K}_{3} \mathrm{Cr}\left(\mathrm{SO}_{4}\right)_{3}$ has not been found in deposits, and so that shows that chromium oxide will resist corrosion from this mechanism, which explains why high chromium content alloys are more resistant to fireside corrosion.

Cain and Nelson[38] proposed a different corrosion mechanism in which the alkali iron trisulfates are formed within the ash deposit. They showed that the "standard corrosion mix" mentioned previously subjected to the flue gas of $3.6 \% \mathrm{O}_{2}$ and $0.25 \% \mathrm{SO}_{2}$ produced molten alkali 
iron trisulfates. The trisulfates formed in fireside ash deposits by the reaction of $\mathrm{Fe}_{2} \mathrm{O}_{3}$ in the ash with alkali sulfates and $\mathrm{SO}_{3}$, and they traveled through the ash deposit to the metal tube surface by means of a thermal gradient in the deposit. The molten trisulfates react with the base tube metal according to the reaction,

$$
9 \mathrm{Fe}+2 \mathrm{~K}_{3} \mathrm{Fe}\left(\mathrm{SO}_{4}\right)_{3}=4 \mathrm{Fe}_{2} \mathrm{O}_{3}+3 \mathrm{FeS}+3 \mathrm{~K}_{2} \mathrm{SO}_{4}
$$

A sulfide scale is formed in this reaction. Sulfides are not frequently found in the corrosion regions where trisulfides are present, so if this corrosion mechanism occurs, the sulfides must be removed by reoxidizing and forming more iron oxide and $\mathrm{SO}_{3}$. This mechanism is shown in Figure 14.

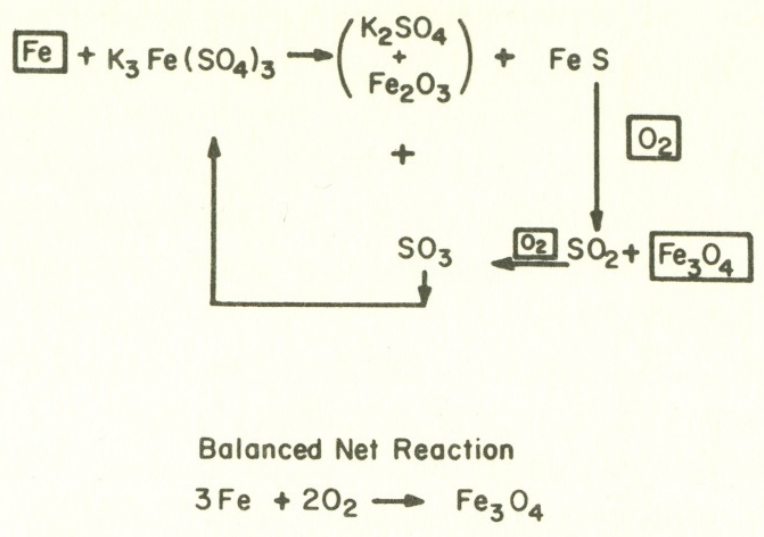

Figure 14: Coal-ash corrosion cycle [38]

This mechanism proposes that only iron and oxygen are consumed and that $\mathrm{Fe}_{3} \mathrm{O}_{4}$ is the only product. Alkali sulfates and $\mathrm{FeS}$ are recycled by the $\mathrm{FeS}$ reoxidizing to $\mathrm{SO}_{2}$ which then oxidizes further to $\mathrm{SO}_{3}$, which then again reacts with $\mathrm{Fe}_{3} \mathrm{O}_{4}$ and alkali sulfates to produce more alkali iron trisulfates, which repeats the cycle. The only problem with this corrosion mechanism is that the metal loss occurs only by direct attack of the base tube metal by the alkali iron trisulfates. The 
base tube metal will most likely form an oxide layer on the surface at the temperatures of interest, so that the exposed surface of the tube is iron oxides. Cracks in the oxide layer on the tube would expose base metal, and the proposed mechanism by Cain and Nelson could then occur, but the amount of metal loss this way would be small. Erosion from ash particles flying at a high velocity can remove the protective oxide scale and accelerate corrosion from the mechanism by Cain and Nelson.[15] The proposed mechanism described later in this thesis is a combination of the mechanisms described by Cain and Nelson[38], the synergistic fluxing mechanism from Rapp[80], as well as the Type II hot corrosion mechanism described by Luthra[39] which will be discussed in a future section.

Corey et.al.[40] showed that sulfides could also be present from unburned pyrites in the coal. The mechanism for large amounts of FeS in the regions of heavy corrosion is as follows[15],

A. Alkalis from the fuel are deposited on the oxide scale surface as alkali sulfates.

B. Unburned coal particles and pyrites become adherent to the tube surface and form a thick deposit layer.

C. The pyrites oxidize to form $\mathrm{Fe}_{3} \mathrm{O}_{4}$, with evolved sulfur forming $\mathrm{SO}_{2}$ and $\mathrm{SO}_{3}$ in the deposit.

D. The sulfur oxides form small quantities of alkali iron trisulfates leading to a loss of some metal.

In places where combustion is complete and there is no unburned fuel or pyrites able to reach the surface of the metal tube, this mechanism is unlikely when compared to the trisulfates.

Shi et al.[41] studied the effects of different deposits on the rate of fireside corrosion of Fe-Al alloys. They found that for a $\mathrm{Fe}-10 \% \mathrm{Al}$ alloy, the corrosion rate for a $\mathrm{K}_{2} \mathrm{SO}_{4}+\mathrm{Na}_{2} \mathrm{SO}_{4}$ 
deposit was twice as high as for deposits of just $\mathrm{K}_{2} \mathrm{SO}_{4}$ or $\mathrm{Na}_{2} \mathrm{SO}_{4}$ alone. The corrosion rate was at a maximum at $650^{\circ} \mathrm{C}$, and it increased with increasing $\mathrm{SO}_{2}$ and $\mathrm{SO}_{3}$ in the atmosphere and decreased with increasing aluminum content. This is similar to deposits of $\mathrm{Na}_{2} \mathrm{SO}_{4}$ alone. The corrosion kinetics curves for the deposits of $\mathrm{K}_{2} \mathrm{SO}_{4}+\mathrm{Na}_{2} \mathrm{SO}_{4}$ and for $\mathrm{Na}_{2} \mathrm{SO}_{4}$ both show a linear segment, but the curve for $\mathrm{K}_{2} \mathrm{SO}_{4}+\mathrm{Na}_{2} \mathrm{SO}_{4}$ became linear much earlier and was linear for a longer time. This can be seen in Figure 15.

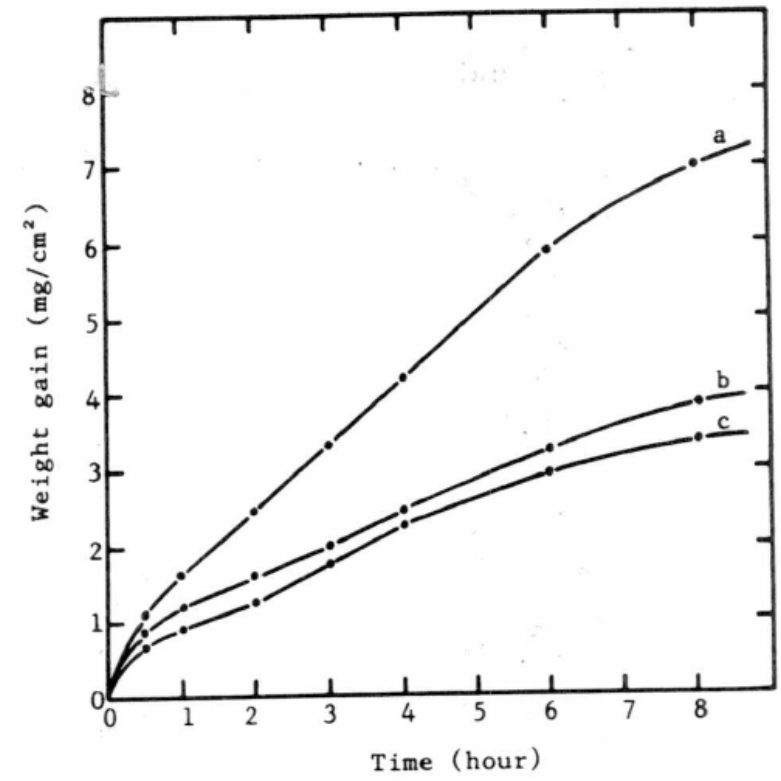

Figure 15: Oxidation kinetics of Fe-10Al Alloy exposed to $\mathrm{O}_{2}-0.5 \%\left(\mathrm{SO}_{2}+\mathrm{SO}_{3}\right)$ at $650^{\circ} \mathrm{C}$ : (a) $\mathrm{Na}_{2} \mathrm{SO}_{4}-\mathrm{K}_{2} \mathrm{SO}_{4}$, (b) $\mathrm{Na}_{2} \mathrm{SO}_{4}$ alone, and (c) $\mathrm{K}_{2} \mathrm{SO}_{4}$ alone [41]

The addition of $\mathrm{K}_{2} \mathrm{SO}_{4}$ to the deposit does not change the corrosion mechanism, but it does significantly increase the corrosion rate. Sulfation tests also showed that the critical amount of $\mathrm{SO}_{3}$ needed to cause liquid trisulfates is dependent on the temperature and decreases by more than an order of magnitude when $\mathrm{K}_{2} \mathrm{SO}_{4}$ is added to the deposit. This can be seen in Figure 16 . 


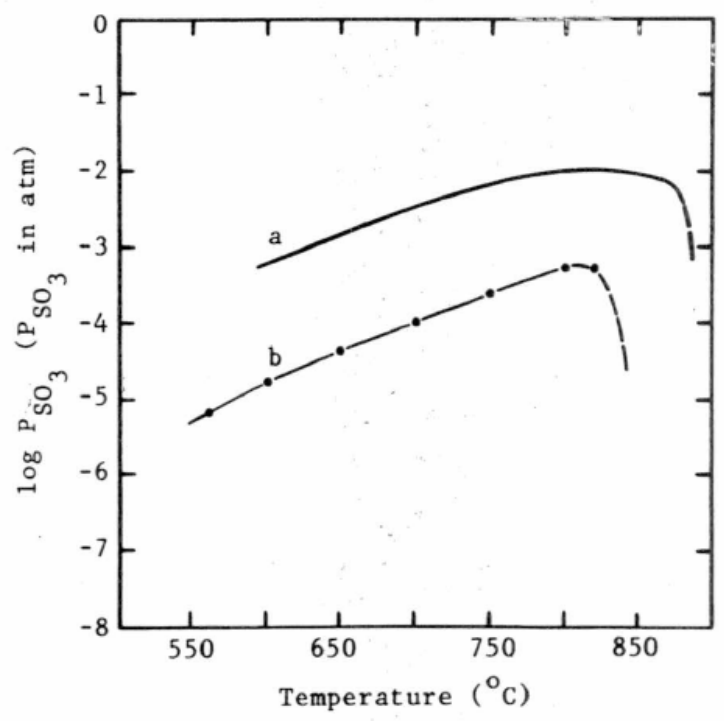

Figure 16: $\mathrm{SO}_{3}$ levels required to stabilize eutectic melts: (a) $\mathrm{Na}_{2} \mathrm{SO}_{4}$-iron trisulfates and (b) $\mathrm{Na}_{2} \mathrm{SO}_{4}-\mathrm{K}_{2} \mathrm{SO}_{4}$ iron trisulfates [41]

The time at which the deposit melts correlates to the start of the linear portion of the corrosion kinetics curve. The liquid solution is forming earlier when $\mathrm{K}_{2} \mathrm{SO}_{4}$ is added to the deposit. The accelerated corrosion was found to occur not because of the formation of complex sulfates or the sulfation of $\mathrm{Fe}_{2} \mathrm{O}_{3}$, but because of the earlier formation of the liquid deposit.

\subsubsection{Alloys for Use in Boilers}

The main components in advanced combustion technologies that require high performance are high pressure steam piping and headers, superheater tubing, and waterwall tubing. With the advancement of new combustion technologies, higher thermal efficiency is needed, and so materials must be able to have high strength at increasing temperatures. Superheater tubing 
components for oxy-fuel combustion must have high creep strength, thermal fatigue strength, weldability, resistance to fireside corrosion, and resistance to steam side oxidation and spallation. Martensitic or ferritic stainless steels would be beneficial from thermal fatigue strength and cost perspectives. However, the strongest of these materials can really only be used at temperatures as high as $620^{\circ} \mathrm{C}$, and even lower temperatures when fireside corrosion is being considered. Poor resistance to steam side oxidation and spallation can cause severe problems such as a loss of cross-section and an increase in temperature due to a decrease in heat transfer that can lead to premature creep failure.[42] Fireside corrosion of superheater tubes by liquid deposits causes severe problems. High strength ferritic stainless steels such as T91 are frequently used in these applications. The standard metal alloys are T-22 for lower temperatures and SS304 or SS347 austenitic stainless steels for higher temperatures.

Development Progress of Ferritic Steels for Boiler

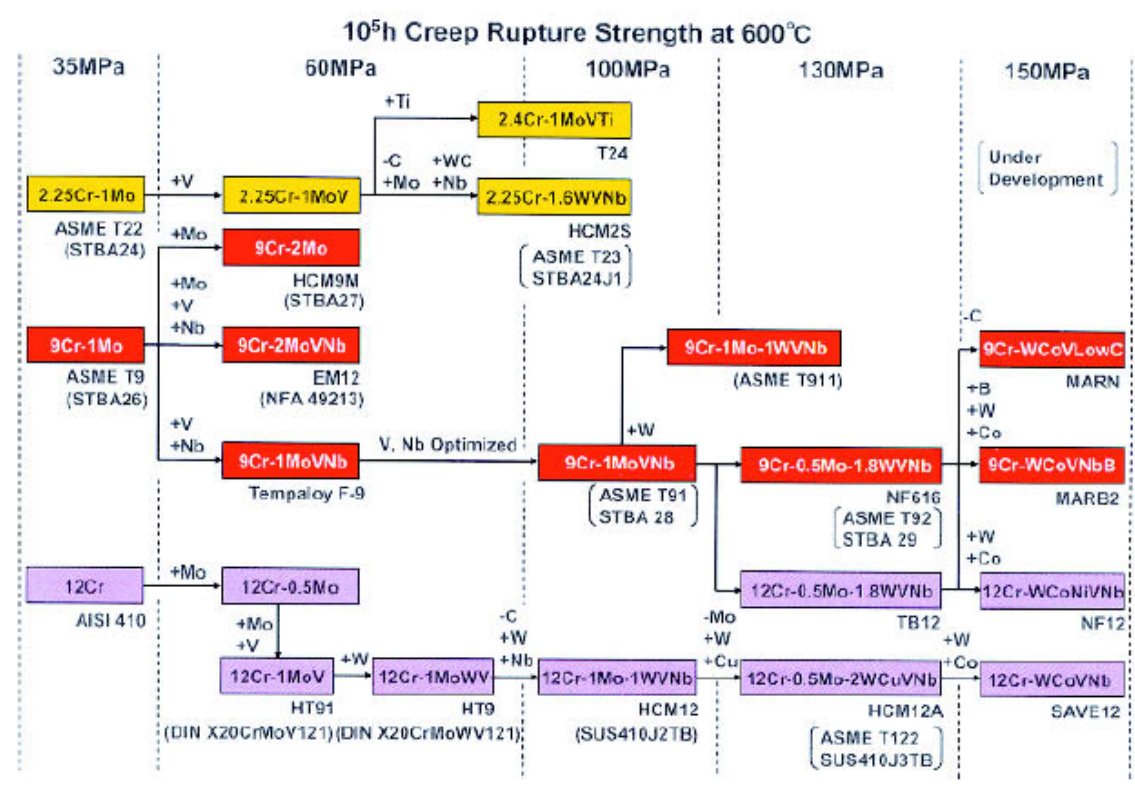

Figure 17: Evolution of ferritic steels for boilers [42] 
The evolution of ferritic stainless steel development is shown in Figure 17. The evolution includes additions of $\mathrm{Mo}, \mathrm{V}$, and $\mathrm{Nb}$ to simple $9-12 \% \mathrm{Cr}$ alloys in the 1960 's and 1970's, with optimization of these alloying additions coming in the 1970's and 1980's, followed by additions of Mo and W in the 1990's. Tungsten, molybdenum, and cobalt are solid solution strengtheners. Niobium and vanadium are precipitation strengtheners forming very fine coherent precipitates in the ferrite matrix. Chromium adds solid solution strength as well as oxidation and corrosion resistance. Nickel improves toughness, but decreases the creep strength of the alloy. Carbon is added to form fine precipitation strengthening carbides, but it must be kept relatively low for weldability considerations. Cobalt is also an austenite stabilizer, promotes the nucleation of secondary carbides on tempering, and slows the coarsening of carbides. Ferritic stainless steels are mainly developed for use in thick section pipes and headers.[42]

Austenitic stainless steels are used for higher temperature applications because of their increased corrosion resistance due to increased chromium and nickel additions. Development of alloy additions to typical $18 \mathrm{Cr}-8 \mathrm{Ni}$ austenitic stainless steels and on very oxidation resistant 2025Cr stainless steels is focused on improving the creep strength. Austenitic stainless steels are used in superheater tubing where fireside corrosion resistance and creep strength are important. They can be placed into four categories based on their chromium contents. These are $15 \% \mathrm{Cr}$, $18 \% \mathrm{Cr}, 20-25 \% \mathrm{Cr}$, and $>25 \% \mathrm{Cr}$. The standard alloy has $18 \mathrm{Cr}-8 \mathrm{Ni}$, but increasing alloy development has led to the formation of $25 \mathrm{Cr}-20 \mathrm{Ni}$ stainless steels, which are much more corrosion resistant. The development of these alloys involves the additions of $\mathrm{Ti}, \mathrm{Nb}$, and Mo to stabilize the stainless steels. Ti, $\mathrm{Nb}$, and Mo preferentially form carbides at the grain boundaries instead of chromium carbides that deplete the grain boundaries of chromium causing decreased 
corrosion resistance. Reducing the amount of $\mathrm{Ti}, \mathrm{Nb}$, and $\mathrm{Mo}$, while adding $\mathrm{C}$ promotes creep strength while decreasing corrosion resistance. A balance between the two must be met. Small additions of $\mathrm{N}$ and $\mathrm{W}$ add solid solution strengthening.[42] Three advanced austenitic stainless steels that have been developed for ultra-super-critical conditions are TP347H, Super304H, and HR3C. These alloys have alloying additions $\mathrm{Nb}, \mathrm{Ti}, \mathrm{Mo}, \mathrm{Cu}, \mathrm{N}$, and $\mathrm{C}$ for the reasons listed above. Chi et al. studied the microstructures and high temperature creep properties of these alloys.[43] Figure 18 shows a plot of the allowable stress versus temperature, comparing the high temperature capabilities of certain classes of alloys.

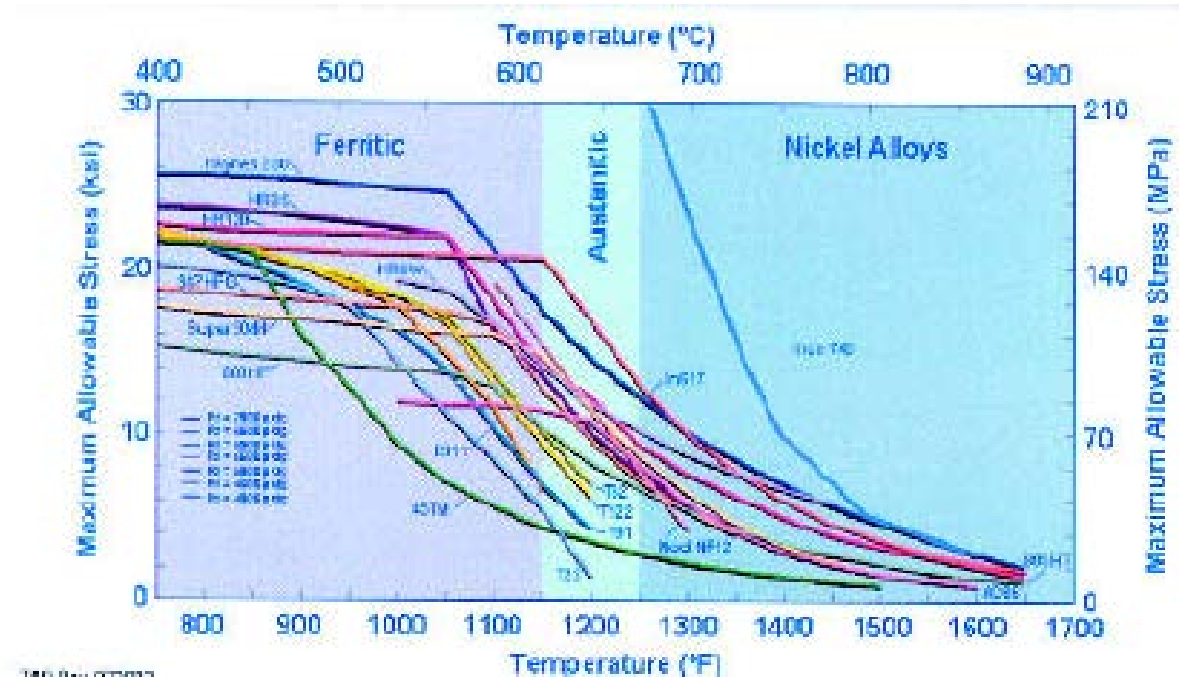

Figure 18: Allowable stress for various classes of alloys [42]

The nickel based alloys have superior creep properties to the austenitic stainless steels, which are superior to the ferritic stainless steels. From a creep perspective, ferritic stainless steels are useful up to about $620^{\circ} \mathrm{C}$. At increased temperatures (above $675^{\circ} \mathrm{C}$ ), stronger and more advanced austenitic stainless steels or nickel based alloys will be needed.[42] There have been major advances in high-temperature materials development including oxide dispersion 
strengthened (ODS) alloys, intermetallic alloys, and nickel-based superalloys. However, these alloys are still not ideal due to either their high cost, or inability to exhibit the right balance of mechanical stability, oxidation and corrosion resistance, and manufacturability. Therefore, advanced austenitic stainless steels have been a focus of recent materials development.[44]

\subsubsection{Alumina Forming Austenitic (AFA) Stainless Steel Alloys}

Austenitic stainless steels have an FCC crystal structure that allows them to have good high-temperature creep resistance. They also have good oxidation resistance at a low cost when compared with Ni-based superalloys. The high-temperature creep strength of these alloys can be improved significantly with dispersions of $\mathrm{MC}$ carbides ( $\mathrm{M}$ can be $\mathrm{Nb}$, $\mathrm{Ti}$, or $\mathrm{V}$ ). However, these alloys still lack the high temperature oxidation and corrosion resistance, especially in the highly aggressive gas atmospheres containing water vapor and sulfur- and carbon-containing gases typically found in coal-fired power plants. Resistance to water atmospheres is extremely crucial, because $\mathrm{Cr}_{2} \mathrm{O}_{3}$ scales typically formed on austenitic stainless steels are compromised due to the formation of volatile oxy-hydroxide species resulting in material loss and accelerated oxidation rates. Alumina scales have a growth rate that is significantly lower than chromia scales and are essentially immune to the water vapor effects that are harmful to chromia in the temperature range of interest. Alumina is thermodynamically more stable in oxygen and offers greater protection in more aggressive environments, therefore an alumina forming alloy would perform better under these aggressive environments. The main problem with creating an AFA stainless steel is that aluminum is a highly bcc stabilizing material in iron. These alloys also require significant quantities of chromium to help promote the formation of an alumina scale. Chromium reduces the critical level of aluminum in the alloy needed to form a protective $\mathrm{Al}_{2} \mathrm{O}_{3}$ 
scale. This is known as the third element effect. Chromium is also a ferrite stabilizer. The concentrations that would typically be needed to form an $\mathrm{Al}_{2} \mathrm{O}_{3}$ scale stabilizes the weaker bcc ferrite phase, decreasing the creep strength of the material. Figure 19 shows the limitations of $\mathrm{Cr}$ and $\mathrm{Al}$ additions in order to avoid bcc and sigma phases. Large additions of Ni can stabilize the austenite phase, but this typically turns the alloy in to a Ni-based alloy, which results in significantly higher cost.[44,46]

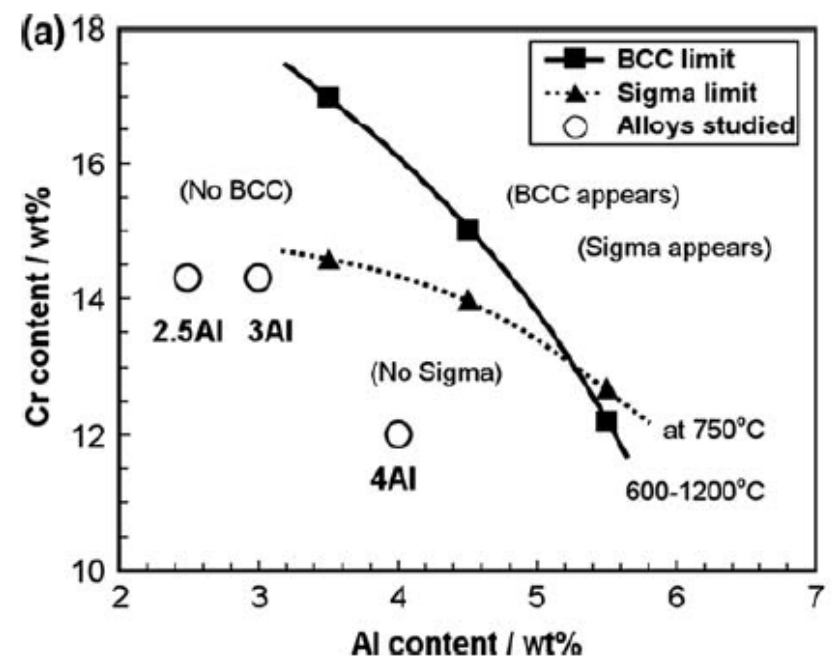

Figure 19: Phase diagram for Fe-Cr-Al-20Ni-1Nb-1Mo-0.1C showing the limitations of additions of $\mathrm{Cr}$ and $\mathrm{Al}$ to avoid formation of bcc and sigma phases, predicted by thermodynamic calculation. [45]

Oak Ridge National Laboratory (ORNL) has developed a class of AFA alloys for use at these highly aggressive temperatures and atmospheres.[44-50] They started with a base family of austenitic stainless steels called the high-temperature ultrafine-precipitation-strengthened steel (HTUPS), which have typical compositions of (wt\%) Fe-14Cr-16Ni-2.5Mo-2Mn with additions of $\mathrm{B}, \mathrm{C}, \mathrm{Nb}, \mathrm{P}, \mathrm{Ti}$, and $\mathrm{V}$ in order to balance mechanical properties and oxidation resistance as well as form nanoscale precipitates (such as $\mathrm{Fe}_{2} \mathrm{Nb}$ Laves phase, $\mathrm{B} 2-\mathrm{NiAl}, \gamma^{\prime}-\mathrm{Ni}_{3} \mathrm{Al}, \mathrm{M}_{23} \mathrm{C}_{6}$ and 
MC) for strength at high temperatures. HTUPS alloys have been shown to have among the highest creep strength of any austenitic stainless steel; however their oxidation and corrosion resistance is relatively poor, as they were initially designed for nuclear power related applications not requiring exceptional oxidation resistance. Small additions (2.4wt\% and $3.8 \mathrm{wt} \%$ ) of $\mathrm{Al}$ and increased $\mathrm{Ni}$ (20wt \% to stabilize the austenite phase) was added to the standard HTUPS alloy and the creep and oxidation resistance in air and air with $10 \%$ water vapor was tested. The alloy with smaller additions of $\mathrm{Al}$ showed a low creep rate, however the alloy with 3.8\% Al contained a weak delta-ferrite phase that changed to brittle sigma phase when heated to temperatures of $750-850^{\circ} \mathrm{C}$. The ferrite phase regions were due to the higher aluminum concentrations and were devoid of strengthening NbC. The transformation to brittle sigma phase caused a lower creep life. With higher Al contents, the Ni content needs to be increased in order to maintain the single austenite phase. The alloys were also unable to grow a protective $\mathrm{Al}_{2} \mathrm{O}_{3}$ scale in air and air with water vapor. Fe-Cr external scales grew over internal alumina scales. The $\mathrm{Al}$ and $\mathrm{Nb}$ contents need to be as high as possible for increased oxidation resistance, however too much will reduce creep properties due to the formation of brittle phases. Another alloy was prepared without additions of $\mathrm{Ti}$ and $\mathrm{V}$, and increased $\mathrm{Nb}$ to compensate in strengthforming carbides without the additions of Ti and V. This alloy showed good creep resistance due to the formation of $\mathrm{MC}$ precipitates. $\mathrm{Fe}_{2} \mathrm{Nb}$ and $\mathrm{B} 2-\mathrm{NiAl}$ precipitates were also formed at the grain boundaries from the $\mathrm{Nb}$ additions; however the increased creep properties were determined to be mostly due to MC precipitates. Oxidation in air and air with 10\% water vapor at $800^{\circ} \mathrm{C}$ showed the formation of an external $\mathrm{Al}_{2} \mathrm{O}_{3}$ scale and growth rates lower than those for typical $\mathrm{Cr}_{2} \mathrm{O}_{3}$ forming alloys. Beneath the alumina scale was a zone denuded of $\mathrm{NiAl}$ precipitates, which shows the low diffusivity of $\mathrm{Al}$ in these alloys. The long term alumina 
formation and oxidation resistance of these alloys will be dependent on whether the remaining $\mathrm{NiAl}$ precipitates and aluminum in the matrix can supply the oxidation front with enough $\mathrm{Al}$ to maintain the $\mathrm{Al}_{2} \mathrm{O}_{3}$ scale. According to Wagner's theory, there is a critical amount of $\mathrm{Al}$ in the alloy needed to form a protective oxide scale and to maintain that protective oxide scale. This was described in a previous section by equations 12 and 13. Alloying additions that increase oxygen permeability or reduce $\mathrm{Al}$ diffusivity will result in a larger amount of $\mathrm{Al}$ needed to form the protective scale. Additions of Ti and V may increase internal oxidation because of increased oxygen permeability due to their thermodynamic stability with oxygen. Low amounts of $\mathrm{Al}$ are therefore sufficient to form $\mathrm{Al}_{2} \mathrm{O}_{3}$ scales on austenitic stainless steels if Ti and $\mathrm{V}$ additions are eliminated or minimized. Small additions of Ti and V individually, not together, may be tolerated. Niobium additions were found to be a key in oxidation resistance. Higher niobium additions allow the formation of a protective external $\mathrm{Al}_{2} \mathrm{O}_{3}$ scale with low $\mathrm{Al}$ additions and small $\mathrm{Ti}$ and $\mathrm{V}$ additions. The small Ti and $\mathrm{V}$ additions allows for an increase in MC during creep deformation. Niobium additions increase the amounts of B2-NiAl precipitates which help to provide $\mathrm{Al}$ to the oxidation front. $\mathrm{Nb}$ also increases the amount of $\mathrm{Cr}$ in the austenite matrix phase, which helps with the third element effect. Increasing the nickel and niobium levels may reduce the oxygen solubility favoring external protective $\mathrm{Al}_{2} \mathrm{O}_{3}$ formation. Adjusting the $\mathrm{Al}, \mathrm{Cr}$, $\mathrm{Ni}, \mathrm{Nb}, \mathrm{Ti}$, and $\mathrm{V}$ levels in these alloys will allow for the formation of a single phase austenitic matrix with increased creep resistance and the growth of a slowly-growing $\mathrm{Al}_{2} \mathrm{O}_{3}$ scale.[44, 4648] Three different grades of AFA alloys have been made. These include the AFA grade \{Fe(14-15)Cr-(2.5-4)Al-(20-25)Ni-(1-3)Nb\}, low nickel AFA \{Fe-14Cr-2.5Al-12Ni-0.6Nb-5Mn3Cu wt.\%\}, and the high creep resistance $\gamma^{\prime}-\mathrm{Ni}_{3} \mathrm{Al}$ strengthened AFA $\{\mathrm{Fe}-(14-19) \mathrm{Cr}-(2.5-$ 3.5)Al-(30-35)Ni-3Nb\}. The AFA grade has a $750-950^{\circ} \mathrm{C}$ temperature limit for $\mathrm{Al}_{2} \mathrm{O}_{3}$ formation. 
Higher temperature ranges will require higher $\mathrm{Ni}$ and $\mathrm{Nb}$ as well as rare earth element additions. The strengthening precipitates for these alloys are $\mathrm{MC}$ and $\mathrm{M}_{23} \mathrm{C}_{6}$. The low nickel AFA grade has a $650-700^{\circ} \mathrm{C}$ temperature limit for $\mathrm{Al}_{2} \mathrm{O}_{3}$ formation, and relies on strength from $\mathrm{M}_{23} \mathrm{C}_{6}$ precipitate formation. The high creep resistance $\gamma^{\prime}-\mathrm{Ni}_{3} \mathrm{Al}$ strengthened AFA has higher nickel concentrations as well as $\mathrm{Zr}$ and $\mathrm{Ti}$ additions to stabilize the $\gamma^{\prime}-\mathrm{Ni}_{3} \mathrm{Al}$ phase. These alloys have a 750-850 ${ }^{\circ} \mathrm{C}$ temperature limit for $\mathrm{Al}_{2} \mathrm{O}_{3}$ formation.[51] The coherent $\gamma^{\prime}-\mathrm{Ni}_{3} \mathrm{Al}$ precipitates significantly increases the strength and creep life of the alloy. Additions of C and B significantly increase the oxidation resistance and creep strength of these alloys as well. The microstructure of a gamma prime grade AFA alloy aged at $750^{\circ} \mathrm{C}$ for 2000 hours is shown below in Figure 20.

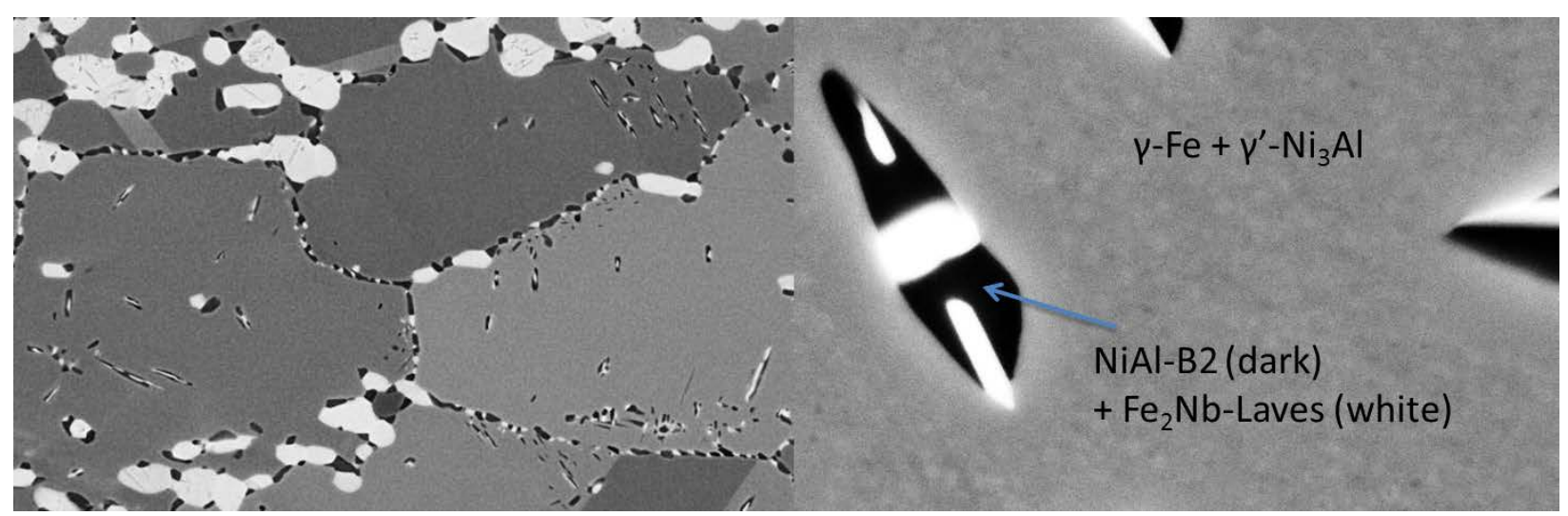

Figure 20: Microstructure of typical $\gamma$ '-Ni $\mathrm{Ni}_{3} \mathrm{Al}$ strengthened AFA alloy [51]

Four different AFA alloys were used as part of this study. Their compositions are given in Table 8 below. The standard AFA grade alloy OC4 has the desired combination of moderate oxidation and creep strength.[52] Increasing the chromium, nickel, and niobium concentration is the OC8 alloy, which is a gamma prime strengthened alloy. This alloy has very promising strength and oxidation resistance, however, at longer times thermodynamic studies show that brittle sigma 
phase can form.[53] OCS and OCT are gamma prime strengthened grade AFA alloys with lower chromium contents, hopefully avoiding the undesirable sigma phase.[54]

Table 8: Composition of AFA alloys used in this study (wt\%)

\begin{tabular}{|c|c|c|c|c|c|c|c|c|c|}
\hline & $\mathrm{Ni}$ & $\mathrm{Fe}$ & $\mathrm{Cr}$ & Co & $\mathrm{Al}$ & Mo & $\mathrm{Ti}$ & $\mathrm{W}$ & Other(Nb, Ta, Hf, Y) \\
\hline $\mathrm{OC}_{4}$ & 25 & Balance & 14 & - & 3.5 & 2 & - & 1 & $2.5 \mathrm{Nb}, 0.1 \mathrm{C}, 0.5 \mathrm{Cu}$ \\
\hline OC8 & 32 & Balance & 18.7 & - & 3 & 0.15 & - & - & $3.3 \mathrm{Nb}, 0.1 \mathrm{C}, 0.5 \mathrm{Cu}$ \\
\hline OCS & 32 & Balance & 13.83 & - & 3 & 0.1 & 2 & - & $\begin{array}{c}2.87 \mathrm{Nb}, 0.32 \mathrm{Zr}, \mathrm{o} .1 \mathrm{C}, \mathrm{o} .13 \mathrm{Mn}, \mathrm{o} .1 \mathrm{Cu}, \\
0.15 \mathrm{Si}\end{array}$ \\
\hline OCT & 35 & Balance & 13.8 & - & 3 & 0.1 & 2 & - & $\begin{array}{c}2.92 \mathrm{Nb}, 0.32 \mathrm{Zr}, 0.1 \mathrm{C}, 0.1 \mathrm{Mn}, 0.1 \mathrm{Cu} \text {, } \\
\text { o.16Si }\end{array}$ \\
\hline
\end{tabular}

\subsubsection{Comparing Oxy-Fired to Air Fired Gas Environments}

Viswanathan et al.[42] studied various ferritic stainless steels, austenitic stainless steels, and nickel based alloys in steam oxidation and fireside corrosion tests. The steam side oxidation tests were conducted at $650^{\circ} \mathrm{C}$ and $800^{\circ} \mathrm{C}$. The austenitic stainless steels and nickel based alloys fared better than the ferritic stainless steels and showed no spallation at $650^{\circ} \mathrm{C}$. An adherent protective chromium oxide scale formed over the alloys. The tests conducted at $800^{\circ} \mathrm{C}$ showed that regardless of the type of alloy, if it had over $10 \% \mathrm{Cr}$, then the oxidation resistance was roughly the same. Some of the ferritic alloys fared as well as the austenitic and nickel based alloys. All of the metals showed worse corrosion resistance at $800^{\circ} \mathrm{C}$ than at $650^{\circ} \mathrm{C}$. The fireside corrosion tests were performed with three different types of coals, Eastern, Midwestern, and Western. Eastern and Midwestern coals typically have more sulfur, and are therefore more corrosive. The alloys tested with Eastern and Midwestern coals had more metal wastage than those tested with Western coals. The corrosion resistance increased with increasing chromium 
content. At $650^{\circ} \mathrm{C}$, the attack was more surface oriented, while at $800^{\circ} \mathrm{C}$ the attack was more subsurface oriented. Molybdenum containing alloys suffered more corrosion than nonmolybdenum containing alloys. Latham, Flatley, and Morris[55] studied the corrosion rates of some typical stainless steel alloys that could be used in coal-fired boilers. The variation in the corrosion resistance between the different alloys tested was not great, but they found that if a standard austenitic stainless steel is to be used, then additions of at least 25\%Cr gives increased corrosion resistance, $1 \% \mathrm{Nb}$ decreases intergranular penetration, and $1 \% \mathrm{Si}$ is also beneficial. Stein-Brzozowska et al.[1] performed fireside corrosion tests on three austenitic alloys with varying chromium contents (18-25\%) at $650^{\circ} \mathrm{C}$ in typical air fired and oxy-fuel combustion atmospheres. The oxy-fired combustion tests produced more corrosion of the metal alloys than the air fired tests, probably due to the increased $\mathrm{SO}_{2}$ partial pressures that result from oxy-firing. A uniform and protective chromium oxide scale is able to be formed with increasing chromium content in the alloy.

Natesan et al.[19] also performed fireside corrosion tests on some model and commercial stainless steels and nickel based alloys. The iron-based alloys had chromium contents in the range of $18-25 \% \mathrm{Cr}$, along with additions of $\mathrm{Nb}, \mathrm{Mo}, \mathrm{V}, \mathrm{N}, \mathrm{Ti}$, and Ta to improve creep strength. The nickel based alloys had chromium contents in the range of $21-28 \% \mathrm{Cr}$, increased Mo contents, and additions of $\mathrm{Al}$ and Si. The tests were conducted with synthetic ash with varying amounts of $\mathrm{Al}_{2} \mathrm{O}_{3}, \mathrm{SiO}_{2}, \mathrm{Fe}_{2} \mathrm{O}_{3}, \mathrm{Na}_{2} \mathrm{SO}_{4}, \mathrm{NaCl}$, and $\mathrm{K}_{2} \mathrm{SO}_{4}$ at temperatures ranging from $650^{\circ} \mathrm{C}$ $800^{\circ} \mathrm{C}$ in an atmosphere containing air and $1 \% \mathrm{SO}_{2}$. The corrosion rates for the iron-based alloys tested showed a bell-shaped curve with a maximum at $725^{\circ} \mathrm{C}$. The addition of $\mathrm{NaCl}$ to the deposit increased the corrosion rate for iron-based alloys. The $\mathrm{NaCl}$ will attack the precipitated carbides there to strengthen the alloy, and it will also form volatile chlorides that cause a non- 
protective porous scale. Cross-sectional images show that the attack looks to be from a low temperature corrosion mechanism caused by liquid eutectic alkali iron trisulfates. They also performed tests in simulated oxy-fuel gas environments.[56] Seven different gas compositions were used to determine the effects of $\mathrm{SO}_{2}, \mathrm{H}_{2} \mathrm{O}, \mathrm{O}_{2}$, and $\mathrm{CO}_{2}$ concentrations on the amount of corrosion. The alloys displayed an initiation stage in which the corrosion rate was low, and a propagation stage in which the corrosion rate followed linear kinetics. They found that there was a Cr-depleted zone near the alloy-corrosion product interface, which allows for more rapid degradation to occur, because there is not enough $\mathrm{Cr}$ near the surface to provide a protective $\mathrm{Cr}_{2} \mathrm{O}_{3}$ scale. Carburization $\left(\mathrm{Cr}_{7} \mathrm{C}_{3}\right)$ was also evident in the alloy substrate. The carbides tie-up chromium and block $\mathrm{Cr}$ diffusion, causing $\mathrm{Cr}$ depletion and increasing the corrosion rate during the propagation stage. Sulfides were found at the base of the corrosion products. Sulfidation was found to play an important role in localized corrosion. The corrosion products are not protective chromium oxide scales, and the diffusion rate of the different element species will be much greater through the corrosion products, allowing for faster corrosion rates. The initiation stage appears to be the time needed to form the corrosion products needed to cause rapid corrosion rates. The addition of steam to the fireside corrosion atmosphere increased the amount of corrosion. As was mentioned previously, steam may increase $\mathrm{SO}_{3}$ formation, which is a major factor in the formation of alkali iron trisulfates and the amount of degradation that occurs.[27] It was also discovered that alloying additions of $\mathrm{Al}$ decreased the corrosion resistance of the alloys. $\mathrm{Al}$ can react with alkali sulfates and $\mathrm{SO}_{3}$ in the gas atmosphere to form $(\mathrm{Na}, \mathrm{K})_{3} \mathrm{Al}\left(\mathrm{SO}_{4}\right)_{3}$ which have a melting point in a range of $646-654^{\circ} \mathrm{C}$ and can increase corrosion.[56] Increasing the oxygen partial pressure in the gas atmospheres decreased the initiation stage. As was mentioned earlier, $\mathrm{SO}_{3}$ formation increases with increasing oxygen content, which will aid in the earlier 
formation of alkali trisulfates. At higher temperatures $\left(750^{\circ} \mathrm{C}\right)$, alkali iron trisulfates may not be stable; however alkali aluminum trisulfates are, which may be the cause of corrosion at higher temperatures in alumina forming alloys. There was more degradation in the oxy-fuel environment that contained $\mathrm{CO}_{2}$, steam and higher $\mathrm{SO}_{2}$ than in the air environment.[56]

Syed et al.[2,57] performed fireside corrosion tests comparing air and oxy-firing for a co-fired biomass boiler on typical ferritic and austenitic stainless steels as well as some nickelbased alloys. The synthetic deposits used on the alloys had varying amounts of $\mathrm{Al}_{2} \mathrm{O}_{3}, \mathrm{SiO}_{2}$, $\mathrm{Fe}_{2} \mathrm{O}_{3}, \mathrm{Na}_{2} \mathrm{SO}_{4}$, and $\mathrm{K}_{2} \mathrm{SO}_{4}$, with the most corrosive being a stoichiometric mix of $\mathrm{Na}_{2} \mathrm{SO}_{4}$, $\mathrm{K}_{2} \mathrm{SO}_{4}$, and $\mathrm{Fe}_{2} \mathrm{O}_{3}$. The other oxides dilute the effects of the sulfates. In the absence of any deposit, the oxy-fired specimens had more corrosion than the air-fired. This is most likely due to the increase in $\mathrm{CO}_{2}, \mathrm{H}_{2} \mathrm{O}$, and $\mathrm{SO}_{2}$ in the oxy-fired atmosphere. The lower chromium content ferritic stainless steels such as T92 suffered the most corrosion. The alloys tested with higher chromium contents performed the best and had the thinnest oxide scales grown on the surface. This includes nickel and iron-based alloys. The alloys tested with deposits had more corrosion in the oxy-fired tests than in the air-fired tests, most likely due to the increased amounts of steam, $\mathrm{CO}_{2}$, and $\mathrm{SO}_{2}$. The T92 alloy as well as the austenitic alloys with the deposit showed compact inner layers and porous outer layers. Cross-sections of the stainless steels showed that there was internal molten deposit penetration of the scales, as sulfur and potassium were found to have penetrated deep into the scale, and a sulfur rich region is observed at the metal/scale interface. For all of the conducted tests, there was a bell shaped curve with the amount of degradation, which had a maximum around $650^{\circ} \mathrm{C}$ in air fired conditions and around $700^{\circ} \mathrm{C}$ in oxy-fired conditions. 
The metal loss values in oxy-fired conditions were less at $600^{\circ} \mathrm{C}$ and $650^{\circ} \mathrm{C}$ than in air fired conditions, which show that oxy-firing might be less destructive than air-firing at lower temperatures. Oxy-firing shifts the bell-shaped curve to the right.

Kung[58] performed a comparison test on the fireside corrosion resistance of a variety of Fe- and Ni-based alloys in oxy-fuel and air fired pilot-scale combustion tests and laboratory exposures. Four different types of coal were used, three bituminous and one sub-bituminous with various sulfur compositions. When burning these coals, there is a significant increase in the steam, $\mathrm{CO}_{2}$, and $\mathrm{SO}_{2}$ concentrations with oxy-fuel combustion compared to air-fired combustion, which had higher $\mathrm{N}_{2}$ concentration. Contrary to the previously mentioned studies, the laboratory tests showed that there was a lower corrosion rate for oxy-firing than for air-firing. Kung[58] proposed that the reason for the lower corrosion rates may be due to a lower diffusivity of corrosive species through the oxy-fuel gas than the air-fired gas. The molecular weight of $\mathrm{CO}_{2}$ is 44 and $\mathrm{N}_{2}$ is 28 , which means the oxy-fuel gas is approximately 1.6 times more dense than the air-fired gas. The combustion kinetics may also be slower in oxy-fired gas possibly due to a higher heat capacity of $\mathrm{CO}_{2}$ than that of $\mathrm{N}_{2}$, and therefore lower combustion temperatures. The salt basicity may also be much lower due to a higher concentration of $\mathrm{CO}_{2}$. If the corrosion mechanism is described by basic fluxing, then a lower salt basicity means a lower solubility gradient and lowering the corrosion rate. The acidic nature of $\mathrm{CO}_{2}$ may be neutralizing the basic salt. Higher concentrations of acidic $\mathrm{SO}_{3}$ may also be neutralizing the basic salt.[58] With the differences in the results from the previously mentioned studies, the effects of oxy-firing compared with air-firing on the amount of fireside corrosion need to be further studied. 
Foster Wheeler Corporation[4,20,34] has also conducted fireside corrosion tests on high strength ferritic and advanced austenitic stainless steels as well as some nickel-based alloys. The evaluation of the alloys in fireside corrosion tests was done in three steps. Laboratory tests with different alloys, temperatures, deposits, and gas atmospheres were conducted to screen for the highest performing alloys. These alloys were then made into corrosion probes that were tested in the superheater and reheater sections of actual coal fired boilers. The third process was testing the best alloys under pressure in actual boiler operating conditions. They found that alloys with higher chromium contents, specifically those with greater that $25 \% \mathrm{Cr}$ had adequate corrosion resistance. Alloys with high molybdenum contents had more corrosion than those without molybdenum. Tantalum, aluminum and silicon were beneficial. The tests performed in eastern coals, which contain higher amounts of sulfur, exhibited the typical attack from liquid alkali iron trisulfates, while the tests conducted in the western coals, exhibited atypical corrosion due to sulfidation from $\mathrm{CaSO}_{4}$ reducing to CaS. There was significantly more corrosion from the alloys tested in the Eastern and Midwestern coals, than from the western coals.

\subsection{SODIUM SULFATE-INDUCED HOT CORROSION}

The corrosion mechanisms used to describe fireside corrosion for this study are similar to those typically described for type II hot corrosion of gas turbine engines. Alloys used in gas turbine engines, especially those used in marine applications, can undergo an aggressive form of corrosion associated with the formation of a salt deposit, which is usually sodium sulfate, on the surface of the metal or thermally grown oxide. This type of corrosion is called hot corrosion. The $\mathrm{Na}_{2} \mathrm{SO}_{4}$ deposits on the gas turbine hardware can be directly deposited from ingested sea 
salt, or they can be condensed from a vapor phase.[59] Vapor phase condensation occurs when the common fuel impurity, sulfur, is oxidized to form $\mathrm{SO}_{2}$ and/or $\mathrm{SO}_{3}$ in the combustion section of the engine. These gases then react with oxygen and $\mathrm{NaCl}$ vapor. If the surface of the turbine hardware is below the dew point of $\mathrm{Na}_{2} \mathrm{SO}_{4}$, then a condensed salt deposit will form. Bornstein and Allen[60] investigated the mechanism of salt deposition on the surface of turbine hardware, and determined that the direct impact of ingested sea salt particles on the turbine hardware is likely to be the main deposition mechanism. The amount of hot corrosion caused is determined by the composition and amount of $\mathrm{Na}_{2} \mathrm{SO}_{4}$ deposit, gas atmosphere, temperature, cycling, erosion, and alloy composition.[35] Once a deposit has been formed on the surface of combustion hardware, the amount of corrosion will depend significantly on whether or not the deposit melts. If the temperature of the combustion environment is above the melting point of $\mathrm{Na}_{2} \mathrm{SO}_{4}\left(\mathrm{~T}_{\mathrm{m}}=884^{\circ} \mathrm{C}\right)[61]$, the corrosion is called type I hot corrosion or high temperature hot corrosion. Below the melting point of $\mathrm{Na}_{2} \mathrm{SO}_{4}$, the salt deposit can become molten because of a reaction between the combustion gas and the oxide scale grown on the alloy. This type of corrosion is called type II hot corrosion or low temperature corrosion. In the research presented, the corrosion mechanisms for type II hot corrosion are used to describe fireside corrosion.

\subsubsection{Stages of Corrosion}

Hot corrosion occurs in two stages. There is an initiation stage, in which the rate of corrosion is slow and resembles that of oxidation without a deposit, and there is a propagation stage in which rapid and possibly catastrophic corrosion occurs.[35] 
The stages are demonstrated in Figure 21 below, which is a plot of weight change per area versus time for IN-738 exposed to Type I hot corrosion conditions with $1 \mathrm{mg} / \mathrm{cm}^{2}$ sodium sulfate deposit.

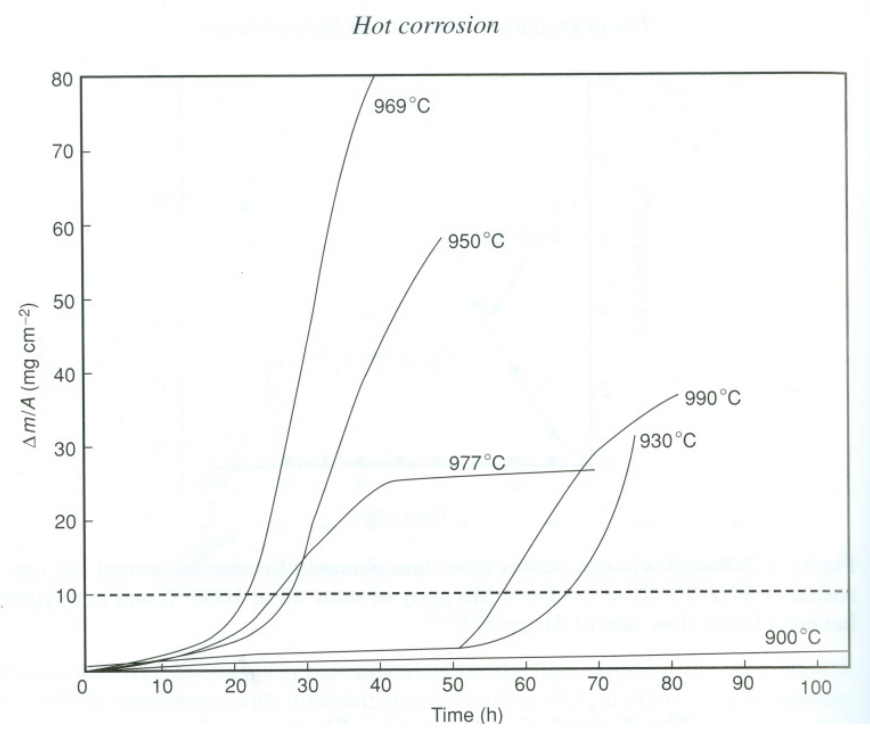

Figure 21: Isothermal mass change versus time for IN-738. The data consists of an initiation stage and a propagation stage with large weight changes (dashed line gives arbitrary end of initiation stage) [35]

Examining the plot in Figure 21, the two distinct stages of corrosion can be seen. During the initiation stage, the weight change is very small, showing that there is little or no severe corrosion occurring. The propagation stage occurs when the weight gains start to become large due to rapid oxidation, and this signifies the occurrence of significant corrosion. The initiation stage of an alloy is very important. Corrosion resistant alloys are able to increase the initiation stage of corrosion, so that the alloy may be used for longer periods of time before failing. The length of the initiation stage can vary from seconds to hundreds of hours, and it is determined by the alloy and the combustion environment. 


\subsubsection{Initiation Stage}

During the initiation stage of hot corrosion, the alloy undergoes a process similar to simple oxidation. The metal will oxidize and the gaseous species, typically oxygen will be reduced to form an external oxide scale. The difference between the initiation stage and simple oxidation is that during the initiation stage of hot corrosion, the oxidizing species comes from the salt deposit, and the alloy or oxide scale is being altered so that it is more susceptible to rapid degradation. The oxide scale/salt interaction can lead to extremely corrosive conditions as the salt becomes basic or acidic. At the end of the initiation stage, the salt deposit becomes sufficiently basic or acidic in order to cause rapid degradation, and the propagation stage begins. In many cases, the end of the initiation stage occurs when the deposit becomes liquid and penetrates the oxide scale and spreads along the alloy/scale interface. The presence of the liquid deposit in this region where the oxygen activity is low and the element producing the protective alloy is depleted produces severe corrosion and starts the propagation stage.[35] A phase stability diagram for the Na-S-O system is shown in Figure 22 below.

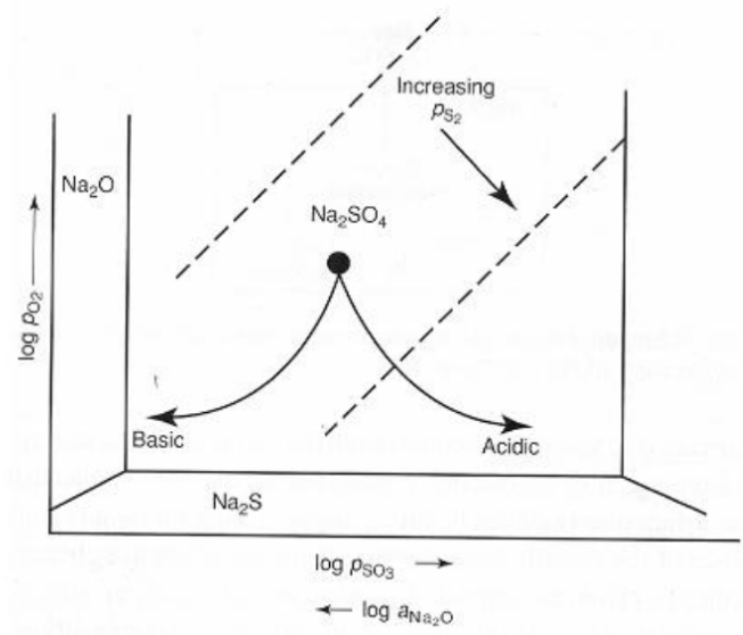

Figure 22: Thermodynamic stability diagram for the Na-O-S system at constant temperature [35] 
The initially deposited salt is in the $\mathrm{Na}_{2} \mathrm{SO}_{4}$ phase field and is defined by the two axis $\log _{\mathrm{PO} 2}$ and $-\log _{a N a 2 O}$. The diagram shows the compositional changes that can happen to the initial salt deposit during the initiation stage of hot corrosion. The salt may become more basic (higher $\mathrm{Na}_{2} \mathrm{O}$ ) or more acidic (lower $\mathrm{Na}_{2} \mathrm{O}$ ) when interacting with the base alloy and its oxides. Giggins and Pettit[62] outlined some of the factors that affect the reactions that occur during the initiation stage as well as its duration. These are summarized below.

Alloy Composition: The initiation stage is longer for Co-based alloys than Ni-based alloys under Type I hot corrosion conditions. The reverse is true under Type II hot corrosion. Increased aluminum contents in Ni-Cr and Co-Cr alloys increases the initiation stage of hot corrosion. The addition of more aluminum produces a protective $\mathrm{Al}_{2} \mathrm{O}_{3}$ scale that is able to be retained for longer times. Increasing the chromium content in alloys is also beneficial, and is the main element added for corrosion resistance. Larger chromium contents enable a protective $\mathrm{Cr}_{2} \mathrm{O}_{3}$ scale to be formed and be maintained for longer periods of time.

Alloy Fabrication: The hot corrosion of alloys can be influenced by the fabrication condition. As-cast alloys can be more susceptible to corrosion than a vapor deposited alloy, because of compositional inhomogeneity. The corrosion will initiate in areas that may be depleted in chromium or aluminum due to the inhomogeneous as-cast nature.

Gas Composition: The gas composition can have a significant influence on the initiation of hot corrosion. This is especially true for low temperature Type II hot corrosion, where corrosion occurs at temperatures below the melting point of $\mathrm{Na}_{2} \mathrm{SO}_{4}$. At these temperatures, the amount of $\mathrm{SO}_{3}$ in the gas influences the duration of the initiation stage, and the amount of corrosion that will occur. In an atmosphere of just oxygen at $700^{\circ} \mathrm{C}$, the initiation stage can go on indefinitely, 
because the presence of $\mathrm{SO}_{3}$ is required for Type II hot corrosion. This will be discussed in more detail in the later section entitled Type II hot corrosion.

Salt Characteristics: The composition of the salt deposit can have an effect on the hot corrosion of the alloy. For hot corrosion, salt deposits with $\mathrm{NaCl}$ mixed with $\mathrm{Na}_{2} \mathrm{SO}_{4}$ can have a different effect than pure $\mathrm{Na}_{2} \mathrm{SO}_{4}$ deposits. The composition of the deposits in fireside corrosion also has a significant effect on the amount of corrosion that occurs. This will be explained in later sections.

The amount of salt that is deposited will also affect the corrosion of the alloy. The amount of salt on the alloy is important, because some modes of corrosion are not selfsustaining, and the more salt there is to consume and cause corrosion, the more corrosion will occur. Some alloys need the right composition of salt in order to induce attack. The amount of salt may influence that amount of time for the deposit to react with the alloy to create the right composition needed to initiate attack. There may also be a limiting deposit thickness. For some propagation modes a thin deposit is more corrosive, while for others a thick deposit may be more corrosive. The amount of corrosion of Ni-based alloys under Type I and Type II hot corrosion conditions was found to be significantly less when the metal was submerged in salt compared to when there was a deposit of $1-8 \mathrm{mg} / \mathrm{cm}^{2}$.[63] This can be compared to fireside corrosion, in which there is the least amount of metal wastage where the deposit is thickest, as was explained earlier.

Temperature: It is generally accepted that a molten salt deposit is needed for hot corrosion. For Type II hot corrosion, the salt deposit becomes liquid at lower temperatures, around $700^{\circ} \mathrm{C}$, in the presence of $\mathrm{SO}_{3}$ gas. At higher temperatures, there are insufficient amounts of $\mathrm{SO}_{3}$ in the gas 
to cause a liquid deposit. The deposit will remain solid, and less corrosion will occur. This will be explained in later sections.

\subsubsection{Propagation Stage}

Once the initiation stage has ended and the alloy or oxide scale has been altered, the propagation stage occurs and the alloy becomes seriously degraded. The type of propagation stage that occurs is dependent on what happens to the alloy and the oxide during the initiation stage, and it is therefore dependent on all of the variables listed in the previous initiation stage section.

The salt that is the cause of hot corrosion attack is typically $\mathrm{Na}_{2} \mathrm{SO}_{4}$. It is an oxyanion salt that exhibits an acid-base relationship with $\mathrm{SO}_{3}(\mathrm{~g})$ being the acidic component and $\mathrm{Na}_{2} \mathrm{O}(\mathrm{s})$ being the basic component. The composition of the $\mathrm{Na}_{2} \mathrm{SO}_{4}$ melt at a fixed temperature can therefore be described by the oxygen partial pressure and the activity of $\mathrm{Na}_{2} \mathrm{O}$ in the melt, $\mathrm{a}_{\mathrm{Na} 2 \mathrm{O}}$, or the $\mathrm{SO}_{3}$ partial pressure, because it is related to the activity of $\mathrm{Na}_{2} \mathrm{O}$ by equation 19 shown below.[64]

$$
\mathrm{Na}_{2} \mathrm{SO}_{4}=\mathrm{SO}_{3}+\underline{\mathrm{Na}_{2}} \underline{\mathrm{O}}
$$

The product of $\mathrm{a}_{\mathrm{Na} 2 \mathrm{O}} \mathrm{P}_{\mathrm{sO}}$ is equal to an equilibrium constant $\mathrm{K}$ at a fixed temperature. This relationship is used to determine the acidity or basicity of $\mathrm{Na}_{2} \mathrm{SO}_{4}$, which was demonstrated in Figure 19. Thermodynamic stability diagrams are able to show the phases that can be stable during hot corrosion. These diagrams have axes of $\log \mathrm{po}_{2}$ and $-\log a_{\mathrm{Na} 2 \mathrm{O}}$, and the thermodynamically stable phase under the given conditions is shown. An example of this is shown in the diagram given below in Figure 23, which is the Cr-S-O system at $\mathrm{T}=1200 \mathrm{~K}$ superimposed on the Na-S-O stability diagram. 


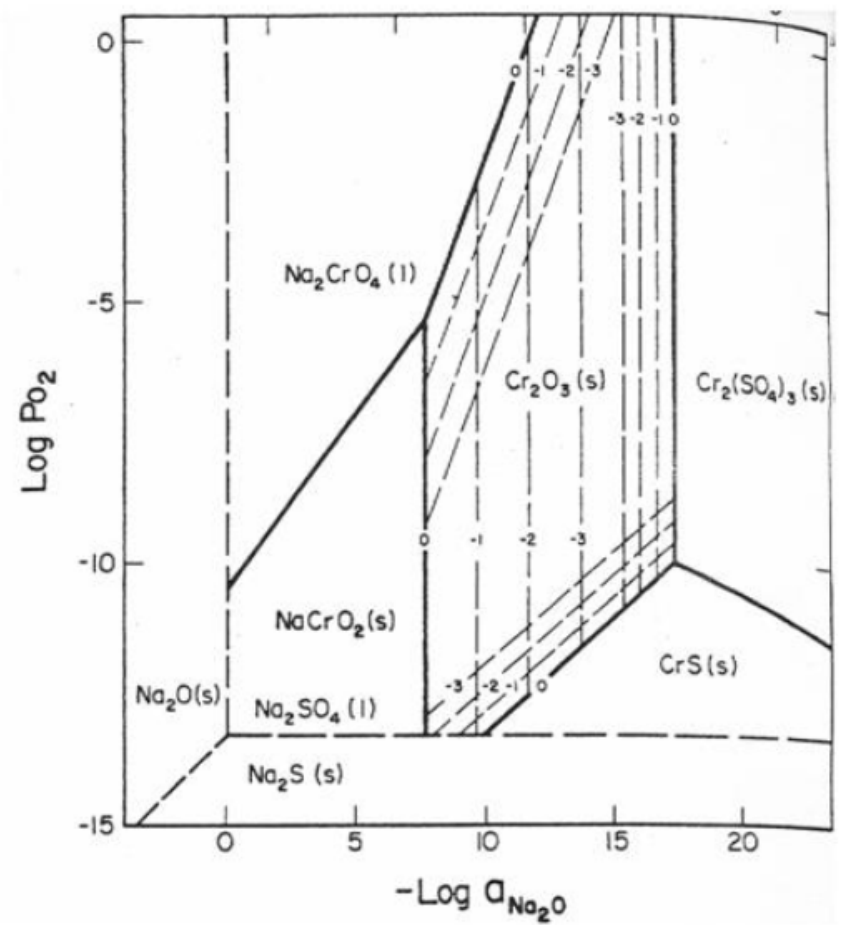

Figure 23: Isothermal stability diagram of the Cr-O-S System superimposed onto the $\mathrm{Na}_{2} \mathrm{SO}_{4}$ portion of the Na-S-O stability diagram for $\mathrm{T}=927^{\circ} \mathrm{C}[65]$

From the diagram in Figure 23, we are able to determine if a protective $\mathrm{Cr}_{2} \mathrm{O}_{3}$ scale will be able to grow or will dissolve in the presence of the salt deposit, and if it does dissolve, what solutes will be able to form. In this diagram, we are able to see that the $\mathrm{Cr}_{2} \mathrm{O}_{3}$ scale will dissolve into basic solutes of $\mathrm{Na}_{2} \mathrm{CrO}_{4}$ or $\mathrm{NaCrO}_{2}$ or in acidic conditions, the acidic solutes of $\mathrm{CrS}$ and $\mathrm{Cr}_{2}\left(\mathrm{SO}_{4}\right)_{3}$. Thermodynamic stability diagrams for other oxide scales were completed by Rapp and coworkers as well as Deanhardt and Stern and can be seen in references [65-69]. They also produced solubility curves for a number of oxides in $\mathrm{Na}_{2} \mathrm{SO}_{4}$ as a function of the activity of $\mathrm{Na}_{2} \mathrm{O}$ in the melt. This was done by using high temperature reference electrodes at $\mathrm{p}_{\mathrm{O} 2}=1 \mathrm{~atm}$ and $\mathrm{T}=1200 \mathrm{~K}$. Some of the typical solubility curves of a number of the oxides are shown below in Figure 24. 


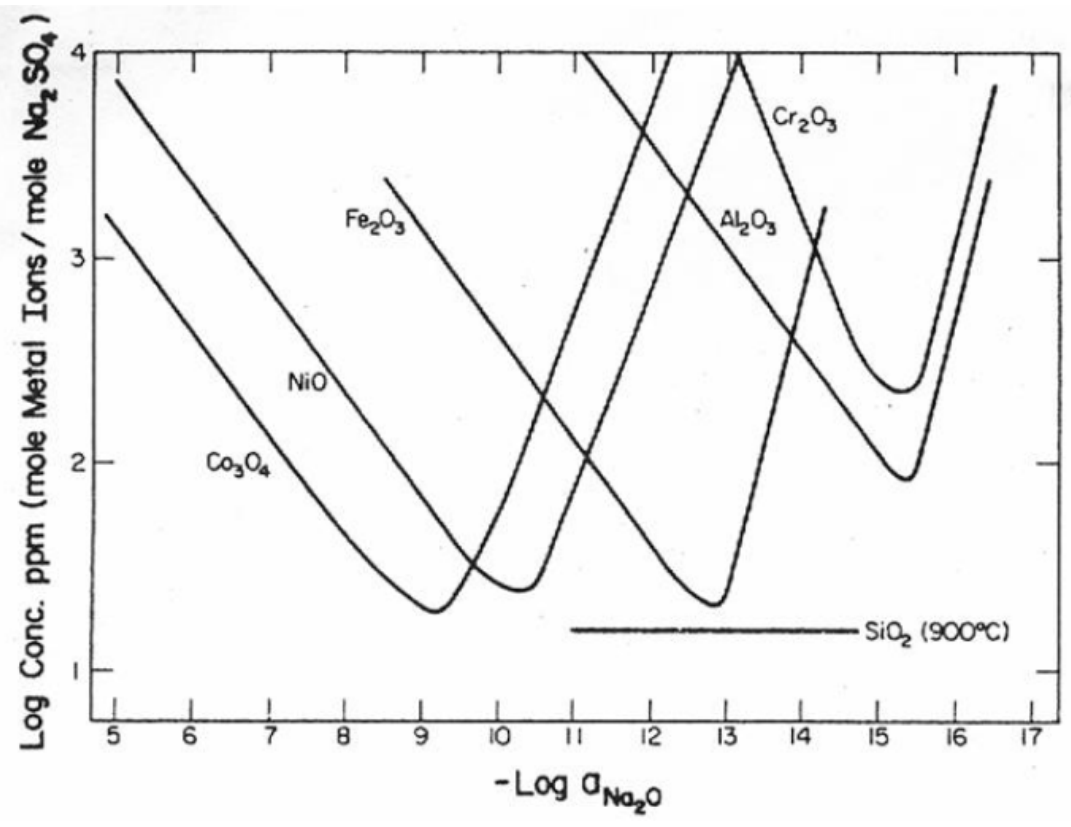

Figure 24: Measured oxide solubilities in $\mathrm{Na}_{2} \mathrm{SO}_{4}$ at $927^{\circ} \mathrm{C}$ and $1 \mathrm{~atm} \mathrm{O}_{2}$ [65]

The solubility minima of these oxides occurs over six orders of magnitude, which show that the salt chemistry is extremely important on the amount of hot corrosion, and it will be later shown for fireside corrosion as well.

As was mentioned earlier, the solubility plots shown in Figure 24 are for a constant po2 $=$ $1 \mathrm{~atm}$, but some of the oxides will be dependent on the oxygen partial pressure. This can be seen from the basic dissolution reaction of $\mathrm{Cr}_{2} \mathrm{O}_{3}$ in $\mathrm{Na}_{2} \mathrm{SO}_{4}$ shown in equation 20 below.

$$
\mathrm{Cr}_{2} \mathrm{O}_{3}+2 \mathrm{Na}_{2} \mathrm{O}+3 / 2 \mathrm{O}_{2}=2 \mathrm{Na}_{2} \mathrm{CrO}_{4}
$$

The $\mathrm{Cr}$ ion is oxidized from a $\mathrm{Cr}^{3+}$ ion to a $\mathrm{Cr}^{6+}$ ion during the dissolution, and so the solubility of $\mathrm{Cr}_{2} \mathrm{O}_{3}$ will increase as a function of Po2. Alumina does not have this effect. This can be seen from the dissolution reaction shown in equation 21 below.

$$
\mathrm{Al}_{2} \mathrm{O}_{3}+\mathrm{Na}_{2} \mathrm{O}=2 \mathrm{NaAlO}_{2}
$$


There is no change in valence of the $\mathrm{Al}^{3+}$ ion during the dissolution, and the solubility of $\mathrm{Al}_{2} \mathrm{O}_{3}$ in $\mathrm{Na}_{2} \mathrm{SO}_{4}$ is therefore independent of oxygen partial pressure. Rapp and Otsuka[70] explained this as the reason that higher chromium contents in alloys produces better hot corrosion resistance. The dependencies of oxide solubility on the oxygen partial pressure for chromia and iron oxides have been measured by Rapp and Zhang[71-72] and they were in good agreement with thermodynamic predictions.

The thermodynamic calculations based on the basic and acidic dissolution reactions are able to determine the shapes of the solubility curves. The oxide will dissolve by either accepting ions (basic) or donating ions (acidic). The slope of the curve is able to be determined by using the basic and acidic dissolution reaction equations, which are shown for $\mathrm{NiO}$ in equations 22 and 23 respectively below.

$$
\begin{aligned}
& \mathrm{NiO}+\mathrm{Na}_{2} \mathrm{O}+1 / 2 \mathrm{O}_{2}=2 \mathrm{NaNiO}_{2} \\
& \mathrm{NiO}+\mathrm{Na}_{2} \mathrm{SO}_{4}=\mathrm{NiSO}_{4}+\mathrm{Na}_{2} \mathrm{O}
\end{aligned}
$$

Assuming that $\mathrm{NiO}$ has unit activity, the equilibrium constant for the basic dissolution reaction can be given by equation 24 below.

$$
K=\frac{a_{\mathrm{NaNiO}_{2}}{ }^{2}}{a_{\mathrm{Na}_{2} \mathrm{Op}_{\mathrm{O}_{2}}{ }^{1 / 2}}}
$$

Taking the logarithm of both sides of the equation, solving for $\mathrm{a}_{\mathrm{Na} 2 \mathrm{O}}$, and then differentiating with respect to $-\log \left(\mathrm{a}_{\mathrm{Na} 2 \mathrm{O}}\right)$ yields the slope of the left side of the solubility curve, which corresponds to basic dissolution. This is shown in equation 25 below.

$$
\left[\frac{\delta \log a_{N a N i O}}{\delta\left(-\log a_{N a_{2} O}\right)}\right]=-1 / 2
$$

The same can be done with the acidic dissolution reaction equation. This is shown in equations 26 and 27 below. This reveals a slope of 1 for the right side of the solubility curve, or the side pertaining to acidic dissolution. 


$$
\begin{aligned}
& K=a_{\mathrm{NiSO}_{4}} \cdot a_{N a_{2} \mathrm{O}} \\
& {\left[\frac{\delta \log a_{\mathrm{NiSO}_{4}}}{\delta\left(-\log a_{\mathrm{Na}_{2} \mathrm{O}}\right)}\right]=1}
\end{aligned}
$$

The minimum in the solubility curve is the point in which the acid and basic dissolution curves intersect. Rapp and Goto[73] have proposed a criterion for which the continued self-sustaining hot corrosion attack can occur. This is known as the Rapp-Goto Criterion, and it is given by equation 28 shown below, where $\mathrm{C}_{\text {oxide }}$ is the solubility of the protective oxide and $\mathrm{x}$ is the distance into the molten salt deposit from the oxide/salt interface.

$$
\left[\frac{\delta C_{\text {oxide }}}{d x}\right]_{\mathrm{x}=\mathrm{o}}<0
$$

When the solubility gradient is positive, the salt can become saturated with oxide and a protective scale is able to form over the metal surface. A negative solubility gradient in the oxide solubility at the oxide/salt interface results in dissolution of the protective oxide scale and a reprecipitation of the oxide as discontinuous non-protective particles in regions of the molten salt deposit where the solubility is much lower. 
Figure 25 shows a schematic of the conditions in the salt that satisfy the Rapp-Goto Criterion and produce hot corrosion of a material with a surface oxide.

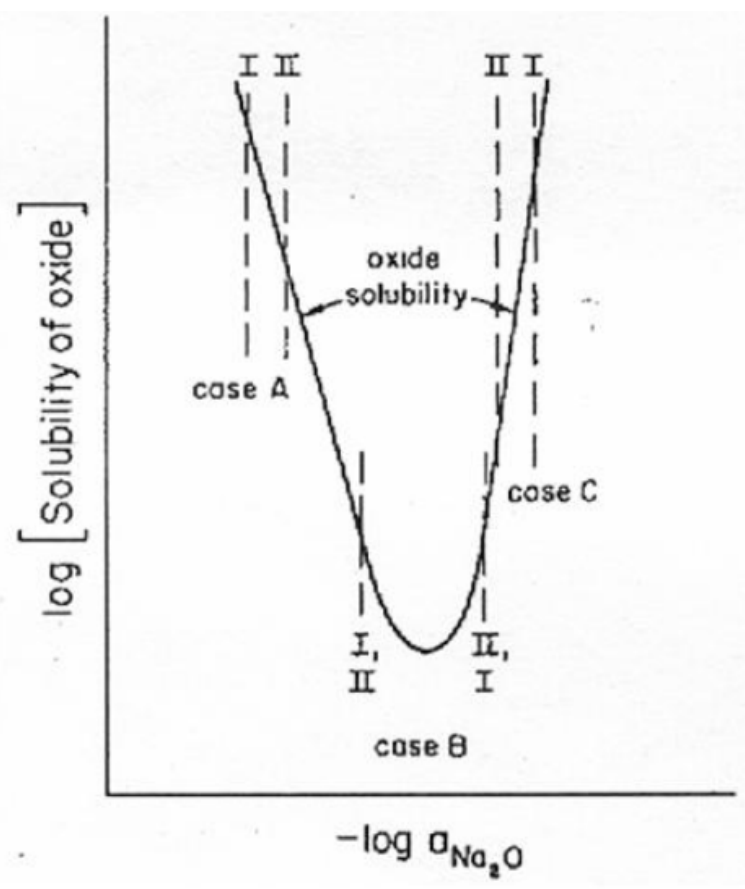

Figure 25: Conditions in the $\mathrm{Na}_{2} \mathrm{SO}_{4}$ salt the satisfy the Rapp-Goto Criterion [73]

Figure 25 is plotted for a constant oxygen partial pressure. Three situations labeled A, B, and C are given in which solubility gradients are established so that hot corrosion can occur. The dashed lines labeled I are for the locations of the oxide/salt interface, and the dashed lines labeled II are for the locations of the salt/gas interface. Whether the dissolution is basic or acidic, the oxide solubility must be higher at interface I than at interface II, which are cases A and C. Continued oxide dissolution occurs for case B if the locations of the interfaces lie on either side of the solubility minimum. A general description of $\mathrm{Na}_{2} \mathrm{SO}_{4}$-induced hot corrosion 
has been given. In the following section the propagation or hot corrosion mechanisms for gas phase-induced acidic fluxing will be described in more detail, as it is applicable to the mechanisms for fireside corrosion.

\subsubsection{Type II Hot Corrosion}

$\mathrm{Na}_{2} \mathrm{SO}_{4}$ has a melting point of $884^{\circ} \mathrm{C}$, so it does not form a molten salt and remains solid at the temperature of interest for this study $\left(650-750^{\circ} \mathrm{C}\right)$. In order for severe degradation to occur, the salt must become liquid, and so severe corrosion would not be expected at $650-700^{\circ} \mathrm{C}$, but severe corrosion occurs in turbine blades and the hot sections of boiler hardware at these low temperatures. This type of low temperature corrosion is called Type II hot corrosion. Type II hot corrosion is not well understood, but the accelerated corrosion is generally believed to be caused by the formation of a $\mathrm{Na}_{2} \mathrm{SO}_{4}-\mathrm{MSO}_{4}$ eutectic melt that has a melting point well below that of $\mathrm{Na}_{2} \mathrm{SO}_{4}$.[74] It is also known that a partial pressure of $\mathrm{SO}_{3}$ of about $10^{-5} \mathrm{~atm}$ is required for this melt to form.[75] This amount of $\mathrm{SO}_{3}$ in the gas atmosphere is not uncommon in industrial gas turbines or superheater tubing for boilers. CoCrAlY coatings are more susceptible than NiCrAlY coatings and Ni-based alloys to this form of corrosion, and so the bulk of research has been conducted with Co-based metals.

\subsubsection{Gas-Phase Induced Acidic Fluxing}

The corrosion mechanism for low temperature Type II hot corrosion is an acidic fluxing mechanism. The $\mathrm{Na}_{2} \mathrm{SO}_{4}$ salt deposit becomes acidic due to $\mathrm{SO}_{3}$ in the gas atmosphere. This is why it is called gas-phase induced acidic fluxing. There has been a great deal of research on the mechanism of Type II hot corrosion of Co-based materials.[76-78] This type of attack on 
CoCrAlY coatings is generally described as very localized pitting attack, with the pits containing porous unprotective $\mathrm{Cr}_{2} \mathrm{O}_{3}, \mathrm{Al}_{2} \mathrm{O}_{3}, \mathrm{CoCr}_{2} \mathrm{O}_{4}$, or $\mathrm{CoAl}_{2} \mathrm{O}_{4}$ with $\mathrm{Al}_{2} \mathrm{~S}_{3}$ forming a layer at the base of the pit. Cobalt oxides or cobalt sulfates will form at the corrosion product/gas interface depending on the partial pressure of $\mathrm{SO}_{3}$ in the gas. Higher $\mathrm{SO}_{3}$ contents will form cobalt sulfates.[61] Binary Co-Cr alloys have similar morphologies as the CoCrAlY coatings, but there are only Cr- and Co- rich corrosion products. $\mathrm{Cr}_{2} \mathrm{~S}_{3}$ forms a layer at the base of the pit. Binary Co-Al alloys sustained a more frontal attack, but the distributions of the elements in the corrosion products were similar to the Co-Cr and CoCrAlY alloys. There were of course only Al- and Co- rich corrosion products as well.[61]

A liquid deposit is generally required for severe corrosion to occur. For low temperature Type II hot corrosion, liquid deposits are able to form below the melting point of $\mathrm{Na}_{2} \mathrm{SO}_{4}$. This can be explained from the $\mathrm{CoSO}_{4}-\mathrm{Na}_{2} \mathrm{SO}_{4}$ phase diagram shown in Figure 26.

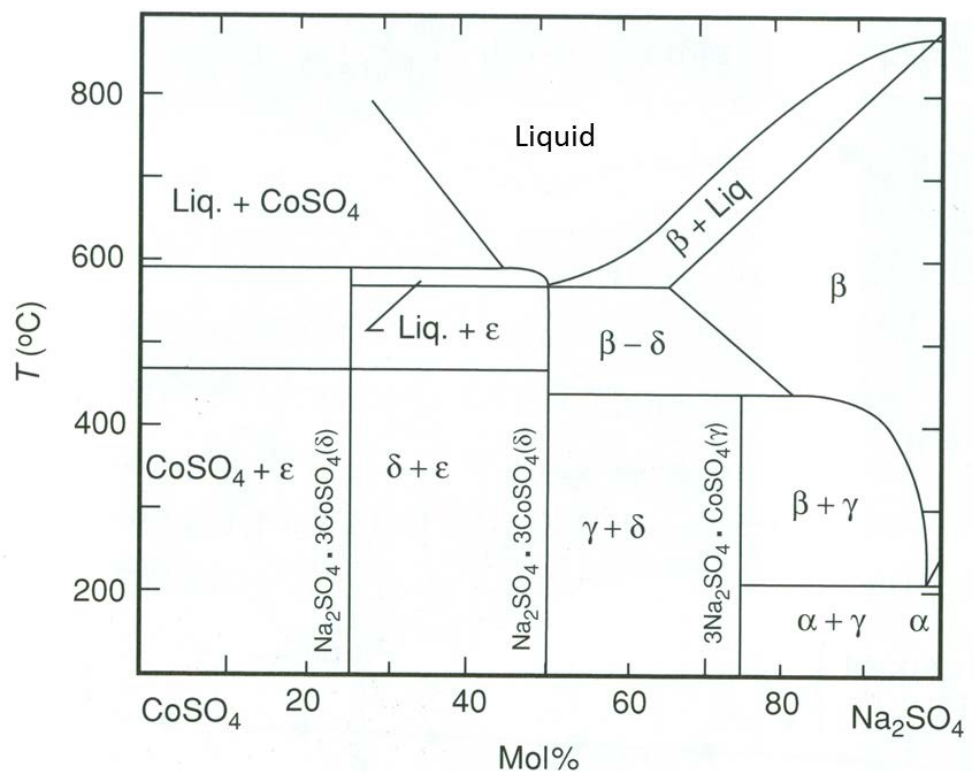

Figure 26: The $\mathrm{CoSO}_{4}-\mathrm{Na}_{2} \mathrm{SO}_{4}$ phase diagram [79] 
A eutectic liquid can be seen on the diagram at approximately $50 \% \mathrm{Na}_{2} \mathrm{SO}_{4}$ at $560^{\circ} \mathrm{C}$. Therefore, if sufficient amounts of $\mathrm{CoSO}_{4}$ can form in the $\mathrm{Na}_{2} \mathrm{SO}_{4}$ deposit, then a liquid will form in the low temperature $650-750^{\circ} \mathrm{C}$ range.

MCrAlY materials oxidized at high temperatures usually will form a slow growing protective $\alpha-\mathrm{Al}_{2} \mathrm{O}_{3}$ scale on its surface. Even though $\mathrm{Al}_{2} \mathrm{O}_{3}$ is the oxide that will preferentially grow on the substrate of these alloys, a small amount of $\mathrm{MO}\left(\mathrm{NiO}\right.$ or $\left.\mathrm{Co}_{3} \mathrm{O}_{4}\right)$ will grow initially before the protective $\mathrm{Al}_{2} \mathrm{O}_{3}$ scale can, because these oxides grow much faster than $\mathrm{Al}_{2} \mathrm{O}_{3}$. This is known as transient oxidation.[35] A CoCrAlY coating covered with a $\mathrm{Na}_{2} \mathrm{SO}_{4}$ deposit will have transient $\mathrm{Co}_{3} \mathrm{O}_{4}$ or $\mathrm{CoO}$, depending on temperature, growing first. The transient cobalt oxides can then react with $\mathrm{SO}_{3}$ in the gas atmosphere to form the liquid $\mathrm{Na}_{2} \mathrm{SO}_{4}-\mathrm{CoSO}_{4}$ eutectic melt. The reactions for this are given in equations 29 and 30.[39]

$$
\begin{aligned}
& 1 / 3 \mathrm{Co}_{3} \mathrm{O}_{4}+\mathrm{SO}_{3}=\underline{\mathrm{CoSO}_{4}}+1 / 6 \mathrm{O}_{2} \\
& \mathrm{CoO}+\mathrm{SO}_{3}=\underline{\mathrm{CoSO}_{4}}
\end{aligned}
$$

$\mathrm{CoSO}_{4}$ is underlined because it will dissolve in the $\mathrm{Na}_{2} \mathrm{SO}_{4}$ at an activity of less than one, and if there is enough $\mathrm{SO}_{3}$ present in the gas atmosphere to cause the formation of sufficient amounts of $\mathrm{CoSO}_{4}$, then the liquid eutectic melt can form. The amount of $\mathrm{SO}_{3}$ needed in the gas atmosphere to cause the formation of the eutectic melt from $\mathrm{Co}_{3} \mathrm{O}_{4} \mathrm{PO}_{\mathrm{O}}=1$ atm was calculated by Shores and Luthra[39] and is shown in the plot in Figure 27 below as a function of temperature. 


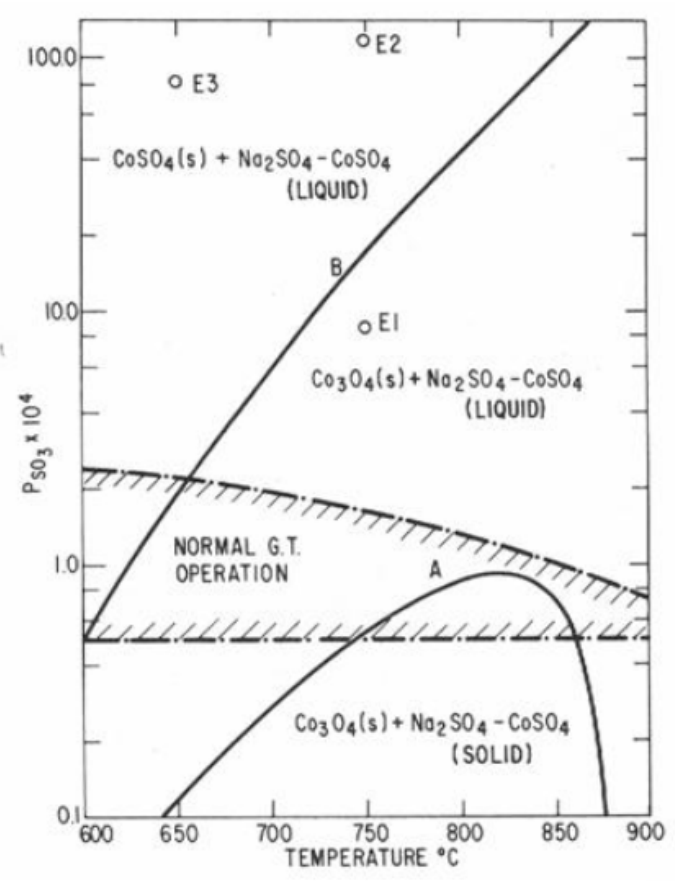

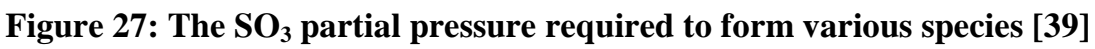

The $\mathrm{Na}_{2} \mathrm{SO}_{4}-\mathrm{CoSO}_{4}$ liquid eutectic is stable above the solid line in the plot marked $\mathrm{A}$. The amount of $\mathrm{SO}_{3}$ present in common gas turbine operating conditions is marked on the plot by the dashed line area. As can be seen, the liquid eutectic is stable at a wide range of $\mathrm{SO}_{3}$ partial pressures within the normal gas turbine operating conditions. This plot is for $\mathrm{p}_{\mathrm{O} 2}=1 \mathrm{~atm}$, and the curves will change with the oxygen partial pressure as can be seen in the equilibrium reaction given in equation 29. Even with significant increases in the oxygen partial pressure, curve A in the plot will only slightly increase, and therefore this plot is still valid for most situations.

Sulfur dioxide and sulfur trioxide both exist in combustion gas atmospheres. The formation of $\mathrm{SO}_{3}$ comes from the oxidation of $\mathrm{SO}_{2}$, which has been explained earlier. The reaction is given by equation 4 . As was discussed earlier, this reaction is very temperature dependent with $\mathrm{SO}_{2}$ being favored at high temperatures and $\mathrm{SO}_{3}$ at lower temperatures. Jones 
studied the interaction between $\mathrm{Co}_{3} \mathrm{O}_{4}$ and $\mathrm{SO}_{2} / \mathrm{SO}_{3}$ gas mixtures.[39] He determined that $\mathrm{SO}_{3}$ was the gas species responsible for turning $\mathrm{Co}_{3} \mathrm{O}_{4}$ into $\mathrm{CoSO}_{4}$ and not $\mathrm{SO}_{2}$. It was also discovered that $\mathrm{Co}_{3} \mathrm{O}_{4}$ is a good catalyst for reaction 4. Even in a gas atmosphere containing only $\mathrm{SO}_{2}$, significant amounts of eutectic liquid will form due to $\mathrm{Co}_{3} \mathrm{O}_{4}$ catalyzing the $\mathrm{SO}_{3}$ reaction.

The corrosion mechanism for low temperature Type II hot corrosion of Co-based alloys was proposed by Luthra.[39] The $\mathrm{SO}_{3}$ levels needed to form the eutectic liquid on the surface of the metal and cause corrosion would dissolve the protective $\mathrm{Al}_{2} \mathrm{O}_{3}$ and $\mathrm{Cr}_{2} \mathrm{O}_{3}$ scales as sulfates and therefore basic fluxing is not possible. The $\mathrm{SO}_{3}$ is consumed at the oxide/salt interface, and therefore the $\mathrm{SO}_{3}$ partial pressure is lower here than at the salt/gas interface. The solubility gradient at the oxide/salt interface would be positive, so acidic fluxing of the $\mathrm{Al}_{2} \mathrm{O}_{3}$ or $\mathrm{Cr}_{2} \mathrm{O}_{3}$ cannot occur. The transport rates of oxygen, $\mathrm{SO}_{2}$, and $\mathrm{SO}_{3}$ through the liquid salt were calculated, and it was found that only $\mathrm{SO}_{3}$, which is present as $\mathrm{S}_{2} \mathrm{O}_{7}{ }^{2-}$ ions, is the primary oxidant at the oxide/salt interface, and is the reason for the increased oxidation rates. $\mathrm{SO}_{3}$ becomes part of the salt deposit by the reaction given in equation 31 below.

$$
\mathrm{Na}_{2} \mathrm{SO}_{4}+\mathrm{SO}_{3}=\mathrm{Na}_{2} \mathrm{~S}_{2} \mathrm{O}_{7}
$$

Luthra[39] explains that it is then transported to the salt/gas interface by an $\mathrm{S}_{2} \mathrm{O}_{7}{ }^{2-} / \mathrm{SO}_{4}{ }^{2-}$ exchange reaction given in equation 32 below.

$$
\mathrm{S}_{2} \mathrm{O}_{7}{ }^{2-}+\mathrm{SO}_{4}{ }^{2-}+\mathrm{SO}_{4}{ }^{2-}=\mathrm{SO}_{4}{ }^{2-}+\mathrm{S}_{2} \mathrm{O}_{7}{ }^{2-}+\mathrm{SO}_{4}{ }^{2-}
$$

Cobalt oxides are commonly found at the corrosion product/gas interface, therefore they must transport somehow through the molten salt. Luthra also proposed a mechanism to explain this.[39] Cobalt is able to exist in a 2+ or 3+ valence state. The outward migration of Co ions requires the coupled movement of additional ions in order to preserve electrical neutrality. There 
are three proposed migration possibilities. The first involves the simultaneous outward diffusion of $\mathrm{Co}^{2+}$ and $\mathrm{SO}_{4}{ }^{2-}$. This requires the activity of $\mathrm{CoSO}_{4}$ be highest at the metal/oxide interface. At high concentrations of $\mathrm{SO}_{3}, \mathrm{CoSO}_{4}$ forms at unit activity at the salt/gas interface, and so the activity gradient needed for this reaction to occur is not possible, and therefore this migration mechanism is not possible. The second migration mechanism proposed is the simultaneous outward diffusion of $\mathrm{Co}^{2+}$ and $\mathrm{SO}_{3}{ }^{2-}$. The partial pressure of oxygen is low, and there should be a negative $\mathrm{SO}_{3}{ }^{2-}$ gradient at the oxide/salt interface. This is shown by the reaction given in equation 33 below.

$$
\mathrm{Na}_{2} \mathrm{SO}_{3}+1 / 2 \mathrm{O}_{2}=\mathrm{Na}_{2} \mathrm{SO}_{4}
$$

The calculated maximum flux for this mechanism is much smaller than the observed flux of cobalt. This confirms that this is not the mechanism for Co migration. The third mechanism for the migration of $\mathrm{Co}$ is a $3 \mathrm{Co}^{2+} / 2 \mathrm{Co}^{3+}$ exchange reaction. The ratio of $\mathrm{Co}^{3+} / \mathrm{Co}^{2+}$ in the molten salt is given by the reaction in equation 34 .

$$
2 \mathrm{CoSO}_{4}+\mathrm{SO}_{3}+1 / 2 \mathrm{O}_{2}=\mathrm{Co}_{2}\left(\mathrm{SO}_{4}\right)_{3}
$$

The partial pressures of oxygen and $\mathrm{SO}_{3}$ are lower at the oxide/salt interface than at the salt/gas interface; therefore the $\mathrm{Co}^{3+} / \mathrm{Co}^{2+}$ ratio should be higher at the salt/gas interface. This causes an outward migration of $\mathrm{Co}^{2+}$ ions that will form $\mathrm{Co}_{3} \mathrm{O}_{4}$ or $\mathrm{CoSO}_{4}$ depending on the oxygen and $\mathrm{SO}_{3}$ partial pressures at the salt/gas interface. $\mathrm{Co}^{3+}$ ions will migrate inward, where they will be reduced to $\mathrm{Co}^{2+}$ at the oxide/salt interface. This is the correct Co migration mechanism.

Using this Co migration mechanism, a sequence of reactions was developed to describe the mechanism of gas-phase induced acidic fluxing.[39] A binary Co-Cr alloy was used as the example material. During the beginning stages of oxidation, transient Co oxides and $\mathrm{Cr}_{2} \mathrm{O}_{3}$ will form. $\mathrm{Cr}_{2} \mathrm{O}_{3}$ is more stable than $\mathrm{Co}_{3} \mathrm{O}_{4}$, so an alloy containing sufficient amounts of $\mathrm{Cr}$ would 
eventually form a continuous, slowly growing, protective $\mathrm{Cr}_{2} \mathrm{O}_{3}$ scale. The dissolution of this protective scale is the reason for increased corrosion. The transient $\mathrm{Co}_{3} \mathrm{O}_{4}$ that initially forms will react with $\mathrm{SO}_{3}$ in the gas to form $\mathrm{CoSO}_{4}$ which will dissolve in the $\mathrm{Na}_{2} \mathrm{SO}_{4}$ salt deposit. If sufficient $\mathrm{SO}_{3}$ is available, then a liquid $\mathrm{Na}_{2} \mathrm{SO}_{4}-\mathrm{CoSO}_{4}$ eutectic will form leaving behind a porous $\mathrm{Cr}_{2} \mathrm{O}_{3}$ scale. The reaction can continue with the inward migration of $\mathrm{SO}_{3}$ and the outward migration of $\mathrm{Co}^{2+}$ as was discussed earlier. The inward migrating $\mathrm{SO}_{3}$ oxidizes the $\mathrm{Cr}$ at the oxide/salt interface releasing $\mathrm{SO}_{2}$, which can penetrate into the alloy and form sulfides. Sulfide rich bands are commonly found at the base of corrosion pits. The sulfide band that formed can be further oxidized generating $\mathrm{S}_{2}$, which can penetrate further into the alloy to form additional sulfides. The sulfide band and the corrosion pit are able to progressively go further into the alloy substrate. Eventually the maximum $\mathrm{CoSO}_{4}$ activity is reached at the salt/gas interface and the outward migrating cobalt will form $\mathrm{Co}_{3} \mathrm{O}_{4}$. This mechanism can be applied to Co-Al and CoCrAl alloys. Luthra[39] explained that the mechanism described above is not likely for Ni-based alloys because nickel does not have any known $\mathrm{Ni}^{3+}$ compounds, even though $\mathrm{Ni}^{3+}$ is possible.

The mechanism for Ni-based alloys is similar and was described by Chiang et al.[78]. A binary Ni-Cr alloy is used as an example. Transient $\mathrm{NiO}$ grows over a protective $\mathrm{Cr}_{2} \mathrm{O}_{3}$ scale on the surface of the metal and reacts with $\mathrm{SO}_{3}$ in the gas to form $\mathrm{NiSO}_{4}$. This will dissolve in the $\mathrm{Na}_{2} \mathrm{SO}_{4}$ deposit, and if there is sufficient $\mathrm{SO}_{3}$ in the gas atmosphere, a liquid $\mathrm{Na}_{2} \mathrm{SO}_{4}-\mathrm{NiSO}_{4}$ eutectic will form and penetrate the $\mathrm{Cr}_{2} \mathrm{O}_{3}$ scale. High $\mathrm{Pso}_{2} / \mathrm{p}_{\mathrm{s} 2}$ values are established at the alloy/salt interface due to low poz $_{2}$ in this area. This leads to acidic fluxing of the protective 
$\mathrm{Cr}_{2} \mathrm{O}_{3}$ scale and reprecipitation of a non-protective scale at places of higher po2. The base metal dissolves in the salt and diffuses to the salt/gas interface where it precipitates as $\mathrm{NiO}$. The high ps2 at the alloy/salt interface results in the precipitation of CrS in the alloy.

Low temperature hot corrosion tests were conducted on $\mathrm{Ni}-\mathrm{Cr}$, Co-Cr, NiCrAl, and CoCrAl alloys at temperatures between $700-750^{\circ} \mathrm{C}$ by Chiang et al.[78] They found that all of the alloys exhibited the degradation morphology similar to that for Co-Cr and CoCrAl described earlier. Even the Ni-based alloys observed severe degradation, but higher $\mathrm{SO}_{3}$ pressures were required for this to occur when compared to Co-based alloys. Chromium sulfides were found at the base of the pits of the Ni-based alloys, along with $\mathrm{NiS}$ in the corrosion product. Aluminum present in the alloy also seems to result in increased degradation, because the ternary Co-18Cr$6 \mathrm{Al}$ alloy sustained more degradation than the binary $\mathrm{Co}-20 \mathrm{Cr}$ at a given $\mathrm{SO}_{3}$ partial pressure. With these results, the authors proposed a Type II hot corrosion mechanism. As was discussed before, a liquid eutectic salt is formed from the reaction of transient $\mathrm{NiO}$ or $\mathrm{Co}_{3} \mathrm{O}_{4}$ with $\mathrm{SO}_{3}$. High values of Pso2 $_{\text {and }}$ ps2 are established at the oxide/salt interface because of low po2 in this region. The acidic fluxing of the protective $\mathrm{Al}_{2} \mathrm{O}_{3}$ scale for $\mathrm{CoCrAl}$ alloys is given by the reaction in equation 35 below.

$$
\mathrm{Al}_{2} \mathrm{O}_{3}+3 \mathrm{SO}_{2}=\mathrm{Al}_{2}\left(\mathrm{SO}_{3}\right)_{3}
$$

Aluminum sulfite is dissolved into the molten salt and is then reprecipitated out as porous $\mathrm{Al}_{2} \mathrm{O}_{3}$ in the outer region of the molten salt where the $\mathrm{SO}_{2}$ partial pressure is low. Chromium may undergo a similar reaction, or it may be oxidized in-situ. As was discussed earlier in the mechanism by Luthra, Co diffuses through the liquid salt and forms Co-oxide at the salt/gas interface. This mechanism is consistent with observed preferential attack of the Al-rich $\beta$-phase in the alloy. The mechanism is a bit different for NiCrAl alloys. The important reaction is at the 
oxide/salt interface in the substrate between $\mathrm{Cr}, \mathrm{Al}$, and $\mathrm{S}$ forming sulfides. These sulfides then oxidize and $\mathrm{S}_{2}$ is released which form NiS and dissolve into the molten salt. This allows Ni to diffuse to the salt/gas interface forming the non-protective NiO.

The morphology and mechanisms of Type II hot corrosion described here will be compared to the severe pitting attack observed in fireside corrosion tests. Both of these types of tests were conducted at low temperatures $\left(650-750^{\circ} \mathrm{C}\right)$, with the only difference being the type of deposit and the varying amounts of $\mathrm{SO}_{3}$ in the gas atmosphere.

\subsubsection{Synergistic Dissolution}

Another possible cause of accelerated deposit-induced corrosion may be synergistic dissolution of oxides in the molten salt deposit. This mechanism was described by Rapp for hot corrosion from molten sodium sulfate deposits.[80] The contact of sodium sulfate with two oxides whose solubility minima having different basicity values could result in an accelerated dissolution of both oxides. The dissolution of protective oxide scales may be acidic or basic in behavior. If the metal alloy produces two oxides in an environment where one oxide undergoes acidic dissolution and one undergoes basic dissolution, a combination of the dissolution reactions may cause accelerated degradation. In the case for this fireside corrosion study, the two oxides of interest

are $\mathrm{Fe}_{2} \mathrm{O}_{3}$ and $\mathrm{Cr}_{2} \mathrm{O}_{3}$. Both iron oxide and chromium oxide exhibit acidic and basic dissolution regimes. This can be seen in Figure 28. 


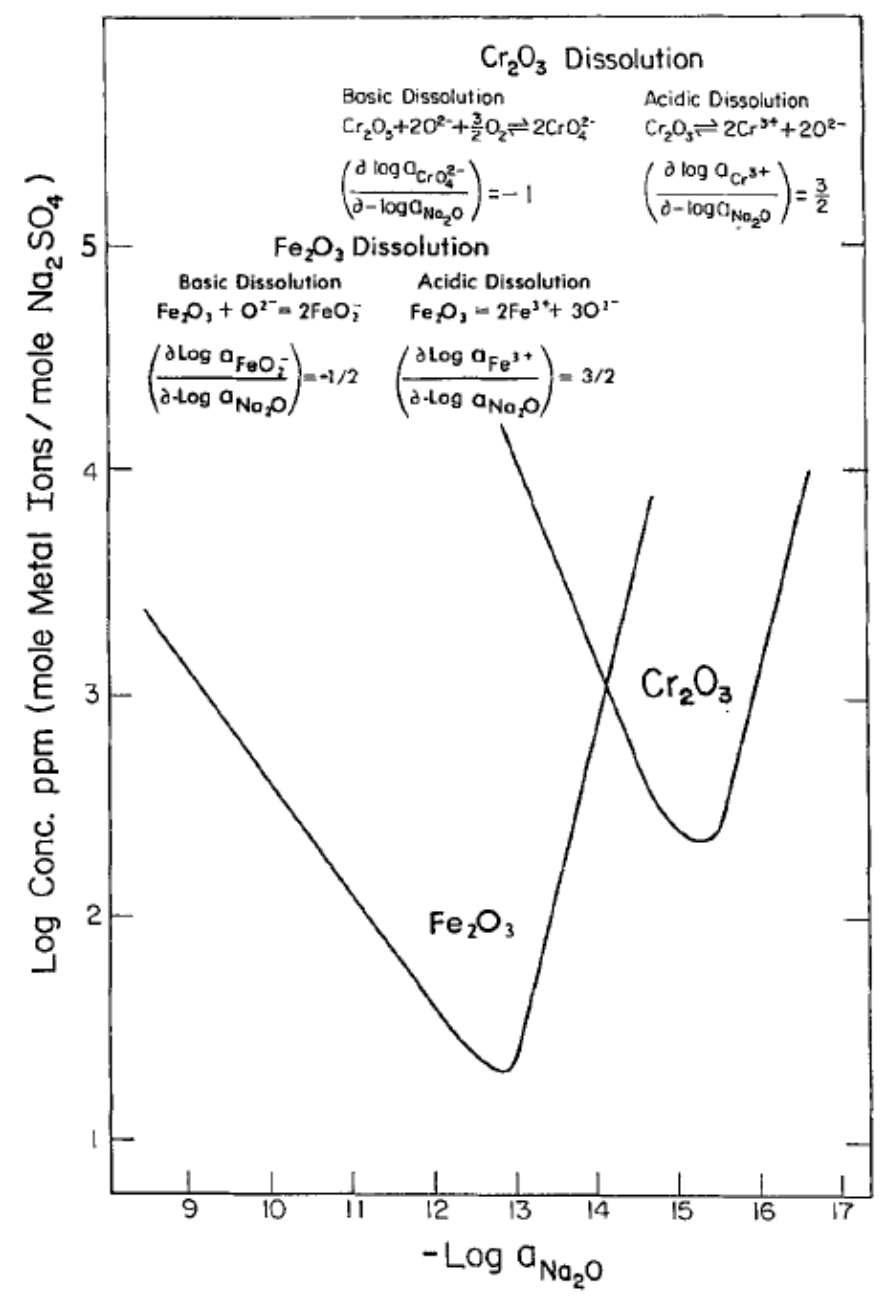

Figure 28: Solubility diagrams of $\mathrm{Fe}_{2} \mathrm{O}_{3}$ and $\mathrm{Cr}_{2} \mathrm{O}_{3}$ in fused $\mathrm{Na}_{2} \mathrm{SO}_{4}$ at $1200 \mathrm{~K}$ and $1 \mathrm{~atm} \mathrm{O}_{2}$ [80]

In order for synergistic dissolution to occur, the melt must have a basicity value between the solubility of the two oxides. If this is the case, then the oxide ions released upon acidic dissolution of $\mathrm{Fe}_{2} \mathrm{O}_{3}$ would supply the reactant anions needed for basic dissolution of $\mathrm{Cr}_{2} \mathrm{O}_{3}$.[80]

$$
\begin{gathered}
2 / 3 \mathrm{Fe}_{2} \mathrm{O}_{3}=4 / 3 \mathrm{Fe}^{3+}+2 \mathrm{O}^{2-} \text { (acidic dissolution) } \\
\mathrm{Cr}_{2} \mathrm{O}_{3}+2 \mathrm{O}^{2-}+3 / 2 \mathrm{O}_{2}=2 \mathrm{CrO}_{4}{ }^{2-} \text { (basic dissolution) } \\
2 / 3 \mathrm{Fe}_{2} \mathrm{O}_{3}+\mathrm{Cr}_{2} \mathrm{O}_{3}+3 / 2 \mathrm{O}_{2}=4 / 3 \mathrm{Fe}^{3+}+2 \mathrm{CrO}_{4}{ }^{2-} \text { (synergistic dissolution) }
\end{gathered}
$$




\subsection{RESEARCH OBJECTIVES}

The previous sections described the complex nature and some of the factors which affect fireside corrosion including sulfur in the corrosion environment, possible mechanisms of fireside corrosion, and alloys for use in coal-fired power plant superheater tubes. The deposits formed in boilers are complex, and despite decades of study, the propagation mechanism of fireside corrosion is not well understood. Alkali iron trisulfates, which are stabilized by $\mathrm{SO}_{3}$ in the gas atmosphere due to sulfur in the coal and the products of combustion, have been thought for years to be the cause of corrosion. Whether or not alkali iron trisulfates are the liquid deposit that is causing corrosion or whether they are a product of the corrosion process needs to be determined. Because $\mathrm{SO}_{3}$ enters the deposit from the gas phase, the solubility gradient for the oxides of the underlying metal alloying elements should be positive, which should eliminate selfsustaining fluxing and degradation. However, fireside corrosion is known to be a self-sustaining form of attack. The main objective of this thesis project is to examine materials in environments related to air- and oxy-firing conditions and provide information on the initiation and propagation mechanisms for fireside corrosion. A wide variety of material chemistry and oxy-firing conditions are examined in short-term laboratory tests with the aim of

determining the controlling corrosion mechanisms. Because of the similar nature to hot corrosion, whether fireside corrosion can be considered a more complicated form of type II hot corrosion is examined. A variety of variables which pertain to the fireside corrosion 
atmosphere and their effect on the initiation and propagation stages also need to be studied. The effects of deposit composition, temperature, gas atmosphere, alloy composition, and deposit thickness are analyzed in this study.

The deposits that form on coal-fired boiler tubes come from the ash from burning coal, and are therefore dependent on the type of coal that is used. Western U.S. coals will typically produce ash with higher $\mathrm{CaO}$ concentrations than Eastern and Midwestern coals, while Eastern and Midwestern coals will have higher sulfur concentrations. Each of the coals will produce ash which contains alumina and silica. The effects of various oxide additions (CaO-basic oxide, $\mathrm{SiO}_{2}$-acidic oxide, $\mathrm{Al}_{2} \mathrm{O}_{3}$-neutral oxide) to deposits on the fireside corrosion mechanism and the amount of corrosion that occurs need to be examined. The liquid salt that causes degradation comes from reactions with iron oxide, alkali sulfates in the ash deposit, and $\mathrm{SO}_{3}$ from the gas atmosphere. The iron oxide can come from a thermally grown oxide scale, or it can come from iron oxide in the ash deposit. The importance of a thermally grown iron oxide scale on the formation of liquid melt rather than the formation from $\mathrm{Fe}_{2} \mathrm{O}_{3}$ in the deposit may affect the corrosion mechanism and is determined in this study.

As was mentioned previously in the Introduction and Background sections, oxy-fuel firing produces gas atmospheres containing higher $\mathrm{CO}_{2}, \mathrm{H}_{2} \mathrm{O}$, and $\mathrm{SO}_{2}$ concentrations than airfiring. The amount of $\mathrm{SO}_{2}$ is of extreme importance, as the oxidation of $\mathrm{SO}_{2}$ leads to $\mathrm{SO}_{3}$ formation and followed by the formation of the liquid eutectic salt. The threshold value of $\mathbf{S O}_{3}$ for the formation of the liquid deposit needs to be examined. A series of gas atmospheres containing oxygen with varying amounts of $\mathrm{SO}_{2}$ are studied to examine the effects of $\mathrm{SO}_{2}$ concentration. 
Gas atmospheres more simulative of those found in oxy-fuel combustion are studied as well, because the effects of adding $\mathrm{CO}_{2}, \mathrm{H}_{2} \mathrm{O}$ and higher $\mathrm{SO}_{2}$ concentrations on the corrosion rate need to be determined.

Increasing temperatures and pressures and highly corrosive steam and $\mathrm{SO}_{2}$ atmospheres encountered in fireside corrosion atmospheres require materials that have higher oxidation resistance and high temperature strength. Alumina-forming austenitic (AFA) stainless steels offer a potential solution to maintain oxidation and corrosion resistance in these atmospheres while maintaining alloy strength and without significantly increasing the alloy cost. The fireside corrosion resistance of these alloys needs to be studied to determine their compositional effects on the fireside corrosion mechanism, and whether alumina-forming austenitic steels can provide protection in these aggressive atmospheres. These alloys are slow to reach their equilibrium microstructure at the temperature of interest. The effect of a slowly changing microstructure on the amount of corrosion also needs to be determined. The results should aid in alloy development for AFA alloys and provide further insight into the corrosion mechanisms.

The temperature of the system plays a significant role on the amount of corrosion that occurs. It was mentioned that the maximum corrosion rate occurs in a temperature range of 650$750^{\circ} \mathrm{C}$ and shows a bell-shaped curve. The maximum corrosion temperature in this bellshaped curve needs to be determined. The gas atmosphere, deposit composition, and alloy composition could possibly have an effect on this maximum temperature, and their effect on the amount of corrosion also is studied.

The amount of corrosion of the superheater tubes in coal-fired power plants decreases as the thickness of the deposit increases. The effect of the deposit thickness on the amount of 
degradation needs to be examined in more detail and this can be done using two different deposition procedures described in the Experimental Procedure sections. 


\subsection{EXPERIMENTAL PROCEDURE}

\subsection{MATERIALS PREPARATION}

Six different alloys were chosen for the fireside corrosion study. T92 is a commercial ferritic boiler steel used in coal-fired power plants. It has about 9\%Cr and will form a Fe-Cr spinel scale when oxidized in the absence of a deposit. A model austenitic alloy was prepared with $12 \% \mathrm{Ni}$ and 18\%Cr. Austenitic stainless steel will provide greater protection with the higher chromium contents, and this alloy has a composition similar to 347 stainless steels used in coal-fired power plants in high temperature applications. AFA alloys offer a potential solution to maintain oxidation and corrosion resistance in these atmospheres without significantly increasing the alloy cost. Alumina grows at a slower rate than chromia, is more thermodynamically stable with oxygen, and allows for a higher degree of protection in the presence of many oxidizing species, such as water vapor which can cause the formation of volatile oxy-hydroxide species in chromiaforming alloys.[5] Four different AFA alloys were used as part of this study. The standard AFA grade alloy OC4 has the desired combination of moderate oxidation and creep strength.[52] Increasing the chromium, nickel, and niobium concentration is the OC8 alloy, which is a gamma prime strengthened alloy. This alloy has very promising strength and oxidation resistance, 
however, at longer times thermodynamic studies show that brittle sigma phase can form.[53] OCS and OCT are gamma prime strengthened grade AFA alloys with lower chromium contents, hopefully avoiding the undesirable sigma phase.[54]

Table 9: Composition of Alloys (wt.\%)

\begin{tabular}{|c|c|c|c|c|c|c|c|}
\hline & $\mathrm{Fe}$ & $\mathrm{Ni}$ & $\mathrm{Cr}$ & $\mathrm{Al}$ & $\mathrm{Mo}$ & $\mathrm{Ti}$ & Other \\
\hline $\mathrm{T92}$ & Balance & 0.32 & 8.84 & - & 0.32 & - & - \\
\hline $\mathrm{FeNiCr}$ & Balance & 12 & 18 & - & - & - & - \\
\hline OC4 & Balance & 25 & 14 & 3.5 & 2 & - & $1 \mathrm{~W}, 2.5 \mathrm{Nb}$ \\
\hline OC8 & Balance & 32 & 18.7 & 3 & 0.15 & - & $3.3 \mathrm{Nb}$ \\
\hline OCS & Balance & 32 & 13.83 & 3 & 0.1 & 2 & $\begin{array}{c}2.87 \mathrm{Nb} \\
0.32 \mathrm{Zr}\end{array}$ \\
\hline OCT & Balance & 35 & 13.8 & 3 & 0.1 & 2 & $\begin{array}{c}2.92 \mathrm{Nb} \\
0.32 \mathrm{Zr}\end{array}$ \\
\hline
\end{tabular}

The compositions of the alloys tested are presented in Table 9. The AFA alloys were cast, solutionized, hot rolled, and re-solutionized near $1100-1200^{\circ} \mathrm{C}$ and then air or water quenched.[53-54] The alloys were cut into rectangular coupon specimens approximately 14$16 \mathrm{~mm} \times 8-13 \mathrm{~mm} \times 2-4 \mathrm{~mm}$. All of the specimens were polished to a $1200 \mathrm{P}$ grit $\mathrm{SiC}$ finish and ultrasonically cleaned in isopropanol. The specimens were then dried and weighed before any deposits were applied. A series of deposits were used in the testing of these alloys. These deposits include:

1. $\mathrm{Na}_{2} \mathrm{SO}_{4}: \mathrm{K}_{2} \mathrm{SO}_{4}$ in a 1:1 molar ratio (M1), this deposit will remain solid until it reacts with sufficient thermally grown iron oxide and $\mathrm{SO}_{3}$ in the gas atmosphere to form the liquid eutectic salt. This allows for analysis of the fireside corrosion propagation mechanism and the importance of a thermally grown iron oxide scale in liquid formation. 
2. $\mathrm{Na}_{2} \mathrm{SO}_{4}: \mathrm{K}_{2} \mathrm{SO}_{4}: \mathrm{Fe}_{2} \mathrm{O}_{3}$ in a 1.5:1.5:1.0 molar ratio, this is the Standard Corrosion Mix (SCM), which has been discussed and tested previously. The ratios for this mix are the stoichiometric coefficients of alkali iron trisulfates. This deposit is designed to form alkali iron trisulfates even without the presence of thermally grown iron oxides on the specimen surface. The alkali iron trisulfates form in the deposit itself. This deposit should be liquid at in the tested temperature range.

3. SCM and M1 + individual additions of oxides typically found in boiler deposits (CaObasic oxide, $\mathrm{SiO}_{2}$-acidic oxide, $\mathrm{Al}_{2} \mathrm{O}_{3}$-neutral oxide). This allows for the examination of more simulative deposits found in coal-fired boiler systems. Previous studies have shown that additions of $\mathrm{SiO}_{2}$ and $\mathrm{Al}_{2} \mathrm{O}_{3}$ dilute the corrosive alkali sulfates. Niles and Siegmund tested kaolin $\left(\mathrm{Al}_{2} \mathrm{O}_{3} \cdot 2 \mathrm{SiO}_{2}\right)$ as an additive to deposits because it is effective in reacting with sodium.[81] The alumina and silica may inhibit the corrosion by absorbing the corrosive molten sulfates.

There were two deposition procedures used for testing. The first is simply keeping the mixed deposits in powder form and placing them into alumina crucibles. The specimens were placed into the crucibles so that half of the specimen was covered in powder and half was not. This was done so that the effect of deposit thickness on the corrosion of the alloy could be determined. This provides three deposit zones in one specimen: a thick deposit zone (where the specimen is buried in the bottom of the crucible), a thin deposit zone (where the deposit powder first starts to cover the specimen), and a no-deposit zone. The second deposition procedure was coating the specimens in a slurry. The powder deposit was mixed with water to make the slurry. For the SCM and the deposits containing the M1 and SCM + oxide additions, the specimens were placed onto a hot plate, and the slurry was dropped onto the specimen with a dropper. The water 
evaporates away leaving the deposit of iron oxide and alkali sulfates remaining on the specimen. For the M1 deposit, the specimens were heated with a heat gun, and then the slurry was sprayed on. Once again, the water evaporates away, leaving the alkali sulfates deposited on the surface. This was repeated until the desired amount of slurry was coated onto the specimens. This allows for more precise study of the effect of deposit thickness on the amount of corrosion.

\subsection{TEST PROCEDURE}

Once the specimens have been deposited with the salt mixture, they were placed into a quartz tube in a horizontal resistance-heated furnace shown schematically in Figure 29.

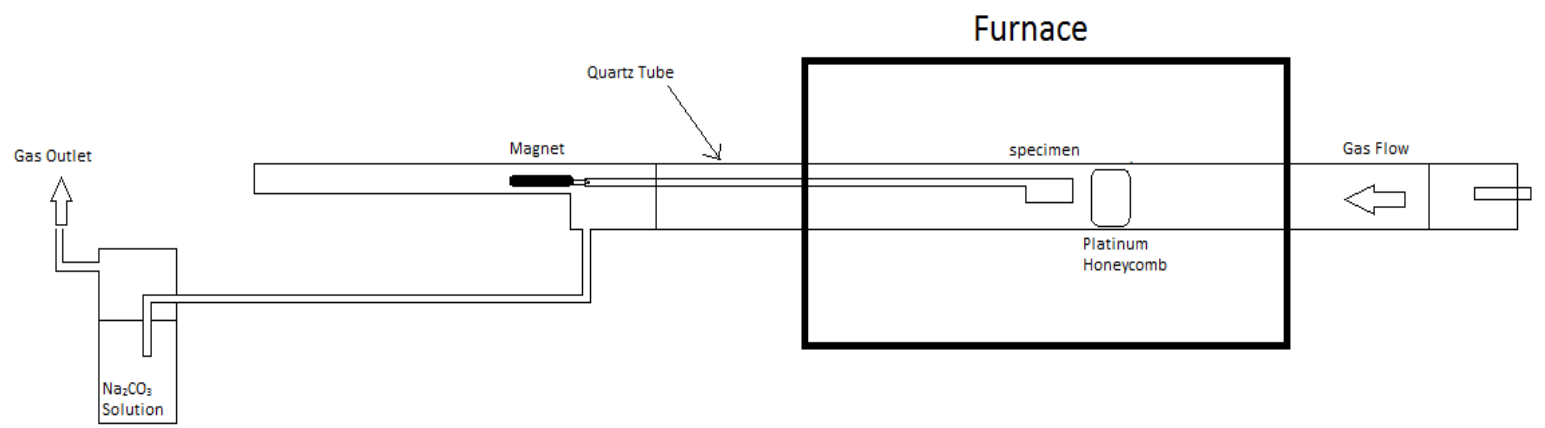

Figure 29: Schematic of horizontal tube furnace apparatus for fireside corrosion tests

The specimens could be cycled in and out of the hot zone of the furnace manually by using a magnet to push a quartz rod that held the specimens. The specimen holder is two crucibles hung by Kanthal wire below the quartz rod, shown in Figure 30. 


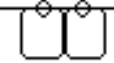

Crucibles

Figure 30: Modified quartz rod for crucible fireside corrosion tests

The hot zone was maintained within 3 degrees of the test temperature. The gas atmospheres tested predominantly contain oxygen with varying amounts of $\mathrm{SO}_{2}$; however some tests were conducted in $\mathrm{O}_{2}+\mathrm{SO}_{2}-\mathrm{H}_{2} \mathrm{O}-\mathrm{CO}_{2}$ atmospheres. The gas flows into the tube at a constant flow rate of $15 \mathrm{~mL} / \mathrm{min}(0.0125 \mathrm{~cm} / \mathrm{s})$ and passes over a platinum honeycomb catalyst placed in the hot

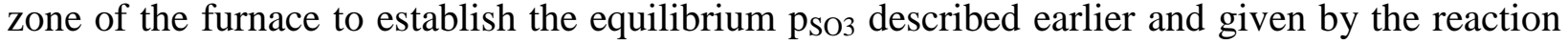
in equation 4. Assuming that equilibrium is attained, the equilibrium $\mathrm{p}_{\mathrm{so}}$ values for the temperatures and gas atmospheres tested are given in Table 10.

Table 10: Equilibrium $\mathrm{SO}_{3}$ partial pressures at experimental temperatures and gas atmospheres

\begin{tabular}{|c|c|c|c|c|c|}
\hline $\begin{array}{l}\mathrm{SO}_{3} \text { Partial } \\
\text { Pressure }\end{array}$ & $\begin{array}{c}\mathrm{O}_{2}+100 \mathrm{ppm} \\
\mathrm{SO}_{2}\end{array}$ & $\begin{array}{c}\mathrm{O}_{2}+500 p p m \\
\mathrm{SO}_{2}\end{array}$ & $\begin{array}{c}\mathrm{O}_{2}+1000 p p m \\
\mathrm{SO}_{2}\end{array}$ & $\begin{array}{c}\mathrm{O}_{2}+2500 p p m \\
\mathrm{SO}_{2}\end{array}$ & $\begin{array}{c}\mathrm{CO}_{2}-25 \% \mathrm{H}_{2} \mathrm{O}- \\
3 \% \mathrm{O}_{2}-0.5 \% \mathrm{SO}_{2}\end{array}$ \\
\hline $650^{\circ} \mathrm{C}$ & $\begin{array}{c}82.92 \mathrm{ppm}= \\
8.29 \times 10^{-5} \mathrm{~atm}\end{array}$ & $\begin{array}{c}414.59 \mathrm{ppm}= \\
4.15 \times 10^{-4} \mathrm{~atm}\end{array}$ & $\begin{array}{c}829.2 \mathrm{ppm}= \\
8.29 \times 10^{-4} \mathrm{~atm}\end{array}$ & $\begin{array}{c}2027.6 \mathrm{ppm}= \\
2.03 \times 10^{-3} \mathrm{~atm}\end{array}$ & $\begin{array}{c}2263 \mathrm{ppm}= \\
2.26 \times 10^{-3} \mathrm{~atm}\end{array}$ \\
\hline $700^{\circ} \mathrm{C}$ & $\begin{array}{c}71.61 \mathrm{ppm}= \\
7.16 \times 10^{-5} \mathrm{~atm}\end{array}$ & $\begin{array}{c}358.09 \mathrm{ppm}= \\
3.58 \times 10^{-4} \mathrm{~atm}\end{array}$ & $\begin{array}{c}716.12 \mathrm{ppm}= \\
7.16 \times 10^{-4} \mathrm{~atm}\end{array}$ & $\begin{array}{c}1789.9 \mathrm{ppm}= \\
1.79 \times 10^{-3} \mathrm{~atm}\end{array}$ & $\begin{array}{c}1510 \mathrm{ppm}= \\
1.51 \times 10^{-3} \mathrm{~atm}\end{array}$ \\
\hline $750^{\circ} \mathrm{C}$ & $\begin{array}{c}58.34 \mathrm{ppm}= \\
5.83 \times 10^{-5} \mathrm{~atm}\end{array}$ & $\begin{array}{c}291.68 \mathrm{ppm}= \\
2.92 \times 10^{-4} \mathrm{~atm}\end{array}$ & $\begin{array}{c}583.4 \mathrm{ppm}= \\
5.83 \times 10^{-4} \mathrm{~atm}\end{array}$ & $\begin{array}{c}1457.8 \mathrm{ppm}= \\
1.46 \times 10^{-3} \mathrm{~atm}\end{array}$ & $\begin{array}{c}970.4 \mathrm{ppm}= \\
9.7 \times 10^{-4} \mathrm{~atm}\end{array}$ \\
\hline
\end{tabular}

When exiting the furnace, the gas is bubbled through a $\mathrm{Na}_{2} \mathrm{CO}_{3}$ plus water mixture before entering the fume hood. This removes the $\mathrm{SO}_{3}$ from the gas, which is shown by the reaction in equation 39. 


$$
\mathrm{SO}_{3}+\mathrm{Na}_{2} \mathrm{CO}_{3}=\mathrm{Na}_{2} \mathrm{SO}_{4}+\mathrm{CO}_{2}
$$

The produced sodium sulfate precipitates out in solution in the bubbler, and the exiting gas is predominantly carbon dioxide.

The alloys in Table 9 were exposed to a range of $\mathrm{O}_{2}+\mathrm{SO}_{2}$ gas atmospheres and oxy-fuel $\left(\mathrm{CO}_{2}-\mathrm{H}_{2} \mathrm{O}-\mathrm{O}_{2}-\mathrm{SO}_{2}\right)$ atmospheres in the temperature range of $650-750^{\circ} \mathrm{C}$ with each of the different deposits described in the previous section for durations of 20,40, 80, and 160 hours. This allows for the examination of the initiation and propagation mechanisms as well as the variables described in the Research Objectives section. The specimens were metallographically prepared for examination with oil instead of water in order to preserve the water soluble corrosion products.

\subsection{EVALUATION OF SPECIMENS}

Weight change versus time measurements were calculated; however it is difficult to obtain an accurate measure of the degradation due to the nature of the deposits. Dimensional metrology measurements were conducted, because they provide the most reliable measurement of the corrosion damage to alloys, as unaffected by deposit material adhering to the specimen.[57] An example of the different regions which can be analyzed in the dimensional metrology measurements is shown in Figure 31. 


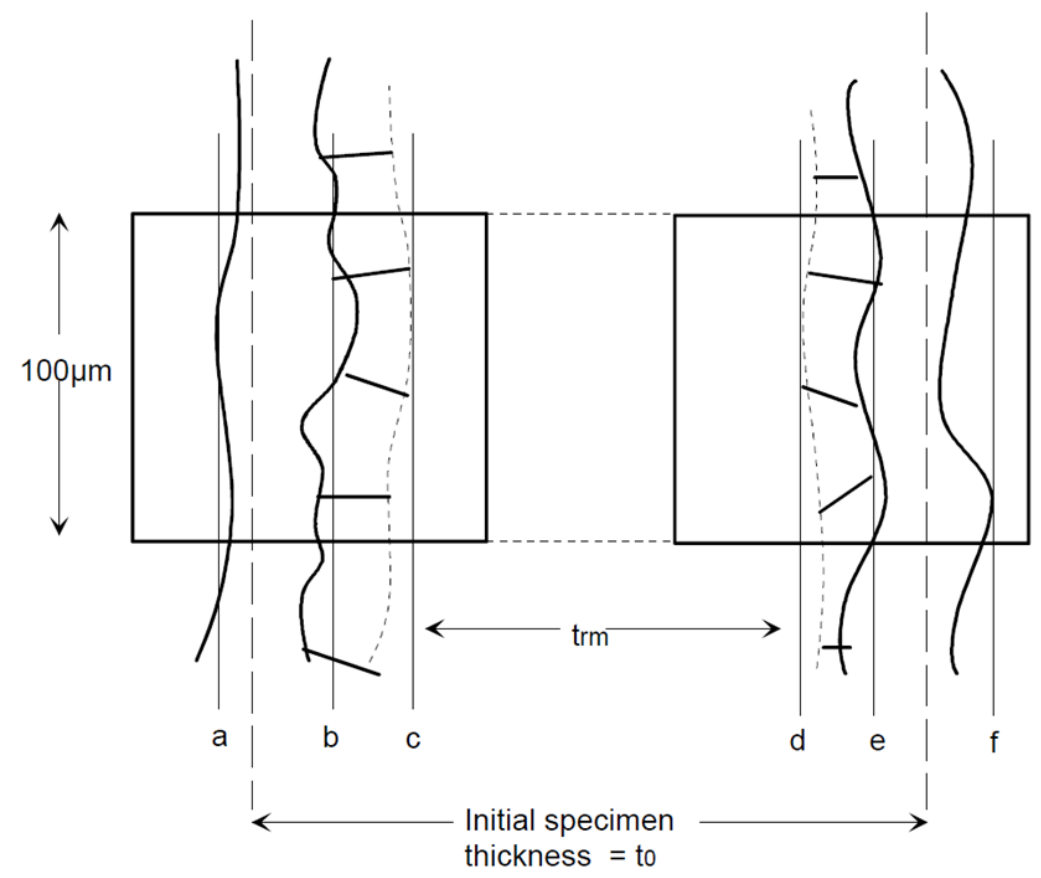

Figure 31: Sample corrosion layer measurement areas [82]

In Figure 31, (a) and (f) are the outermost positions of the corrosion scale within the field of View, positions (b) and (e) are the position of the scale/metal interface, defined as the lines for which there were equal amounts of metal on the corroded side as corrosion product on the metal side, and (c) and (d) are the deepest positions of grain boundary penetration or internal corrosion products whichever is relevant, within the field of view. Measurements of deepest positions of grain boundary penetration or internal corrosion products were taken at a minimum of 20 locations along the length of the specimen, and the metal loss $\left(\mathrm{t}_{\mathrm{ml}}\right)$ will be given by equation 40 below, where $t_{0}$ is the initial metal thickness, and trm is the minimum remaining metal thickness.

$$
\mathrm{t}_{\mathrm{ml}}=\left(\mathrm{t}_{\mathrm{o}}-\mathrm{t}_{\mathrm{rm}}\right) / 2
$$


The results were plotted as metal loss values according to the draft standards for high temperature corrosion measurements.[82] The deepest positions of internal corrosion products provide the most information, but the thickness of the other layers can provide supplementary information on the extent of the different corrosion layers.

Macroscopic images of the specimens were taken after each test. The surfaces of some of the specimens were viewed under the scanning electron microscope. The specimens were metallographically prepared in water-free lubricants and viewed under the scanning electron microscope again so that cross-sectional images could be taken. Two different SEMs were used. One is a Phillips XL-30 Field Emission Gun microscope. This microscope is equipped with secondary electron (SE), backscatter electron (BSE), and X-ray detectors and is thus capable of performing image acquisition and energy dispersive spectroscopic analysis (EDS). The other is a JEOL JSM-6610LV equipped with SE, BSE, and EDS. Other characterization techniques such as $\mathrm{x}$-ray diffraction and chemical analysis of the corrosion products was also performed on some of the tested specimens.

\subsection{ANALYSIS OF RESULTS}

The extent of the attack on the specimens was analyzed from the weight change measurements and metal loss calculations. The thickness and compositions of the corrosion products along with the metal loss calculations will give a better understanding of the amount and type of degradation that occurred. The macroscopic and microscopic images and EDS analysis obtained from each test helped determine the composition and morphology of the corrosion products. The different duration experiments gave information on the kinetics and oxidation rates. The time 
before propagation and the mechanism of corrosion for each of the alloys were examined with respect to the different deposits, gas atmospheres, and alloy compositions. The results of the $\mathrm{x}$ ray diffraction scans and chemical analysis provide further information on the composition of the corrosion products. 


\subsection{RESULTS AND DISCUSSION}

\subsection{MECHANISM STUDY}

Two spinel and chromia-forming steel alloys were chosen for the determination of the fireside corrosion initiation and propagation mechanisms, namely T92 (a common boiler steel) and a model austenitic stainless steel $(\mathrm{Fe}-12 \% \mathrm{Ni}-18 \% \mathrm{Cr})$. These alloys were exposed at $700^{\circ} \mathrm{C}$ with the M1 and SCM deposits in $\mathrm{O}_{2}+1000 \mathrm{ppm} \mathrm{SO}_{2}$ for durations of 20, 40, 80, and 160 hours. Information regarding the initiation and propagation stages of corrosion with respect to alloy composition was obtained.

\subsubsection{M1 Results}

The M1 deposit contains equimolar concentrations of sodium sulfate and potassium sulfate. This deposit should remain solid on the surface of the test specimens until it reacts with a thermally grown iron oxide scale and sufficient $\mathrm{SO}_{3}$ from the gas atmosphere. The $\mathrm{M} 1$ deposit allows for the study of the importance of a thermally grown iron oxide scale on the formation of a liquid deposit and the amount of corrosion that occurs, as well as insight into the initiation and propagation mechanisms. Macroscopic results for each alloy are presented in Figure 32. The extent of the corrosion can be seen in the plots of the weight change and metal loss for both alloys in Figures 33 and 34. It should be noted that the weight changes may be exaggerated due 
to adhesion of the deposit with the corrosion products. The metal loss calculations give a better representation of the amount of degradation that occurred. The metal loss calculations for this study are the average metal loss for the entire deposit zone (thick and thin deposit zones). The amount of metal loss with respect to deposit thickness and position on the specimen will be examined in a subsequent section.
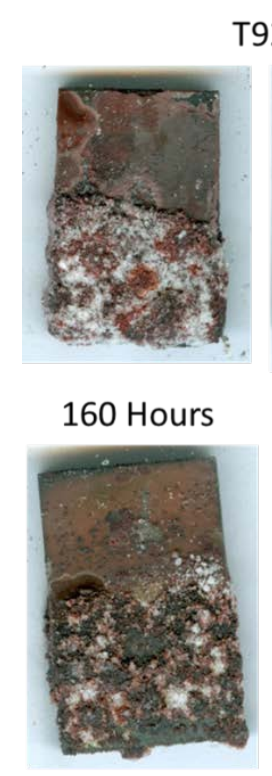

40 Hours
T92

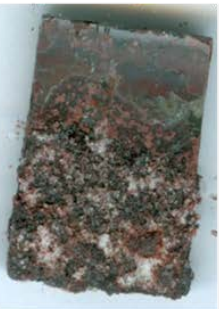

80 Hours

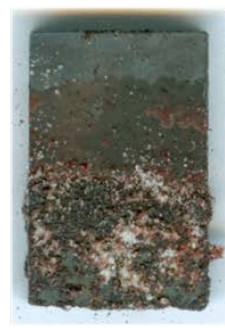

20 Hours
$\mathrm{FeNiCr}$

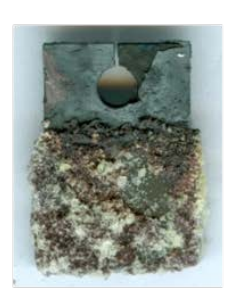

160 Hours

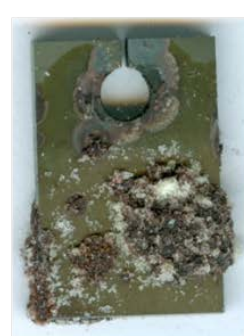

40 Hours

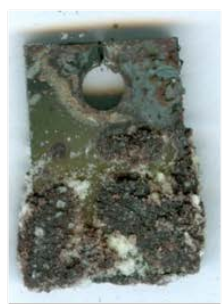

80 Hours

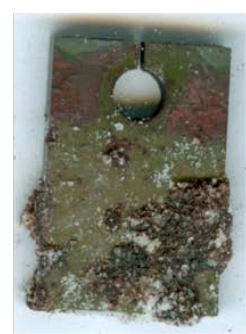

20 Hours

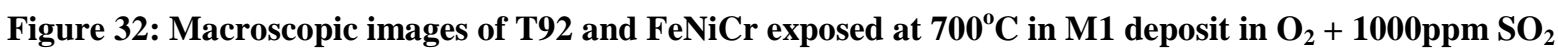




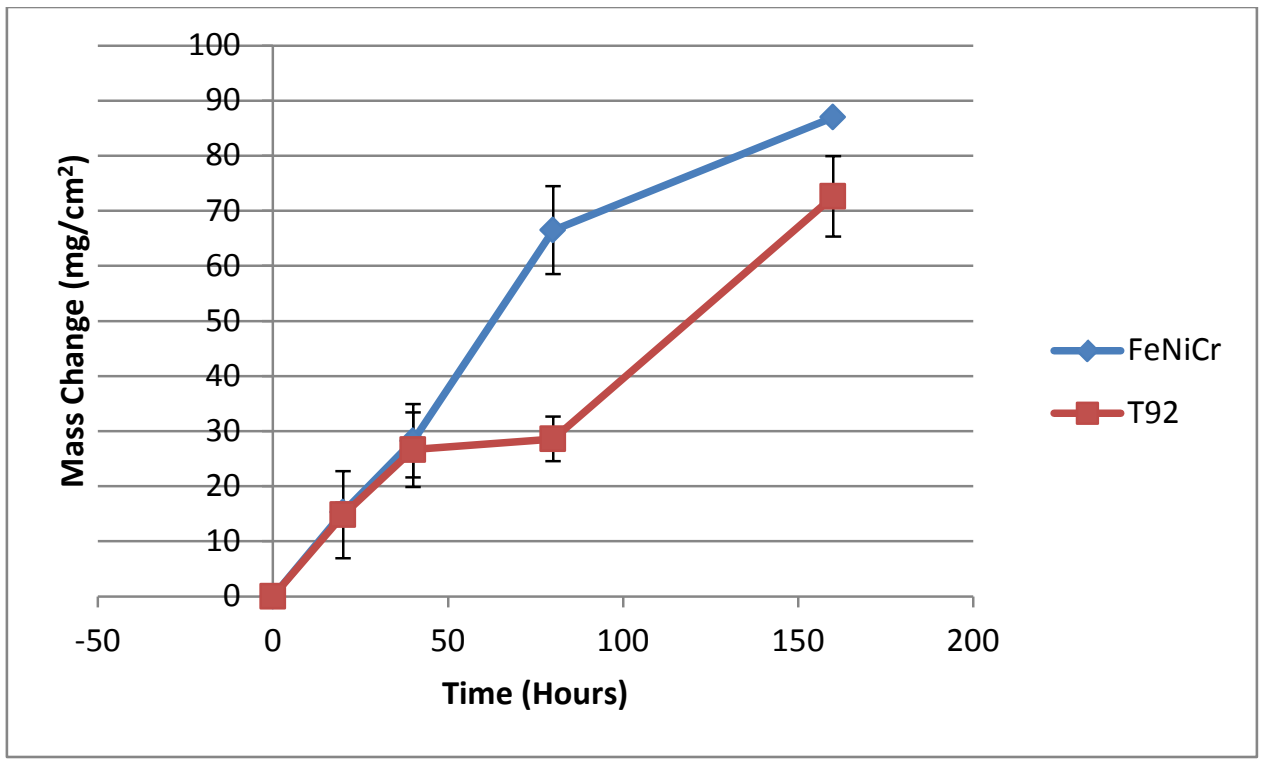

Figure 33: Kinetics of alloys exposed at $700^{\circ} \mathrm{C}$ with the $\mathrm{M1}$ in $\mathrm{O}_{2}+1000 \mathrm{ppm} \mathrm{SO}$

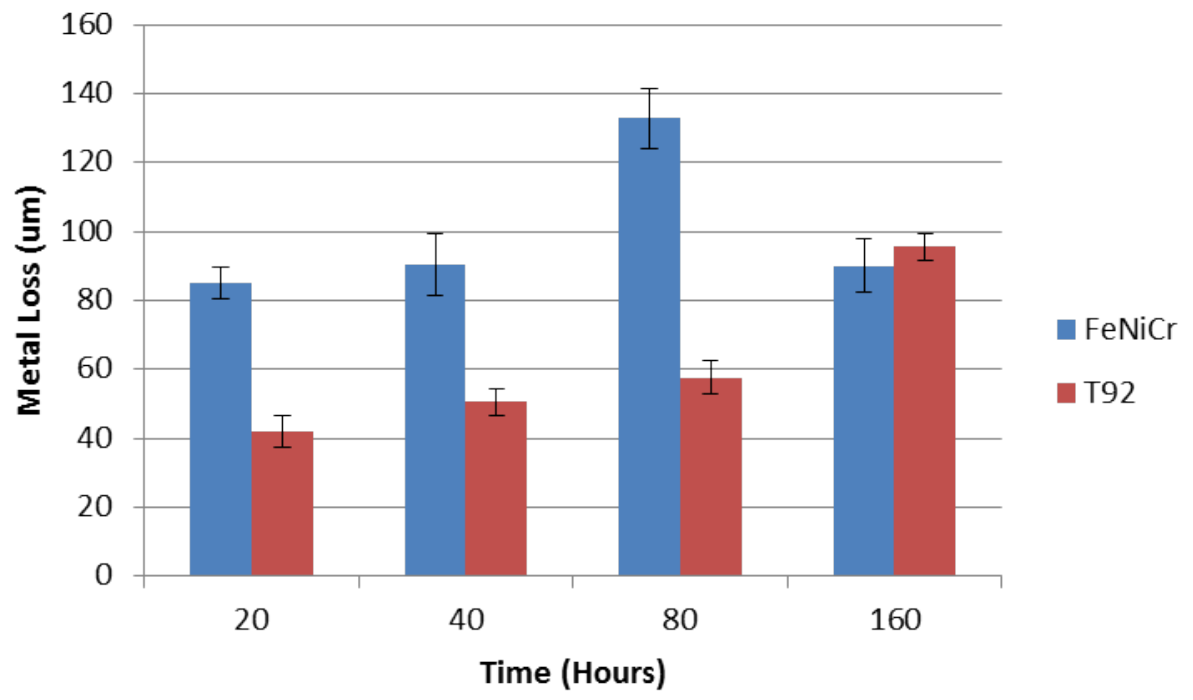

Figure 34: Metal loss of FeNiCr and T92 exposed at $700^{\circ} \mathrm{C}$ with the $\mathrm{M1}$ deposit in $\mathrm{O}_{2}+1000 \mathrm{ppm} \mathrm{SO}$

Both of the alloys were severely degraded using the M1 deposit. Chromium is believed to be the best alloying element for corrosion resistance, however the model austenitic alloy had 
more weight gain and metal loss than T92 at most durations, even though it has twice the amount of chromium. The weight change plot shows that there was essentially no initiation stage as degradation occurred very rapidly and the oxide growth rates are linear. The metal loss plot matches the weight loss plot and the macroscopic images. Significant metal losses occur in a short amount of time as the alloys are in the propagation stage after 20 hours, at which point the amount of degradation is independent of the alloy composition.

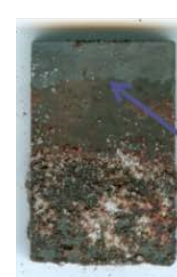

20 Hours

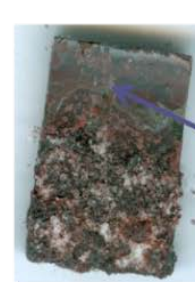

80 Hours

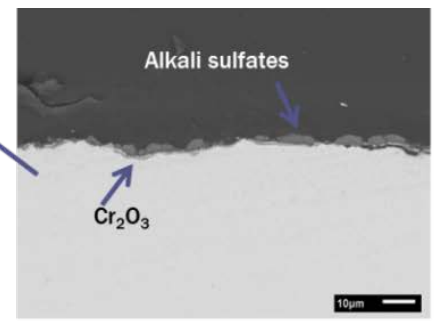

$10 \mathrm{~mm}$

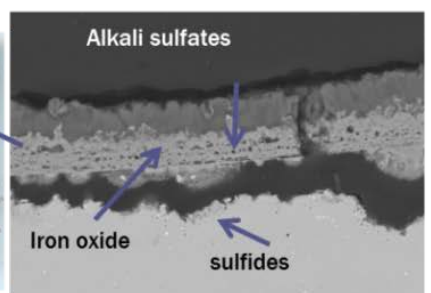

$10 \mathrm{~mm}$
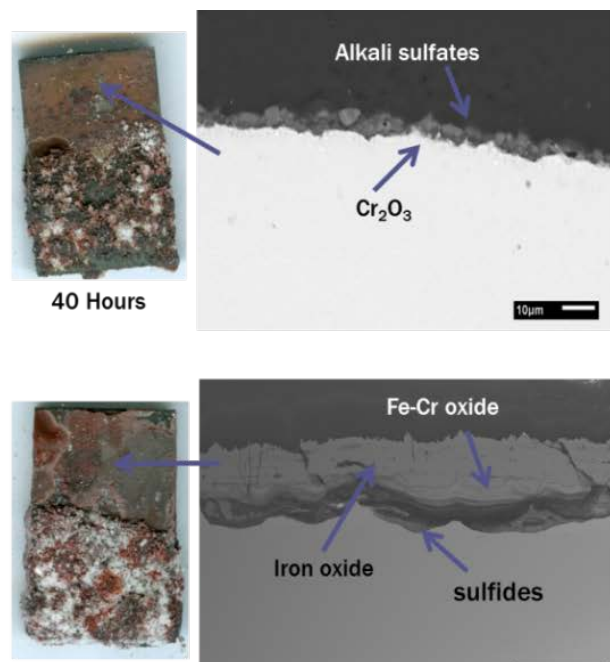

160 Hours

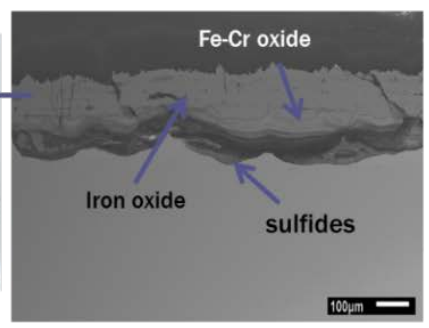

Figure 35: Cross-sectional micrographs of the non-deposit zone of $\mathrm{T92}$ tested at $700^{\circ} \mathrm{C}$ with the $\mathrm{M1}$ deposit in a crucible in $\mathrm{O}_{2}+1000 \mathrm{ppm} \mathrm{SO}_{2}$ for $20,40,80$, and 160 hours 

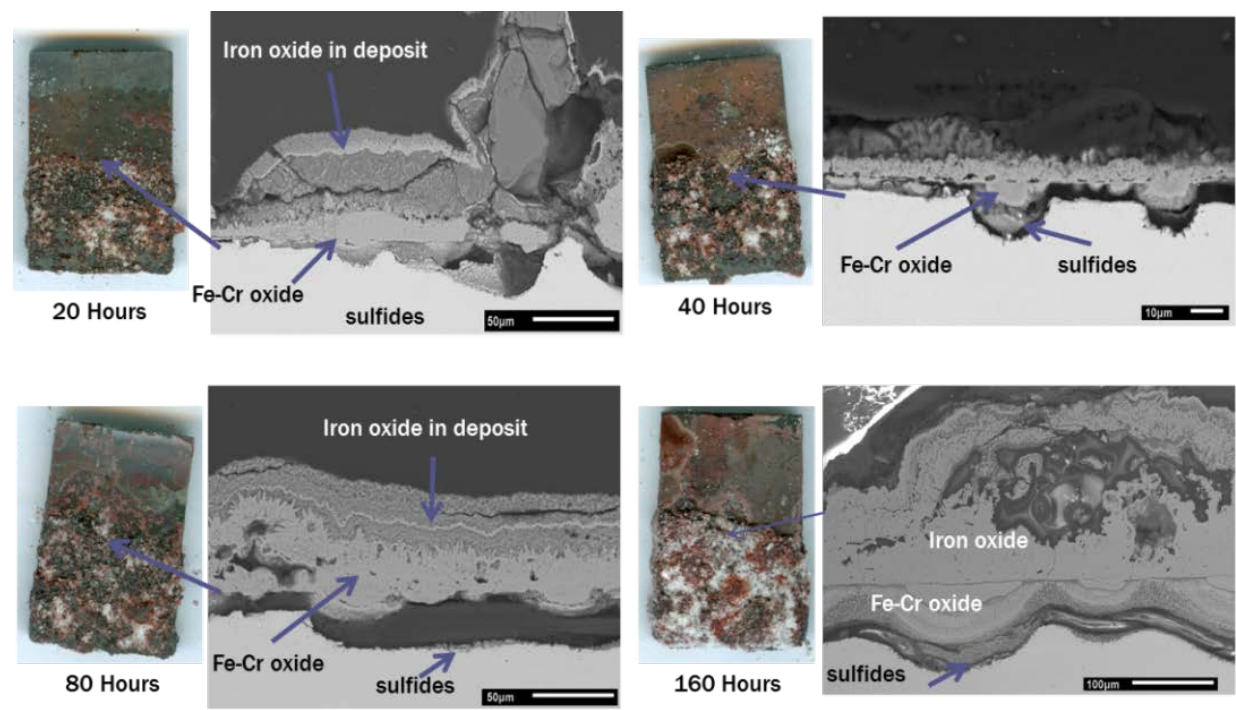

Figure 36: Cross-sectional micrographs of the thin-deposit zone of $\mathrm{T92}$ tested at $700^{\circ} \mathrm{C}$ with the $\mathrm{M1}$ deposit in a crucible in $\mathrm{O}_{2}+1000 \mathrm{ppm} \mathrm{SO}_{2}$ for $20,40,80$, and 160 hours

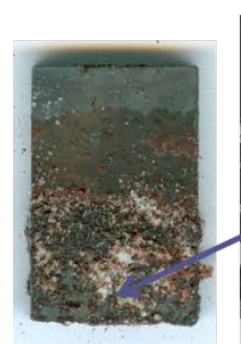

20 Hours
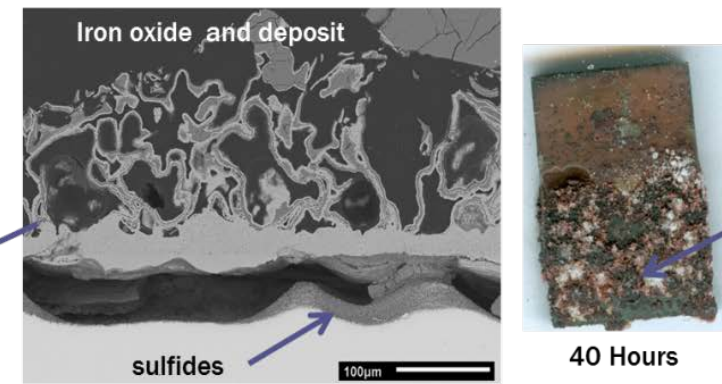

40 Hours

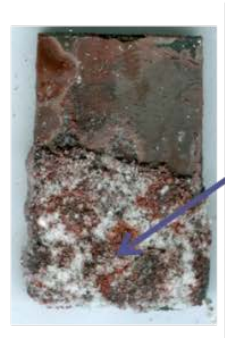

160 Hours
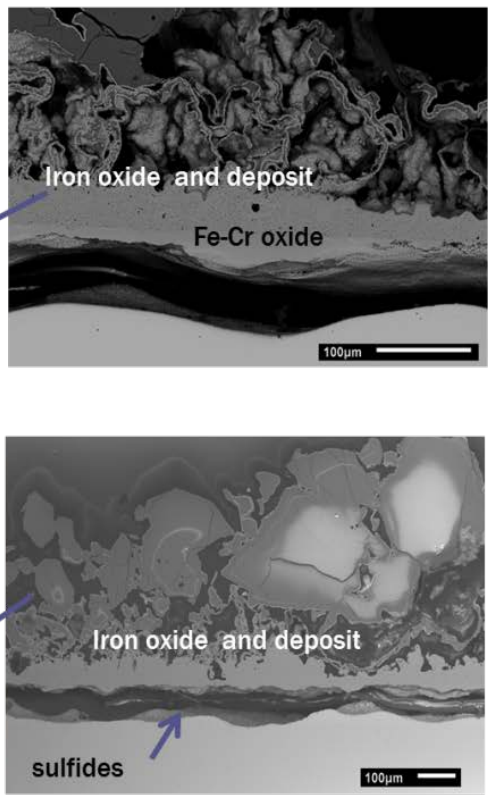

Figure 37: Cross-sectional micrographs of the thick-deposit zone of $\mathrm{T} 92$ tested at $700^{\circ} \mathrm{C}$ with the $\mathrm{M1}$ deposit in a crucible in $\mathrm{O}_{2}+1000 \mathrm{ppm} \mathrm{SO}_{2}$ for $20,40,80$, and 160 hours 
Cross-sectional SEM images of the results for T92 in the three different deposit zones are presented in Figures 35-37. The images that are presented are typical of the extent of corrosion and the corrosion products and morphologies for each deposit zone. In the no-deposit zone and in areas which were not yet degraded, chromium and iron rich oxide scales grew. As time increases (80-160 hours) the corrosion spreads into the no-deposit zone, and the scale consists of thicker iron oxide scales. The liquid is migrating up the specimens and is a precursor to the corrosion spreading. The thick and thin deposit zones are severely degraded after each test duration. The corrosion starts out covering large areas in the deposit zone, and these areas and the amount of corrosion increases with time until the entire deposit zone is completely degraded. The corrosion products consisted of external thick porous iron oxide scales which grew around remaining alkali sulfates from the deposit. Below the thick iron oxide scales are internal corrosion pits rich in $\mathrm{Fe}, \mathrm{Cr}, \mathrm{S}$, and $\mathrm{O}$ with layers rich in alkali sulfates. The sulfur content increases with depth into the pits until a thick layer of iron and chromium sulfide (identified with EDS) forms at the base.

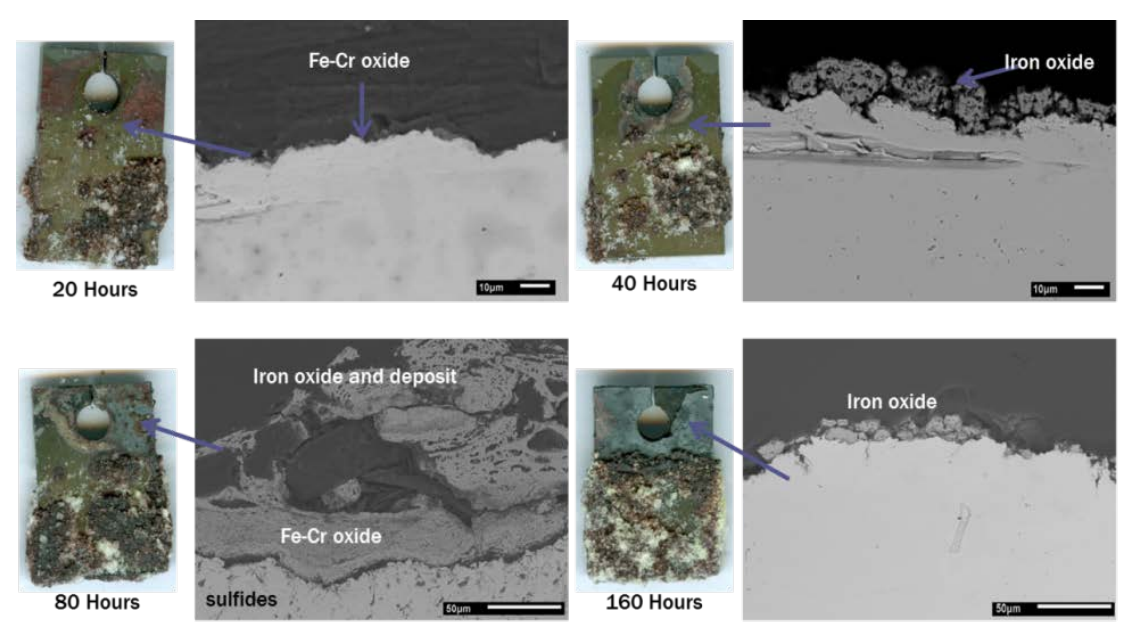

Figure 38: Cross-sectional micrographs of the no deposit zone of FeNiCr tested at $700^{\circ} \mathrm{C}$ with the $\mathrm{M} 1$ deposit in a crucible in $\mathrm{O}_{2}+1000 \mathrm{ppm} \mathrm{SO} 2$ for $20,40,80$, and 160 hours 


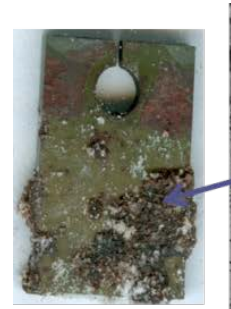

20 Hours

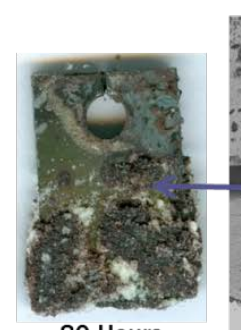

80 Hours
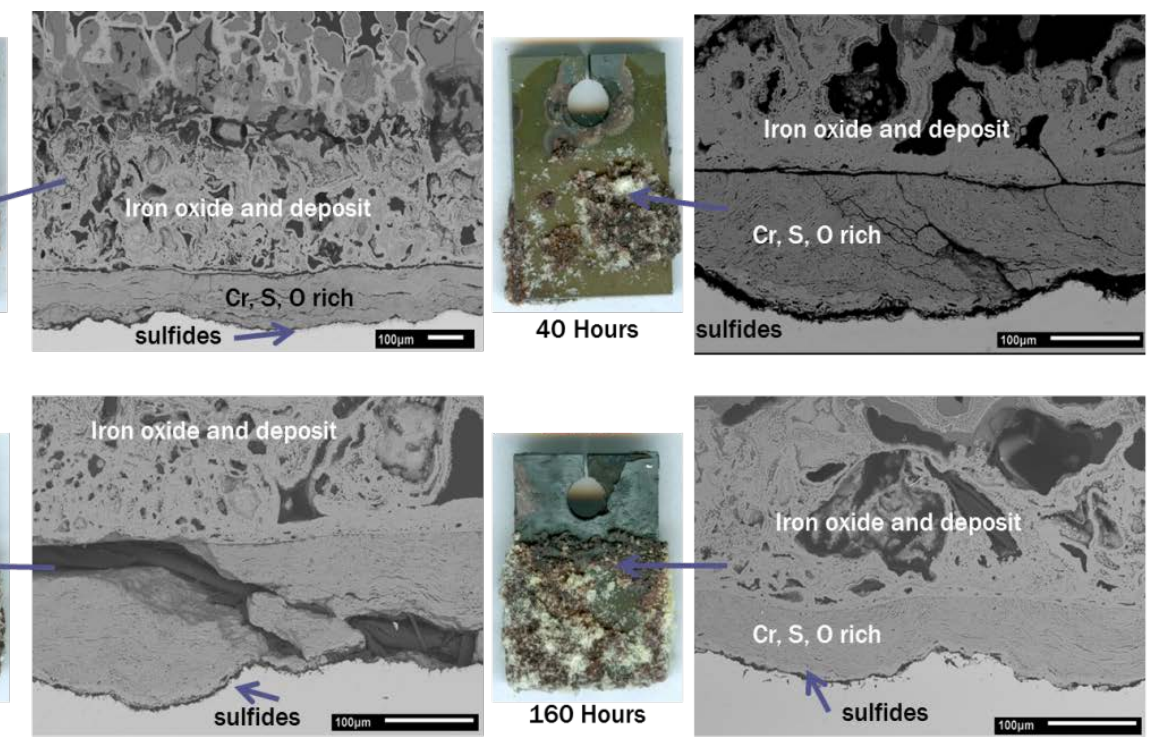

Figure 39: Cross-sectional micrographs of the thin deposit zone of $\mathrm{FeNiCr}$ tested at $700^{\circ} \mathrm{C}$ with the M1 deposit in a crucible in $\mathrm{O}_{2}+1000 \mathrm{ppm} \mathrm{SO}_{2}$ for 20, 40, 80, and 160 hours
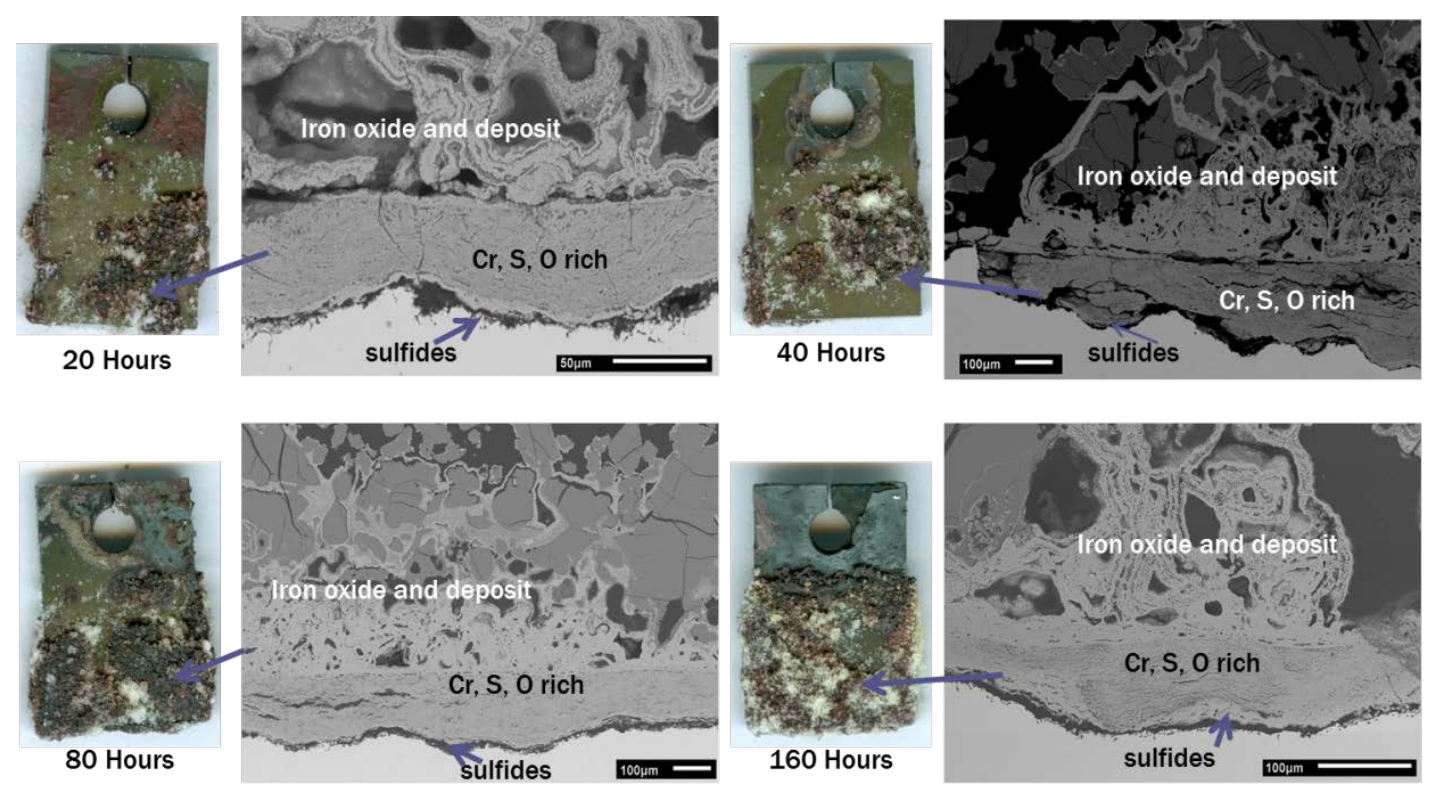

Figure 40: Cross-sectional micrographs of the thick deposit zone of $\mathrm{FeNiCr}$ tested at $700^{\circ} \mathrm{C}$ with the $\mathrm{M1}$ deposit in a crucible in $\mathrm{O}_{2}+1000 \mathrm{ppm} \mathrm{SO}_{2}$ for 20, 40, 80, and 160 hours 
Cross-sectional SEM images for the results in the three deposit zones of FeNiCr at each test duration are presented in Figures 38-40. Once again, these images are typical of the corrosion products and morphologies of each deposit zone. In the no-deposit zone, thin chromium rich oxide scales grew after short durations, but as time increases the scales turn into thicker iron oxide scales and eventually the corrosion spreads from the deposit zone up into the no-deposit zone. The results are similar to those for T92 for the thick and thin deposit zones, even though the chromium content is double for this alloy. Areas of corrosion can be seen after 20 and 40 hours. They are not as large as those on T92, so the higher chromium content may offer a little protection, but these areas quickly spread with time until the entire deposit zone is degraded. The corrosion products were similar to T92, but the chromium sulfide layer at the base of the corrosion pits was not as extensive. The corrosion pits formed a layered structure with a layer rich in $\mathrm{Cr}, \mathrm{S}$, and $\mathrm{O}$ and a layer rich in Fe and alkali sulfates. This layered structure supports the proposed corrosion mechanism, which will be described in a subsequent section. 


\subsubsection{SCM Results}

The macroscopic results for FeNiCr and T92 with the SCM are shown in the images in Figure 41.

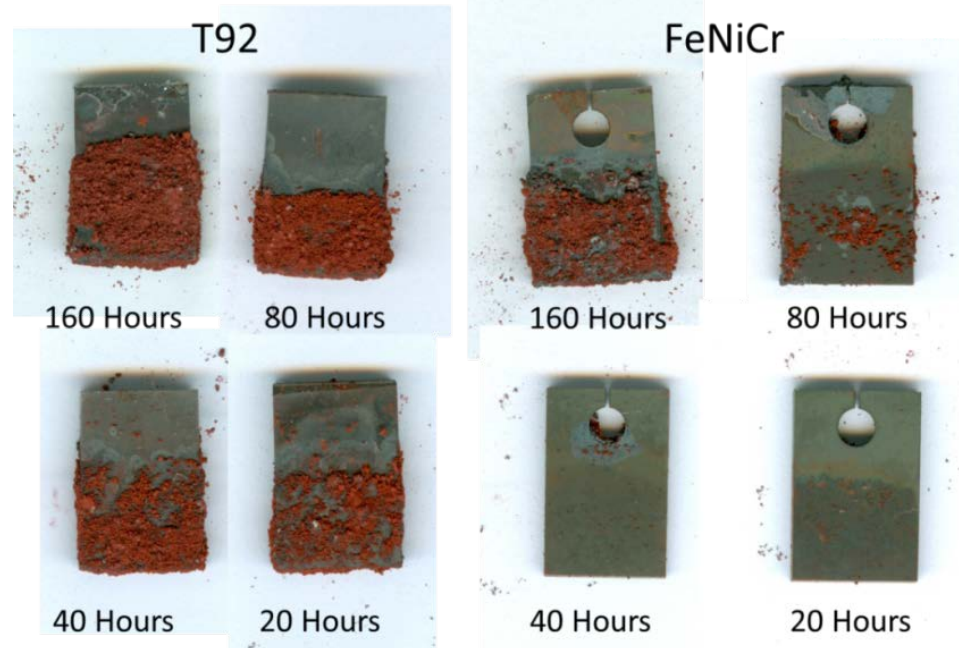

Figure 41: Macroscopic images of $\mathrm{T} 92$ and $\mathrm{FeNiCr}$ exposed at $700^{\circ} \mathrm{C}$ with the standard corrosion mix powder in a crucible in $\mathrm{O}_{2}+1000 \mathrm{ppm} \mathrm{SO}_{2}$ for $20-160$ hours

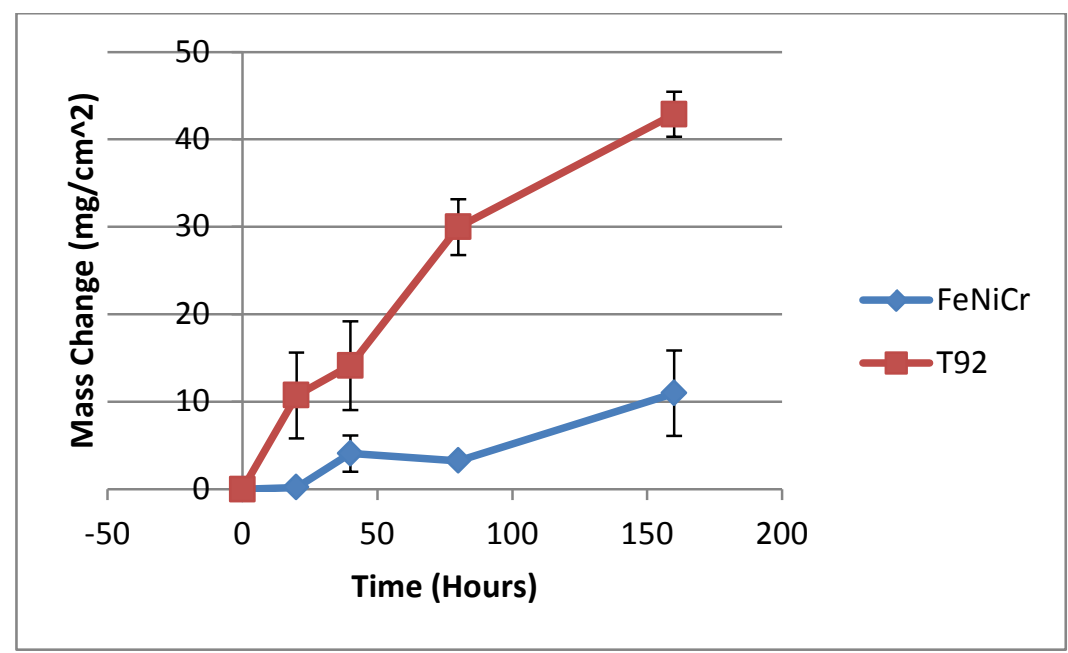

Figure 42: Kinetics of $\mathrm{FeNiCr}$ and $\mathrm{T} 92$ oxidized at $700^{\circ} \mathrm{C}$ in $\mathrm{O}_{2}+1000 \mathrm{ppm} \mathrm{SO}_{2}$ with the standard corrosion mix powder in a crucible 


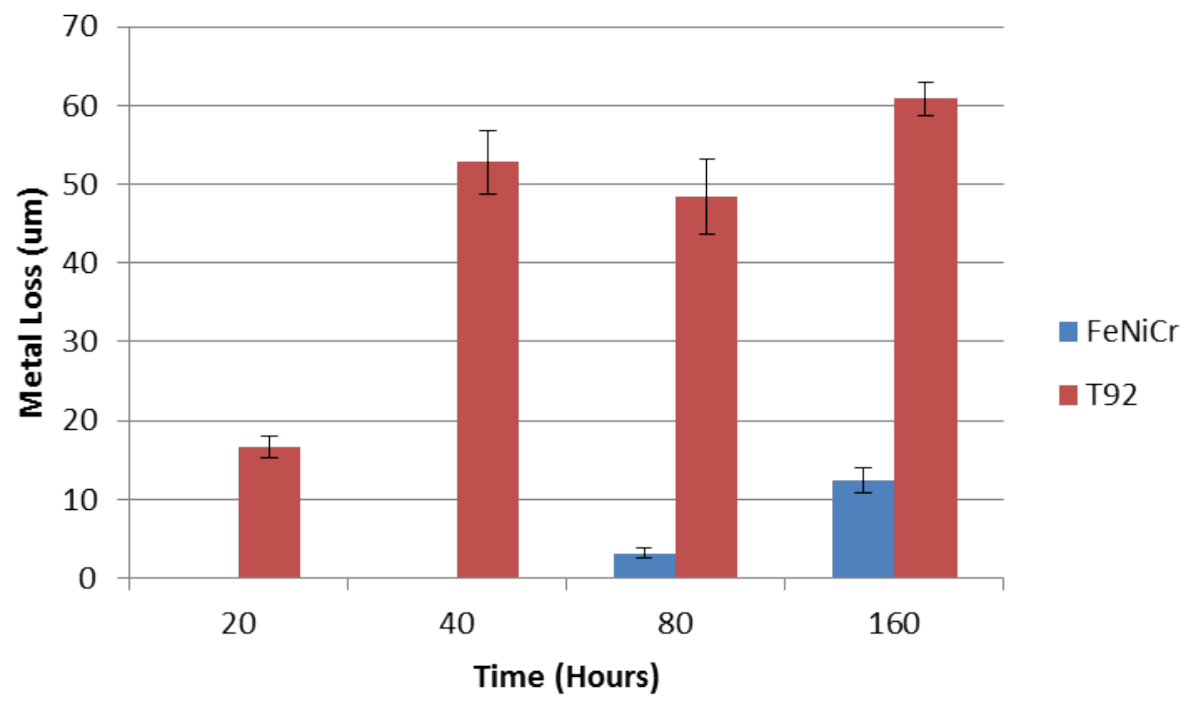

Figure 43: Metal loss of FeNiCr and $\mathrm{T} 92$ oxidized at $700^{\circ} \mathrm{C}$ in $\mathrm{O}_{2}+1000 \mathrm{ppm} \mathrm{SO}_{2}$ with the standard corrosion mix powder in a crucible (missing bars means minimal or no metal loss)

The extent of the corrosion can be seen in the weight change per area plot and the metal loss plot shown in Figures 42 and 43 respectively. The weight change plot indicates T92 has no initiation stage for fireside corrosion in the $\mathrm{SCM}$ at $700^{\circ} \mathrm{C}$, as the growth rates are essentially linear. The metal loss plot shows significant metal loss for T92 even after 20 hours, and supports the weight change plot showing rapid degradation. FeNiCr exhibits an initiation stage, and propagation of corrosion does not take place until after 80 hours of exposure. After 160 hours, the metal loss was still much less than for T92. The lack of initiation stage in T92 and the fact that the FeNiCr alloy has an initiation stage may be due once again to the difference in chromium content in the alloys. There is twice the amount of chromium in the model austenitic stainless steel (18wt\%), than there is in T92 (9wt\%). More chromium in the alloy may be delaying the onset of corrosion by continuously forming a protective chromium oxide layer on the surface and temporarily 
preventing any liquid melt that has formed from transient iron oxides or from iron oxides in the deposit from producing corrosion. This is the initiation stage. Eventually the $\mathrm{Cr}_{2} \mathrm{O}_{3}$ scale breaks down or is dissolved, and there will be insufficient amounts of $\mathrm{Cr}$ to maintain it and nonprotective $\mathrm{Fe}_{2} \mathrm{O}_{3}$ scales form allowing for the liquid melt to reach the metal surface. This is when the propagation stage starts.

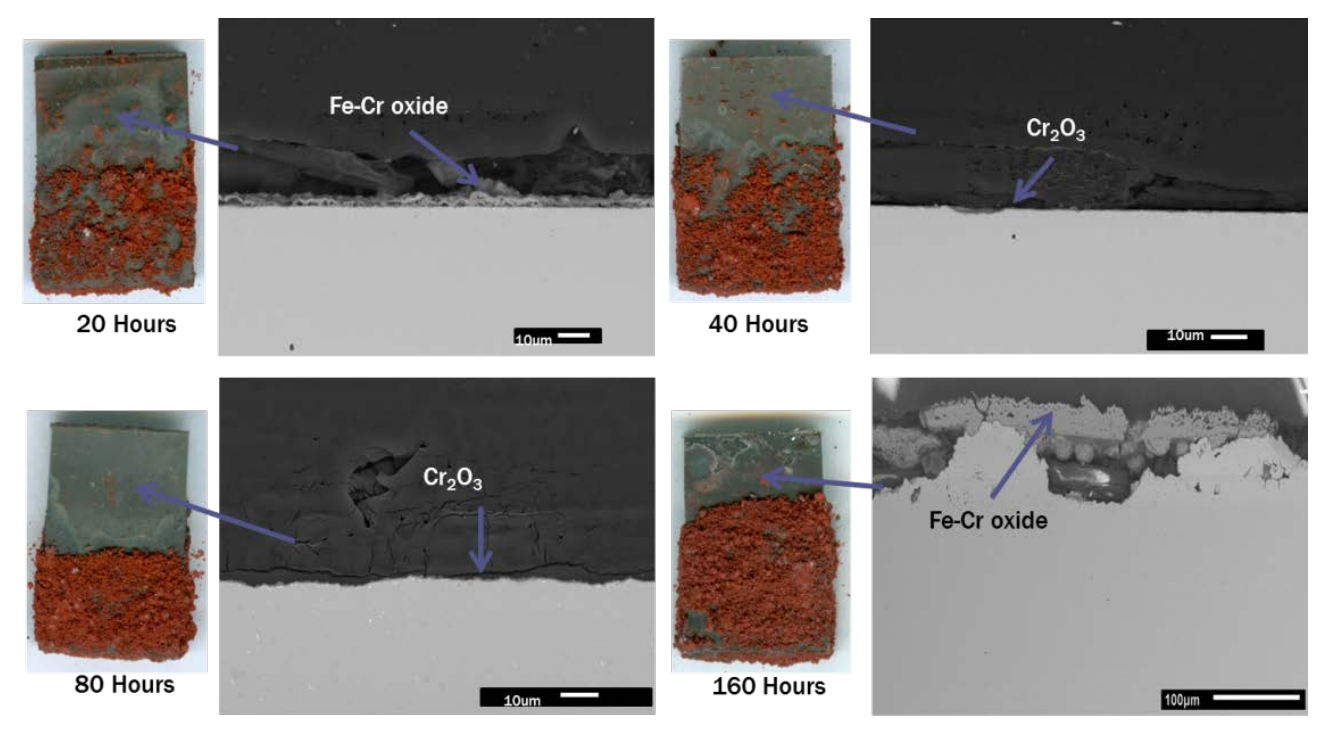

Figure 44: Cross-sectional micrographs of the non-deposit zone of $\mathrm{T92}$ tested at $700^{\circ} \mathrm{C}$ with the standard corrosion mix powder in a crucible in $\mathrm{O}_{2}+1000 \mathrm{ppm} \mathrm{SO}_{2}$ for 20, 40, 80, and 160 hours 


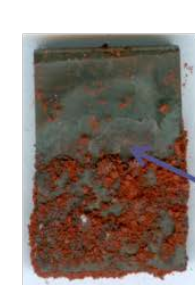

20 Hours

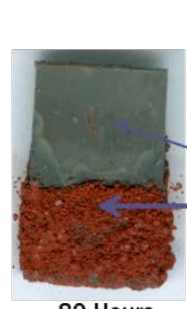

80 Hours
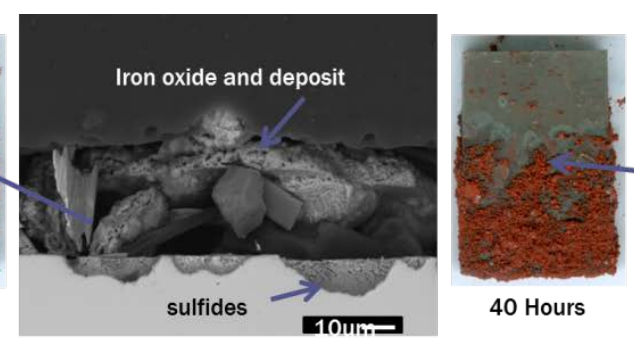

40 Hours
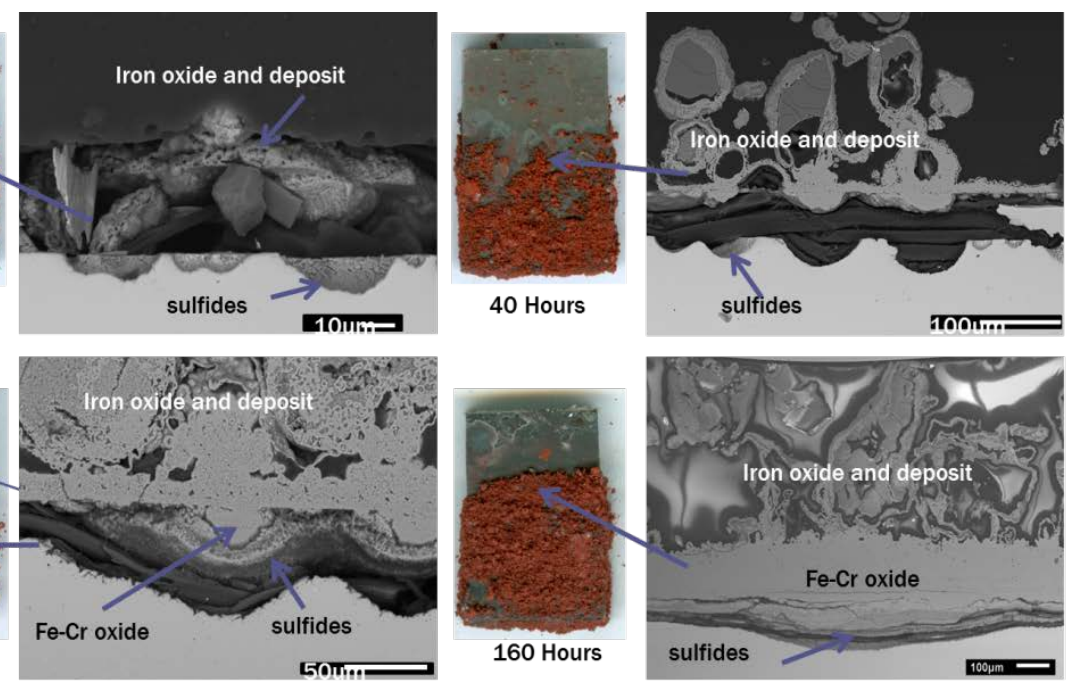

160 Hours

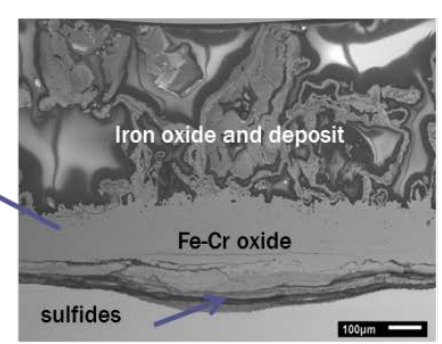

Figure 45: Cross-sectional micrographs of the thin deposit zone of $\mathrm{T92}$ tested at $700^{\circ} \mathrm{C}$ with the standard corrosion mix powder in a crucible in $\mathrm{O}_{2}+1000 \mathrm{ppm} \mathrm{SO}_{2}$ for 20,40, 80, and 160 hours

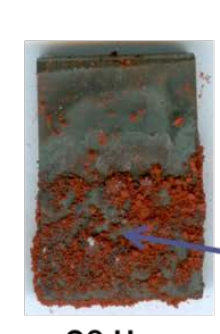

20 Hours
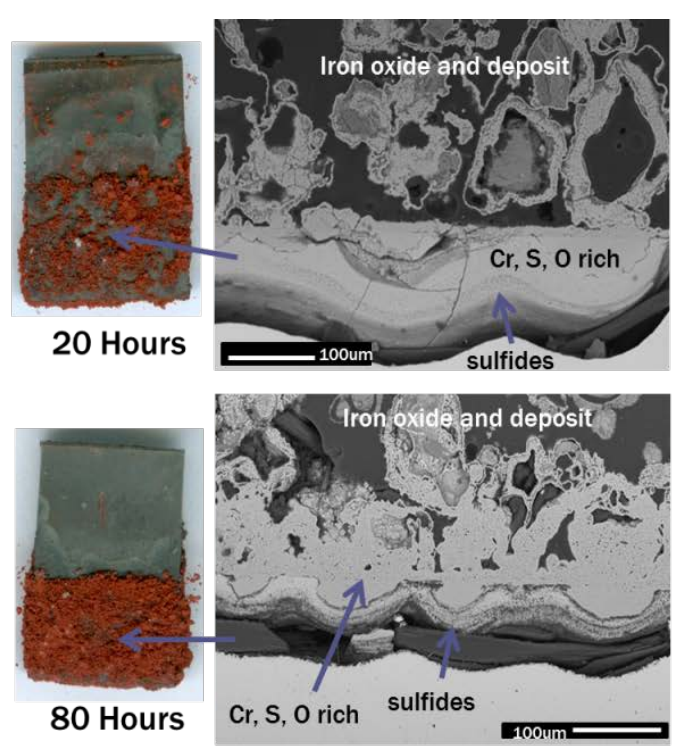
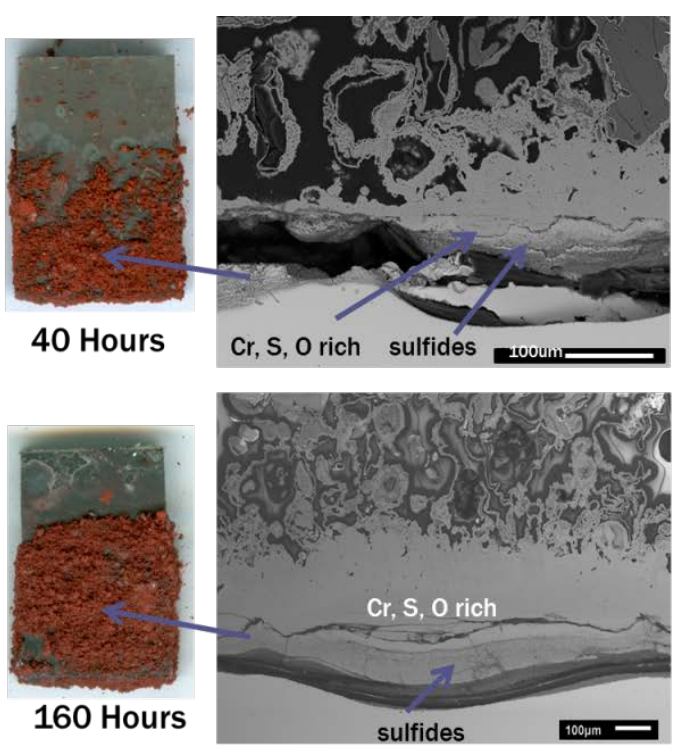

Figure 46: Cross-sectional micrographs of the thick deposit zone of $\mathrm{T} 92$ tested at $700^{\circ} \mathrm{C}$ with the standard corrosion mix powder in a crucible in $\mathrm{O}_{2}+1000 \mathrm{ppm} \mathrm{SO}_{2}$ for 20,40, 80, and 160 hours

Cross-sectional SEM images for each deposit zone for T92 at each of the test durations are shown in Figures 44-46. In the non-deposit zone, thin iron and chromium rich oxide scales grew 
on the surface. A thicker iron rich oxide scale grew after 160 hours. The liquid is migrating up the specimens as well and encroaching into the non-deposit zone, as was mentioned previously with the M1 deposit. This would result in corrosion if the test was run for a longer duration. Severe corrosion occurred throughout the entire deposit zone during each duration. The crosssectional images match well with the lack of initiation stage and linear growth seen in the kinetics plot and the amount of rapid metal loss shown in the metal loss plot. The corrosion products are similar to those for the M1 deposit. Thick, porous, external iron oxide scales grew and surrounded remaining alkali sulfates in the deposit. These grew over internal pits rich in Cr, $\mathrm{Fe}, \mathrm{S}$, and $\mathrm{O}$ with a thick iron and chromium sulfide layer at the base. The $\mathrm{SO}_{3}$ migrates in through the liquid melt and forms the corrosion pits rich in sulfides and chromium oxides. This will be discussed in more detail with a proposed propagation mechanism in section 5.1.3. The pits grow with time until they coalesce to form a continuous corrosion product layer. Surface micrographs showed that at the boundary between degraded and non-degraded areas, in the corrosive area, a thicker iron oxide scale has grown. Alkali sulfates can be seen through the iron oxide and can be seen protruding into the non-degraded region. The alkali sulfates can therefore be considered to be preceding severe degradation. An example is shown in Figure 47. The protective $\mathrm{Cr}_{2} \mathrm{O}_{3}$ scale had breaks down, leading to the propagation stage.

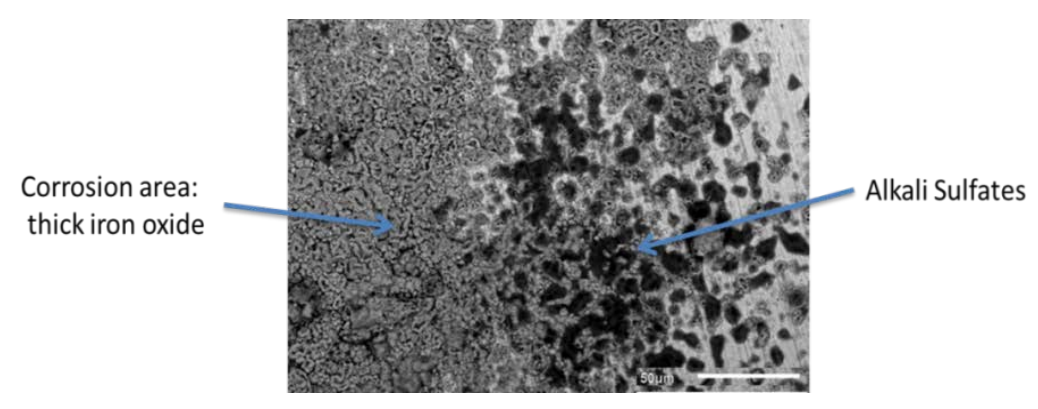

Figure 47: Surface SEM image of T92 showing corrosion boundary 

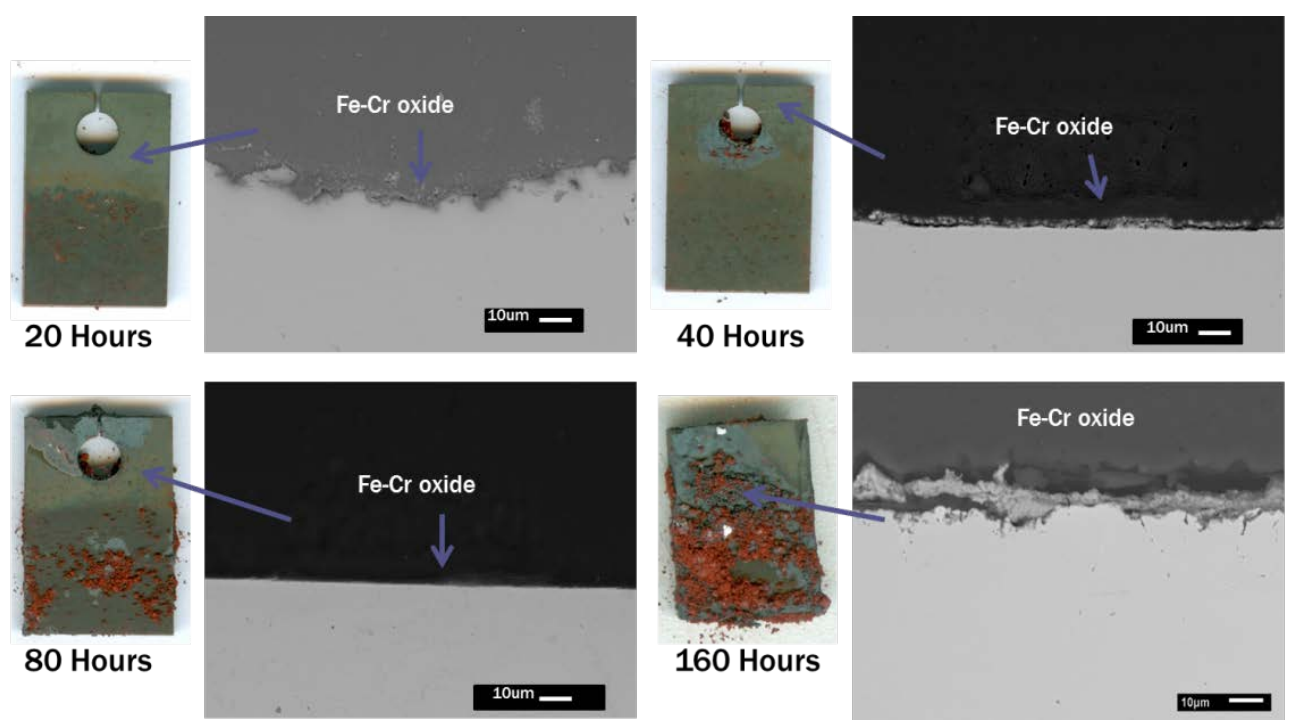

Figure 48: Cross-sectional micrographs of the non-deposit zone of $\mathrm{FeNiCr}$ tested at $700^{\circ} \mathrm{C}$ with the standard corrosion mix powder in a crucible in $\mathrm{O}_{2}+1000 \mathrm{ppm} \mathrm{SO}_{2}$ for 20,40, 80, and 160 hours

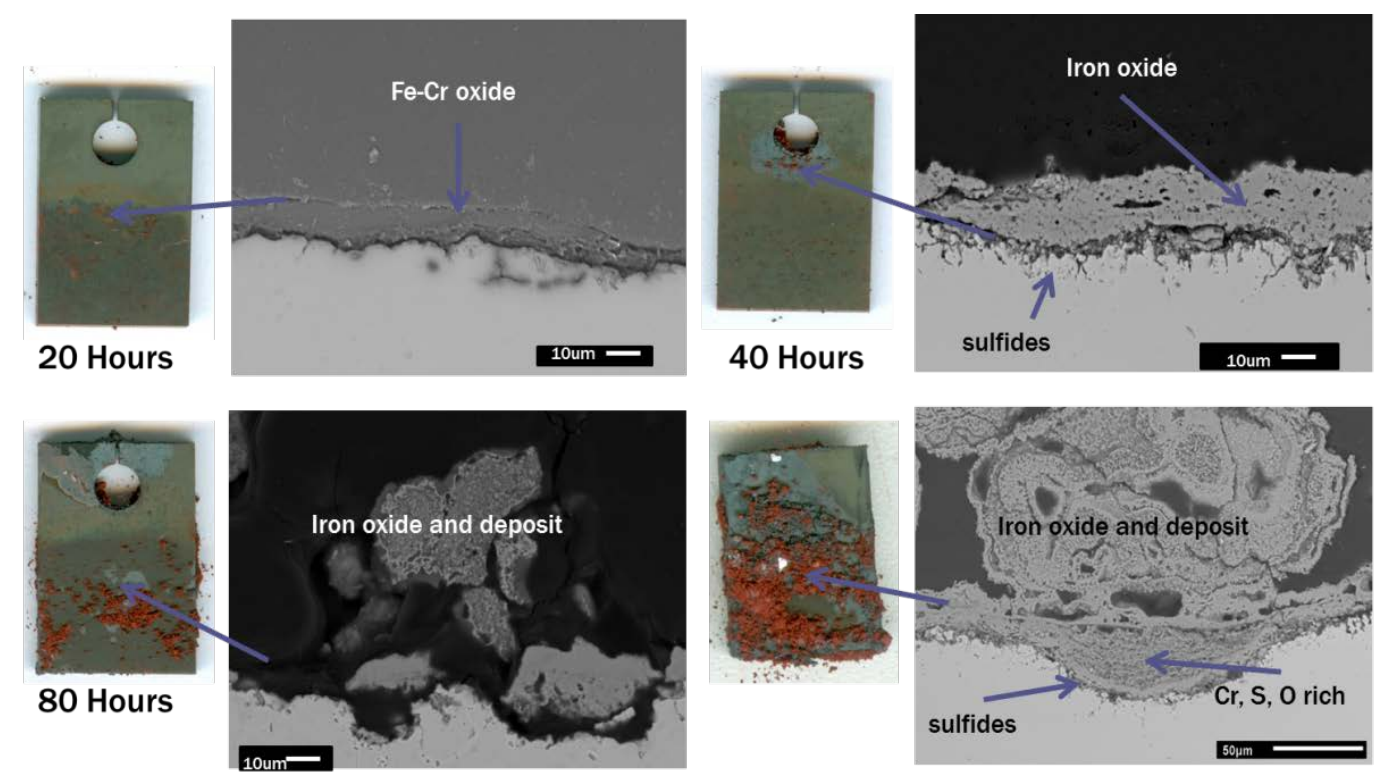

Figure 49: Cross-sectional micrographs of thin deposit zone of $\mathrm{FeNiCr}$ tested at $700^{\circ} \mathrm{C}$ with the standard corrosion mix powder in a crucible in $\mathrm{O}_{2}+1000 \mathrm{ppm} \mathrm{SO}_{2}$ for $20,40,80$, and 160 hours 

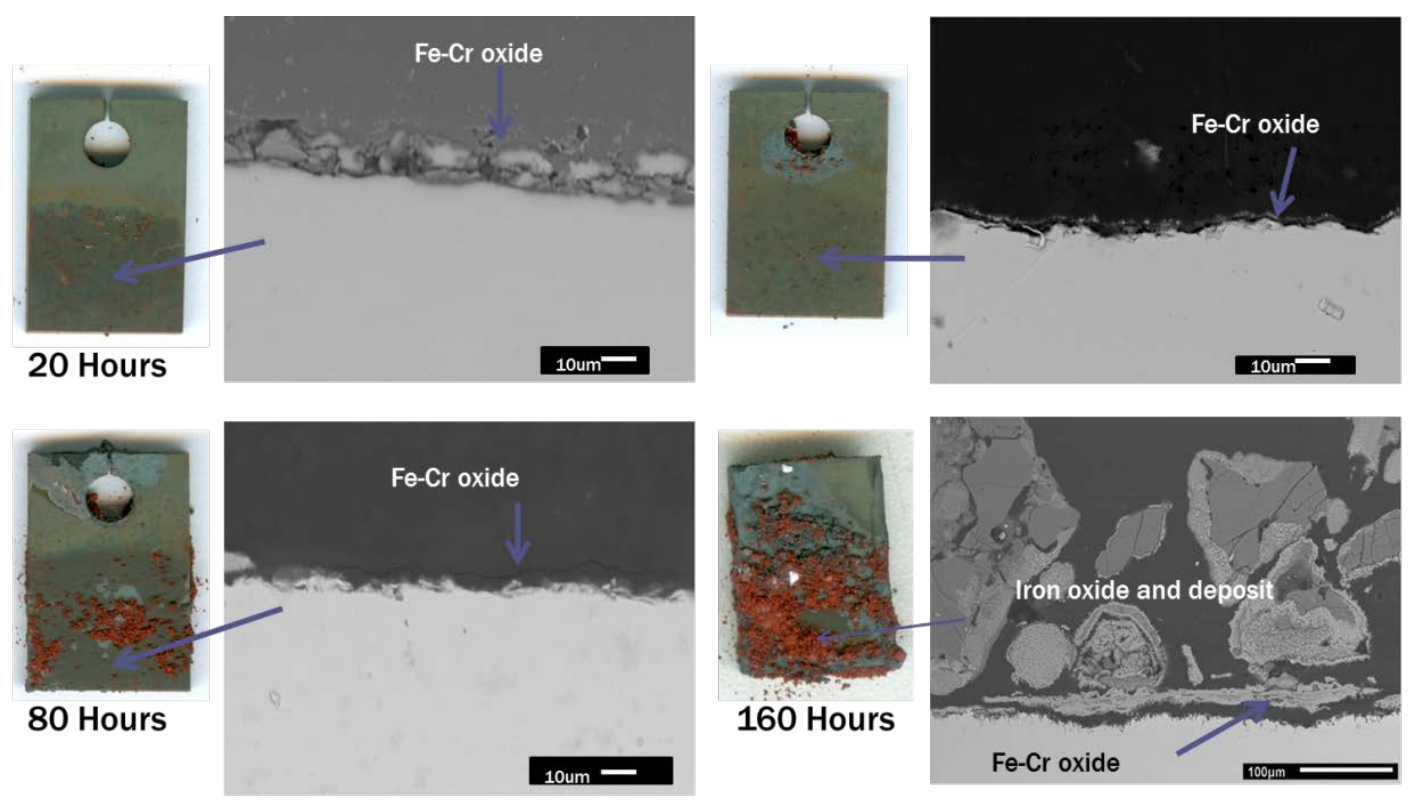

Figure 50: Cross-sectional micrographs of the thick deposit zone of FeNiCr tested at $700^{\circ} \mathrm{C}$ with the standard corrosion mix powder in a crucible in $\mathrm{O}_{2}+1000 \mathrm{ppm} \mathrm{SO}_{2}$ for $20,40,80$, and 160 hours

Cross-sectional SEM images for each deposit zone for FeNiCr at each of the test durations are shown in Figures 48-50. In the no-deposit zone, thin iron and chromium rich oxides grew on the surface. After 160 hours a thicker scale formed. The amount of corrosion in the deposit zones matches well with the kinetics and weight change plots. After 20 and 40 hours, there was minimal corrosion of the specimens. Thin iron and chromium rich oxides were present throughout the deposit zone. A thicker iron oxide grew around the hole in the specimen in some of the tests, but this can be explained by edge effects. After 80 hours there were some small areas of severe degradation in the thin deposit zone. As was mentioned previously, the propagation of corrosion accelerates sometime after 80 hours for this alloy. It is at this point in which thick external iron oxides grow on the surface and corrosion pits begin to form. Perhaps it takes this long for the protective $\mathrm{Cr}_{2} \mathrm{O}_{3}$ scale to break down or for the liquid melt to form, either at the expense of thermally grown iron oxide or from iron oxide already in the deposit, and allow 
dissolution and fluxing of the oxide scales. The degradation occurs first in areas where the deposit is the thinnest. The thicker deposit zones likely prevent the $\mathrm{SO}_{3}$ gas from reaching the surface of the metal as quickly as in the thin deposit zones. This will be examined in more detail in a subsequent section. The entire deposit region was degraded after 160 hours. The corrosion products consisted of thick external porous iron oxides with adherent deposit materials over more chromium-rich oxide rich pits. The pits had the repeating layers rich in $\mathrm{Cr}, \mathrm{S}, \mathrm{O}$ and $\mathrm{Fe}$, Na, K, S, O seen previously with the M1 deposit. The amount of sulfur increases with depth into the pit until at the base there is a layer rich in $\mathrm{Cr}$ and S. The higher chromium content in this alloy compared with T92 may cause the longer length of protection due to the growth of a chromium oxide scale. However eventually this becomes compromised as well. Surface micrographs of the corrosion front show that alkali sulfates precede severe corrosion just as with the T92 alloy. This can be seen in Figure 51.

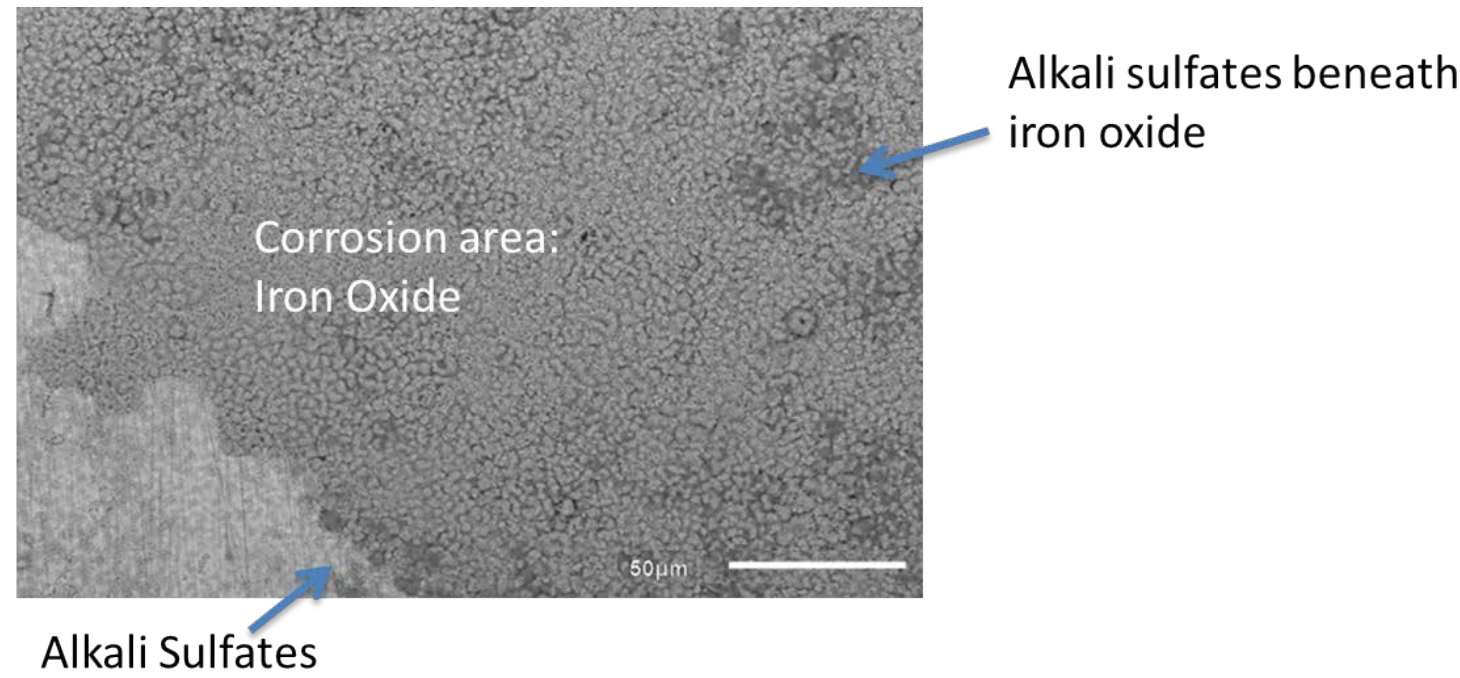

Figure 51: Surface SEM image of FeNiCr showing corrosion boundary 
The corrosion products of T92 and FeNiCr exposed with the SCM were crushed into a powder and examined using $\mathrm{x}$-ray diffraction (XRD). A sample of the resulting scan is shown in Figure 52. Peaks were identified and the corrosion products contain $\mathrm{Fe}_{2} \mathrm{O}_{3}$ and $\mathrm{KNaSO}_{4}$. Liquid is clearly forming in the corrosion process for the SCM and M1 deposits, and a low melting eutectic formed from iron oxides and alkali sulfates are the likely corrosion product.

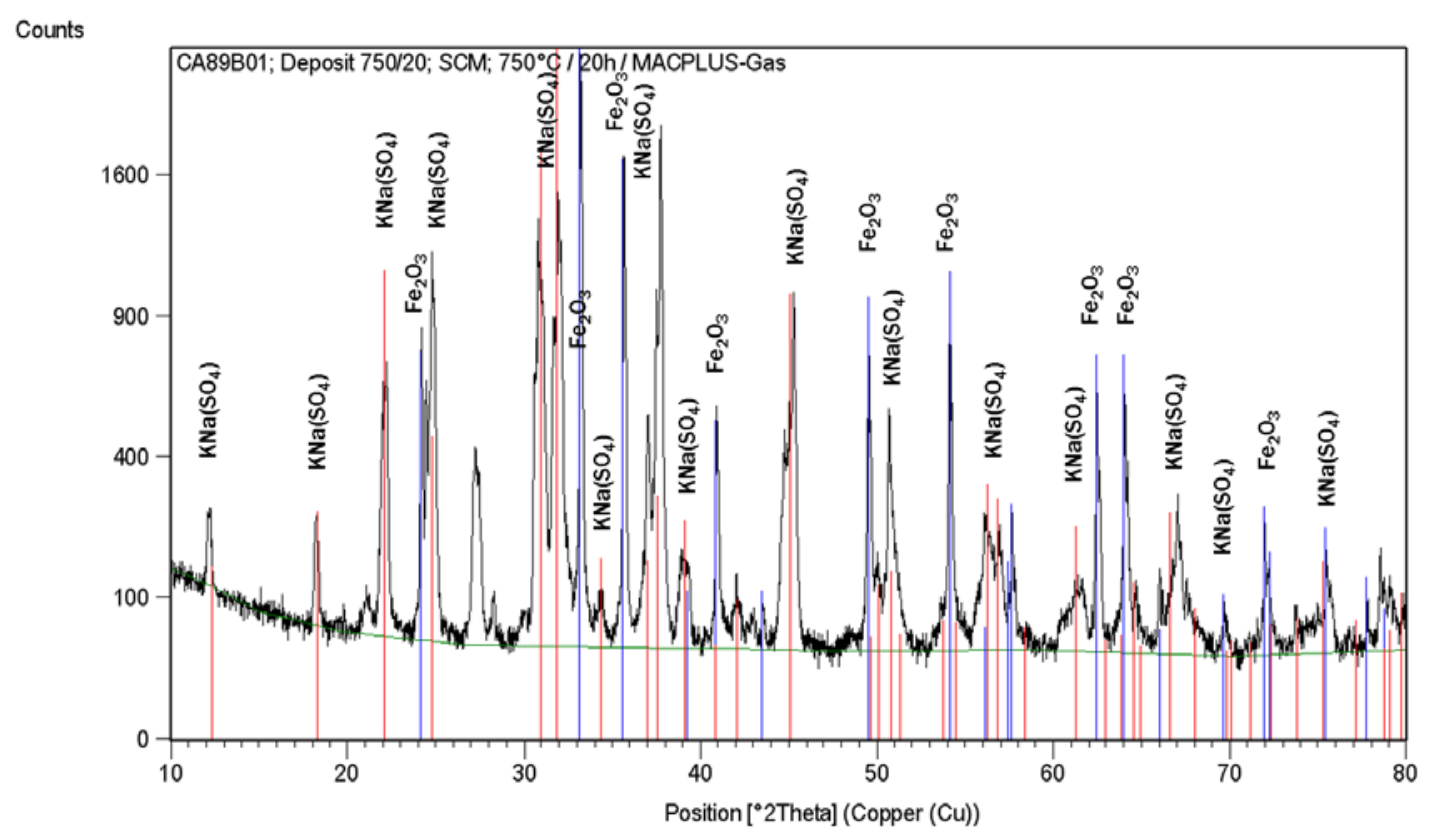

Figure 52: X-ray diffraction scan of SCM powder exposed at $700^{\circ} \mathrm{C}$ in $\mathrm{O}_{2}+2500 \mathrm{ppm} \mathrm{SO}_{2}$

\subsubsection{Proposed Fireside Corrosion Mechanism}

Weight change and metal loss plots comparing the M1 and SCM deposits are shown in Figure

53. The weight changes and the amount of metal loss are more severe with M1 than with the 
SCM. It was originally thought that the SCM would be the most corrosive deposit used because alkali iron trisulfates could form in the deposit and did not need a thermally grown iron oxide scale. Alkali iron trisulfates form by reaction of iron oxide (either in the deposit or from a thermally grown oxide scale) with alkali sulfates in the deposit and $\mathrm{SO}_{3}$ in the gas atmosphere. The formation of liquid alkali iron trisulfates at the expense of a thermally grown iron oxide scale was originally thought to be important in the amount of degradation which occurs. It was thought that the rapid removal of $\mathrm{Fe}$ from the alloy could disrupt protective $\mathrm{Cr}_{2} \mathrm{O}_{3}$ scale formation and the mechanism for corrosion may be the similar to Type II hot corrosion described by Luthra.[39] The fact that the M1 deposit was more corrosive than the SCM indicates that alkali iron trisulfates may not be the primary cause of severe corrosion and that reactions with alkali sulfates are causing severe degradation, and the process would therefore be similar to Type II hot corrosion caused by $\mathrm{Na}_{2} \mathrm{SO}_{4}$ salt deposits that was described in previous sections. Type II hot corrosion of gas turbine engines typically occurs at temperatures around $700^{\circ} \mathrm{C}$ (same temperature range of interest as fireside corrosion) below the melting point of $\mathrm{Na}_{2} \mathrm{SO}_{4}\left(884^{\circ} \mathrm{C}\right)$ on Co- and Ni-based superalloys used for engine hardware. When $\mathrm{SO}_{3}$ in the gas atmosphere reacts with a thermally grown cobalt or nickel transient oxide scale, it forms a low melting compound ((Co, $\mathrm{Ni}) \mathrm{SO}_{4} \mathrm{~T}_{\mathrm{m}}=565^{\circ} \mathrm{C}, 671^{\circ} \mathrm{C}$ respectively). This was shown for Co on the $\mathrm{CoSO}_{4^{-}}$ $\mathrm{Na}_{2} \mathrm{SO}_{4}$ phase diagram in Figure 26. The $\mathrm{Fe}_{2}\left(\mathrm{SO}_{4}\right)_{3}-\mathrm{K}_{2} \mathrm{SO}_{4}$ phase diagram is presented in Figure 54. A reliable $\mathrm{Fe}_{2}\left(\mathrm{SO}_{4}\right)_{3}-\mathrm{Na}_{2} \mathrm{SO}_{4}$ diagram is not available, but one would expect it to behave in a similar way. At $700^{\circ} \mathrm{C}$ on the diagram, a liquid $\mathrm{K}_{2} \mathrm{SO}_{4}-\mathrm{Fe}_{2}\left(\mathrm{SO}_{4}\right)_{3}$ solution will form with small additions of $\mathrm{Fe}_{2}\left(\mathrm{SO}_{4}\right)_{3}$, and alkali iron trisulfates are not necessary to form liquid at this temperature and therefore are not initially causing corrosion in these atmospheres, which is contradictory to what was believed to be the cause of corrosion for decades. 
Because the low melting solution forms similarly to Type II hot corrosion, the initiation and propagation stages for fireside corrosion can be modeled after the mechanisms for Type II hot corrosion.

$\mathrm{T92} 700^{\circ} \mathrm{C} 1000 \mathrm{ppm} \mathrm{SO}_{2}$

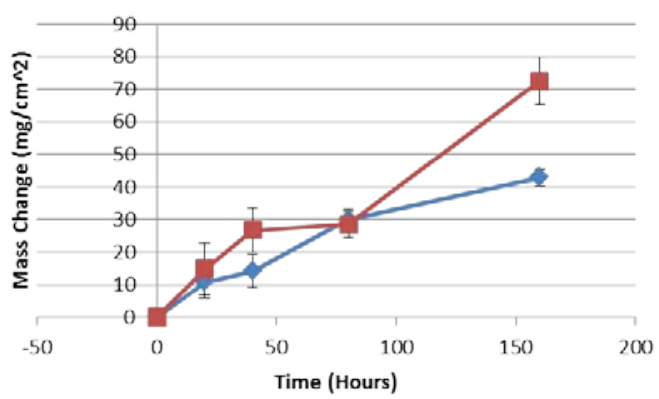

$\mathrm{FeNiCr} 700^{\circ} \mathrm{C} 1000 \mathrm{ppm} \mathrm{SO}_{2}$

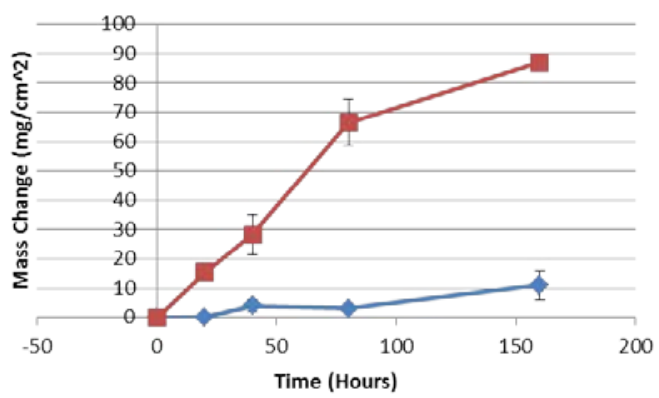

$\mathrm{T92} 700^{\circ} \mathrm{C} 1000 \mathrm{ppm} \mathrm{SO}_{2}$
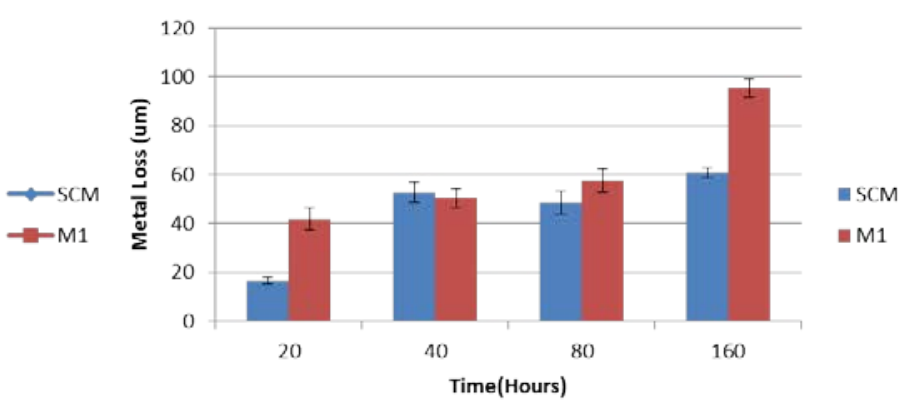

$\mathrm{FeNiCr} 700^{\circ} \mathrm{C} 1000 \mathrm{ppm} \mathrm{SO}_{2}$

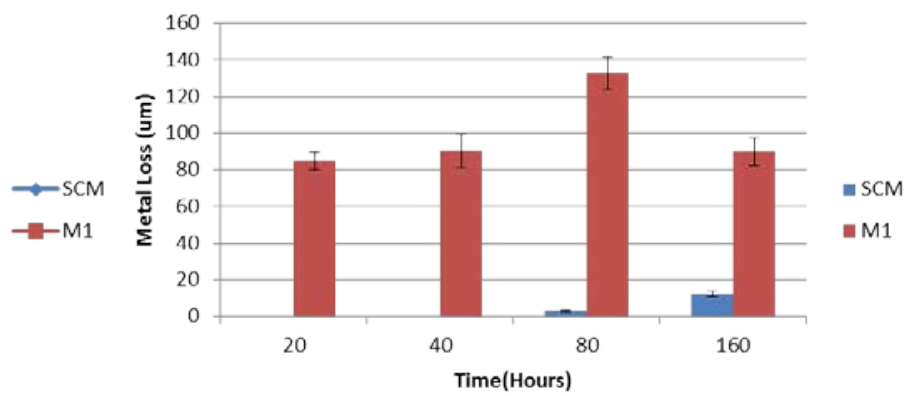

Figure 53: Comparison of T92 and FeNiCr exposed in the M1 and SCM deposits at $700^{\circ} \mathrm{C}$ in $\mathrm{O}_{2}+1000 \mathrm{ppm}$ $\mathrm{SO}_{2}$ for 160 hours 


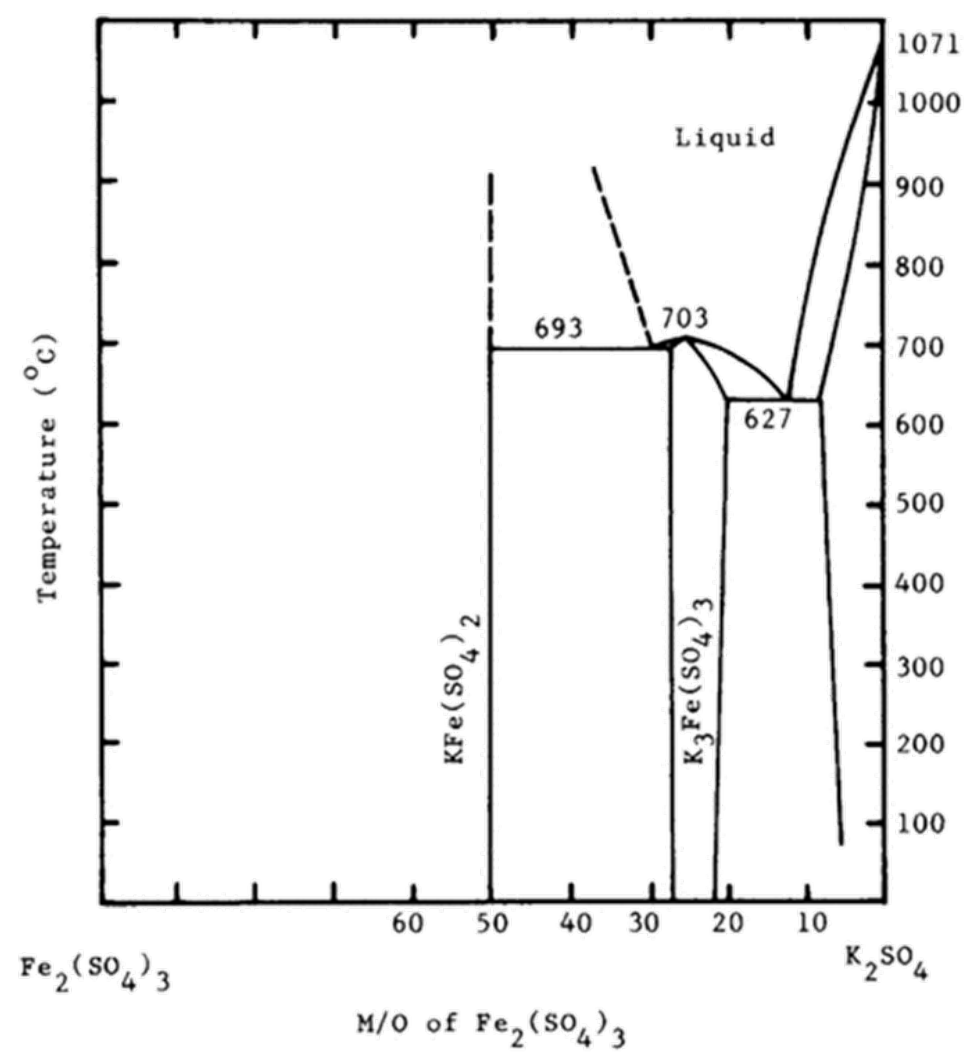

Figure 54: $\mathrm{K}_{2} \mathrm{SO}_{4}-\mathrm{Fe}_{2}\left(\mathrm{SO}_{4}\right)_{3}$ phase diagram [83]

Based on the results, the following fireside corrosion initiation and propagation mechanism is proposed. This mechanism is somewhat different from the work of Cain and Nelson[38] outlined in a previous section, and involves aspects of the mechanisms of Type II hot corrosion explained by the work of Luthra[39], and the mechanisms of synergistic dissolution explained by Rapp[80]. During the initiation stage, transient iron oxides and chromium oxide grows on the surface of the alloy. The alloy is covered by the deposit that contains alkali sulfates $\mathrm{K}_{2} \mathrm{SO}_{4}$ and $\mathrm{Na}_{2} \mathrm{SO}_{4}$. The $\mathrm{SO}_{3}$ from the catalyzed $\mathrm{O}_{2}+\mathrm{SO}_{2}$ mixture migrates through the deposit to the oxide/deposit interface, and when sufficient amounts are present, it reacts with transient $\mathrm{Fe}_{2} \mathrm{O}_{3}$ to form $\mathrm{Fe}_{2}\left(\mathrm{SO}_{4}\right)_{3}$. When sufficient $\mathrm{Fe}_{2}\left(\mathrm{SO}_{4}\right)_{3}$ is dissolved in the alkali sulfates the deposit 
will melt as seen on the phase diagram in Figure 54. The formation of the liquid salt allows dissolution and fluxing of the protective oxide scales and base metal to take place which is responsible for the lack of protective $\mathrm{Cr}_{2} \mathrm{O}_{3}$ and the observed metal loss. It is at this point that the propagation stage occurs. The liquid melt forms at the expense of the $\mathrm{Fe}_{2} \mathrm{O}_{3}$ scale. It was originally thought that formation of the liquid melt from the oxidation of the base metal iron was undercutting and leaving unprotective porous $\mathrm{Cr}_{2} \mathrm{O}_{3}$ in the melt. The rapid dissolution of the base metal disrupts protective $\mathrm{Cr}_{2} \mathrm{O}_{3}$ formation. This is similar to the mechanism proposed by Luthra[39] for Type II hot corrosion. However, the lack of a protective oxide scale and the degradation is more likely due to synergistic fluxing.

The M1 deposit was more corrosive than the SCM. Based on these results, the cause of the increased corrosion of the M1 deposit and the likely controlling fireside corrosion propagation mechanism is synergistic dissolution of oxides in the molten salt deposit. This mechanism was described briefly in a previous section by the work of Rapp for hot corrosion from molten sodium sulfate deposits.[80] Once a liquid solution has formed, it will react with the protective oxide scales and base metal becoming highly basic or acidic and causing dissolution and fluxing, creating the observed corrosion products. The alloys used in this study and commonly used in the superheater and reheater tubes of coal-fired power plants are chromia forming steel alloys. The dissolution reactions for $\mathrm{Cr}_{2} \mathrm{O}_{3}$ and $\mathrm{Fe}_{2} \mathrm{O}_{3}$ are limited by the diffusion of either oxygen or pyrosulfate $\left(\mathrm{S}_{2} \mathrm{O}_{7}{ }^{2-}\right)$ ions. If the oxide dissolution reactions are considered individually, $\mathrm{Fe}_{2} \mathrm{O}_{3}$ would be expected to undergo acidic dissolution in the $\mathrm{SO}_{3}$ containing atmosphere with the reaction given in equation 41 . This reaction would consume $\mathrm{SO}_{3}$ in the form of pyrosulfate.

$$
\mathrm{Fe}_{2} \mathrm{O}_{3}+3 \mathrm{Na}_{2} \mathrm{~S}_{2} \mathrm{O}_{7}=\mathrm{Fe}_{2}\left(\mathrm{SO}_{4}\right)_{3}+3 \mathrm{Na}_{2} \mathrm{SO}_{4}
$$


The $\mathrm{SO}_{3}$ concentration would be greater at the gas salt interface than at the oxide/salt interface, setting up a positive solubility gradient at the oxide/salt interface. This is demonstrated by the schematic diagram and solubility plot for $\mathrm{Fe}_{2} \mathrm{O}_{3}$ in $\mathrm{Na}_{2} \mathrm{SO}_{4}$ in Figure 55 .
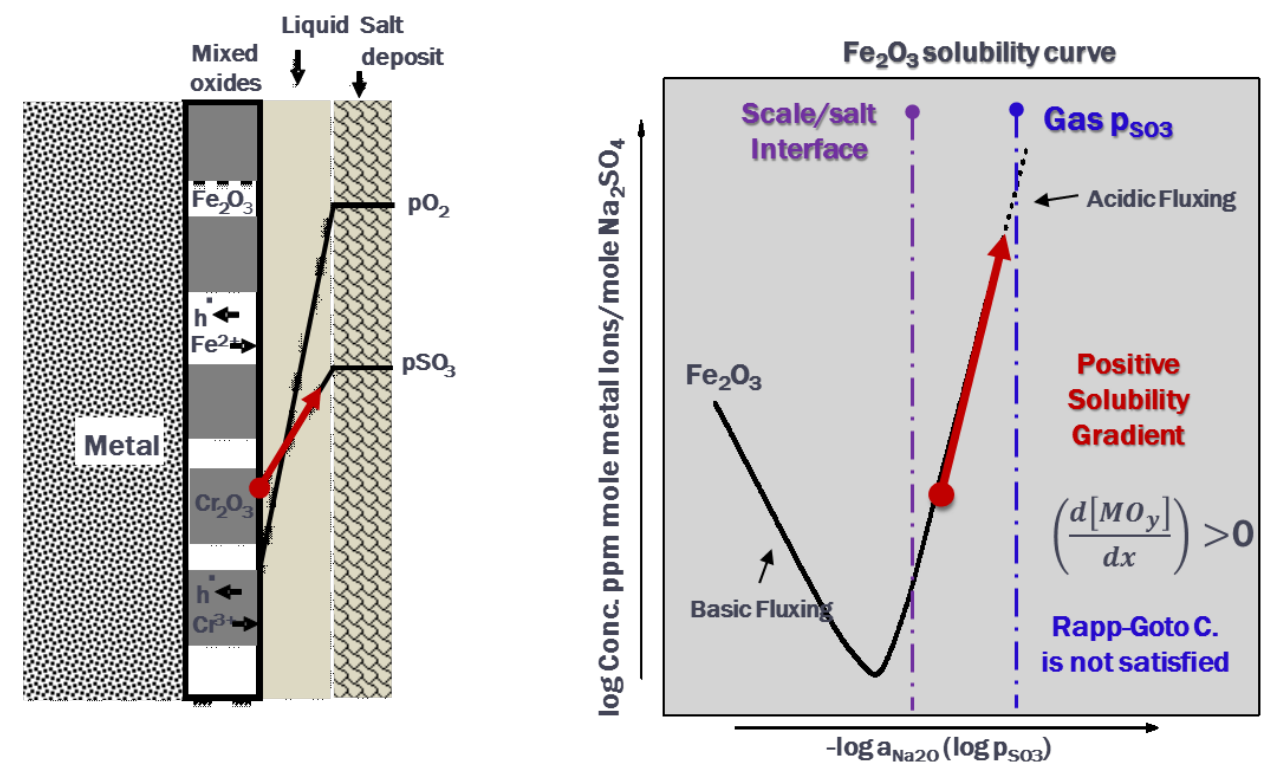

Figure 55: Schematic of $\mathrm{SO}_{3}$ gradient at oxide/salt interface and $\mathrm{Fe}_{2} \mathrm{O}_{3}$ solubility curve for acidic fluxing

The Rapp-Goto criterion explained previously states that a negative solubility gradient is needed for the dissolution of the oxide scale at the oxide/salt interface and reprecipitation as nonprotective discontinuous particles at a distance further out in the melt where the solubility is lower. Acidic dissolution of $\mathrm{Fe}_{2} \mathrm{O}_{3}$ would produce a positive solubility gradient, so the oxide would become saturated in the melt near the oxide/salt interface, minimizing further dissolution. In the $\mathrm{SO}_{3}$ gas atmosphere, $\mathrm{Cr}_{2} \mathrm{O}_{3}$ would also be expected to undergo acidic dissolution, given by the reaction in equation 42. This reaction would also consume $\mathrm{SO}_{3}$.

$$
\mathrm{Cr}_{2} \mathrm{O}_{3}+3 \mathrm{Na}_{2} \mathrm{~S}_{2} \mathrm{O}_{7}=\mathrm{Cr}_{2}\left(\mathrm{SO}_{4}\right)_{3}+3 \mathrm{Na}_{2} \mathrm{SO}_{4}
$$



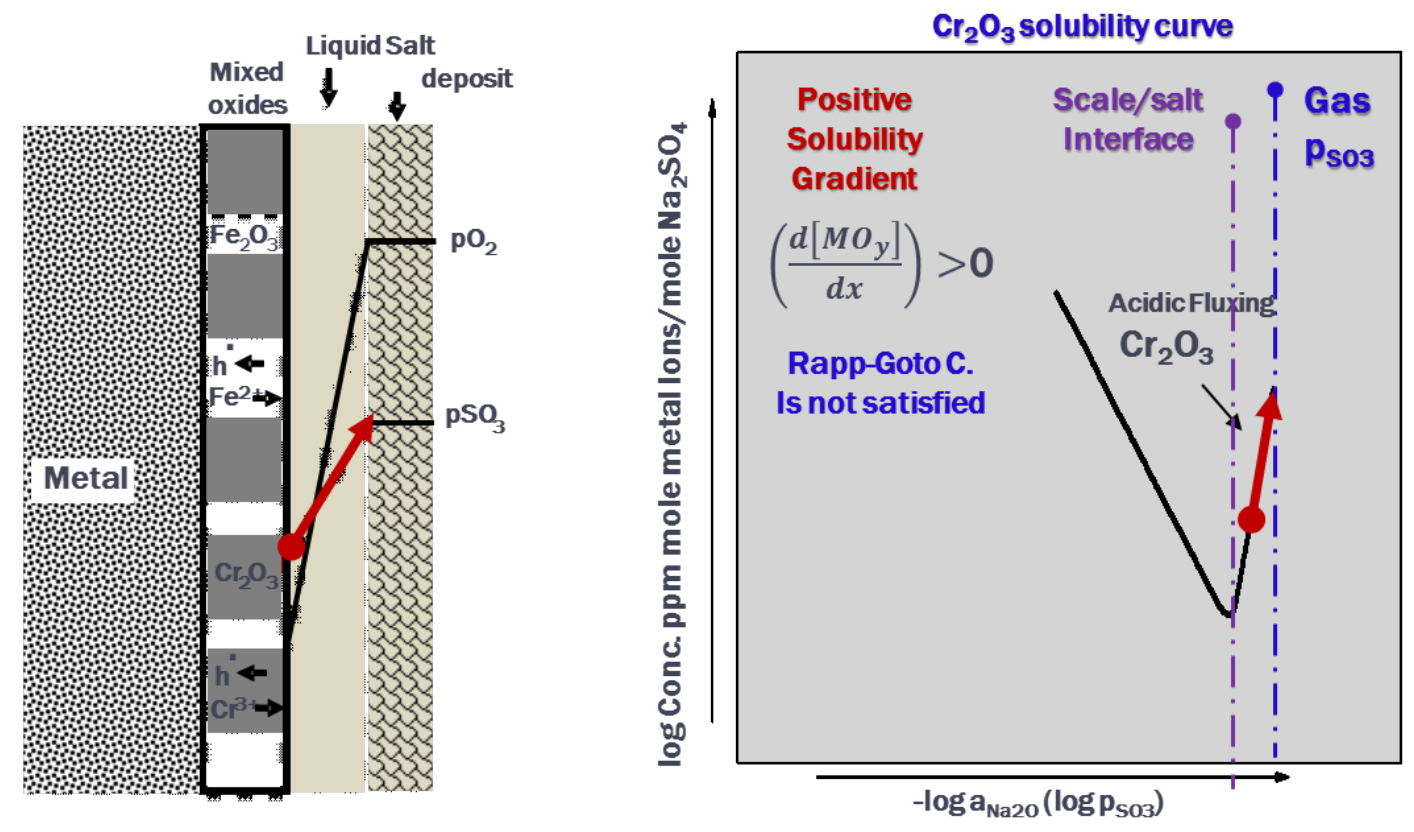

Figure 56: Schematic of $\mathrm{SO}_{3}$ gradient at oxide/salt interface and $\mathrm{Cr}_{2} \mathrm{O}_{3}$ solubility curve for acidic fluxing

A positive solubility gradient would also be set up at the oxide/salt interface and the protective scale would remain intact. This can be seen in the schematic and solubility plot for $\mathrm{Cr}_{2} \mathrm{O}_{3}$ in Figure 56. Individually the oxides should remain protective in the liquid salt and $\mathrm{SO}_{3}$ gas atmosphere.

When the two oxides are together the melt basicity is shifted in between the solubility minima for $\mathrm{Fe}_{2} \mathrm{O}_{3}$ and $\mathrm{Cr}_{2} \mathrm{O}_{3}$, then rapid degradation can occur when one oxide undergoes basic fluxing and the other undergoes acidic fluxing. Synergistic fluxing and the simultaneous occurrence of the two dissolution reactions for $\mathrm{Cr}_{2} \mathrm{O}_{3}$ and $\mathrm{Fe}_{2} \mathrm{O}_{3}$ could support each other by creating negative solubility gradients for both species and accelerating corrosion by short circuiting the rate-limiting diffusion process.[80] The protective $\mathrm{Cr}_{2} \mathrm{O}_{3}$ scale initially grown by 
the alloy would experience basic dissolution described by equation 43, locally creating $\mathrm{SO}_{3}$ (in the form of pyrosulfate) and consuming oxygen. The basic dissolution of $\mathrm{Cr}_{2} \mathrm{O}_{3}$ disrupts protective scale formation. $\mathrm{Fe}_{2} \mathrm{O}_{3}$ would experience acidic dissolution described by equation 44, consuming the locally created $\mathrm{SO}_{3}$. The basic dissolution of the $\mathrm{Cr}_{2} \mathrm{O}_{3}$ and the local formation of $\mathrm{SO}_{3}$ make the melt more acidic and shifts the solubility so that the melt is then under favorable conditions for acidic dissolution of the $\mathrm{Fe}_{2} \mathrm{O}_{3}$. The oxide ions released upon acidic dissolution of $\mathrm{Fe}_{2} \mathrm{O}_{3}$ in turn supply the reactant anions needed for basic dissolution of $\mathrm{Cr}_{2} \mathrm{O}_{3}$.[80] This can repeat indefinitely, so that repeating acidity and basicity of the melt would produce a continuous cycle of accelerated corrosion. The layered corrosion products mentioned in the previous sections supports this repeating cycle. The repeating of the basic and acidic dissolution reactions is shown in the schematic diagrams and solubility curves in Figure 57. 


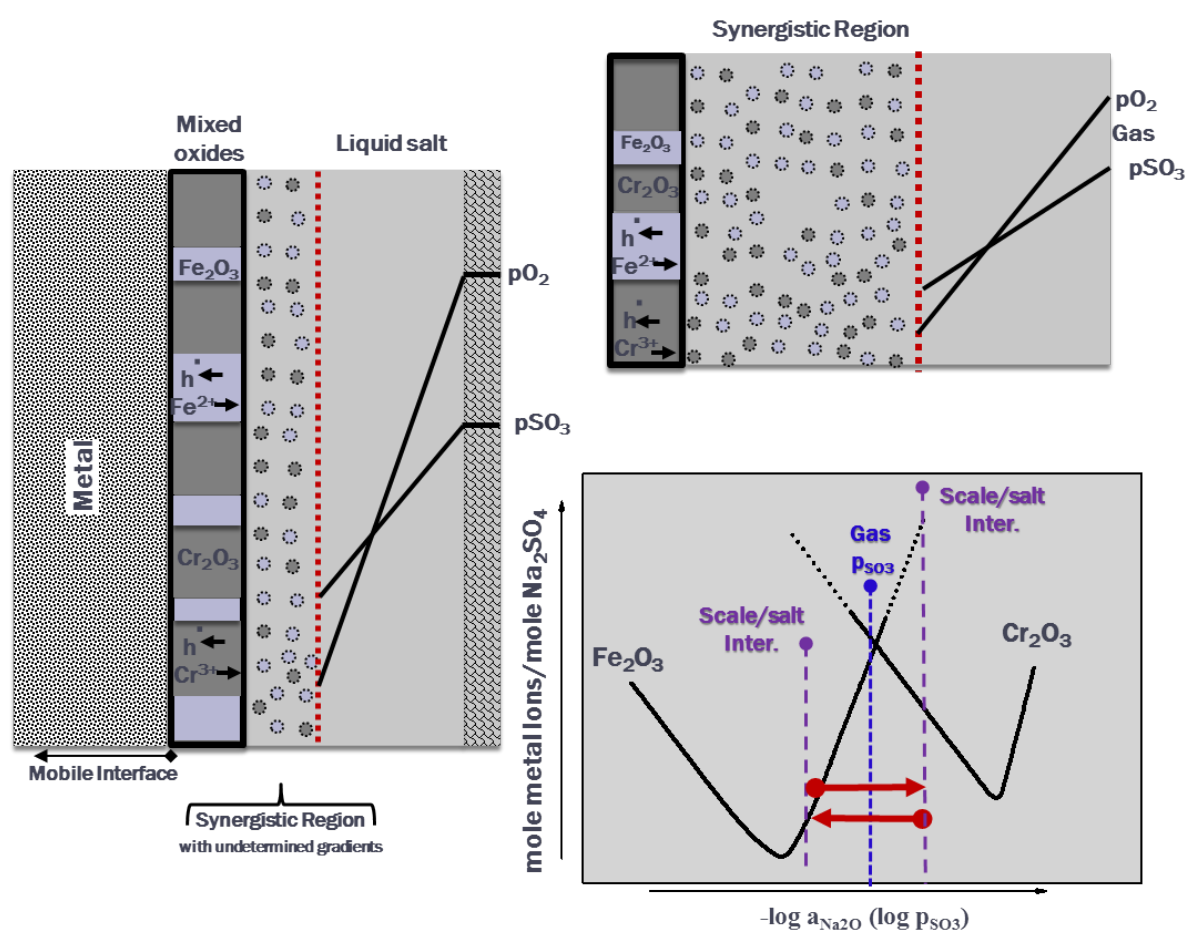

Figure 57: Schematic and solubility curves demonstrating synergistic fluxing the repeating acidic and basic dissolution reactions

The overall synergistic dissolution reaction is described by equation 45 . The concentrations of both $\mathrm{S}_{2} \mathrm{O}_{7}^{2-}$ ions and oxygen would be reduced by reaction 45 . Therefore, since the dissolution reactions are limited by the diffusion of $\mathrm{S}_{2} \mathrm{O}_{7}{ }^{2-}$ or oxygen, negative solubility gradients in the oxygen activity or basicity at the oxide/salt interface occur during the dissolution process.[80]

$$
\begin{aligned}
& \mathrm{Cr}_{2} \mathrm{O}_{3}+3 / 2 \mathrm{O}_{2}+4 \mathrm{Na}_{2} \mathrm{SO}_{4}=2 \mathrm{Na}_{2} \mathrm{CrO}_{4}+2 \mathrm{Na}_{2} \mathrm{~S}_{2} \mathrm{O}_{7} \\
& \mathrm{Fe}_{2} \mathrm{O}_{3}+3 \mathrm{Na}_{2} \mathrm{~S}_{2} \mathrm{O}_{7}=\mathrm{Fe}_{2}\left(\mathrm{SO}_{4}\right)_{3}+3 \mathrm{Na}_{2} \mathrm{SO}_{4}
\end{aligned}
$$

$2 \mathrm{Fe}_{2} \mathrm{O}_{3}+\mathrm{Cr}_{2} \mathrm{O}_{3}+5 / 4 \mathrm{O}_{2}+7 / 2 \mathrm{Na}_{2} \mathrm{~S}_{2} \mathrm{O}_{7}=3 / 2 \mathrm{Fe}_{2}\left(\mathrm{SO}_{4}\right)_{3}+2 \mathrm{Na}_{2} \mathrm{CrO}_{4}+3 / 2 \mathrm{Na}_{2} \mathrm{SO}_{4}$ 


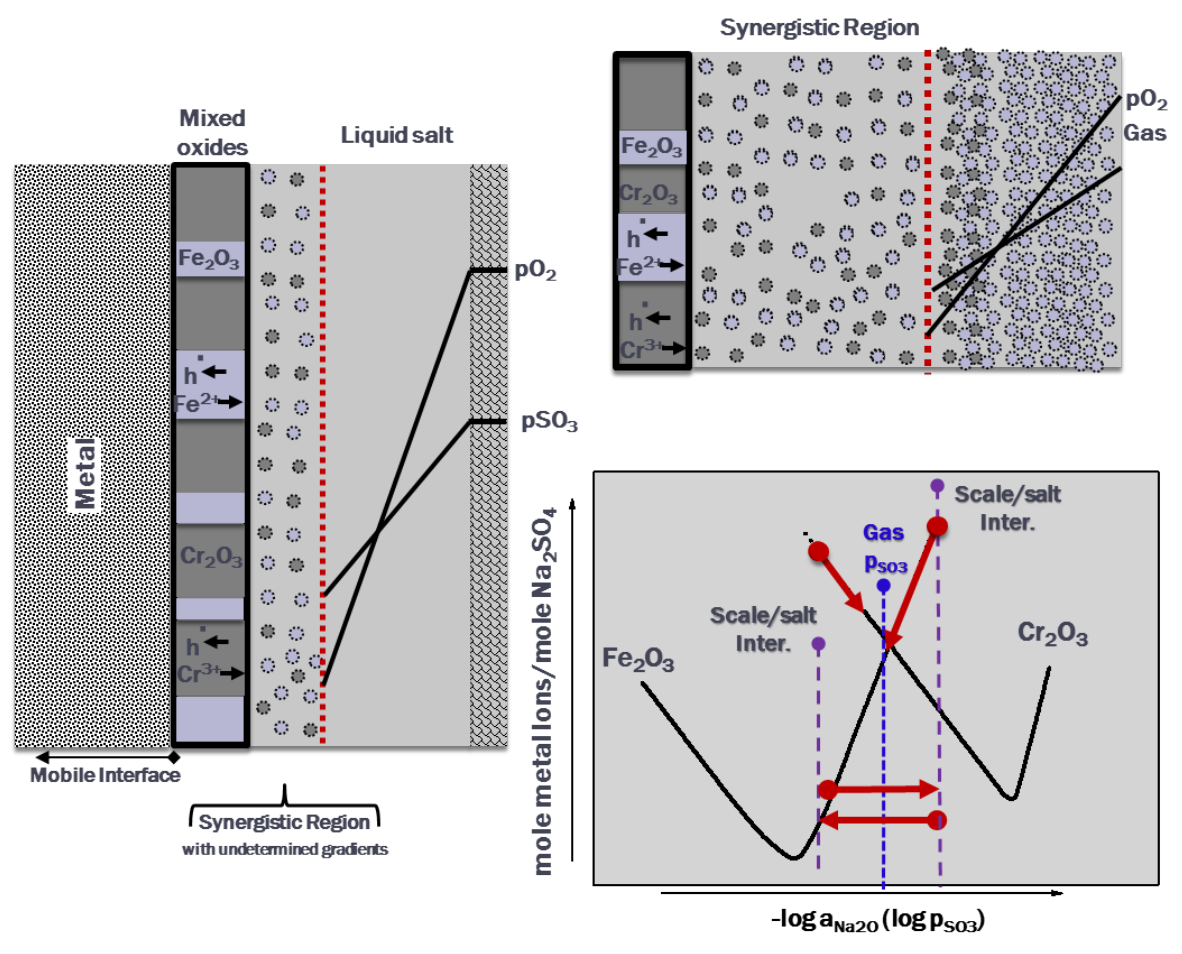

Figure 58: Negative solubility gradients on the $\mathrm{Fe}_{2} \mathrm{O}_{3}$ and $\mathrm{Cr}_{2} \mathrm{O}_{3}$ solubility curves due to synergistic fluxing and schematic of reprecipitation process

The non-protective iron oxide scale observed in the external corrosion products forms when iron oxide is dissolved via equation 44 in the synergistic dissolution region at the oxide/salt interface and reprecipitated in the salt further away from the interface. This is the most significant contribution to the observed metal loss. There is a negative solubility gradient set up where the iron oxide has a higher solubility at the oxide/salt interface than at the gas/salt interface. The iron oxide reprecipitates where there is a locally low solubility and a higher po2. The chromium solute also experiences a negative solubility gradient. However, the results imply that the solubility of $\mathrm{Cr}_{2} \mathrm{O}_{3}$ in the melt must be less than that for $\mathrm{Fe}_{2} \mathrm{O}_{3}$, because the chromium reprecipitates earlier, creating the observed internal corrosion pits. The negative solubility gradients and a schematic of the oxide reprecipitation is presented in Figure 58. 
Luthra[39] reported that the solubilities of $\mathrm{Cr}_{2} \mathrm{O}_{3}$ in $\mathrm{Na}_{2} \mathrm{SO}_{4}$ melts was very low (e.g. $2 \times 10^{-9}$ at $\mathrm{p}_{\text {so3 }}=10^{-3} \mathrm{~atm}$ at $750^{\circ} \mathrm{C}$ ), so chromium would be expected to stay below the original surface.

The proposed fireside corrosion propagation mechanism requires that the salt basicity be between the solubility minima of $\mathrm{Cr}_{2} \mathrm{O}_{3}$ and $\mathrm{Fe}_{2} \mathrm{O}_{3}$. We can use these curves to determine whether this process is possible under the test conditions. The solubility curves constructed by Hwang and Rapp[80] were at 1200K. Leblanc and Rapp[84] studied the solubilities of $\mathrm{Cr}_{2} \mathrm{O}_{3}$ and $\mathrm{SiO}_{2}$ in $\mathrm{Na}_{2} \mathrm{SO}_{4}-\mathrm{K}_{2} \mathrm{SO}_{4}-\mathrm{Fe}_{2}\left(\mathrm{SO}_{4}\right)_{3}$ at $963 \mathrm{~K}$ and found that the concentration of soluble $\mathrm{Cr}_{2} \mathrm{O}_{3}$ was six times higher than at $1200 \mathrm{~K}$ in $\mathrm{Na}_{2} \mathrm{SO}_{4}$. This can be seen in Figure 59. No thermodynamic data is available for the $(\mathrm{K}, \mathrm{Na})_{2} \mathrm{SO}_{4}-\mathrm{Fe}_{2}\left(\mathrm{SO}_{4}\right)_{3}$ liquid eutectic, but if the equilibrium reaction for sodium sulfate given in equation 19 is used along with the equilibrium $\mathrm{SO}_{3}$ partial pressure at $700^{\circ} \mathrm{C}$ in $\mathrm{O}_{2}+1000 \mathrm{ppm} \mathrm{SO}_{2}$ of $7.16 \times 10^{-4}$ atm (logpso3 $=-3.14$ ), then the equilibrium melt basicity (-log $a_{\mathrm{Na} 2 \mathrm{O}}$ ) equals 19.23 at $700^{\circ} \mathrm{C}$. With the data from Figure 59 , the $\mathrm{Cr}_{2} \mathrm{O}_{3}$ solubility curve in Figure 28 would shift to the right and about six times higher in solubility. Assuming at the lower temperature and in the $\mathrm{Na}_{2} \mathrm{SO}_{4}-\mathrm{K}_{2} \mathrm{SO}_{4}-\mathrm{Fe}_{2}\left(\mathrm{SO}_{4}\right)_{3}$ melt that the $\mathrm{Fe}_{2} \mathrm{O}_{3}$ solubility curve would shift in a similar manner, then synergistic dissolution should be feasible under fireside corrosion conditions. 


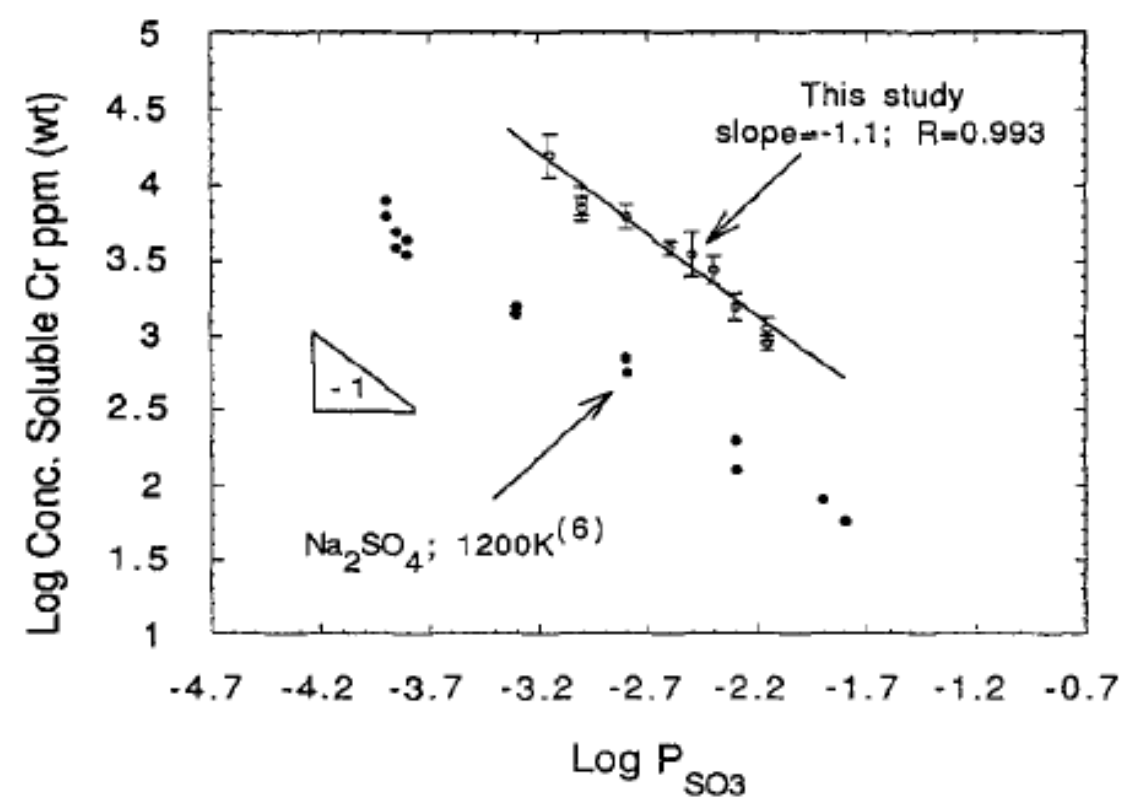

Figure 59: Solubility of $\mathrm{Cr}_{2} \mathrm{O}_{3}$ in sulfate melts (top data at 963K) [84]

Synergistic fluxing produces negative solubility gradients and the disruption of a protective oxide scale. Once this occurs, degradation continues as the observed porous external iron oxide scale forms over the internal corrosion pits rich in $\mathrm{Cr}, \mathrm{S}$, and $\mathrm{O}$. The transport mechanisms of the various species through the liquid melt for the formation of the porous external $\mathrm{Fe}_{2} \mathrm{O}_{3}$ scale and the inward growing corrosion pits can be described similarly to the Type II gas-phase induced acidic fluxing hot corrosion mechanism for Co-based alloys described by Luthra[39]. Inward migrating $\mathrm{SO}_{3}$ can pass through the liquid solution via an $\mathrm{S}_{2} \mathrm{O}_{7}{ }^{2-} / \mathrm{SO}_{4}{ }^{2-}$ exchange reaction, where it will react with $\mathrm{Cr}$ in the substrate to form the inward growing $\mathrm{Cr}_{2} \mathrm{O}_{3}$ and $\mathrm{CrS}$ corrosion pits due to a low $\mathrm{po}_{02}$, high $\mathrm{ps}_{2} / \mathrm{psO}_{\mathrm{sO}}$ at the melt/alloy interface. The external $\mathrm{Fe}_{2} \mathrm{O}_{3}$ scale will simultaneously form via an $3 \mathrm{Fe}^{2+} / 2 \mathrm{Fe}^{3+}$ exchange reaction similar to that for Co under Type II hot corrosion. The iron reprecipitates as an external porous $\mathrm{Fe}_{2} \mathrm{O}_{3}$ scale at higher Po2. The mechanisms of transport of various reactants through the liquid salt deposit causing the 
observed corrosion products were examined in more detail and can be explained similarly to the calculations performed by Luthra.[39] $\mathrm{SO}_{3}$ migrates through the liquid salt and causes the internal $\mathrm{Cr}_{2} \mathrm{O}_{3}$ and $\mathrm{CrS}$ corrosion pits. The predominant species in the gas atmosphere are $\mathrm{O}_{2}$, $\mathrm{SO}_{2}$, and $\mathrm{SO}_{3}$. By comparing the transport rates of these species through the liquid salt with the corrosion rates, whether or not it is the $\mathrm{SO}_{3}$ that is the major oxidant at the scale salt interface can be determined. This was performed for $\mathrm{Na}_{2} \mathrm{SO}_{4}$ salt deposits by Luthra[39] in order to explain his Type II hot corrosion mechanism. The transport rate of the species through a liquid salt can be calculated using Fick’s First Law:

$$
\mathrm{J}_{\mathrm{x}}=-\mathrm{D}_{\mathrm{x}} \frac{C_{x}^{g}-C_{x}^{S}}{\delta}
$$

Where $\mathrm{J}_{\mathrm{x}}$ and $\mathrm{D}_{\mathrm{x}}$ are the transport rate and diffusivity of the species $\mathrm{x}, C_{x}^{g}-C_{x}^{s}$ are the concentrations of the species $\mathrm{x}$ at the gas/salt and scale/salt interfaces, respectively, and $\delta$ is the thickness of the liquid salt. For inward migration of the gas species, $C_{x}^{s} \ll C_{x}^{g}$, which reduces equation 46 to:

$$
\mathrm{J}_{\mathrm{x}}=-\frac{D_{x} C_{x}^{g}}{\delta}
$$

For the calculations, a value of $100 \mu \mathrm{m}$ was used for $\delta$ and a value of $10^{-5} \mathrm{~cm}^{2}$ per second was used for $D_{x}$, which is typical for liquid diffusivities. The concentrations of the various gas species through the liquid salt used by Luthra were those found by Andresen at $900-1100^{\circ} \mathrm{C}[85]$, and they were extrapolated to $750^{\circ} \mathrm{C}$. The solubility of oxygen in $\mathrm{Na}_{2} \mathrm{SO}_{4}$ was extrapolated to $7.7 \times 10^{-8} \mathrm{~mol} / \mathrm{cm}^{3}$ at $750^{\circ} \mathrm{C}$, making the maximum flux through the salt $0.01 \mathrm{mg} / \mathrm{cm}^{2}$ per hour. The liquid salt that facilitates the proposed fireside corrosion mechanism is $(\mathrm{Na}, \mathrm{K})_{3} \mathrm{Fe}\left(\mathrm{SO}_{4}\right)_{3}$. Data are not available for the solubilities of various species in this molten salt deposit, but values in $\mathrm{Na}_{2} \mathrm{SO}_{4}$ will be used to model the transport rates for this study. The observed weight gains in this fireside corrosion study were on the order of $0.1-0.5 \mathrm{mg} / \mathrm{cm}^{2}$ per hour. Oxygen can therefore 
not be the major oxidant at the scale/salt interface, and the partial pressure of oxygen at this interface will be much lower than that at the gas/salt interface. The solubility of $\mathrm{SO}_{2}$ in $\mathrm{Na}_{2} \mathrm{SO}_{4}$ was found to be significantly less than that of $\mathrm{O}_{2}$, with a value of $10^{-10} \mathrm{~mol} / \mathrm{cm}^{3}$. The transport rate would therefore be significantly smaller than oxygen making it not possible for $\mathrm{SO}_{2}$ to be the main oxidant at the scale/salt interface. Most of the $\mathrm{SO}_{3}$ that can dissolve in $\mathrm{Na}_{2} \mathrm{SO}_{4}$ should be in the form of $\mathrm{S}_{2} \mathrm{O}_{7}{ }^{2-}$. The transport of $\mathrm{SO}_{3}$ through the liquid salt deposit will occur through an $\mathrm{S}_{2} \mathrm{O}_{7}{ }^{2-} / \mathrm{SO}_{4}{ }^{2-}$ exchange reaction shown in Figure 60. The $\mathrm{SO}_{3}$ migrates in via $\mathrm{S}_{2} \mathrm{O}_{7}{ }^{2-}$ ions by rotating positions with the $\mathrm{SO}_{4}{ }^{2-}$ ions.

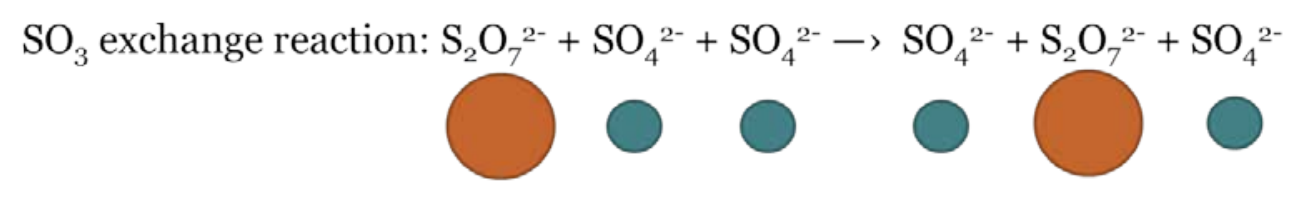

Figure 60: Schematic showing $\mathrm{SO}_{3}$ exchange reaction and migration through liquid salt

The $\mathrm{SO}_{3}$ concentration in $\mathrm{Na}_{2} \mathrm{SO}_{4}$ was determined by Luthra[39] to be $1 \times 10^{-5} \mathrm{~mol} / \mathrm{cm}^{3}$ in an atmosphere of $\mathrm{O}_{2}+1.5 \% \mathrm{SO}_{2}$, making the flux $3.3 \mathrm{mg} / \mathrm{cm}^{2}$ per hour. This is much larger than the observed corrosion rates for this fireside corrosion study. Because the fluxes of oxygen and $\mathrm{SO}_{2}$ were much less than the observed corrosion rates, and the maximum flux of $\mathrm{SO}_{3}$ was higher than the observed corrosion rates, $\mathrm{SO}_{3}$ should be the dominant oxidant at the scale/salt interface. The observed corrosion rates for this fireside corrosion study may be less than the maximum flux of $\mathrm{SO}_{3}$ found by Luthra due to the lower $\mathrm{SO}_{2}$ contents in the gases used in this study.

The external iron oxide scale can form via an $3 \mathrm{Fe}^{2+} / 2 \mathrm{Fe}^{3+}$ exchange reaction similar to that for Co under Type II hot corrosion.[39] The liquid melt the forms is due to $\mathrm{Fe}_{2}\left(\mathrm{SO}_{4}\right)_{3}$ 
reacting with alkali sulfates. A deposit was made in which $\mathrm{Fe}_{2}\left(\mathrm{SO}_{4}\right)_{3}$ was added to the M1 deposit. This deposit as well as the SCM were placed in alumina crucibles without any specimens and exposed to an atmosphere of $\mathrm{O}_{2}+2500 \mathrm{ppm} \mathrm{SO}_{2}$. The SCM remained in powder form. The M1 deposit with the $\mathrm{Fe}_{2}\left(\mathrm{SO}_{4}\right)_{3}$ became molten and a solidified pool of the liquid eutectic remained at the bottom of the crucible. This supports the previous statement that alkali iron trisulfates are not the liquid responsible for corrosion and that the low melting $\mathrm{K}_{2} \mathrm{SO}_{4}$ $\mathrm{Fe}_{2}\left(\mathrm{SO}_{4}\right)_{3}$ solution is the liquid that is forming and causing corrosion. The reaction that can describe the $\mathrm{Fe}^{3+} / \mathrm{Fe}^{2+}$ ratio in the liquid salt can be described by the following equation:

$$
2 \mathrm{FeSO}_{4}+\mathrm{SO}_{3}+1 / 2 \mathrm{O}_{2}=\mathrm{Fe}_{2}\left(\mathrm{SO}_{4}\right)_{3}
$$

which is equivalent to the following reaction, showing the species present in the salt:

$$
2 \mathrm{Fe}^{2+}+\mathrm{S}_{2} \mathrm{O}_{7}{ }^{2-}+1 / 2 \mathrm{O}_{2}(\text { dissolved })=2 \mathrm{Fe}^{3+}+2 \mathrm{SO}_{4}{ }^{2-}
$$

The oxygen and $\mathrm{SO}_{2}$ partial pressures at the scale/salt interface will be lower than at the gas/salt interface, therefore the $\mathrm{Fe}^{2+} / \mathrm{Fe}^{3+}$ ratio at the scale/salt interface should be higher than at the gas/salt interface. $\mathrm{Fe}^{2+}$ ions can migrate outward through the salt from the scale/salt interface, while $\mathrm{Fe}^{3+}$ ions migrate inward. The outward migrating ions will form $\mathrm{Fe}_{2} \mathrm{O}_{3}$ or $\mathrm{FeSO}_{4}$ near the gas/salt interface where the oxygen and $\mathrm{SO}_{2}$ partial pressures are higher. The inward migrating $\mathrm{Fe}^{3+}$ ions will be reduced to $\mathrm{Fe}^{2+}$ at the scale/salt interface. This is reasonable because iron can exist both in trivalent and divalent states. A rough calculation can be made in order to determine the $\mathrm{Fe}^{3+} / \mathrm{Fe}^{2+}$ ratio for the observed fireside corrosion rates to be maintained. The outward flux of iron is roughly $0.5 \mathrm{mg} / \mathrm{cm}^{2}$ per hour. (This value was obtained from the fireside corrosion of Fe-12Ni-18Cr with the $\mathrm{M} 1$ deposit in $\mathrm{O}_{2}+1000 \mathrm{ppm} \mathrm{SO}_{2}$ at $700^{\circ} \mathrm{C}$, assuming the observed $\mathrm{Fe}_{2} \mathrm{O}_{3}$ external scale grew linearly with time). This results in a $\mathrm{Fe}^{3+} / \mathrm{Fe}^{2+}$ ratio of $\approx 5 \times 10^{-4}$, which is a reasonable value due to the fact that iron exists readily in trivalent and divalent states. 
In an acidic gas atmosphere containing $\mathrm{SO}_{3}$ such as the one used for this study, pyrosulfate is used in the synergistic dissolution reactions instead of oxygen as described in the previous Synergistic Dissolution section, because $\mathrm{SO}_{3}$ and the pyrosulfate is the dominant species migrating through the melt.[80] The dissolution of oxides is limited by the diffusion of $\mathrm{SO}_{3}$ (as $\mathrm{S}_{2} \mathrm{O}_{7}{ }^{2-}$ ), and is the rate limiting step for acidic dissolution. Synergistic dissolution reduces the need for such diffusion as it "short circuits" the diffusion of the pyrosulfate ions to the reaction site.[80] This causes rapid corrosion when synergistic dissolution occurs. Higher $\mathrm{SO}_{3}$ partial pressures would accelerate the attack by inducing higher local oxygen partial pressures at the base of the pit since oxygen is transported in the melt by pyrosulfate ions.

In order to further prove if synergistic dissolution is occurring, the FeNiCr and T92 alloys were exposed to a deposit containing $\mathrm{M} 1+30 \% \mathrm{Cr}_{2} \mathrm{O}_{3}$ at $700^{\circ} \mathrm{C}$ in $\mathrm{O}_{2}+1000 \mathrm{ppm} \mathrm{SO}_{2}$ for 160 hours. It is thought that synergistic dissolution is occurring with the M1 deposit, and that the addition of $\mathrm{Fe}_{2} \mathrm{O}_{3}$ to the alkali sulfate mix (SCM) is causing the melt to become locally more basic and pushing it out of the solubility region between where synergistic dissolution would occur at a maximum rate, shown previously in Figure 28. Similarly, the $\mathrm{Cr}_{2} \mathrm{O}_{3}$ in the deposit of $\mathrm{M} 1+30 \% \mathrm{Cr}_{2} \mathrm{O}_{3}$ would push the melt to be locally more acidic and out of the region for synergistic dissolution to occur at a maximum rate. Synergistic dissolution causes the melt to undergo a cycle of basic and acidic fluxing, and changes in the local melt basicity or acidity with the additions of oxides to the alkali sulfates will slow down this cycle and reduce negative the solubility gradients. Macroscopic and microscopic cross section images of the results in $\mathrm{M} 1+30 \% \mathrm{Cr}_{2} \mathrm{O}_{3}$ are shown in Figure 61. The images presented are the areas of the specimen where the corrosion was the worst. There was significantly less degradation when chromia was added to the deposit. T92 had some small areas of localized pitting, and the FeNiCr alloy grew a 
thick iron and chromium rich oxide scale on the surface with minimal mass change and metal loss.

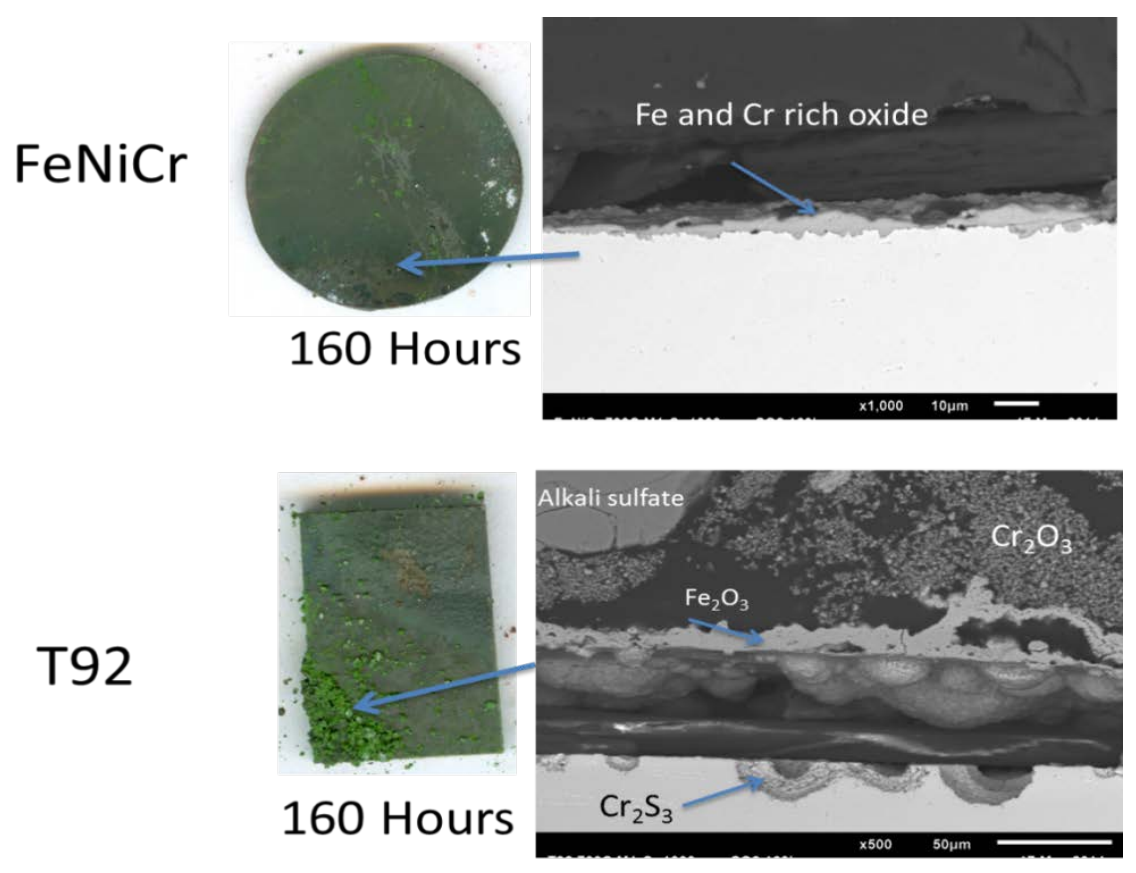

Figure 61: Macroscopic and microscopic SEM images of $\mathrm{FeNiCr}$ and $\mathrm{T92}$ exposed at $700^{\circ} \mathrm{C}$ with $\mathrm{M1}+30 \% \mathrm{Cr}_{2} \mathrm{O}_{3}$ powder deposit in $\mathrm{O}_{2}+1000 \mathrm{pppm} \mathrm{SO}_{2}$ for 160 hours

The results of the test in $\mathrm{M} 1+30 \% \mathrm{Cr}_{2} \mathrm{O}_{3}$ are shown in Figures 62 and 63 as mass change and metal loss values compared with the results under the same conditions when using the M1 and SCM deposits. 
$\mathrm{T92} 700^{\circ} \mathrm{C} 1000 \mathrm{ppm} \mathrm{SO}_{2}$

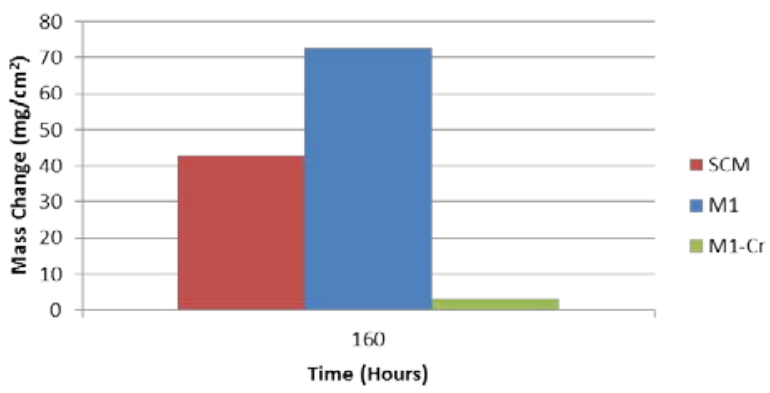

T92 $700^{\circ} \mathrm{C} 1000 p p m$ SO2

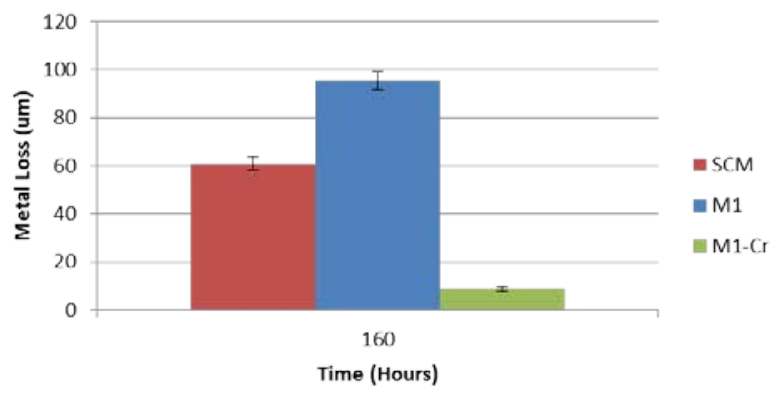

Figure 62: Mass change and metal loss for T92 exposed at $700^{\circ} \mathrm{C}$ with the $\mathrm{M1}, \mathrm{SCM}$, and $\mathrm{M1}+30 \% \mathrm{Cr}_{2} \mathrm{O}_{3}$ powder deposits in a crucible in $\mathrm{O}_{2}+1000 \mathrm{ppm} \mathrm{SO}_{2}$ for 160 hours

\section{FeNiCr $700^{\circ} \mathrm{C} 1000 \mathrm{ppm} \mathrm{SO}{ }_{2}$}

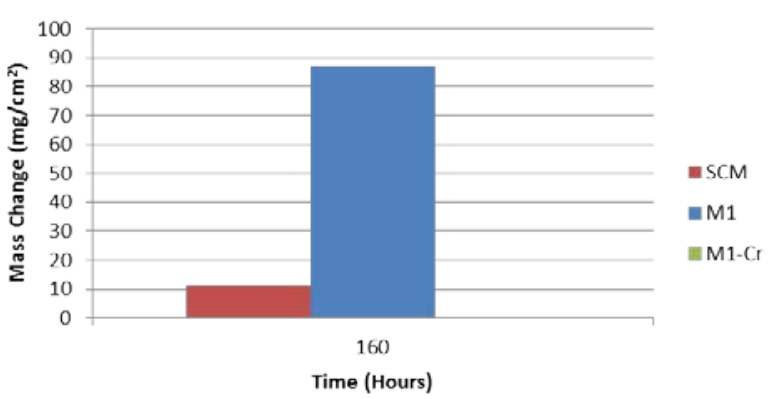

FeNiCr $700^{\circ} \mathrm{C} 1000 \mathrm{ppm} \mathrm{SO}_{2}$

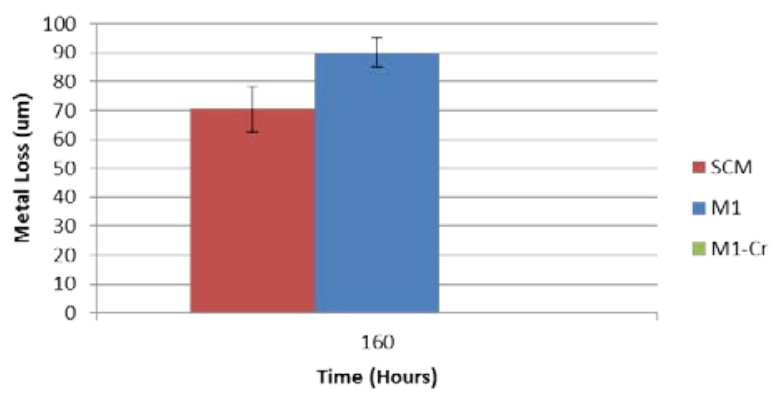

Figure 63: Mass change and metal loss for $\mathrm{FeNiCr}$ exposed at $700^{\circ} \mathrm{C}$ with the M1, SCM, and M1+30\% $\mathrm{Cr}_{2} \mathrm{O}_{3}$ powder deposits in a crucible in $\mathrm{O}_{2}+1000 \mathrm{ppm} \mathrm{SO}_{2}$ for 160 hours

The addition of either $\mathrm{Fe}_{2} \mathrm{O}_{3}$ or $\mathrm{Cr}_{2} \mathrm{O}_{3}$ to the base $\mathrm{M} 1$ deposit, significantly decreases the amount of mass change and metal loss of these alloys (The mass change and metal loss for FeNiCr in the M1-Cr deposit was so small that it is not seen in the plots). It is proposed the M1 deposit at the salt/gas interface has a melt basicity that is in the solubility range where synergistic dissolution can occur. The SCM is less corrosive than the M1 deposit because the iron oxide in the deposit changes the local basicity of the melt. The melt basicity may no longer be in a region where the maximum corrosion rate can occur. Synergistic dissolution has been slowed down, 
but not stopped completely. The cycle between acidic and basic fluxing that occurs with synergistic dissolution takes longer due to the change in the basicity with the iron oxide addition. The simultaneous dissolution reactions are no longer able to support each other as quickly and there is a lower solubility gradient.

Tests were conducted using specimens of pure iron with the SCM and M1 powder deposits in $\mathrm{O}_{2}+1000 \mathrm{ppm} \mathrm{SO}_{2}$ for 160 hours. Macroscopic images of the results as well as cross-sectional microscopic images are presented in Figures 64 and 65 . With both deposits very thick iron oxide scales grew displaying the various forms of iron oxide that will grow when pure iron is oxidized. This was explained in a previous section. The deposit is clearly becoming molten and it is evident that the liquid is once again migrating up the specimen into the nondeposit zone.

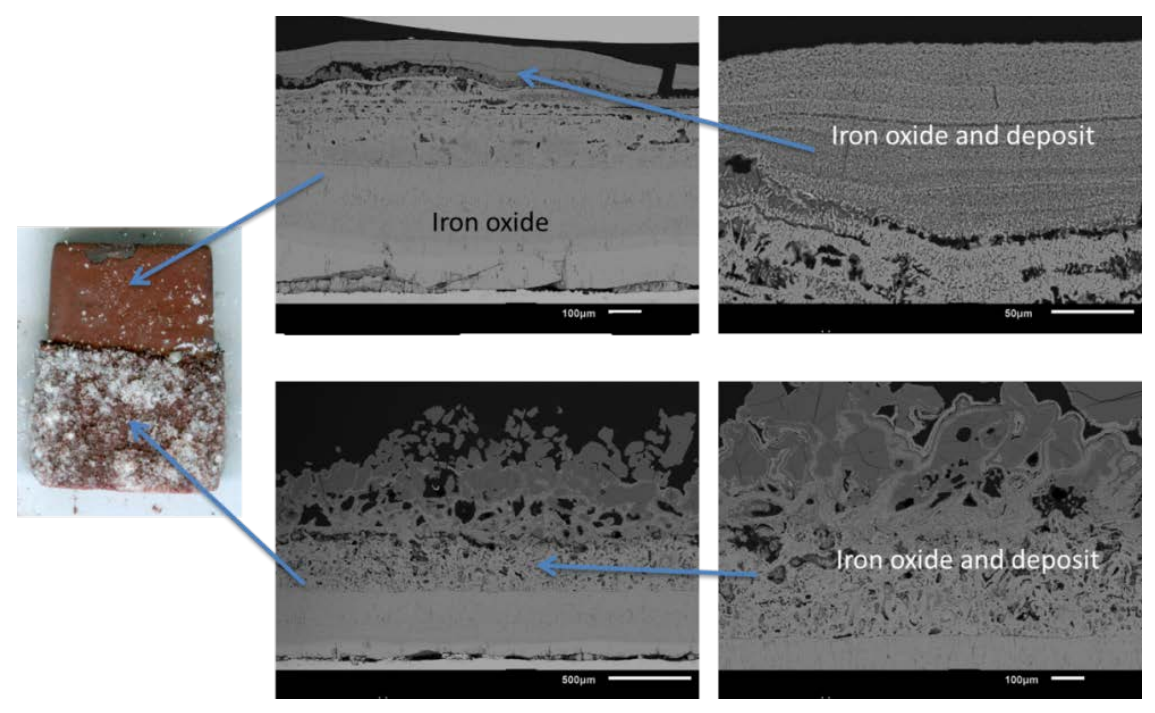

Figure 64: Macroscopic and cross-sectional SEM images of Fe exposed at $700^{\circ} \mathrm{C}$ with the $\mathrm{M1}$ powder deposit in $\mathrm{O}_{2}+1000 \mathrm{ppm} \mathrm{SO} \mathrm{S}_{2}$ for 160 hours 


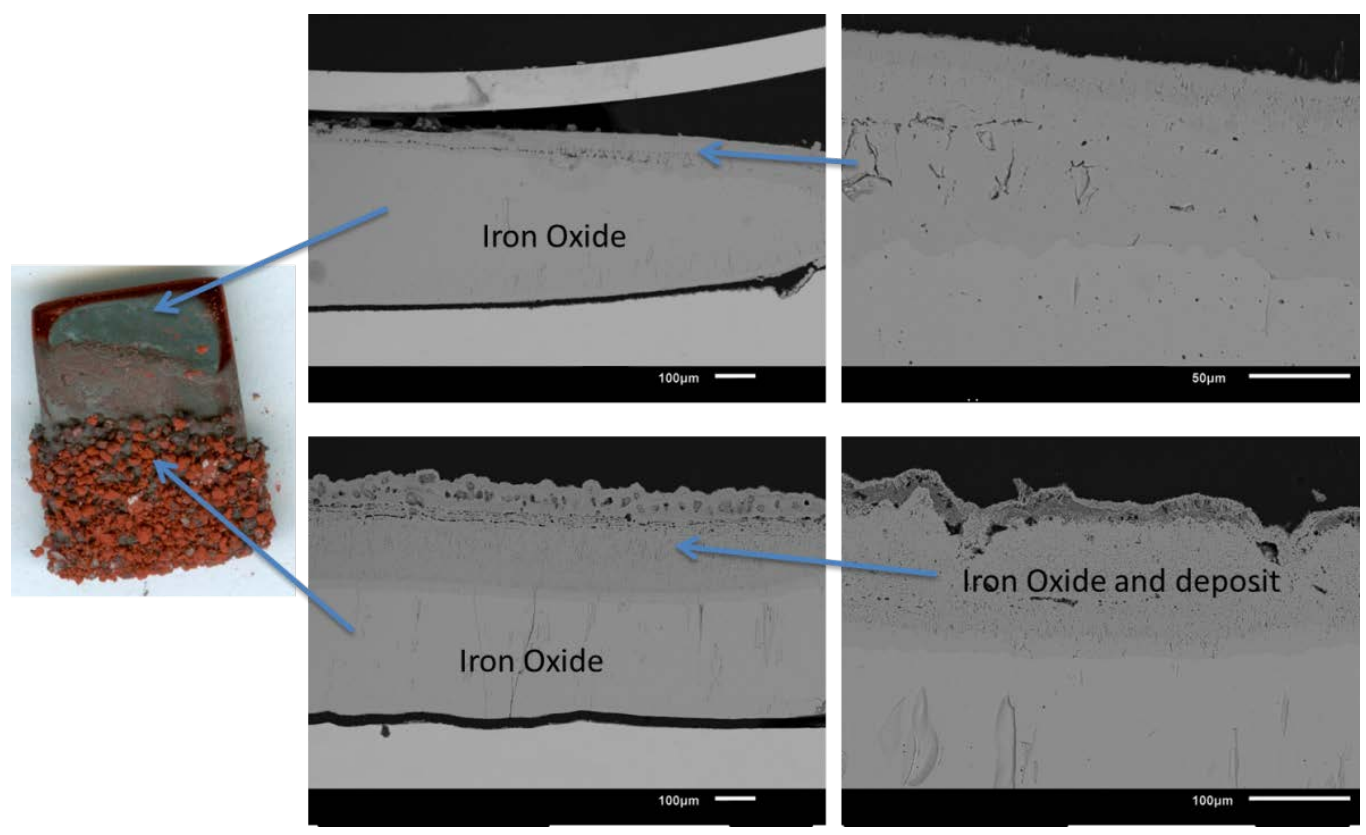

Figure 65: Macroscopic and cross-sectional SEM images of Fe exposed at $700^{\circ} \mathrm{C}$ with the SCM powder deposit in $\mathrm{O}_{2}+1000 \mathrm{ppm} \mathrm{SO}_{2}$ for 160 hours

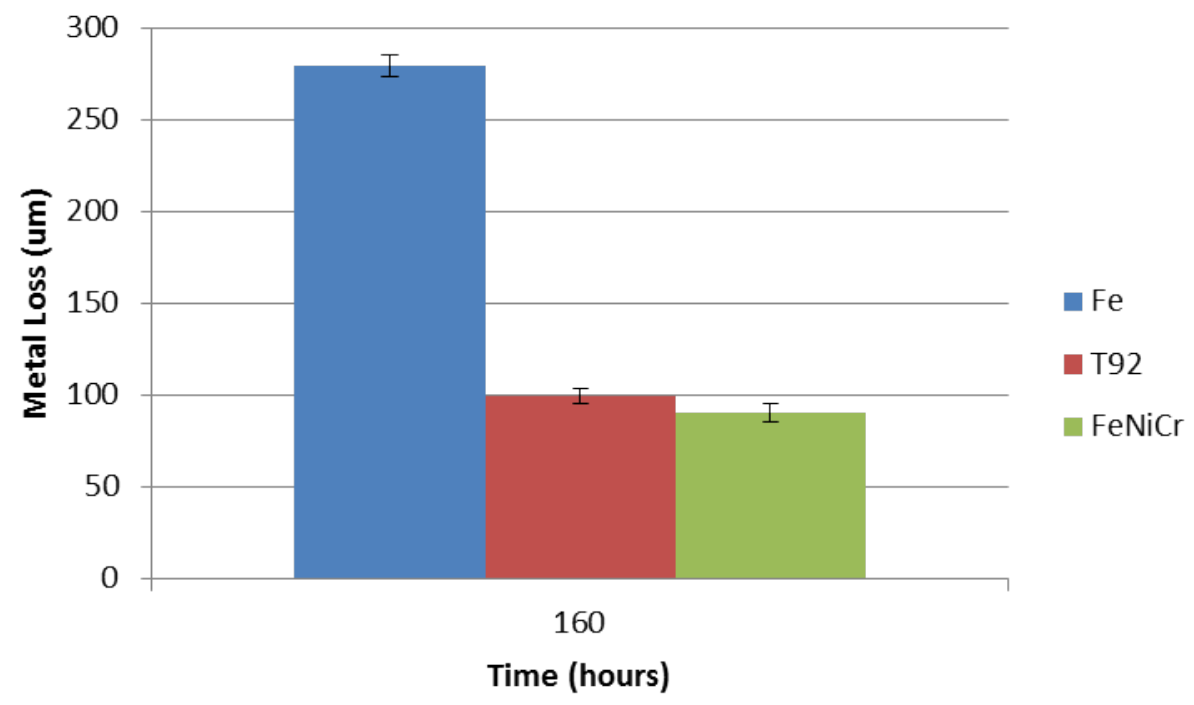

Figure 66: Metal loss of Fe exposed at $700^{\circ} \mathrm{C}$ with the $\mathrm{M1}$ powder deposit in $\mathrm{O}_{2}+1000 \mathrm{ppm} \mathrm{SO} \mathrm{S}_{2}$ for 160 hours compared with the results of the T92 and FeNiCr alloys 


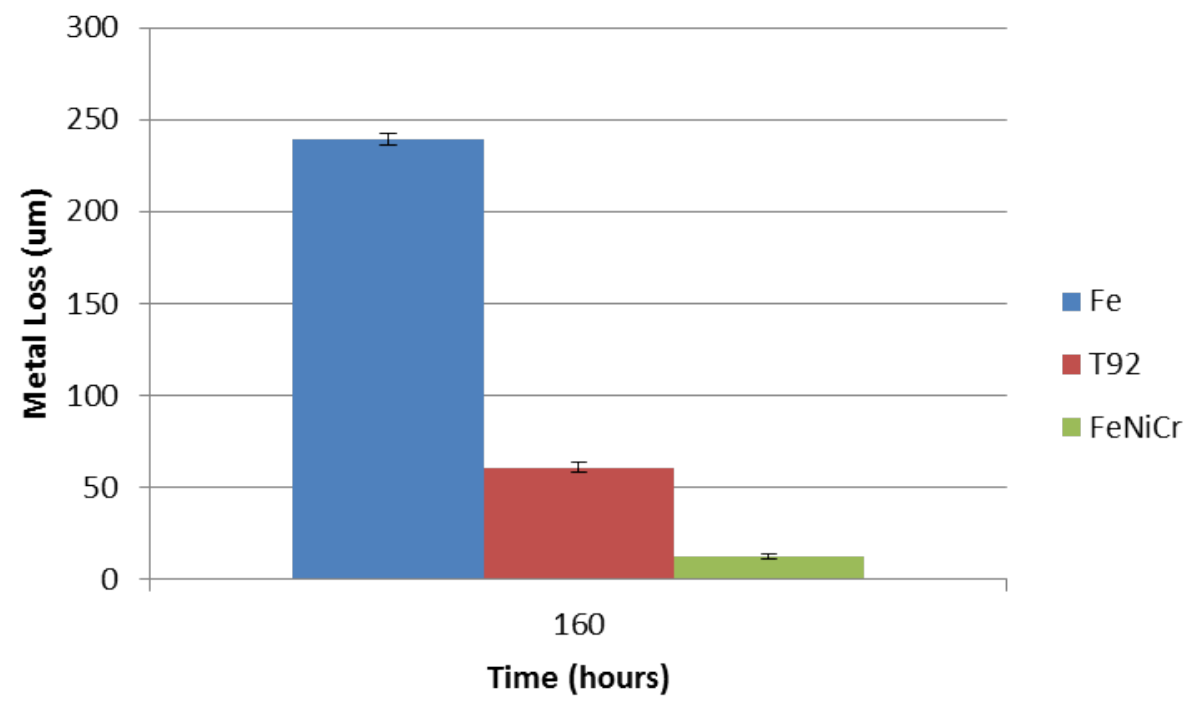

Figure 67: Metal loss of Fe exposed at $700^{\circ} \mathrm{C}$ with the SCM powder deposit in $\mathrm{O}_{2}+1000 \mathrm{ppm} \mathrm{SO}_{2}$ for 160 hours compared with the results of the T92 and FeNiCr alloys

Metal loss values were calculated for each specimen and are presented in Figures 66 and 67 compared with the T92 and FeNiCr alloys. The degradation is significantly worse with the pure iron specimens. This does not negate the proposed synergistic fluxing mechanism for the T92 and FeNiCr alloys however, as pure iron would oxidize at a significant rate without the presence of a deposit on the surface. Synergistic fluxing is not needed to dissolve a protective $\mathrm{Cr}_{2} \mathrm{O}_{3}$ scale in this case as there is only non-protective iron oxide forming. Another mechanism is likely occurring in the case of pure iron.

With the SCM, the liquid solution can form from iron oxide in the deposit or at the expense of a thermally grown oxide scale. When the liquid melt forms at the expense of the thermally grown iron oxide scale, there is likely more corrosion, as the liquid melt would then have direct access to the base metal and the described fluxing mechanism would occur. When the liquid solution forms in the deposit, it will only have access to the base metal to facilitate 
corrosion in cracks or defects in the protective oxide scale or in areas where fluxing of the protective $\mathrm{Cr}_{2} \mathrm{O}_{3}$ oxide scale has occurred. The inward migrating corrosion pits and outward migration of Fe from the base metal will occur with the mechanisms described in the previous paragraphs. The M1-Cr deposit is even less corrosive than the SCM. The addition of $\mathrm{Cr}_{2} \mathrm{O}_{3}$ increases the local acidity of the melt so much that it has essentially stopped synergistic dissolution from occurring and significantly slowed the corrosion rate.

$\mathrm{M} 1+30 \% \mathrm{Co}_{3} \mathrm{O}_{4}$
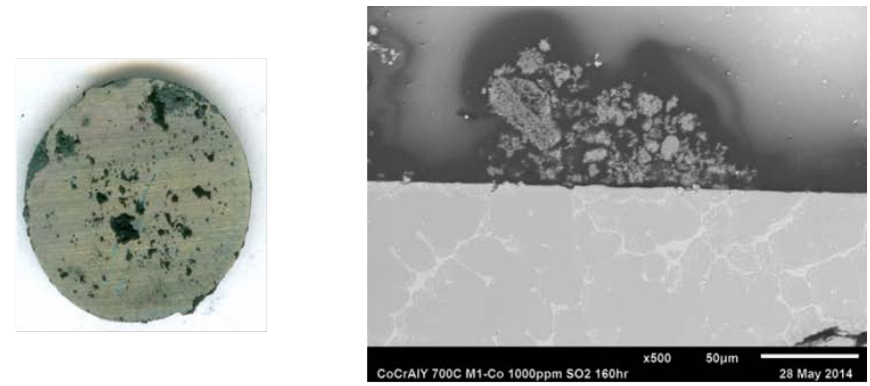

M1
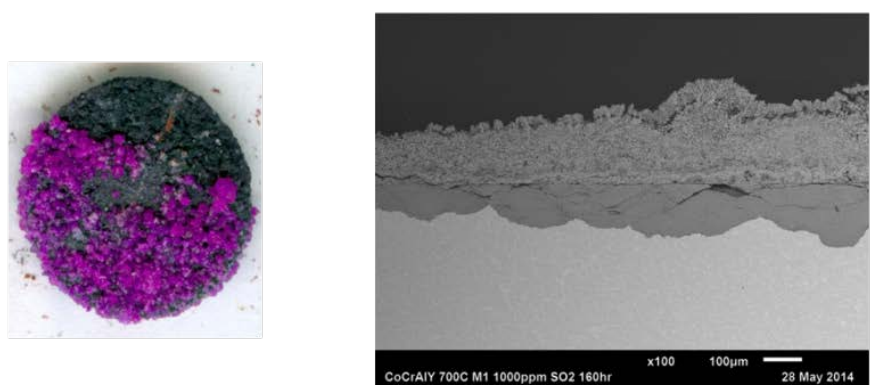

Figure 68: Macroscopic and microscopic SEM images of CoCrAlY exposed at $700^{\circ} \mathrm{C}$ with the M1 and M1 $+30 \% \mathrm{Co}_{3} \mathrm{O}_{4}$ deposits in $\mathrm{O}_{2}+1000 \mathrm{ppm} \mathrm{SO}_{2}$ for 160 hours

Type II hot corrosion occurs from $\mathrm{Na}_{2} \mathrm{SO}_{4}$ deposits on the surface of turbine engine hardware. Co-based alloys typically do not perform well under Type II hot corrosion conditions. This was previously explained in more detail in the Type II hot corrosion section. In order to further support this fireside corrosion synergistic dissolution theory, a CoCrAlY alloy, of 
composition Co-20\%Cr-26\%Al-0.4\%Y (at.\%), was tested with the M1 powder deposit and with a deposit containing $\mathrm{M} 1+30 \% \mathrm{Co}_{3} \mathrm{O}_{4}$ at $700^{\circ} \mathrm{C}$ in $\mathrm{O}_{2}+1000 \mathrm{ppm} \mathrm{SO}_{2}$ for 160 hours. The results are shown in Figure 68 as macroscopic and cross-sectional SEM images. The M1 deposit severely degraded the specimens, as would be expected under these Type II hot corrosion conditions. The addition of $\mathrm{Co}_{3} \mathrm{O}_{4}$ to the $\mathrm{M} 1$ deposit significantly decreased the amount of degradation, as the alloy grew a thin protective oxide scale on the surface. The addition of $\mathrm{Co}_{3} \mathrm{O}_{4}$ changed the melt basicity to places on the solubility curves so that synergistic dissolution is no longer able to occur. The $\mathrm{Co}_{3} \mathrm{O}_{4}$ in the deposit has likely stopped synergistic dissolution from occurring.

There are a large number of similarities between fireside corrosion and Type II hot corrosion. Both forms of corrosion occur at the same temperature range $\left(650-750^{\circ} \mathrm{C}\right)$ and in gas atmospheres containing $\mathrm{SO}_{3}$. The main difference between the two is that fireside corrosion has a more complex deposit and occurs typically on steel boiler tubes rather than $\mathrm{Ni}$ or Co-based gas turbine hardware. The liquid melts that form are therefore different, but, they both have the same effect on their respective alloy substrates. The deposit that occurs in the fireside corrosion of steels becomes liquid due to reactions with the deposit and gas atmosphere and forms at the expense of the thermally grown iron oxide or from iron oxide already in the deposit. This liquid allows the dissolution and fluxing of protective oxide scales and continued corrosion of the base metal. The same could be said of that for Type II hot corrosion. The deposit becomes liquid due to reactions with the deposit and the gas atmosphere and forms at the expense of the thermally grown transient nickel oxide, and the liquid allows fluxing of the protective oxides and base metal in a similar manner. Because of the similar effects of the liquid deposit on the metal 
substrates, the corrosion products and morphologies are similar. It could therefore be argued that fireside corrosion is a form of Type II hot corrosion, and there are just more complex materials in the deposit.

\subsection{DEPOSIT COMPOSITION EFFECT}

It was originally believed that the SCM would be the most severe deposit for the fireside corrosion studies, because the alkali iron trisulfates could form in the deposit and did not need a thermally grown iron oxide scale for liquid formation and for corrosion to occur. The results in the Mechanism Study sections showed that this was not the case. M1 was more severe than the SCM. The proposed mechanism explained in the previous section states that synergistic dissolution is the likely reason that the M1 deposit is more corrosive than the SCM. The addition of iron oxide to the alkali sulfates in the deposit (SCM) shifts the melt basicity out of the region where synergistic dissolution can occur at a maximum rate. The effect of other oxide additions to the deposit on the proposed mechanism and the amount of corrosion will now be discussed in the subsequent sections. The additions of other oxides $\left(\mathrm{Al}_{2} \mathrm{O}_{3}, \mathrm{CaO}\right.$, and $\left.\mathrm{SiO}_{2}\right)$ to the deposit more accurately simulate the ash deposits that occur in coal fired boilers. Metal loss plots are shown in Figures 69 and 70 compared with the results of the SCM and M1 deposit (The SCM-A and SCM-S bars cannot be seen because the metal loss was minimal). 


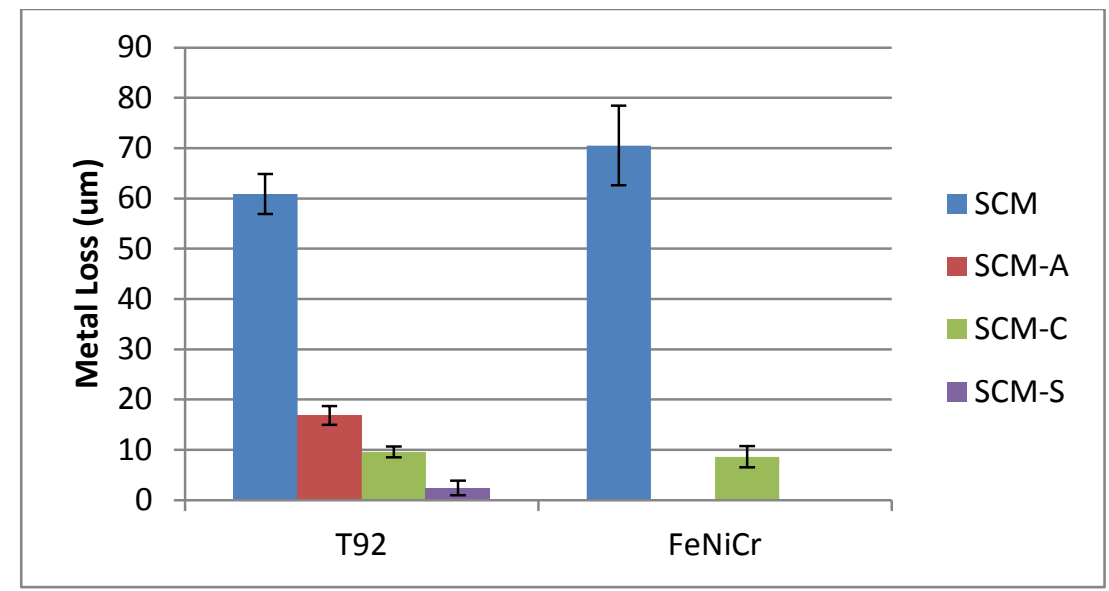

Figure 69: Metal loss of FeNiCr and T92 exposed in various deposits containing the SCM with oxide additions at $700^{\circ} \mathrm{C}$ in $\mathrm{O}_{2}+1000 \mathrm{ppm} \mathrm{SO}_{2}$ for 160 hours

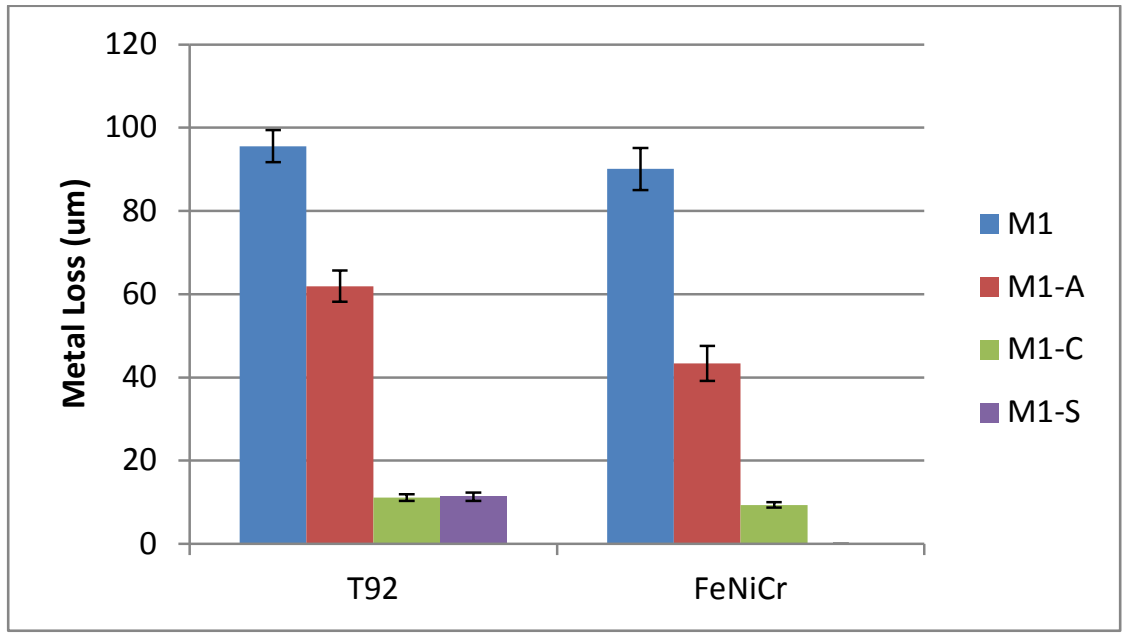

Figure 70: Metal loss of FeNiCr and T92 exposed in various deposits containing M1 with oxide additions at $700^{\circ} \mathrm{C}$ in $\mathrm{O}_{2}+1000 \mathrm{ppm} \mathrm{SO}_{2}$ for 160 hours 


\subsubsection{Alumina Additions}

\subsubsection{1 $\mathrm{SCM}+\mathrm{Al}_{2} \mathrm{O}_{3}(\mathrm{SCM}-\mathrm{A})$}

The SCM was used as a base deposit for additional deposit composition studies. Alumina is found in large quantities in the ash that forms when burning coals from all over the United States. Thirty molar percent $\mathrm{Al}_{2} \mathrm{O}_{3}$ was added to the SCM, (SCM-A). The spinel and chromiaforming alloys T92 and model FeNiCr were exposed with this deposit powder at $700^{\circ} \mathrm{C}$ in $\mathrm{O}_{2}+$ 1000ppm $\mathrm{SO}_{2}$ for 160 hours. The macroscopic results are shown in Figure 71.

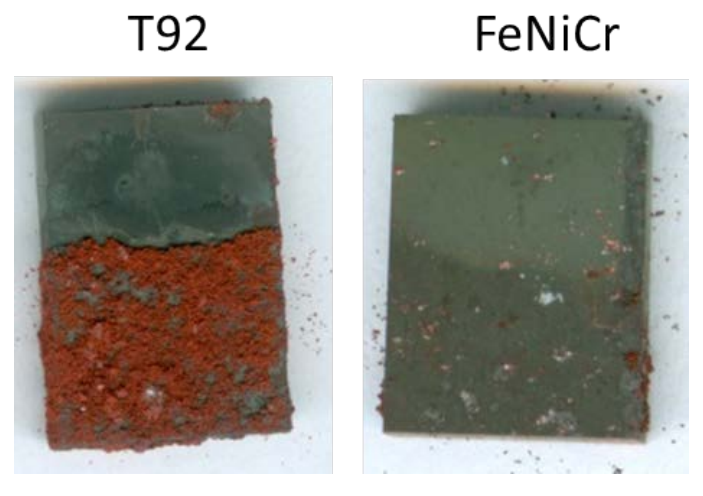

Figure 71: Macroscopic images of $\mathrm{T} 92$ and $\mathrm{FeNiCr}$ exposed at $700^{\circ} \mathrm{C}$ with the SCM-A powder in $\mathrm{O}_{2}+$ $1000 \mathrm{ppm} \mathrm{SO} \mathrm{S}_{2}$ for 160 hours

There was significantly less metal loss with the SCM-A deposit than with the SCM deposit. Microscopic cross-sectional images are shown in Figure 72. Protective chromium rich oxide scales grew on the surfaces in the non-deposit zone for both alloys. Corrosion occurred throughout the entire deposit zone for T92. The corrosion products were similar to that when the SCM deposit was used, however the depth of the pits and the amount of metal loss was not as severe. Thick porous iron oxide scales grew over internal pits rich in Fe, Cr, S, and oxygen. The 
sulfur content increases with depth in the pits, and large amounts of internal sulfides formed. Remnant alumina can be seen engulfed by the porous external iron oxide scale. The FeNiCr alloy suffered relatively no corrosion in the entire deposit zone. Iron and chromium rich oxide scales grew on the surface. The better corrosion resistance with this alloy can be attributed to the higher chromium content. More chromium is able to regrow the protective $\mathrm{Cr}_{2} \mathrm{O}_{3}$ scale after basic fluxing occurs via the mechanism described previously. This delays the liquid melt from reaching the base metal and facilitating synergistic fluxing.
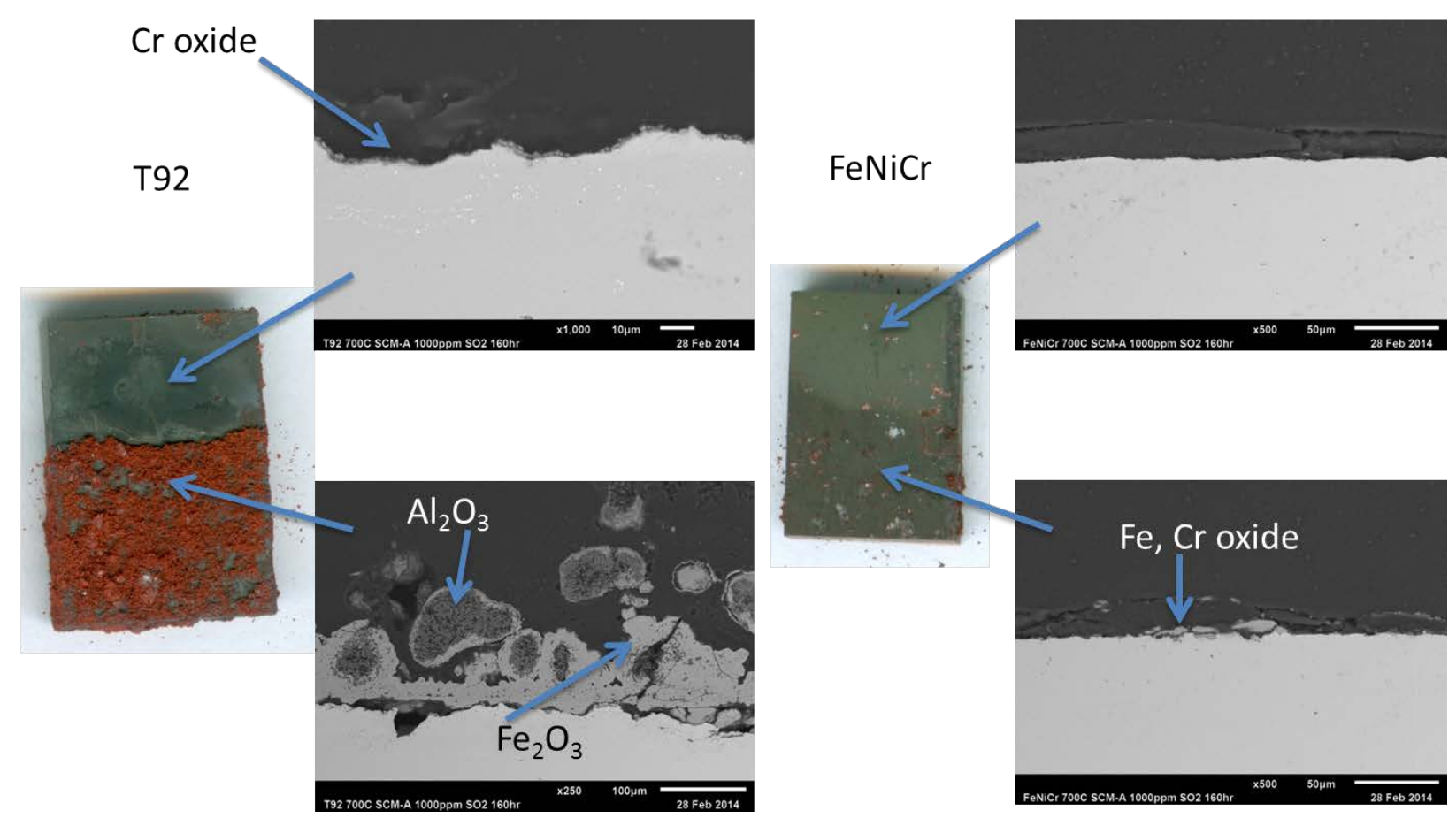

Figure 72: Cross-sectional micrographs of $\mathrm{T} 92$ and FeNiCr exposed at $700^{\circ} \mathrm{C}$ with the SCM-A powder deposit in $\mathrm{O}_{2}+1000 \mathrm{ppm} \mathrm{SO} \mathrm{S}_{2}$ for 160 hours

Alumina in the deposit is reducing the amount of corrosion that occurs. Alumina is a neutral oxide and may undergo acidic or basic fluxing when reacting with alkali sulfates. The SCM already has iron oxide mixed in with the alkali sulfates, which as was shown in the mechanism 
section, pushes the melt basicity out of the solubility region where synergistic dissolution can occur at a maximum rate. The addition of alumina to the SCM may further shift the melt basicity out of the region where synergistic dissolution can occur at a rapid rate. Because alumina is a neutral oxide and may undergo acidic or basic fluxing when reacting with alkali sulfates, it may react in a basic manner in this case, shifting melt basicity even further away from the maximum synergistic zone. The cycle between acidic and basic fluxing does not occur as rapidly due to the local increase in basicity of the melt. The corrosion mechanism would still be the same as described in the Mechanism Study sections, however the synergistic fluxing rate is slowed down even more compared to the SCM.

The $(\mathrm{Na}, \mathrm{K})_{2} \mathrm{SO}_{4}-\mathrm{Fe}_{2}\left(\mathrm{SO}_{4}\right)_{3}$ liquid solution may not be the only liquid that is forming and causing the fluxing that is occurring. The alumina in the deposit may react with alkali sulfates in the deposit and $\mathrm{SO}_{3}$ in the gas atmosphere to form alkali aluminum trisulfates via the reaction in equation 50.

$$
3 \mathrm{~K}_{2} \mathrm{SO}_{4}+\mathrm{Al}_{2} \mathrm{O}_{3}+3 \mathrm{SO}_{3}=2 \mathrm{~K}_{3} \mathrm{Al}\left(\mathrm{SO}_{4}\right)_{3}
$$

X-ray diffraction of the corrosion products confirmed that $\mathrm{K}_{3} \mathrm{Al}\left(\mathrm{SO}_{4}\right)_{3}$ was present. Alkali aluminum trisulfate has a melting point of $654^{\circ} \mathrm{C}$, and would be molten at the temperature of interest. The liquid alkali aluminum trisulfates would form in the deposit and not at the expense of a thermally grown iron oxide scale as occurs with the SCM deposit.

\subsubsection{2 $\mathrm{M1}+\mathrm{Al}_{2} \mathrm{O}_{3}(\mathrm{M1}-\mathrm{A})$}

The M1 deposit was also used as a base deposit for additional deposit composition studies. Thirty molar percent alumina was added to the M1 deposit, M1-A. T92 and FeNiCr were exposed at $700^{\circ} \mathrm{C}$ in $\mathrm{O}_{2}+1000 \mathrm{ppm} \mathrm{SO}_{2}$ for 160 hours in this deposit. The macroscopic results are shown in Figure 73. 


\section{T92 \\ $\mathrm{FeNiCr}$}

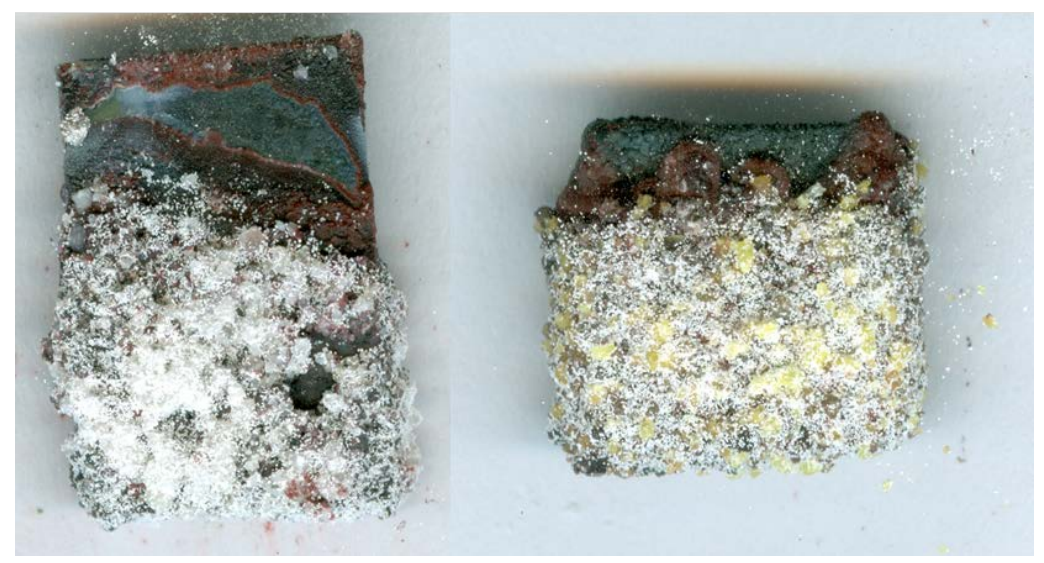

Figure 73: Macroscopic images of T92 and FeNiCr exposed at $700^{\circ} \mathrm{C}$ with the M1-A powder in $\mathrm{O}_{2}+1000 \mathrm{ppm}$ $\mathrm{SO}_{2}$ for 160 hours

Microscopic cross-sectional SEM images are presented in Figure 74. The corrosion products were very similar to what was seen with the SCM-A. Thick, porous, external iron oxide scales grew over top of corrosion pits rich in $\mathrm{Cr}, \mathrm{S}$, and $\mathrm{O}$ with a $\mathrm{Cr}$ and $\mathrm{S}$ rich layer at the base. Alumina from the deposit can be seen mixed in along with remaining alkali sulfates with the porous external iron oxide scale. 


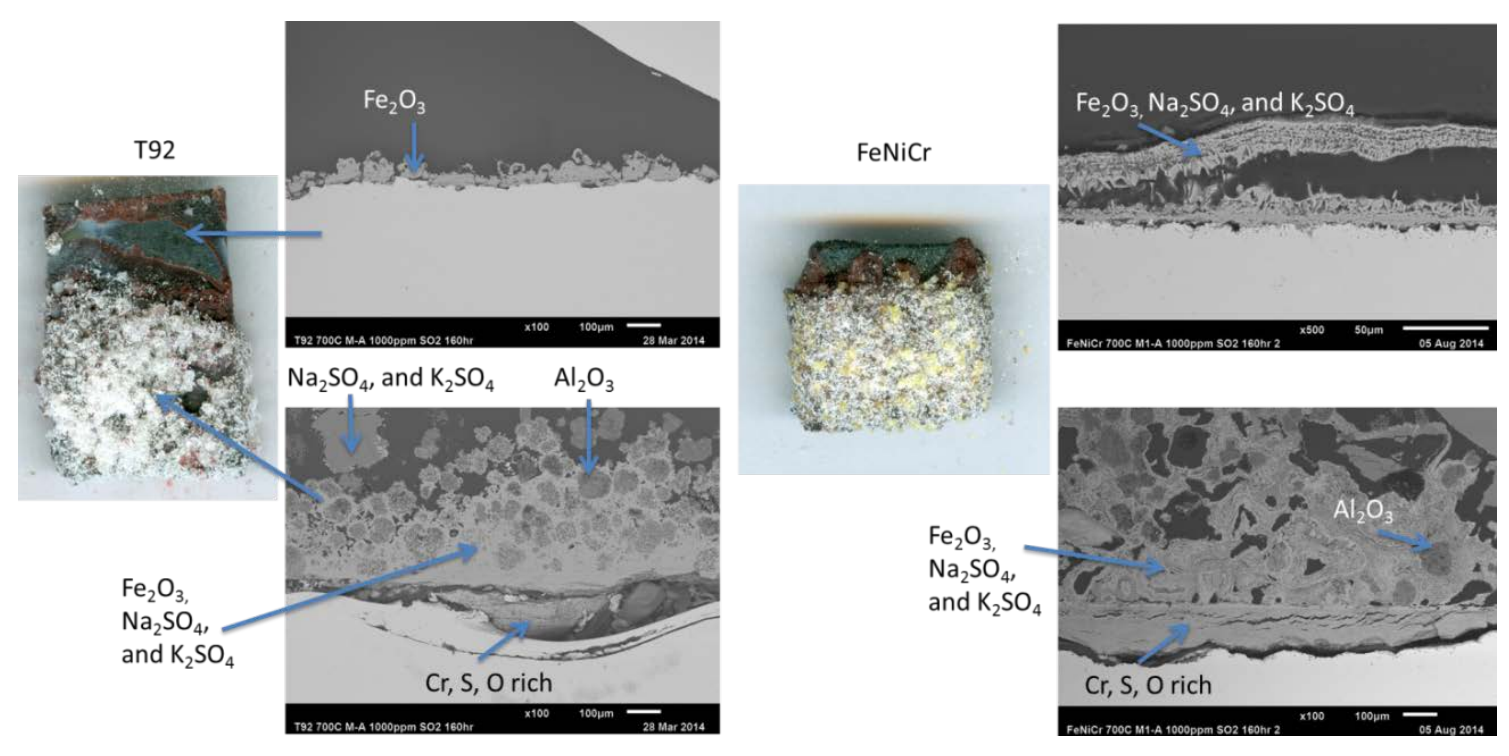

Figure 74: Cross-sectional micrographs of $\mathrm{T} 92$ and $\mathrm{FeNiCr}$ exposed at $700^{\circ} \mathrm{C}$ with the M1-A powder deposit in $\mathrm{O}_{2}+1000 \mathrm{ppm} \mathrm{SO} \mathrm{S}_{2}$ for 160 hours

The extent of the corrosion is presented in the metal loss plots back in Figures 69 and 70. T92 had more metal loss than the model austenitic alloy. Once again, this is likely due to a lower chromium content. There is less corrosion for the M1-A deposit than the M1 deposit, and a comparable amount to the SCM. The addition of alumina to the alkali sulfates (M1-A) had a similar effect as the addition of $\mathrm{Fe}_{2} \mathrm{O}_{3}(\mathrm{SCM})$. As was stated in the previous section, alumina is a neutral oxide that can undergo basic or acidic fluxing when reacting with alkali sulfates. Alumina is likely increasing the local melt basicity so that it is no longer in the zone where the maximum amount of corrosion can occur, similar to what occurred with the SCM-A deposit with the additions of $\mathrm{Fe}_{2} \mathrm{O}_{3}$ and $\mathrm{Al}_{2} \mathrm{O}_{3}$. The cycle between acidic and basic fluxing that occurs with synergistic dissolution takes longer due to the change in the basicity. The rate of synergistic dissolution is decreased, however a significant amount of corrosion is still occurring. As was the case with the SCM-A deposit, liquid alkali aluminum trisulfates may be forming in the deposit as well. 


\subsubsection{Calcia Additions}

\subsubsection{SCM + CaO (SCM-C)}

Calcia (along with $\mathrm{SiO}_{2}$ and $\mathrm{Al}_{2} \mathrm{O}_{3}$ ), is present in large amounts in western United States coals. Western coals are typically described as those for which the $\mathrm{CaO}+\mathrm{MgO}$ content exceeds the $\mathrm{Fe}_{2} \mathrm{O}_{3}$ content of the ash. Thirty percent calcia was added to the SCM in order to examine its effects on the amount of corrosion that occurs. This simulates the ash that would occur when burning western coals. This deposit was called SCM-C and it was used in exposing T92 and FeNiCr at $700^{\circ} \mathrm{C}$ in $\mathrm{O}_{2}+1000 \mathrm{ppm} \mathrm{SO}_{2}$ for 160 hours. The macroscopic results are shown in Figure 75. (Remaining deposit can be seen on the material, which could be brushed away revealing minimal degradation.)

T92

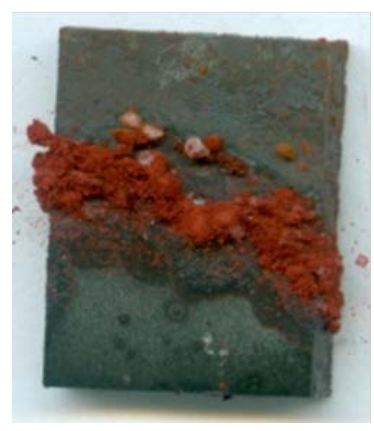

$\mathrm{FeNiCr}$

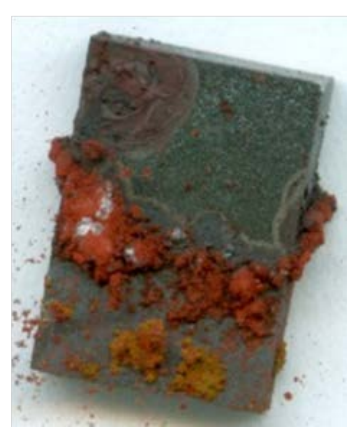

Figure 75: Macroscopic images of T92 and FeNiCr exposed at $700^{\circ} \mathrm{C}$ with SCM-C powder deposit in $\mathrm{O}_{2}+$ $1000 \mathrm{ppm} \mathrm{SO}_{2}$ for 160 hours

The metal loss plots in Figures 69 and 70 show that there is a further decrease in the amount of corrosion when $\mathrm{CaO}$ is added to the deposit compared to SCM-A (there was some degradation of the FeNiCr alloy with the SCM-C deposit and not the SCM-A deposit, but it was 
still a small amount). Microscopic cross-sectional images are shown in Figure 76. There was corrosion in the thin deposit zone for both alloys. It was noticed previously that corrosion starts in the thin deposit zone works its way down into the thick deposit zone with time. This will be examined in more detail in a subsequent section. The corrosion products were similar to those that occurred for the SCM. Thick, porous, iron oxide scales grow around remaining deposit material and over top of internal corrosion pits rich in $\mathrm{Cr}$, S, and $\mathrm{O}$. The sulfur content increases with depth into the pits until a sulfide layer forms at the base along with some internal sulfidation. The degradation is less for the model austenitic alloy, most likely due to the increased amount of chromium. In the thick deposit zone, thick iron rich oxide scales grew on the surface.

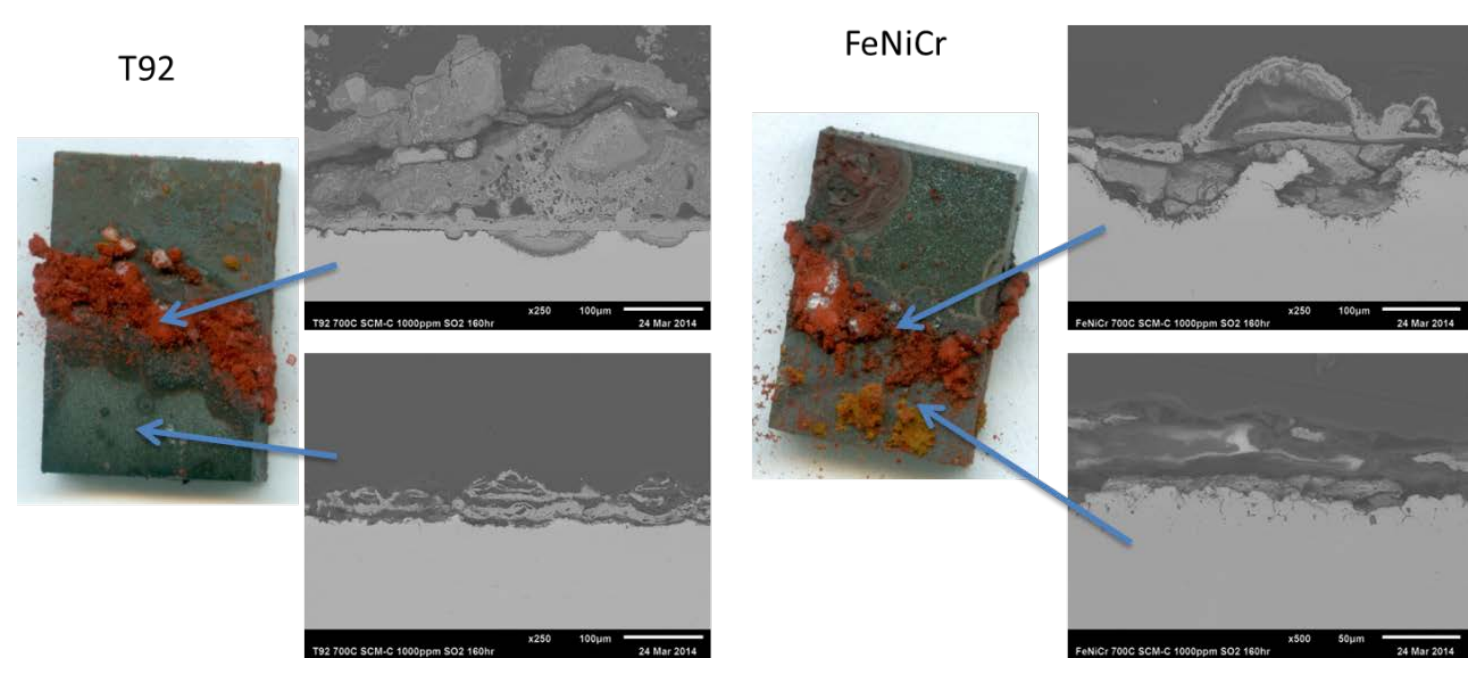

Figure 76: Microscopic cross-sectional images of $\mathrm{T} 92$ and $\mathrm{FeNiCr}$ exposed at $700^{\circ} \mathrm{C}$ with $\mathrm{SCM}-\mathrm{C}$ powder in $\mathrm{O}_{2}+1000 \mathrm{ppm} \mathrm{SO} \mathrm{S}_{2}$ for 160 hours

Calcia is a highly basic oxide and its addition along with the iron oxide addition to the alkali sulfates in the SCM would make the melt highly basic and therefore much less corrosive. 
Synergistic fluxing is significantly slowed down due to the localized increase in basicity of the melt. Calcia is more basic than alumina, so the effects are even greater. The SCM-C deposit is also likely less corrosive than the SCM and even the SCM-A deposit, because calcia can react with $\mathrm{SO}_{3}$ in the gas to form $\mathrm{CaSO}_{4}$, and this can further react with alkali sulfates in the deposit to form $\mathrm{K}_{2} \mathrm{Ca}_{2}\left(\mathrm{SO}_{4}\right)_{3}$, which has a melting point of $875^{\circ} \mathrm{C}$. It will not be liquid at the temperature range of interest and therefore not corrosive. The $\mathrm{CaSO}_{4}$ ties up alkali sulfates making less available to form the $(\mathrm{Na}, \mathrm{K})_{2} \mathrm{SO}_{4}-\mathrm{Fe}_{2}\left(\mathrm{SO}_{4}\right)_{3}$ liquid and causing corrosion.[15] It also locally ties up $\mathrm{SO}_{3}$ and possibly increasing the local basicity of the melt. X-ray diffraction scans of the powder corrosion products were able to identify $\mathrm{CaSO}_{4}$ and $\mathrm{K}_{2} \mathrm{Ca}_{2}\left(\mathrm{SO}_{4}\right)_{3}$.

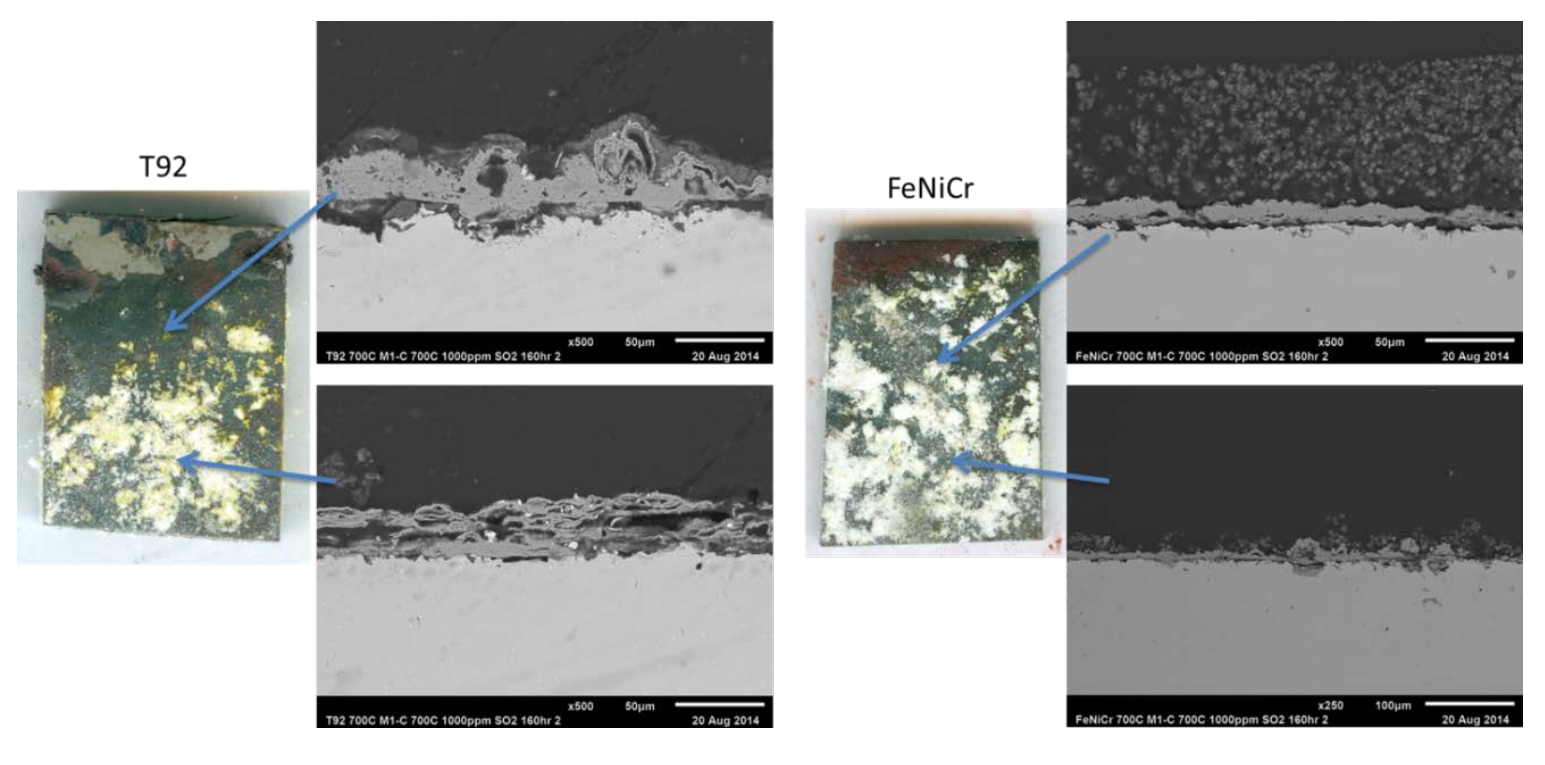

Figure 77: Microscopic cross-sectional images of $\mathrm{T} 92$ and $\mathrm{FeNiCr}$ exposed at $700^{\circ} \mathrm{C}$ with $\mathrm{M1}-\mathrm{C}$ powder in $\mathrm{O}_{2}$ $+1000 \mathrm{ppm} \mathrm{SO}_{2}$ for 160 hours 


\subsubsection{M1 + $\mathrm{CaO}(\mathrm{M} 1-\mathrm{C})$}

Thirty molar percent calcia was added to the M1 deposit and this was called M1-C. T92 and $\mathrm{FeNiCr}$ alloys were exposed with this deposit at $700^{\circ} \mathrm{C}$ in $\mathrm{O}_{2}+1000 \mathrm{ppm}^{\mathrm{SO}} \mathrm{O}_{2}$ for 160 hours. The macroscopic and microscopic cross-sectional SEM results are given in Figure 77. The corrosion products are similar to what was seen in previous deposits. For T92 in the thin deposit zone, thick, porous, external iron oxide scales grew mixed in with remaining deposit over top of internal corrosion pits rich in $\mathrm{Cr}, \mathrm{S}, \mathrm{O}$ with internal sulfides at the base. In the thick deposit zone, thick iron oxide scales grew on the surface. Remaining $\mathrm{CaO}$ and alkali sulfates from the deposit can be seen above and mixed in with the thermally grown oxide scale. For FeNiCr, thick iron oxide scales grew on the surface, with remaining $\mathrm{CaO}$ from the deposit above it. Again, the degradation was not as severe as the T92 alloy. The metal loss plot back in Figure 70 shows that the addition of calcia severely decreases the amount of corrosion from the M1 deposit and the M1-A deposit. The addition of basic $\mathrm{CaO}$ to the alkali sulfates in the $\mathrm{M} 1$ deposit increases the local melt basicity so much that the synergistic dissolution and the corrosion rate are minimized greatly, as was explained in the SCM-C section.

\subsubsection{Silica Additions}

\subsubsection{1 $\mathrm{SCM}+\mathrm{SiO}_{2}(\mathrm{SCM}-\mathrm{S})$}

Silica is also found in large quantities in the ash that forms when burning coals from all over the United States. Thirty percent $\mathrm{SiO}_{2}$ was added to the SCM , SCM-S, and the spinel and chromia-forming alloys T92 and model FeNiCr were exposed with this deposit powder at $700^{\circ} \mathrm{C}$ in $\mathrm{O}_{2}+1000 \mathrm{ppm} \mathrm{SO}$ for 160 hours. The macroscopic results are shown in Figure 78 . 


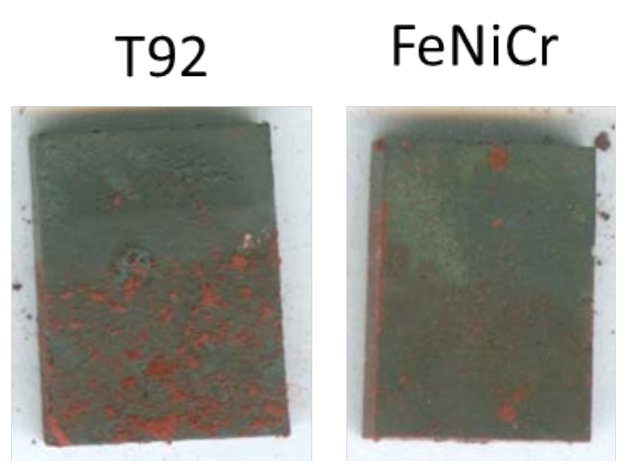

Figure 78: Macroscopic images of T92 and FeNiCr exposed at $700^{\circ} \mathrm{C}$ with SCM-S powder in $\mathrm{O}_{2}+1000 \mathrm{ppm}$ $\mathrm{SO}_{2}$ for 160 hours

There is significantly less weight change and metal loss when using this deposit as essentially no corrosion occurs for either alloy. Microscopic cross-sectional images are shown in Figure 79. For both alloys in the deposit zone, some deposit materials could be seen still on the surface, but below the remaining deposit thin chromium rich oxide scales grew. There was no internal pitting, but there was some internal sulfidation. 

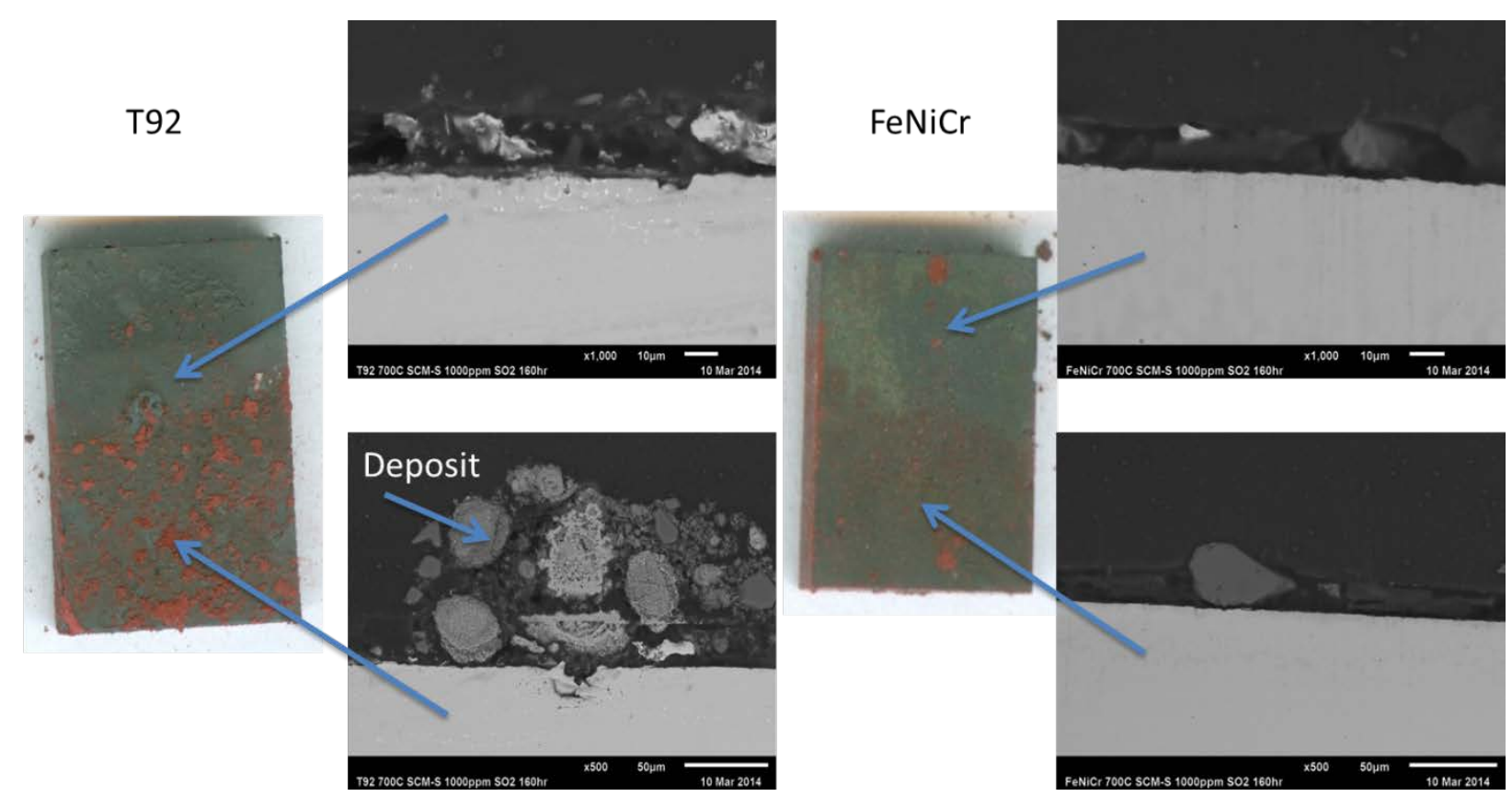

Figure 79: Microscopic cross-sectional images of $\mathrm{T} 92$ and $\mathrm{FeNiCr}$ exposed at $700^{\circ} \mathrm{C}$ with $\mathrm{SCM}-\mathrm{S}$ powder in $\mathrm{O}_{2}+1000 \mathrm{ppm} \mathrm{SO}_{2}$ for 160 hours

Silica is a highly acidic oxide that undergoes basic dissolution when reacting with alkali sulfates. The dissolution of silica in liquid sodium sulfate melts can be described by the reaction in equation 51.

$$
2 \mathrm{SiO}_{2}+\mathrm{Na}_{2} \mathrm{O}=\mathrm{Na}_{2} \mathrm{Si}_{2} \mathrm{O}_{5}
$$

Jacobson[86] calculated the minimum $\mathrm{Na}_{2} \mathrm{O}$ activity and maximum $\mathrm{P}_{\text {so3 }}$ in order to form $\mathrm{Na}_{2} \mathrm{Si}_{2} \mathrm{O}_{5}$ and cause dissolution of $\mathrm{SiO}_{2}$ from $900-1200^{\circ} \mathrm{C}$. This is shown in Table 11. 
Table 11: Minimum $\mathrm{Na}_{2} \mathrm{O}$ activities and maximum $\mathrm{p}_{\text {so3 }}$ partial pressures for $\mathrm{SiO}_{2}$ dissolution [86]

\begin{tabular}{rccc}
\hline$T$ & & & \\
$\left({ }^{\circ} \mathrm{C}\right)$ & $\mathrm{a}\left(\mathrm{Na}_{2} \mathrm{O}\right)$ & $\mathrm{P}_{\mathrm{SO}_{3}}$ & $\mathrm{P}_{\mathrm{SO}_{2}}$ \\
\hline 900 & $2.0 \times 10^{-11}$ & $3.4 \times 10^{-7}$ & $1.0 \times 10^{-6}$ \\
1000 & $9.2 \times 10^{-11}$ & $4.9 \times 10^{-6}$ & $3.2 \times 10^{-5}$ \\
1100 & $3.6 \times 10^{-10}$ & $4.9 \times 10^{-5}$ & $6.1 \times 10^{-4}$ \\
1200 & $1.4 \times 10^{-9}$ & $3.6 \times 10^{-4}$ & $7.8 \times 10^{-3}$ \\
\hline
\end{tabular}

${ }^{a} \mathrm{SiO}_{2}, \mathrm{Na}_{2} \mathrm{Si}_{2} \mathrm{O}_{5}, \mathrm{O}_{2}$ taken as unit activity.

The minimum $\mathrm{Na}_{2} \mathrm{O}$ activity and the maximum $\mathrm{psoz}_{\text {soz }}$ decreases as the temperature decreases. There is no data for $700^{\circ} \mathrm{C}$, but if this trend is continued, the relatively high $\mathrm{SO}_{3}$ partial pressures of $1.76 \times 10^{-4}$ atm used in this study and low calculated $\mathrm{Na}_{2} \mathrm{O}$ activity at $700^{\circ} \mathrm{C}$ of $1.82 \times 10^{-20}$ may actually prevent the dissolution of silica. The formed $\mathrm{Na}_{2} \mathrm{Si}_{2} \mathrm{O}_{5}$ has a melting point of $874^{\circ} \mathrm{C}$, and would remain solid and be non-reactive at the temperature of interest for this study. The data by Jacobson is for temperatures above the melting point of $\mathrm{Na}_{2} \mathrm{SO}_{4}\left(884^{\circ} \mathrm{C}\right)$ and $\mathrm{Na}_{2} \mathrm{Si}_{2} \mathrm{O}_{5}$ and may not be accurate in describing the dissolution at $700^{\circ} \mathrm{C}$ in ternary melts. Leblanc and Rapp[84] measured the solubility of $\mathrm{SiO}_{2}$ in $\mathrm{Na}_{2} \mathrm{SO}_{4}-\mathrm{K}_{2} \mathrm{SO}_{4}-\mathrm{Fe}_{2} \mathrm{SO}_{4}$ melts at $963 \mathrm{~K}$. They observed that there was no apparent dependence of the measured solubilities on Pso3, which indicates that the dissolution of $\mathrm{SiO}_{2}$ in ternary melts at temperatures around $700^{\circ} \mathrm{C}$ takes place by molecular dissolution without a chemical reaction. The solubility was also about three times higher than that found by Rapp in Figure 24. This can be seen in Figure 80 below. The solubility measurements compared were obtained by two different techniques (atomic absorption and colorimetric absorption). 
An increase in the solubility of molecular species in aqueous solution with decreasing temperature is observed, therefore, silica dissolving as a molecular species in the salt could behave in the same way.[84]

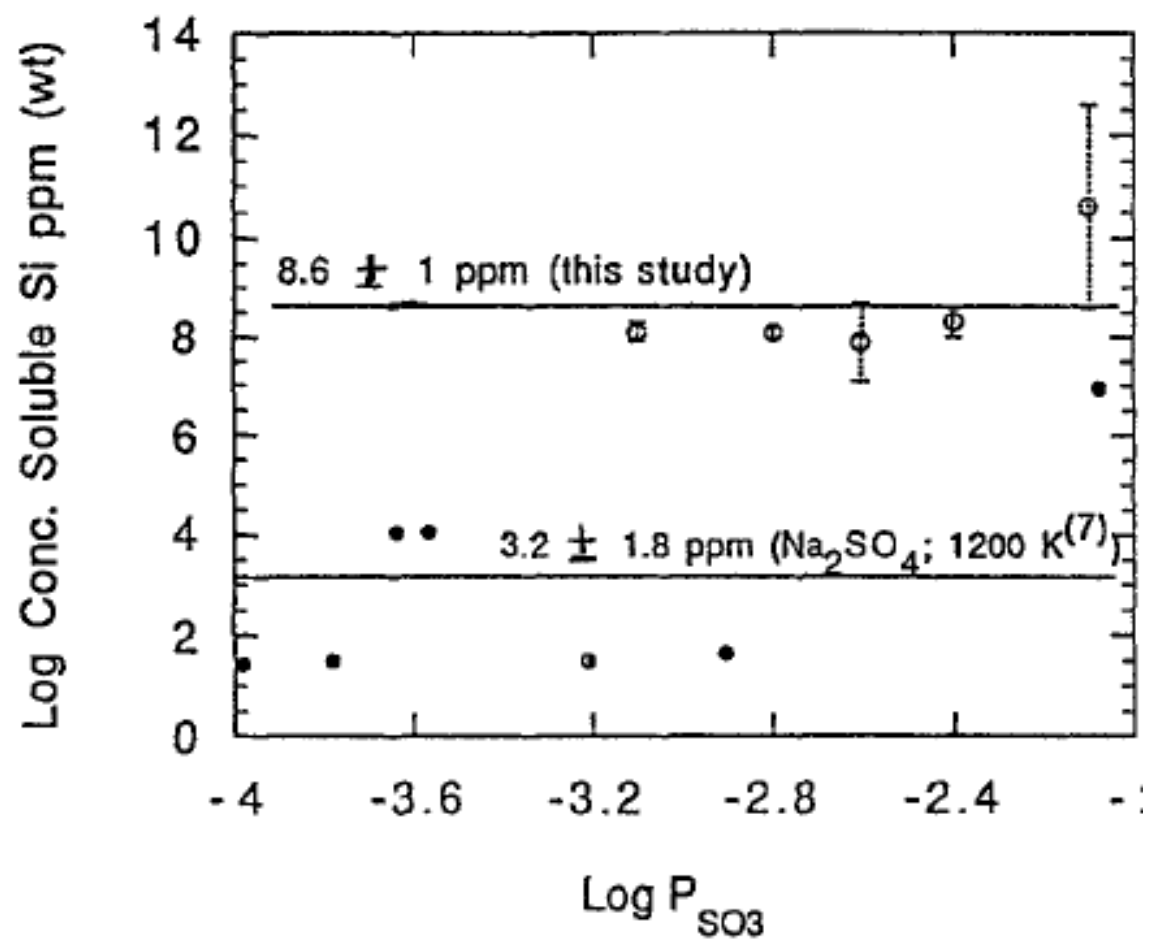

Figure 80: Solubility of $\mathrm{SiO}_{2}$ in sulfate melts [84]

The solubility curve for silica in Figure 24 is a straight line, and it is well below the curves for iron oxide and chromium oxide. The curve will never cross paths with the other oxides and therefore synergistic dissolution is not possible with silica. Silica would also increase the localized acidity of the melt so much that synergistic dissolution does not occur. The lack of corrosion supports this. 
When acidic $\mathrm{Cr}_{2} \mathrm{O}_{3}$ was added to the $\mathrm{M} 1$ deposit, the corrosion rate was significantly decreased as well. It appears there is a greater impact on the corrosion rate and the amount of degradation when the melt becomes more acidic, than when it becomes more basic.

Silica may be reacting to form the higher melting $\mathrm{Na}_{2} \mathrm{Si}_{2} \mathrm{O}_{5}$. The formation of higher melting compounds is reducing the amount of alkali sulfates available to form the liquid solution and allow corrosion to occur. X-ray diffraction scans of the exposed deposit corrosion products were unable to specifically identify $\mathrm{Na}_{2} \mathrm{Si}_{2} \mathrm{O}_{5}$, however unidentified peaks are likely a complex compound containing Si, Na, K, S, and/or O. This may be an amorphous structure and unidentifiable with X-ray diffraction. Previous studies by Niles and Sigmund[81] tested kaolin $\left(\mathrm{Al}_{2} \mathrm{O}_{3} \cdot 2 \mathrm{SiO}_{2}\right)$ as an additive to deposits and they found that it is effective in reacting with sodium sulfate. They described it as the alumina and silica inhibiting the corrosion by absorbing the corrosive molten sulfates. The results of the tests from this study support this.

\subsubsection{2 $\mathrm{M1}+\mathrm{SiO}_{2}(\mathrm{M} 1-\mathrm{S})$}

Thirty molar percent $\mathrm{SiO}_{2}$ was also added to the M1 deposit, M1-S. T92 and FeNiCr were exposed at $700^{\circ} \mathrm{C}$ in $\mathrm{O}_{2}+1000 \mathrm{ppm} \mathrm{SO}_{2}$ for 160 hours in this deposit. The extent of the corrosion is shown in the metal loss plots in Figure 70. Macroscopic photos and microscopic cross-sectional SEM images are presented in Figure 81. 

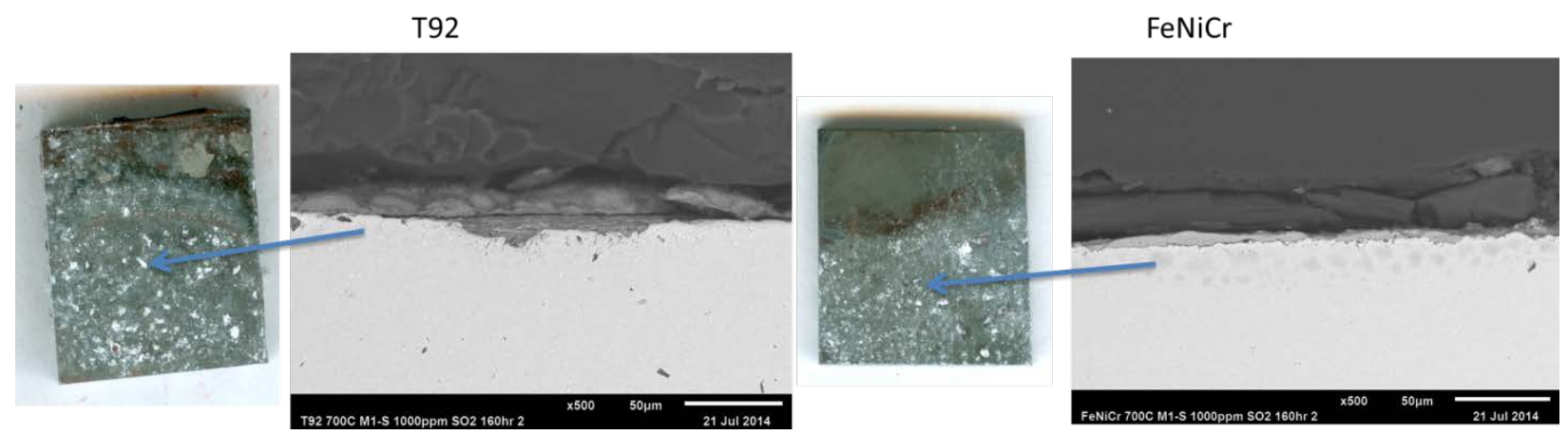

Figure 81: Microscopic cross-sectional images of $\mathrm{T} 92$ and $\mathrm{FeNiCr}$ exposed at $700^{\circ} \mathrm{C}$ with M1-S powder in $\mathrm{O}_{2}$ $+1000 \mathrm{ppm} \mathrm{SO}_{2}$ for 160 hours

For both alloys, thin Fe and Cr-rich oxide scales grew on the surface. There was some internal sulfidation, but there was significantly less corrosion compared to the M1 deposit when $\mathrm{SiO}_{2}$ is added. Synergistic dissolution is essentially stopped. Silica is a highly acidic oxide and it most likely increased the acidity of the melt, and the solubility curve is below the solubility curves for iron oxide and chromium oxide, and therefore out of the synergistic dissolution region. Silica would also react similarly to what occurred with the SCM-S deposit in which the $\mathrm{SiO}_{2}$ takes $\mathrm{Na}_{2} \mathrm{O}$ from the alkali sulfates to create the relatively non-corrosive $\mathrm{Na}_{2} \mathrm{Si}_{2} \mathrm{O}_{5}$. There is therefore less alkali sulfate available to form the corrosive liquid salt.

\subsubsection{Coal Ash}

Tables 2-4 list the components and the compositions of typical coal ash from Eastern and Western U.S. coals. There are significant amounts of alumina, silica, iron oxide, and in the case of western coals, calcium and magnesium oxide. The previous sections were a mechanistic study to determine the effects of each of these additions to the corrosive alkali sulfates in the coal ash. When all of these oxides are added together to alkali sulfates in the coal ash, the corrosion rate 
may change significantly. Each of the oxide additions will change the local melt basicity so that synergistic dissolution will be significantly reduced. Oxides such as $\mathrm{CaO}$ or $\mathrm{SiO}_{2}$ will also react with alkali sulfates in the deposit to form higher melting point compounds that will not be corrosive at the temperature range of interest. They will tie-up alkali sulfates from forming lower melting corrosive species. FeNiCr and $\mathrm{T} 92$ were exposed at $700^{\circ} \mathrm{C}$ to a deposit containing $30 \% \mathrm{Fe}_{2} \mathrm{O}_{3}-30 \% \mathrm{Al}_{2} \mathrm{O}_{3}-30 \% \mathrm{SiO}_{2}-5 \% \mathrm{Na}_{2} \mathrm{SO}_{4}-5 \% \mathrm{~K}_{2} \mathrm{SO}_{4}$ (Deposit D) in $\mathrm{O}_{2}+1000 \mathrm{ppm} \mathrm{SO}_{2}$ for 160 hours. There was negligible corrosion, as very thin protective oxide scales grew on the surface of the deposit zone. This can be seen in the results in Figure 82. There were some areas of internal sulfidation, but these areas were small. Large amounts of $\mathrm{Fe}_{2} \mathrm{O}_{3}, \mathrm{Al}_{2} \mathrm{O}_{3}$, and $\mathrm{SiO}_{2}$ as well as decreased amounts of alkali sulfates have stopped the corrosion mechanism from occurring. Synergistic fluxing is likely stopped due to changes in the local melt basicity from the various oxide additions. $\mathrm{SiO}_{2}$ is also likely tying up the already reduced amounts of alkali sulfates to form higher melting compounds as described earlier. The acidity and basicity of the localized melt due to all of the oxide additions would need to be studied in more detail. The tests performed for this study are short-term tests studying the corrosion mechanisms. Long-term corrosion tests could be used to study the effects of all of these oxides on the mechanism of corrosion and the amount of degradation. 

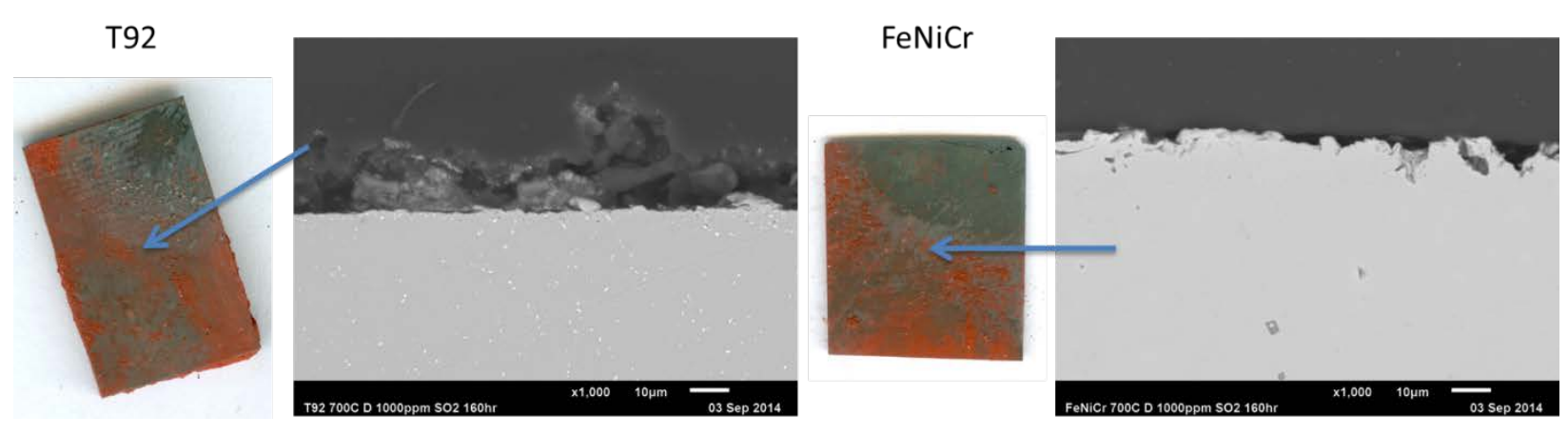

Figure 82: Macroscopic and microscopic SEM images of T92 and FeNiCr exposed at $700^{\circ} \mathrm{C}$ with the Deposit $D$ powder in $\mathrm{O}_{2}+1000 \mathrm{ppm} \mathrm{SO}_{2}$ for 160 hours

\subsection{GAS ATMOSPHERE EFFECT}

\subsection{1 $\mathrm{SO}_{2}$ Concentration Effect}

The formation of a low melting solution between $(\mathrm{Na}, \mathrm{K})_{2} \mathrm{SO}_{4}$ and $\mathrm{Fe}_{2}\left(\mathrm{SO}_{4}\right)_{3}$ and the corrosion mechanism that occurs is due to $\mathrm{SO}_{3}$ in the gas atmosphere. The amount of $\mathrm{SO}_{3}$ that can form is highly dependent on the amount of $\mathrm{SO}_{2}$ and $\mathrm{O}_{2}$ in the atmosphere as well as the temperature. $\mathrm{SO}_{2}$ reacts with oxygen to form $\mathrm{SO}_{3}$ via the reaction given in equation 4 . The higher the amounts of oxygen and $\mathrm{SO}_{2}$ there are in the gas atmosphere, the more $\mathrm{SO}_{3}$ that can form. In order for the equilibrium amount of $\mathrm{SO}_{3}$ to form, a catalyst is needed. $\mathrm{Fe}_{2} \mathrm{O}_{3}$ and platinum, which was used in this study, have been shown to be effective catalysts for producing $\mathrm{SO}_{3}$. The temperature is also a large factor in the amount of $\mathrm{SO}_{3}$ that can form and therefore the maximum amount of corrosion that occurs. $\mathrm{SO}_{3}$ is the dominant form of the gas at lower temperatures; however at higher temperatures, the reaction in equation 4 shifts the other direction and $\mathrm{SO}_{2}$ is the more dominant form of the gas as $\mathrm{SO}_{3}$ is not able to form. The temperature effect on the amount of $\mathrm{SO}_{3}$ that can form and the amount of corrosion that occurs will be discussed in a future section. 
The amount of $\mathrm{SO}_{3}$ in the gas atmosphere needed to stabilize the low melting solution $\left(\mathrm{CoSO}_{4}\right.$ $\mathrm{Na}_{2} \mathrm{SO}_{4}$ ) in order for Type II hot corrosion of cobalt alloys to occur was found to be on the order of $10^{-5} \mathrm{~atm}$. At the temperature of interest, a threshold value of $\mathrm{SO}_{3}$ is needed to form melts and allow corrosion to occur. Shi et. al [41] studied the partial pressure of $\mathrm{SO}_{3}$ required to stabilize liquid solutions of $\mathrm{Na}_{2} \mathrm{SO}_{4}$-iron sulfates and $\mathrm{Na}_{2} \mathrm{SO}_{4}-\mathrm{K}_{2} \mathrm{SO}_{4}$-iron sulfates. The results were presented in Figure 16. Additions of a second salt $\left(\mathrm{K}_{2} \mathrm{SO}_{4}\right)$ to the $\mathrm{Na}_{2} \mathrm{SO}_{4}$ reduced the amount of $\mathrm{SO}_{3}$ needed to form the liquid solution. This can be tied back to the $\mathrm{K}_{2} \mathrm{SO}_{4}-\mathrm{Fe}_{2}\left(\mathrm{SO}_{4}\right)_{3}$ phase diagram shown in Figure 54. Having two salts $\left(\mathrm{Na}_{2} \mathrm{SO}_{4}\right.$ and $\left.\mathrm{K}_{2} \mathrm{SO}_{4}\right)$ reduces the amount of $\mathrm{Fe}_{2}\left(\mathrm{SO}_{4}\right)_{3}$ needed to form the liquid solution at $700^{\circ} \mathrm{C}$, and therefore less $\mathrm{SO}_{3}$ is needed to create sufficient $\mathrm{Fe}_{2}\left(\mathrm{SO}_{4}\right)_{3}$. According to their calculations, $\mathrm{p}_{\mathrm{so}} \approx 10^{-4} \mathrm{~atm}$ is needed in order to form the $\mathrm{Na}_{2} \mathrm{SO}_{4}-\mathrm{K}_{2} \mathrm{SO}_{4}$-iron sulfate liquid solution at $700^{\circ} \mathrm{C}$. This value decreases as temperature decreases and increases as the temperature increases. The amount of $\mathrm{SO}_{3}$ in the gas atmosphere therefore influences the corrosion mechanism by forming the liquid melt. Higher concentrations in the gas atmosphere will also make the melt more acidic and will reduce the dependence of the migration of $\mathrm{SO}_{3}$ through the liquid a limiting factor on the corrosion rate.

The effect of the amount of $\mathrm{SO}_{2}\left(\right.$ or $\left.\mathrm{SO}_{3}\right)$ in the gas atmosphere was studied by testing the model austenitic (FeNiCr) and T92 alloys at $700^{\circ} \mathrm{C}$ with the SCM powder in gas atmospheres containing $\mathrm{O}_{2}+$ varying amounts of $\mathrm{SO}_{2}(100,500,1000,2500 \mathrm{ppm})$. The equilibrium $\mathrm{SO}_{3}$ partial pressures were presented in Table 8. According to the study conducted by Shi[41] in Figure 16, liquid should form in all of the gas atmospheres tested at $700^{\circ} \mathrm{C}$ except for $100 \mathrm{ppm}$ $\mathrm{SO}_{2}$. The results from this study are presented in the metal loss plots in Figure 83. 

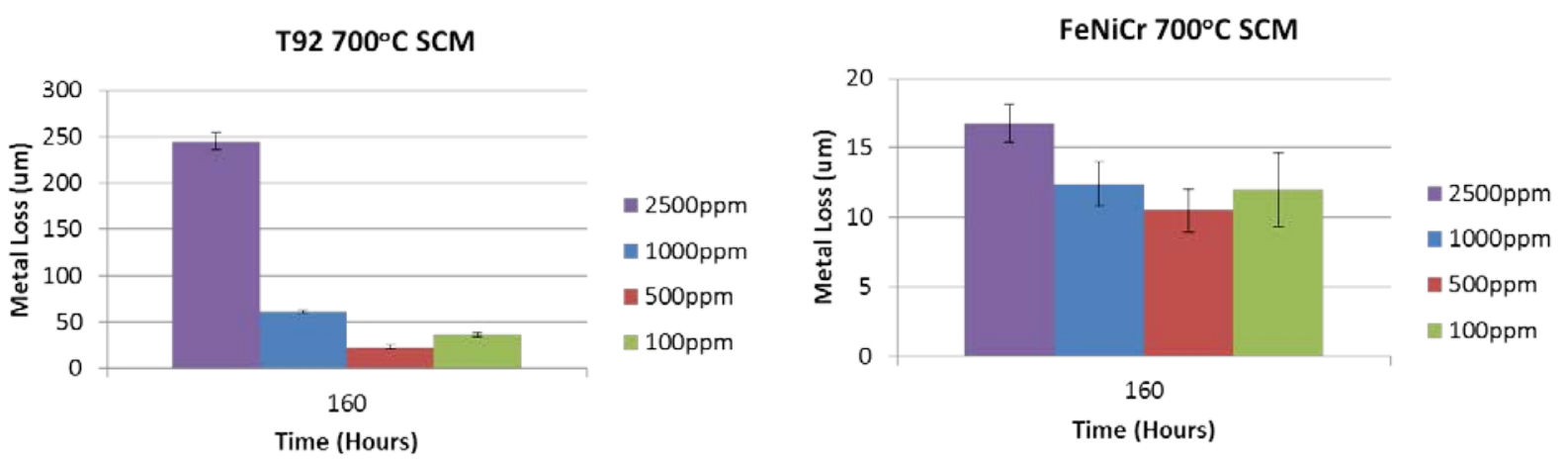

Figure 83: Metal loss of T92 and FeNiCr exposed at $700^{\circ} \mathrm{C}$ with the SCM powder deposit in crucibles as a function of the amount of $\mathrm{SO}_{2}$ in the gas atmosphere

Except for the very high psoz gas atmospheres, the degradation is independent of psoз. The rates are therefore controlled by the conditions at the oxide/salt interface established by synergisitic fluxing. Higher $\mathrm{SO}_{3}$ partial pressures accelerate the attack by inducing higher local oxygen partial pressures at the base of the pit since oxygen is transported in the melt by pyrosulfate ions. Higher $\mathrm{p}_{\mathrm{so}}$ increases the fluxing rate of $\mathrm{Fe}_{2} \mathrm{O}_{3}$ and $\mathrm{Cr}_{2} \mathrm{O}_{3}$ creating more metal loss. The equilibrium $\mathrm{SO}_{3}$ levels used in this study range from $10^{-5}-10^{-3} \mathrm{~atm}$. Kung[28-29,58] measured the average gas concentrations in the oxidizing zone for four different types of coals from a heavily instrumented pilot scale combustion facility. The concentrations can be seen in Table 6 . The concentrations in the flue gas from burning the four different coals ranged from 150$3000 \mathrm{ppm} \mathrm{SO}_{2}$ and 8-68ppm $\mathrm{SO}_{3}$. This range of $\mathrm{SO}_{2}$ is approximately the range of gas compositions used in this study, however the $\mathrm{SO}_{3}$ equilibrium values are around 1-8 $\times 10^{-5} \mathrm{~atm}$. This is on the low end of the $\mathrm{SO}_{3}$ gas atmospheres used in this study. This is due to the other additions in the flue gas $\left(\mathrm{CO}_{2}, \mathrm{H}_{2} \mathrm{O}, \mathrm{H}_{2} \mathrm{~S}\right.$ etc.), whereas the tests conducted for this study had a balance of oxygen only. The basicity of the melt was calculated with the equilibrium constant and tested $\mathrm{SO}_{3}$ partial pressures based on the acid-base relationship for $\mathrm{Na}_{2} \mathrm{SO}_{4}$ in equation 19 . 
The range of melt basicity from the various $\mathrm{SO}_{3}$ containing gas atmospheres is plotted with the solubility curves for $\mathrm{Fe}_{2} \mathrm{O}_{3}$ and $\mathrm{Cr}_{2} \mathrm{O}_{3}$ at $1200 \mathrm{~K}$ in Figure 84. Each of the gas atmospheres is within the range where synergistic fluxing should be possible (between the solubility minima for $\mathrm{Fe}_{2} \mathrm{O}_{3}$ and $\left.\mathrm{Cr}_{2} \mathrm{O}_{3}\right)$. The lower $\mathrm{SO}_{3}$ containing gas atmosphere $\left(10^{-5} \mathrm{~atm}\right)$ is on the border where synergistic fluxing is possible, however since degradation was observed, then it must be in a region where synergistic fluxing can occur. The solubility curves are not available at $700^{\circ} \mathrm{C}$, as was discussed in the mechanism study section. At the lower temperature, the curves will have shifted to the right and the tested gas atmospheres may fit better between the solubility minima.

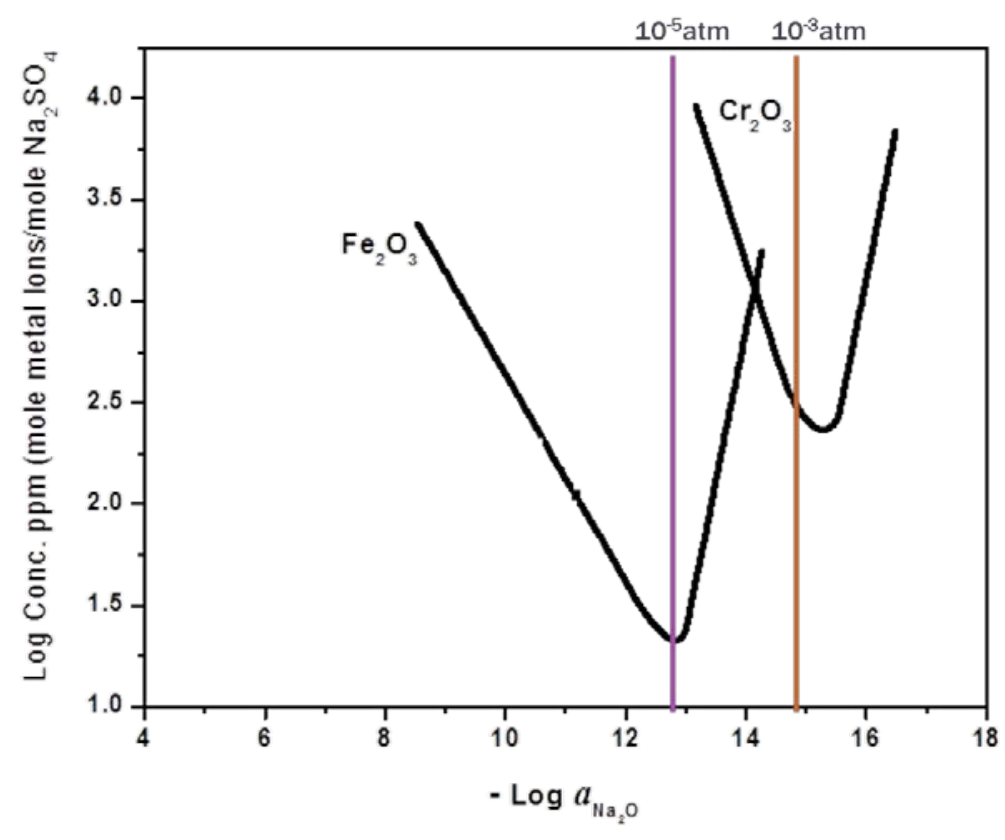

Figure 84: $\mathrm{SO}_{3}$ equilibrium partial pressures plotted on the solubility plot for $\mathrm{Fe}_{2} \mathrm{O}_{3}$ and $\mathrm{Cr}_{2} \mathrm{O}_{3}$

For both alloys, corrosion does occur in the lowest $\mathrm{SO}_{2}$ content tested $\left(\mathrm{O}_{2}+100 \mathrm{ppm}\right.$ $\mathrm{SO}_{2}$ ). It just takes longer with the $\mathrm{FeNiCr}$ alloy to occur (longer initiation stage). The equilibrium $\mathrm{SO}_{3}$ partial pressure at $700^{\circ} \mathrm{C}$ for this gas atmosphere is $7.16 \times 10^{-5}$ atm, which is 
slightly less than the approximate value of $10^{-4}$ atm found by Shi[41] to be needed for the formation of the liquid salt. The results suggest that the actual threshold value may be a little less than $10^{-4}$ atm and may be very close to the equilibrium value in $\mathrm{O}_{2}+100 \mathrm{ppm} \mathrm{SO}_{2}$. This is likely also a threshold value in which synergistic fluxing would be possible. T92 does not have sufficient $\mathrm{Cr}$ contents to be protective in most of the atmospheres tested and the initiation stage is significantly shorter and non-existent as the $\mathrm{SO}_{2}$ content increases. The FeNiCr alloy has a much longer initiation stage, most likely due to higher chromium content. After 160 hours, the propagation stage occurred in all of the gas atmospheres, and the trend of increasing $\mathrm{SO}_{2}$ content increasing the amount of degradation is clear. It should be noted that the 2500ppm $\mathrm{SO}_{2}$ results for FeNiCr are less than would be expected for that high $\mathrm{SO}_{2}$ content. This may be due to the fact that a new batch of $\mathrm{Fe}-12 \% \mathrm{Ni}-18 \% \mathrm{Cr}$ was used for these tests. The previous specimens of this model alloy came from an ingot that had been worked into a plate, while the tests in $\mathrm{O}_{2}+$ $2500 \mathrm{ppm} \mathrm{SO} \mathrm{S}_{2}$ were conducted with an unworked ingot that was triple arc melted and heat treated at $1100^{\circ} \mathrm{C}$ for 24 hours in argon. Even though the composition of the two batches of alloys was the same, the microstructures were different, and gave different results. 
Ingot

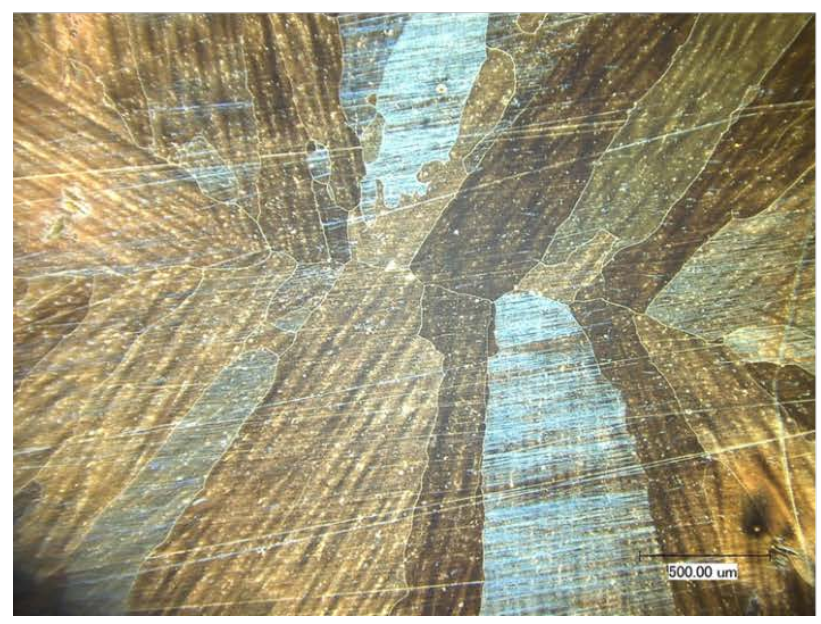

Plate

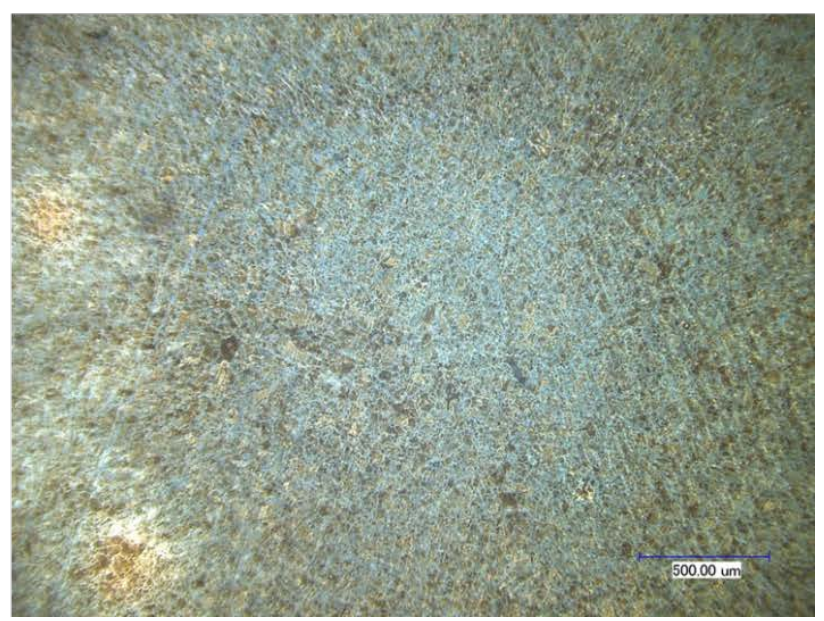

Figure 85: Microstructure of batches $\mathrm{FeNiCr}$ alloy that came from an ingot and a plate (same magnification)

Figure 85 shows the different microstructures of the two batches of the alloy (same magnification). The specimens that came from the ingot had large columnar grains, while the specimens that came from the plate had much smaller grains. The plate had been worked, and so it went through recrystallization and the grain size was much smaller. Typically a smaller grain size material would help with oxidation resistance, as a higher density of grain-boundary rapiddiffusion paths allows for protective $\mathrm{Cr}$ to reach the surface faster. However this was not the case for the fireside corrosion tests in this study. The specimens from the ingot with the large columnar grains had better corrosion resistance. Diffusion will be faster along the grain boundaries. A larger number of small size grains may not only help with providing protective $\mathrm{Cr}$ to the reaction surface, but it may be detrimental and providing faster diffusion and faster degradation when the protective scales have been compromised. 


\subsection{ALLOY COMPOSITION EFFECT}

The beneficial effect of chromium was observed and described in the Mechanism Study and Deposit Composition Effect sections. When exposed in the SCM at $700^{\circ} \mathrm{C}$, the model austenitic alloy $(18 \% \mathrm{Cr})$ had an initiation stage and took longer than 80 hours for corrosion to occur, while T92 essentially had no initiation stage and followed linear kinetics as significant amounts of degradation occurred in a short time period. Higher chromium contents increase fireside corrosion resistance with their ability to continuously form a protective $\mathrm{Cr}_{2} \mathrm{O}_{3}$ scale delaying the liquid from reaching the metal surface and producing the dissolution and fluxing mechanism described previously of the base metal.

\subsubsection{AFA M1 Results}

Alumina-forming austenitic (AFA) stainless steels offer a potential solution to maintain oxidation and corrosion resistance in these atmospheres while maintaining alloy strength and without significantly increasing the alloy cost. Alumina does not have the volatilization issues in a steam atmosphere that a chromia scale may have. Four alumina-forming austenitic alloys (OC4, OC8, OCS, and OCT) were tested. The compositions of these alloys are given in Table 8. The development of these alloys and the benefits and weaknesses of individual alloying elements were described in section 2.3.3.1 Alumina Forming Austenitic Stainless Steel Alloys and section 3.0 Research Objectives. The AFA alloys were tested using the M1 deposit in $\mathrm{O}_{2}+1000 \mathrm{ppm}$ $\mathrm{SO}_{2}$ for 20, 40, 80, and 160 hours. Macroscopic images of the results are presented in Figure 86 along with the results of the chromia-forming alloys for comparison. Each of the alloys was degraded at every test duration using the M1 deposit. Weight change and metal loss plots are 
shown in Figure 87. Significant degradation occurs even after 20 hours with this deposit. There was essentially no initiation stage as the weight change plot is linear and the metal loss increased very rapidly. There is a general trend of increasing degradation with time; however some of the alloys have more rapid degradation then others. This could just be some variability in the experiments. Once the liquid eutectic has formed and started synergistic fluxing of the base metal (propagation stage), the amount of degradation appears to be independent of alloy composition. Large amounts of corrosion and metal loss occurred for each of the alloys regardless of the $\mathrm{Cr}, \mathrm{Al}, \mathrm{Ni}$, or $\mathrm{Nb}$ contents. The OC4 alloy spalled. It is unknown why this is the only alloy that spalls, and more work would be needed to determine this.

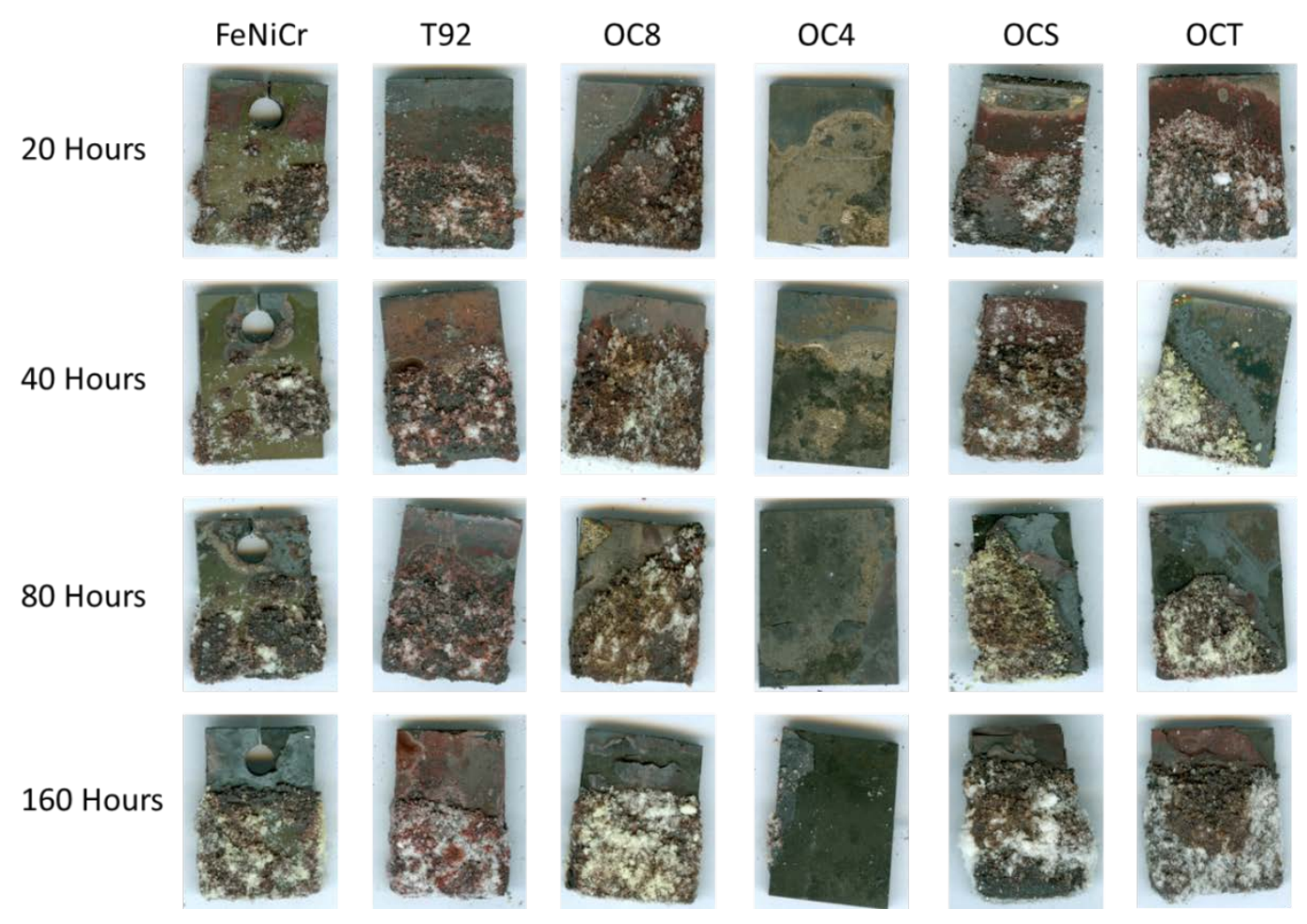

Figure 86: Macroscopic images of alloys exposed at $700^{\circ} \mathrm{C}$ in $\mathrm{M} 1$ deposit in $\mathrm{O}_{2}+1000 \mathrm{ppm} \mathrm{SO}_{2}$ 

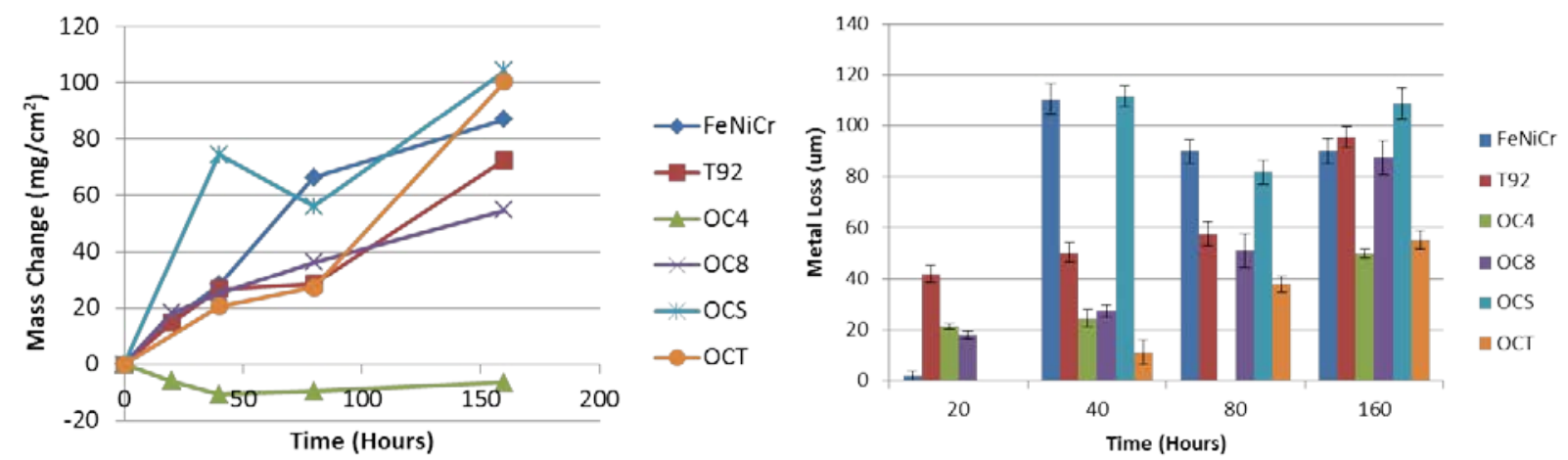

Figure 87: Kinetics and Metal Loss of alloys exposed at $700^{\circ} \mathrm{C}$ in the $\mathrm{M1}$ in $\mathrm{O}_{2}+1000 \mathrm{ppm} \mathrm{SO}_{2}$

The corrosion products for each of the AFA alloys when exposed with the M1 deposit were similar after each test duration. Sample results of the OC8 alloy are shown in Figure 88 below. Thick porous external iron oxide scales grew in and around the alkali sulfate deposit and over internal corrosion pits rich in $\mathrm{Cr}, \mathrm{Al}, \mathrm{Fe}, \mathrm{S}$, and $\mathrm{O}$, with a $\mathrm{Cr}$ and $\mathrm{Al}$ sulfide rich layer at the base of the pits. The internal corrosion pits formed the similar repeating layered structure of a $\mathrm{Cr}_{2} \mathrm{O}_{3}-\mathrm{Al}_{2} \mathrm{O}_{3}$ rich oxide layer and a layer rich in $\mathrm{Fe}, \mathrm{S}, \mathrm{Na}, \mathrm{K}$, and $\mathrm{O}$ (likely $(\mathrm{Na}, \mathrm{K})_{2} \mathrm{SO}_{4^{-}}$ $\left.\mathrm{Fe}_{2}\left(\mathrm{SO}_{4}\right)_{3}\right)$ that was seen and explained earlier in the mechanism sections for the fireside corrosion results for T92 and FeNiCr. 


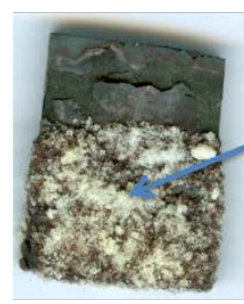

160 Hours
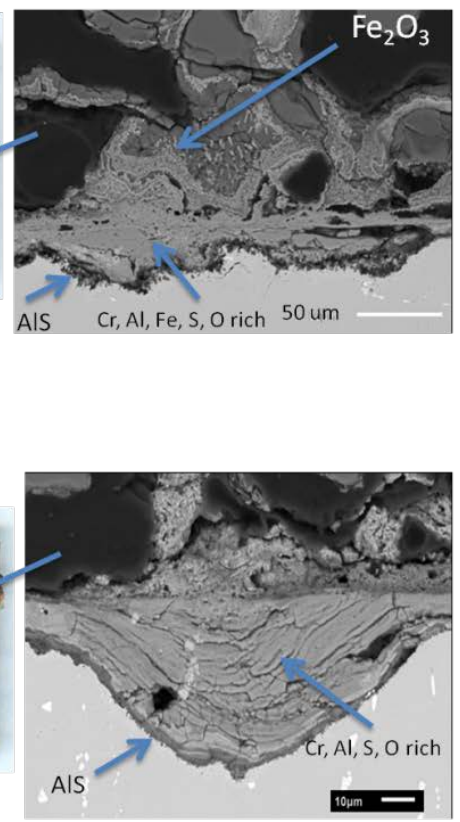

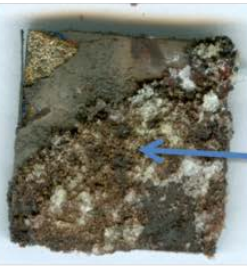

80 Hours
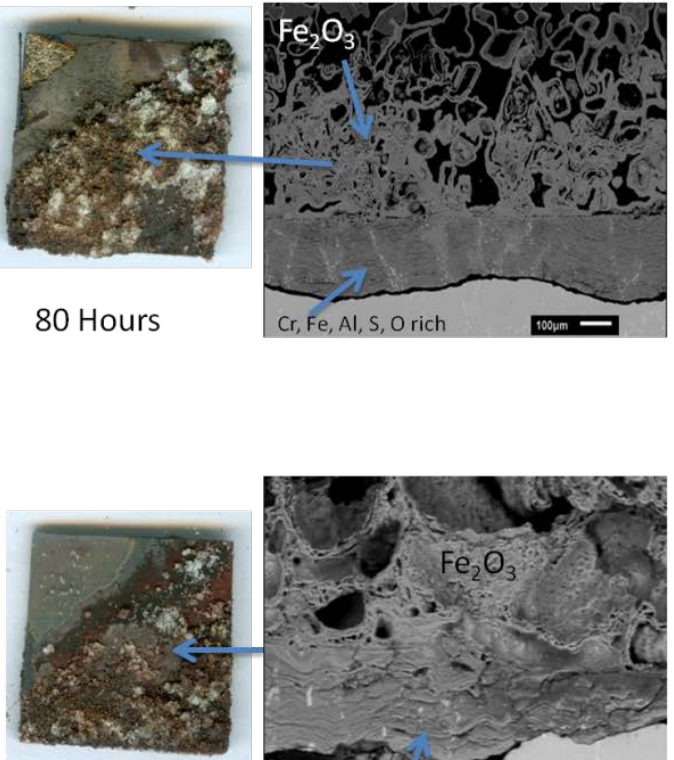

20 Hours

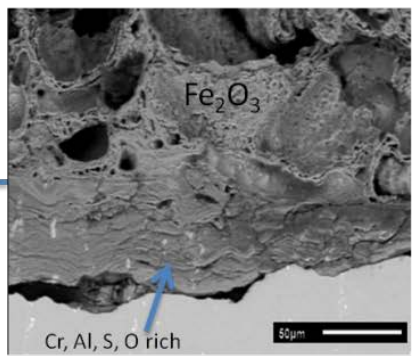

Figure 88: Macroscopic photographs and cross-sections of $\mathrm{OC} 8$ after fireside corrosion at $700^{\circ} \mathrm{C}$ with $\mathrm{M1}$ powder in a crucible in $\mathrm{O}_{2}+1000 \mathrm{ppm} \mathrm{SO}_{2}$

The corrosion mechanism for the AFA alloys in the M1 deposit should be similar to that described in the Mechanism Study sections. The M1 deposit allows for the formation of the liquid salt from a thermally grown iron oxide scale, which then causes rapid synergistic fluxing of the protective oxide scales and base metal material. The synergistic dissolution is not slowed by the addition of $\mathrm{Al}$ in the alloys. The solubility curve in Figure 24 for $\mathrm{Al}_{2} \mathrm{O}_{3}$ is almost the same as the solubility curve for $\mathrm{Cr}_{2} \mathrm{O}_{3}$, so it would experience synergistic dissolution with $\mathrm{Fe}_{2} \mathrm{O}_{3}$ in a similar manner. The aluminum solute experiences a negative solubility gradient just like chromium, but it becomes saturated earlier in the melt due to a lower solubility. The solute therefore precipitates out earlier than the iron and similarly to the chromium and is seen in the internal corrosion pits. 


\subsubsection{OC4 and OC8 SCM Results}

The AFA alloys were also tested at $700^{\circ} \mathrm{C}$ with the standard corrosion mix deposit in $\mathrm{O}_{2}+$ $1000 \mathrm{ppm} \mathrm{SO}_{2}$ for durations of 20,40, 80, and 160 hours. The results of tests on the OC4 and OC8 alloys can be seen in the macroscopic images shown in Figure 89. There is more corrosion of the OC4 alloy than of the OC8 alloy. The reason for this is most likely due to the higher chromium content in OC8, which could help extend the initiation stage for corrosion by continuously forming a protective $\mathrm{Cr}_{2} \mathrm{O}_{3}$ scale and also help promote protective $\mathrm{Al}_{2} \mathrm{O}_{3}$ formation via the third element effect.[35] OC8 also contains more $\mathrm{Nb}$ and $\mathrm{Ni}$, which has been shown to help promote $\mathrm{Al}_{2} \mathrm{O}_{3}$ formation in these alloys, which was discussed in the previous AluminaForming Austenitic Stainless Steel Alloys section.[44,46-48] Continuous $\mathrm{Al}_{2} \mathrm{O}_{3}$ and $\mathrm{Cr}_{2} \mathrm{O}_{3}$ formation would delay the liquid from reaching surface and causing corrosion of the base metal. OC8 was tested out to 320 hours, at which point some corrosion occurred, however it was still minimal compared to that of the OC4 alloy. 

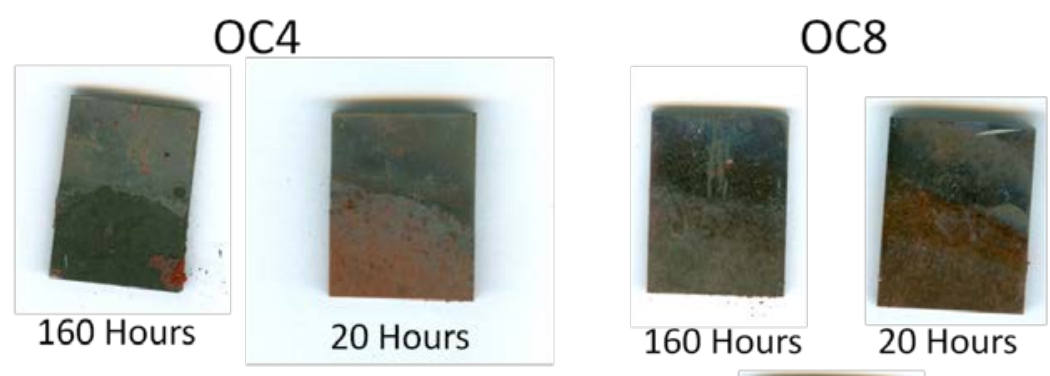

Figure 89: Macroscopic images of OC4 and OC8 exposed at $700^{\circ} \mathrm{C}$ with the standard corrosion mix powder in a crucible in $\mathrm{O}_{2}+1000 \mathrm{ppm} \mathrm{SO}_{2}$

The amount of corrosion with time for the two alloys compared with the Cr-forming alloys, T92 and FeNiCr, in the SCM is presented in the weight change per area plots shown in Figure 90 and the metal loss plot shown in Figure 91. There was minimal if any metal loss with the OC8 alloy after all exposures, so there are no bars on the plot for this alloy. There was some metal loss for the OC4 alloy after 80 and 160 hours. The chromia and spinel-forming alloys (T92 and FeNiCr) were significantly more degraded after 160 hours than the AFA alloys. The beneficial alloying additions ( $\mathrm{Al}, \mathrm{Nb}, \mathrm{Ni}$ ) described previously are responsible for this. The weight change plot and metal loss plots are comparable with the corrosion seen in macroscopic and microscopic images. OC4 lost weight after only 40 hours due to spallation upon cooling. It is unknown why the OC4 alloys spalled and the other alloys did not, because where there was no spallation, the corrosion products were similar. Severe spallation occurred throughout the deposit zone with OC4 after 160 hours. OC8 had very small weight gains, significantly lower than any of the alloys tested, even after 320 hours. The initiation stage for this alloy is much 
greater than any of the other alloys tested. This may be due to its alloying contents described previously. The higher $\mathrm{Cr}, \mathrm{Nb}$, and $\mathrm{Ni}$ contents promote $\mathrm{Al}_{2} \mathrm{O}_{3}$ formation and extend the initiation stage significantly for this alloy. The formation of protective $\mathrm{Cr}_{2} \mathrm{O}_{3}$ or $\mathrm{Al}_{2} \mathrm{O}_{3}$ scales may be delaying the liquid salt from reaching the metal surface and causing synergistic fluxing. The metal loss plots are also consistent with the amount of degradation. OC8 had essentially no metal loss, as it formed very thin protective oxide scales, while OC4 did have some metal loss with the spallation throughout the deposit zone. However, it was still much less than that which occurred for the chromia-forming alloys.

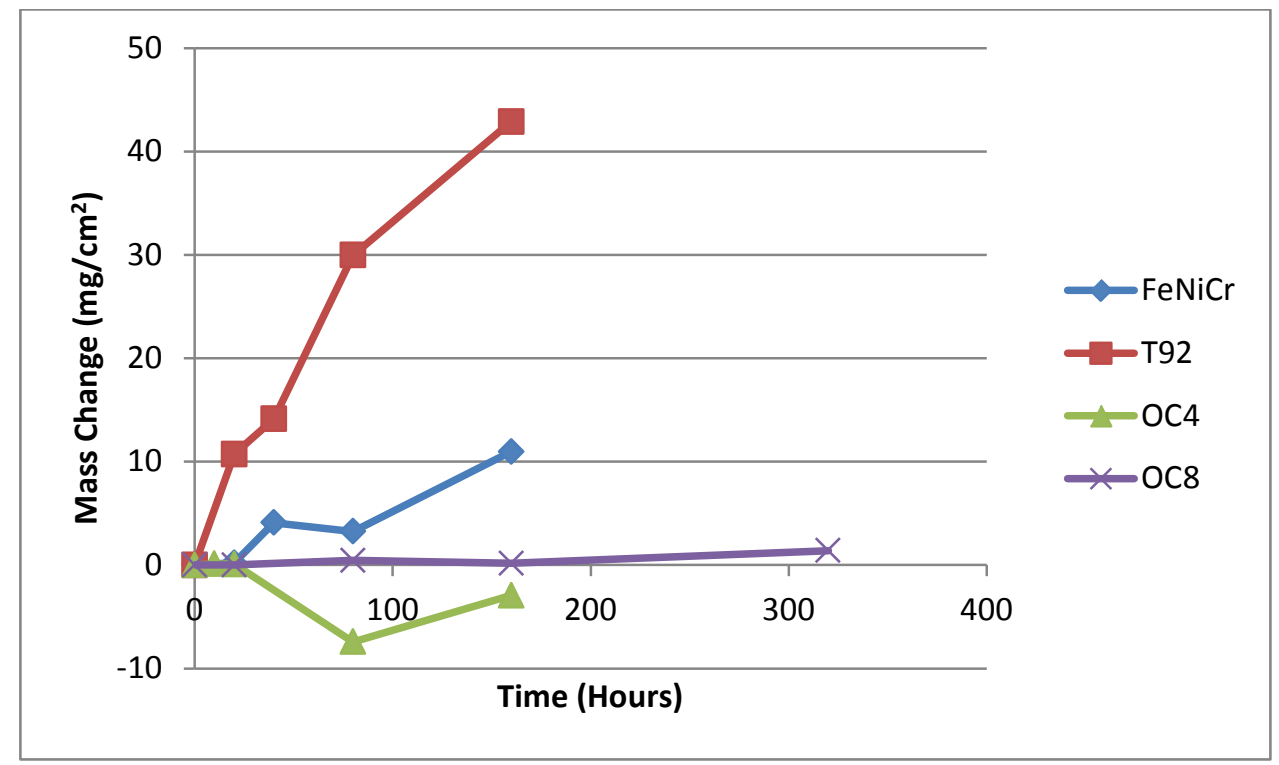

Figure 90: Weight change per area of fireside corrosion test of OC4 and OC8 alloys compared with chromiaforming alloys at $700^{\circ} \mathrm{C}$ with the SCM in a crucible in $\mathrm{O}_{2}+1000 \mathrm{ppm} \mathrm{SO}_{2}$ 


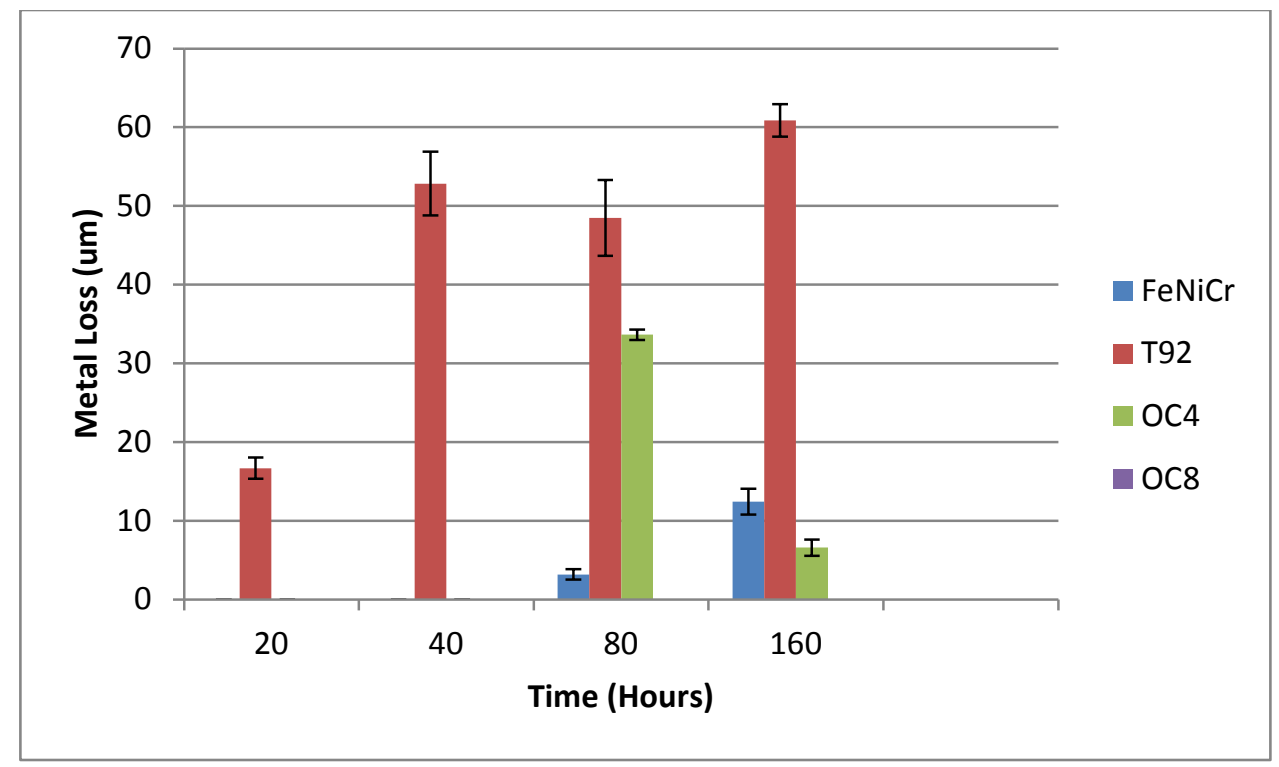

Figure 91: Metal Loss of fireside corrosion test OC4 and OC8 alloys compared with chromia-forming alloys at $700^{\circ} \mathrm{C}$ with the $\mathrm{SCM}$ in a crucible in $\mathrm{O}_{2}+1000 \mathrm{ppm} \mathrm{SO} \mathrm{S}_{2}$

Cross-sectional images of the OC4 specimens are shown in Figure 92. On each of the test specimens, where there was no deposit, an extremely thin $\mathrm{Cr}$ and $\mathrm{Al}$ rich oxide scale grew on the surface (Identified with EDS). In the deposit zone after 20 and 40 hours, the oxide scales remained intact (there is a small black gap between the corrosion products and the base metal specimen which formed upon preparation for characterization). Thick iron oxide scales and corrosion pits can be seen in the thin deposit zone (the area where the deposit powder first starts to cover the specimen) after 20 hours. The corrosion starts in the thin deposit zone and works its way down to the thicker deposit zone, as was the case with the chromia-forming alloys. This will be examined in more detail in a subsequent section. Surface and cross-sectional images of the thick deposit zone after 20 hours showed the presence of thick iron oxides on the surface along with alkali sulfates. A liquid solution initiates the attack on the surface of the alloy, and corrosion pits appear as though they are just forming. This is shown in Figure 93. The 
spallation occurs sometime between 40 and 80 hours, which is consistent with the weight change per area plot. The degradation after 80 hours was very similar to that after 160 hours, the amount of degradation and spallation increases with time. The metal loss plot shows that there is more degradation after 80 hours but this is likely because these times are in the range where corrosion accelerates. After 160 hours there was severe spallation in the entire deposit zone. External iron oxides scales grew over pits rich in $\mathrm{Cr}, \mathrm{Al}, \mathrm{Ni}, \mathrm{S}$, and $\mathrm{O}$, where the oxide scales remained intact. The aluminum and sulfur content increases with depth into the pits with a layer rich in $\mathrm{Al}, \mathrm{Cr}$, and $\mathrm{S}$ at the base of the pits. The corrosion products and morphology are very similar to those of T92 and FeNiCr, however there is the addition of aluminum to the corrosion pits. The aluminum in the alloy fluxes similarly to the chromium in that it experiences a negative solubility gradient but does not precipitate out far in the melt due to a lower solubility, which is why it is in the internal corrosion pits. The largest amount of pitting occurred in some areas where the Nb-rich Laves phase or Nb-rich carbides reached or were near the surface. This is likely due to the fact that $\mathrm{Nb}$ and iron rich oxide scales will grow in these areas leading to faster degradation than an area with a protective $\mathrm{Cr}_{2} \mathrm{O}_{3}$ or $\mathrm{Al}_{2} \mathrm{O}_{3}$ scale. 

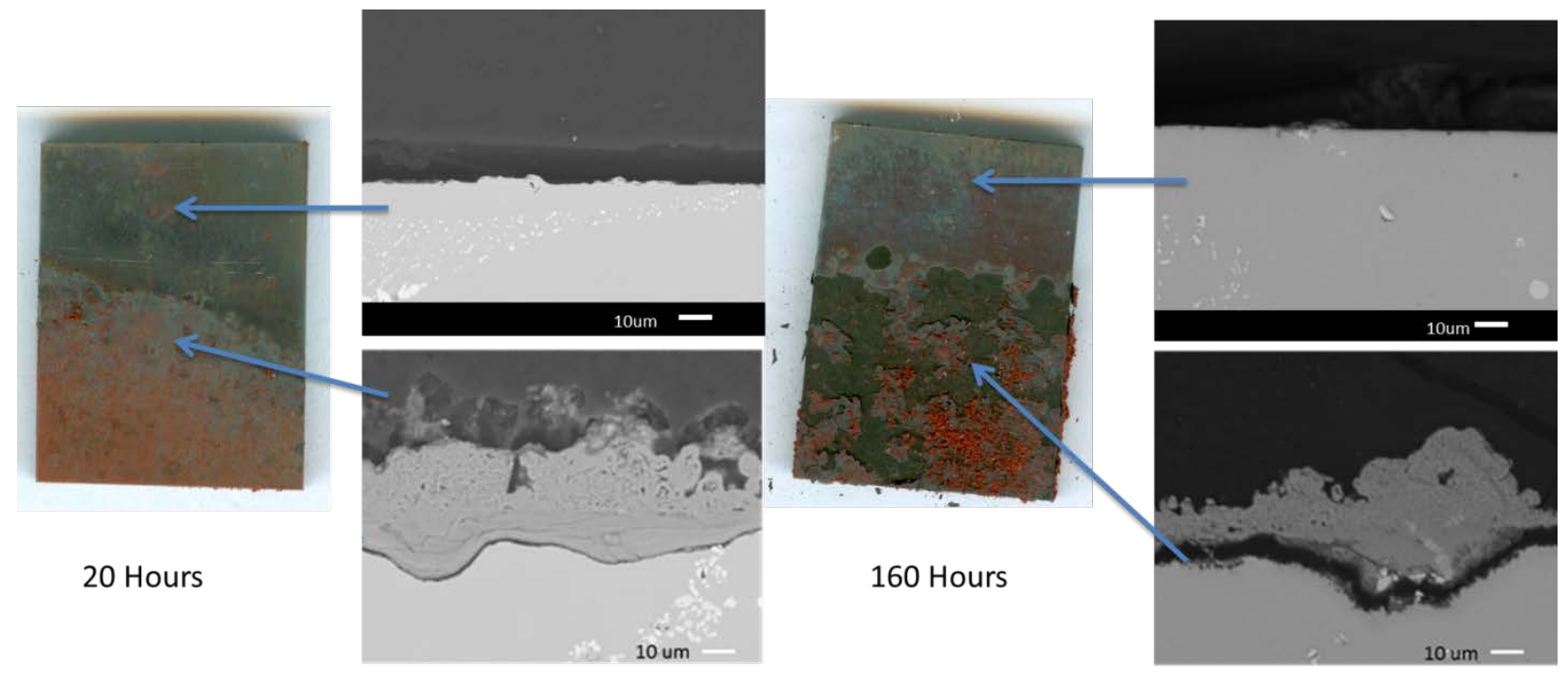

Figure 92: Microscopic cross-sectional images of $\mathrm{OC} 4$ exposed at $700^{\circ} \mathrm{C}$ with the standard corrosion mix powder in a crucible in $\mathrm{O}_{2}+1000 \mathrm{ppm} \mathrm{SO}_{2}$

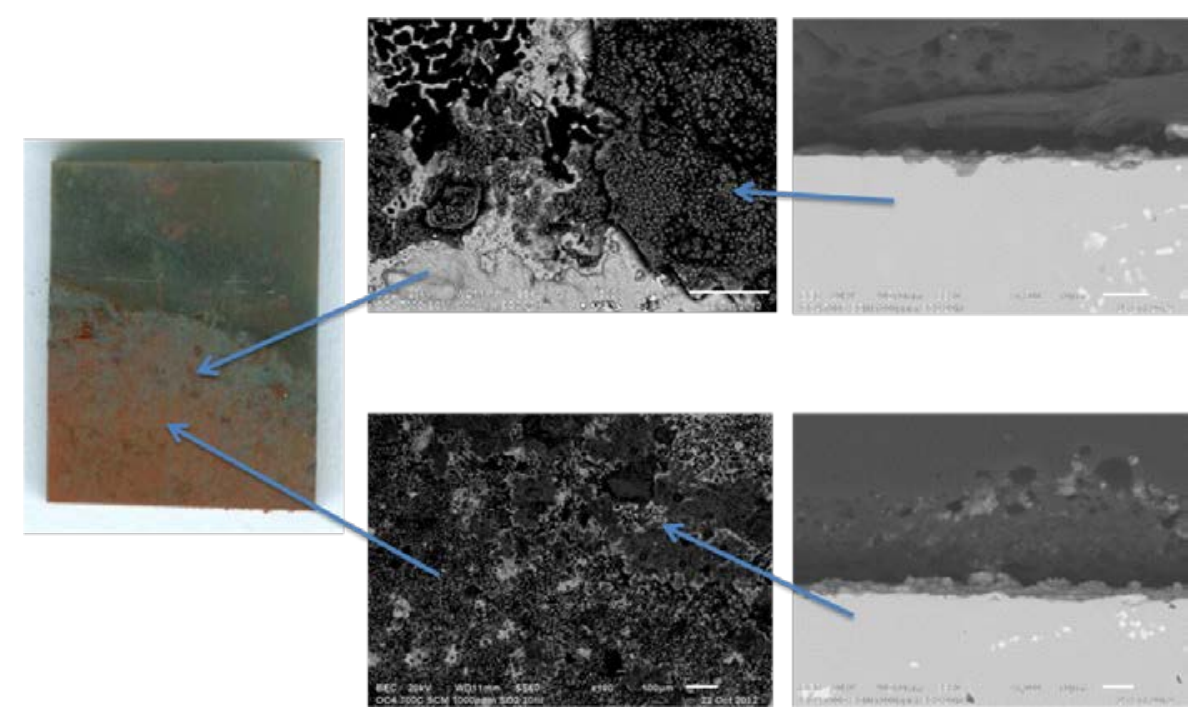

Figure 93: Fireside Corrosion of $\mathrm{OC} 4$ at $700^{\circ} \mathrm{C}$ with the standard corrosion mix powder in a crucible in $\mathrm{O}_{2}+$ 1000ppm $\mathrm{SO}_{2}$ for 20 hours 
Cross-sectional images of the OC8 specimens are shown in Figure 94. This alloy performed the best of all of the steel alloys tested with the SCM. There was no corrosion between 20 and 160 hours. Very thin oxide scales grew in the non-deposit and deposit zones. The oxide scales were rich in $\mathrm{Fe}, \mathrm{Cr}$, and Al. OC8 has higher chromium contents than OC4, which was shown with the chromia-forming alloys to be beneficial for corrosion resistance. The higher $\mathrm{Ni}$ and $\mathrm{Nb}$ contents in OC8 compared to OC4 also help to promote $\mathrm{Al}_{2} \mathrm{O}_{3}$ formation, as was discussed in the AFA Alloys section. The continuous formation of a protective $\mathrm{Cr}_{2} \mathrm{O}_{3}$ or $\mathrm{Al}_{2} \mathrm{O}_{3}$ scale increases the initiation stage as the liquid takes longer to reach the metal surface, delaying the dissolution and fluxing of the base metal as described in the Mechanism Study section. Only after 320 hours did this alloy undergo any significant corrosion. There was no spallation, as with the OC4 alloy, but a small amount of pitting did form in the thin deposit zone. However, it was minimal compared to the amount that occurred with the other alloys. The corrosion products were similar with an external iron rich oxide scale and internal pits rich in $\mathrm{Cr}$, $\mathrm{Al}, \mathrm{S}$, and O. For comparison, cross-sectional images of the FeNiCr alloy with the SCM in $\mathrm{O}_{2}+$ 1000ppm $\mathrm{SO}_{2}$ were shown in Figures 48-50. The amount of degradation of this alloy is greater than the OC8 alloy with similar Cr-contents. 

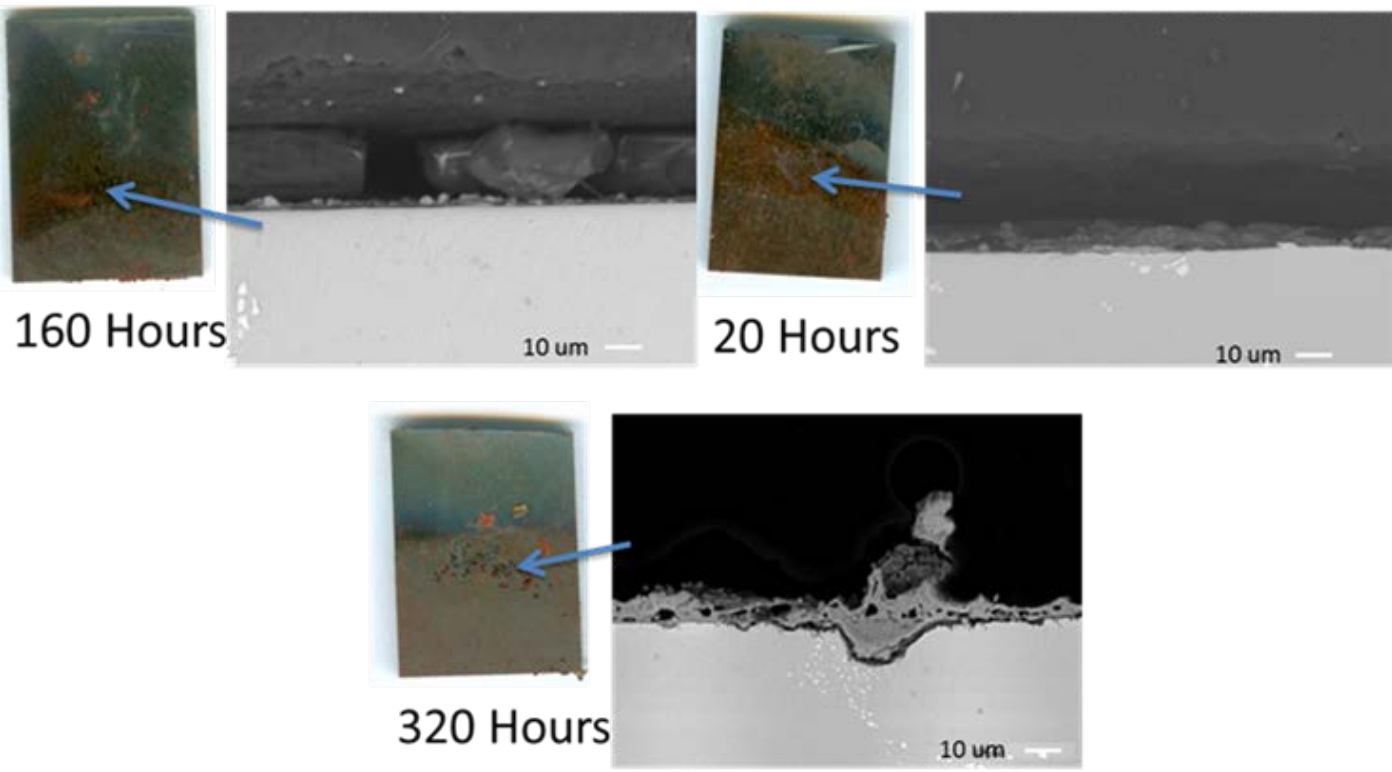

Figure 94: Microscopic cross-sectional images of $\mathrm{OC} 8$ exposed at $700^{\circ} \mathrm{C}$ with the standard corrosion mix powder in a crucible in $\mathrm{O}_{2}+1000 \mathrm{ppm} \mathrm{SO}_{2}$

The results with the SCM can be compared with the plots for the M1 deposit in Figure 87. There is significantly less corrosion with the SCM than there is with the M1 deposit. The addition of iron oxide to the alkali sulfates in the M1 deposit increases the melt basicity and synergistic fluxing is slowed down, as was described in Proposed Fireside Corrosion Mechanism section.

\subsubsection{OCS and OCT SCM Results}

The alloys OCS and OCT have high nickel and niobium concentrations similar to OC8, as well as $\mathrm{Ti}$ and $\mathrm{Zr}$ additions to stabilize the high temperature strengthening $\gamma^{\prime}-\mathrm{Ni}_{3} \mathrm{Al}$ phase, but they also have low chromium concentrations similar to OC4 to minimize sigma phase formation. It was hoped that the higher strength OCS and OCT alloys would have sufficient fireside corrosion 
resistance. The benefits of $\mathrm{Nb}$ and $\mathrm{Ni}$ additions in promoting $\mathrm{Al}_{2} \mathrm{O}_{3}$ would have to make up for the lower chromium content. The macroscopic results of the tests on the OCS and OCT alloys in $\mathrm{O}_{2}+1000 \mathrm{ppm} \mathrm{SO}$ are shown in Figures 95 and 96.

Volume Fraction: $5.22 \%$

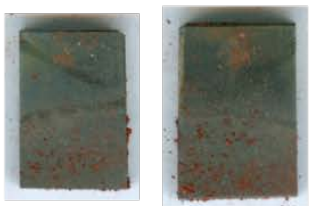

160 hours ( $1^{\text {st }}$ test $)$
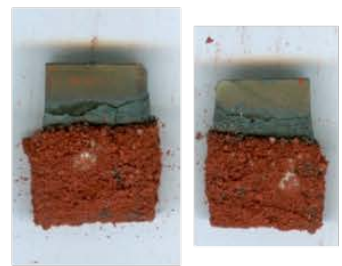

160 hours ( $2^{\text {nd }}$ test)

Volume Fraction: $3.81 \%$
Volume Fraction: $4.40 \%$

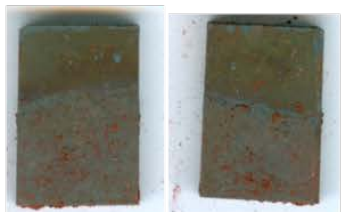

80 hours $\left(1^{\text {st }}\right.$ test $)$
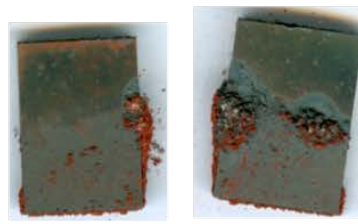

80 hours $\left(2^{\text {nd }}\right.$ test $)$

Volume Fraction: $4.55 \%$
Volume Fraction: $3.44 \%$
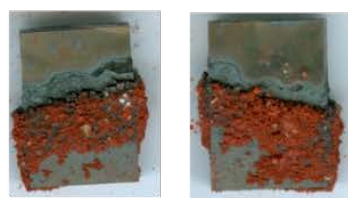

40 hours $\left(1^{\text {st }}\right.$ test $)$

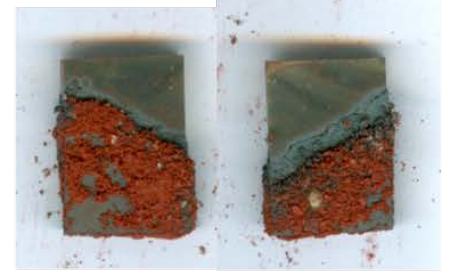

40 hours ( $2^{\text {nd }}$ test)

Volume Fraction: 3.92\%
Volume Fraction: $4.42 \%$

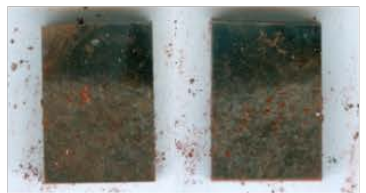

20 hours $\left(1^{\text {st }}\right.$ test $)$

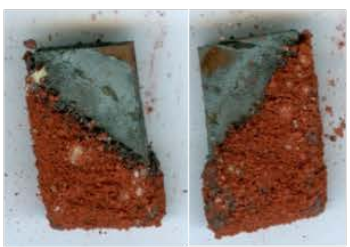

20 hours ( $2^{\text {nd }}$ test)

Figure 95: Macroscopic Results of OCS exposed at $700^{\circ} \mathrm{C}$ with the SCM powder in a crucible in $\mathrm{O}_{2}+$ $1000 \mathrm{ppm} \mathrm{SO} \mathrm{S}_{2}$ (Volume fraction of Laves phase and $\mathrm{NbC}$ shown in red) 
Volume Fraction: $3.54 \%$
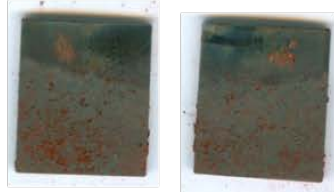

160 hours ( $1^{\text {st }}$ test $)$

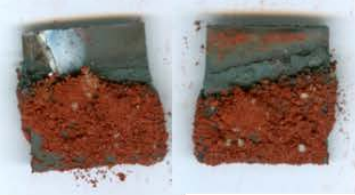

160 hours ( $2^{\text {nd }}$ test)

Volume Fraction: 4.01\%
Volume Fraction: $3.44 \%$

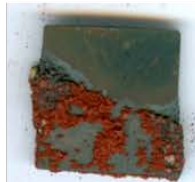

80 hours $\left(1^{\text {st }}\right.$ test $)$

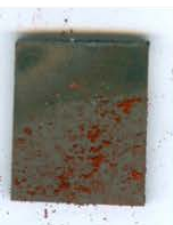

80 hours ( $2^{\text {nd }}$ test)

Volume Fraction: 5.92\%
Volume Fraction: $2.96 \%$

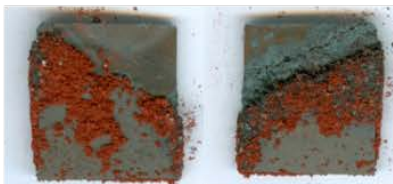

40 hours ( $1^{\text {st }}$ test)

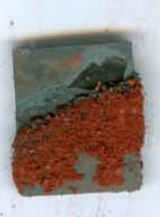

40 hours ( $1^{\text {st }}$ test)

Volume Fraction $3.27 \%$
Volume Fraction $3.82 \%$
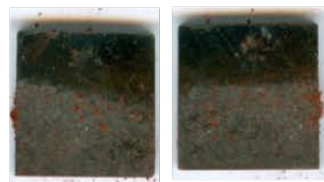

20 hours ( $1^{\text {st }}$ test $)$

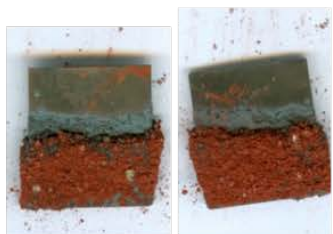

20 hours ( $2^{\text {nd }}$ test)

Figure 96: Macroscopic Results of OCT exposed at $700^{\circ} \mathrm{C}$ with the SCM powder in a crucible in $\mathrm{O}_{2}+$ $1000 \mathrm{ppm} \mathrm{SO} \mathrm{S}_{2}$ (Volume fraction of Laves phase and $\mathrm{NbC}$ shown in red)

There was significant variability in the results of these two alloys, so duplicate tests were performed. Weight change and metal loss plots are not shown for these two alloys in the SCM due to the large amount of variability in the results. Microscopic cross-sectional images of the results in $\mathrm{O}_{2}+1000$ ppm $\mathrm{SO}_{2}$ are shown in Figures 97 and 98 . 

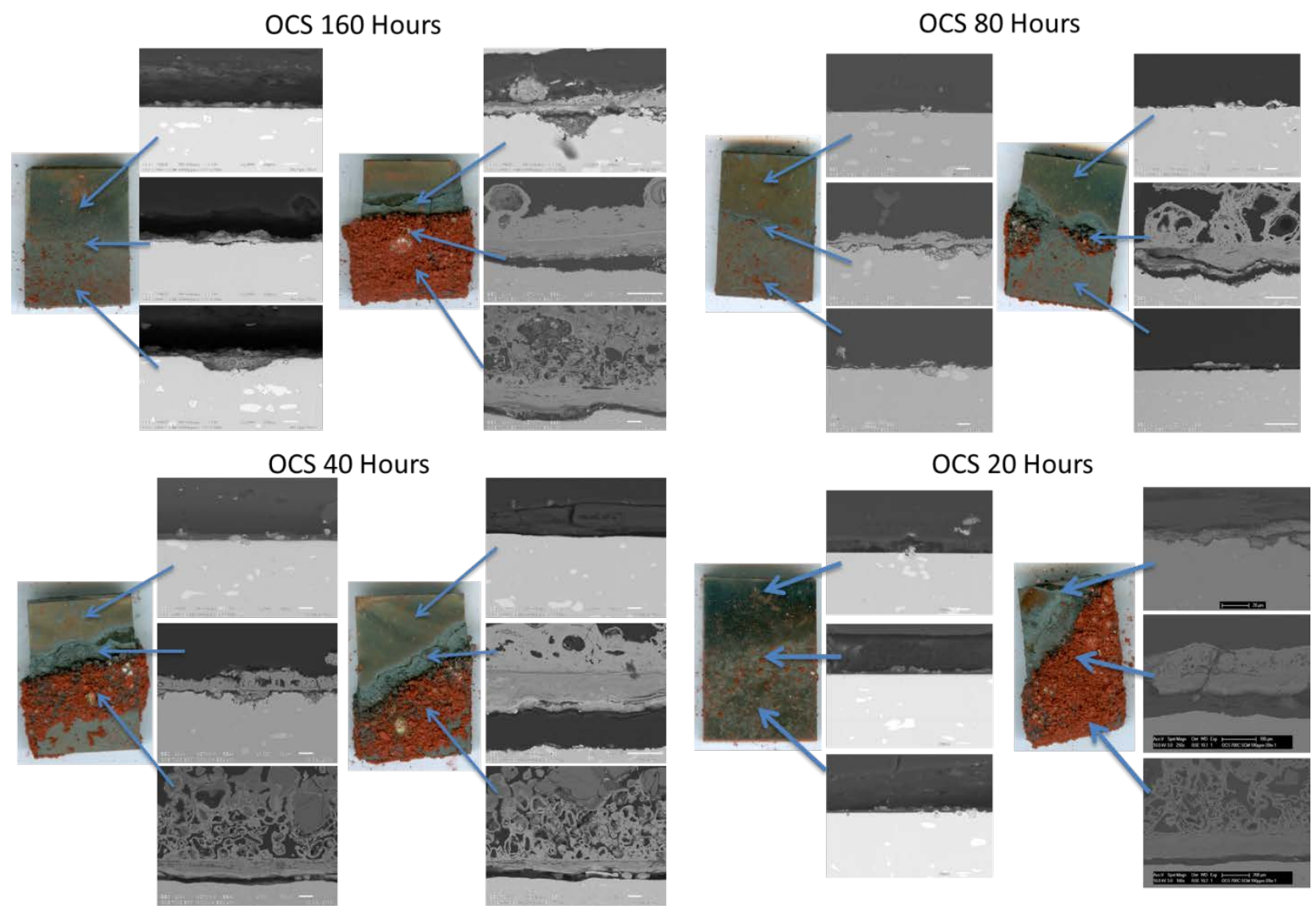

Figure 97: Fireside corrosion of $\mathrm{OCS}$ at $700^{\circ} \mathrm{C}$ with the standard corrosion mix powder in a crucible in $\mathrm{O}_{2}+$ 1000ppm $\mathrm{SO}_{2}$ 

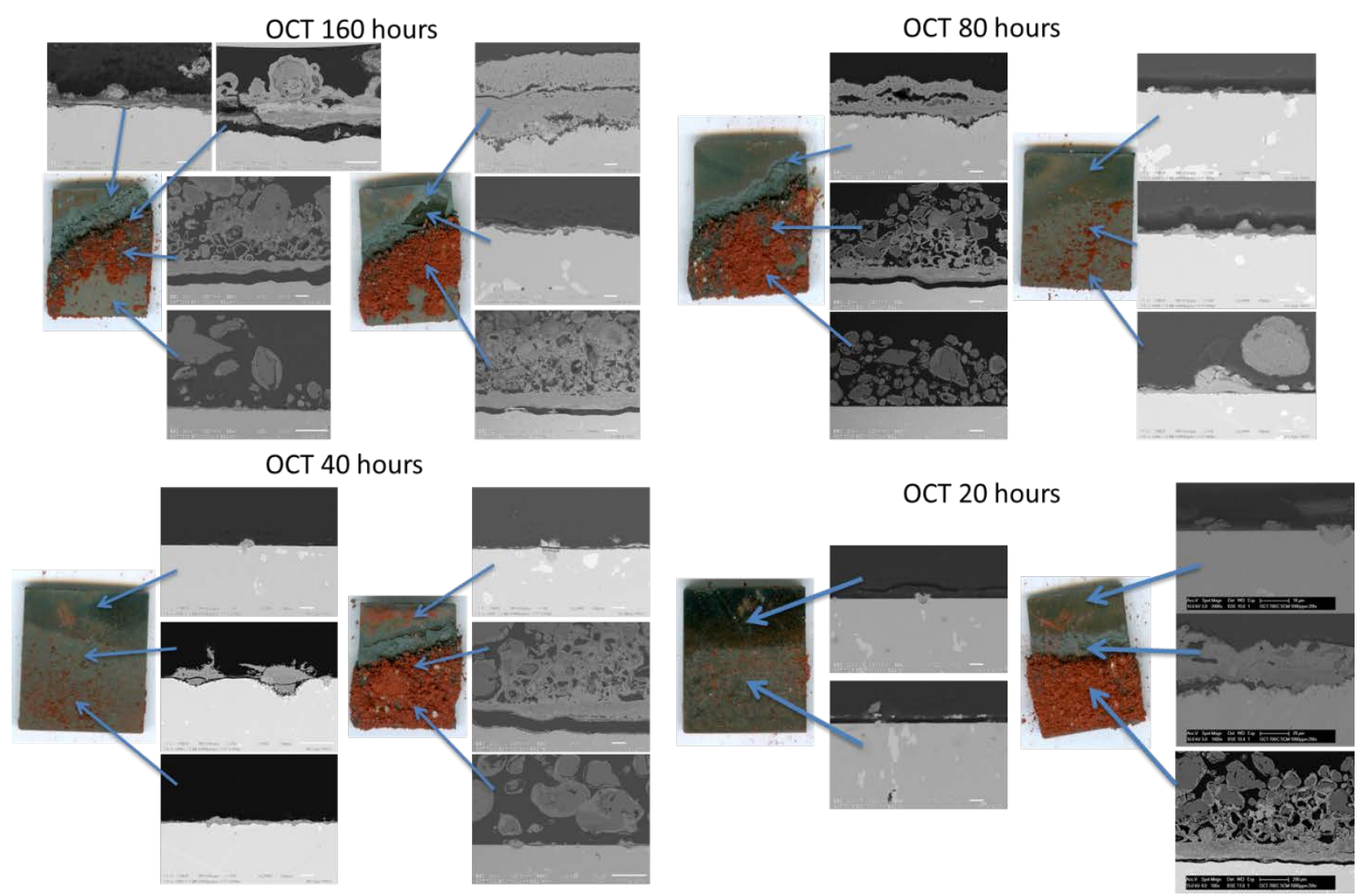

Figure 98: Fireside corrosion of $\mathrm{OCT}$ at $700^{\circ} \mathrm{C}$ with the standard corrosion mix powder in a crucible in $\mathrm{O}_{2}+$ 1000ppm $\mathrm{SO}_{2}$

In the areas where there was no deposit, thin $\mathrm{Fe}, \mathrm{Cr}$, and $\mathrm{Al}$ rich oxides grew on the surface. The attack is again initiated in the thin deposit zone. Where significant degradation occurred, the corrosion products are very similar to the results of the T92 and FeNiCr alloys. Thick, porous, external iron rich oxides grew over internal pits rich in $\mathrm{Cr}, \mathrm{Al}, \mathrm{Ni}, \mathrm{S}$, and $\mathrm{O}$ with a layer or $\mathrm{CrS}$ and AlS at the base. Bands of NiS can also be seen going through the corrosion products as well. The internal pits have also engulfed the Laves phase and carbides that it encountered on further penetration, and these can be seen in the internal corrosion products as well. 
The cause of the variability in the results is currently unknown, but such a large variability in short duration tests suggests these alloys have a borderline $\mathrm{Cr}$ content to exhibit the improved behavior of OC8 over that of OC4. The as processed microstructure contains significant amounts of $(\mathrm{Fe}, \mathrm{Ni})_{2} \mathrm{Nb}$ Laves Phase, $\mathrm{MC}$ carbides and very small amounts of $\mathrm{NiAl}$. The Laves Phase and MC carbides can be seen in Figure 99. Where the Laves and MC phases meet the surface, $\mathrm{Nb}$ and Fe-rich oxides preferentially grow and could be initiation sites for corrosion. The amount of these phases was then examined to determine whether the variability in the results was due to variability in the amount of these phases.

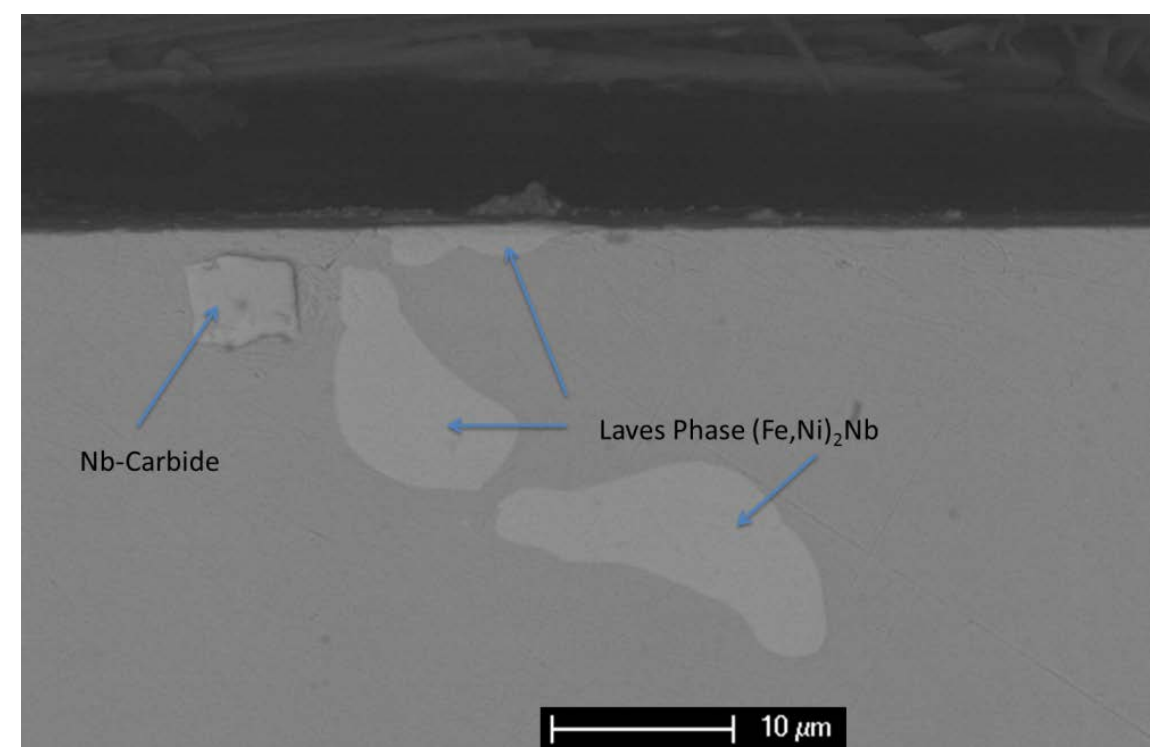

Figure 99: Microstructure of OCT Alloy Displaying Laves Phase and Nb-Carbides

Calculations determining the volume fraction of Laves phase and Nb-carbides for many of the tested specimens were performed and the results are shown above the macroscopic images in Figures 95 and 96 as well as in Figure 100. This was done by using the GIMP photo editing software. The images were converted to black and white. The light Laves and NbC phases were 
able to be identified and separated from the rest of the image and the area fractions of these phases were calculated for 50 random areas within each specimen cross-section. The averages of these 50 areas were taken to be the volume fraction of each specimen. The results are plotted in Figure 100.

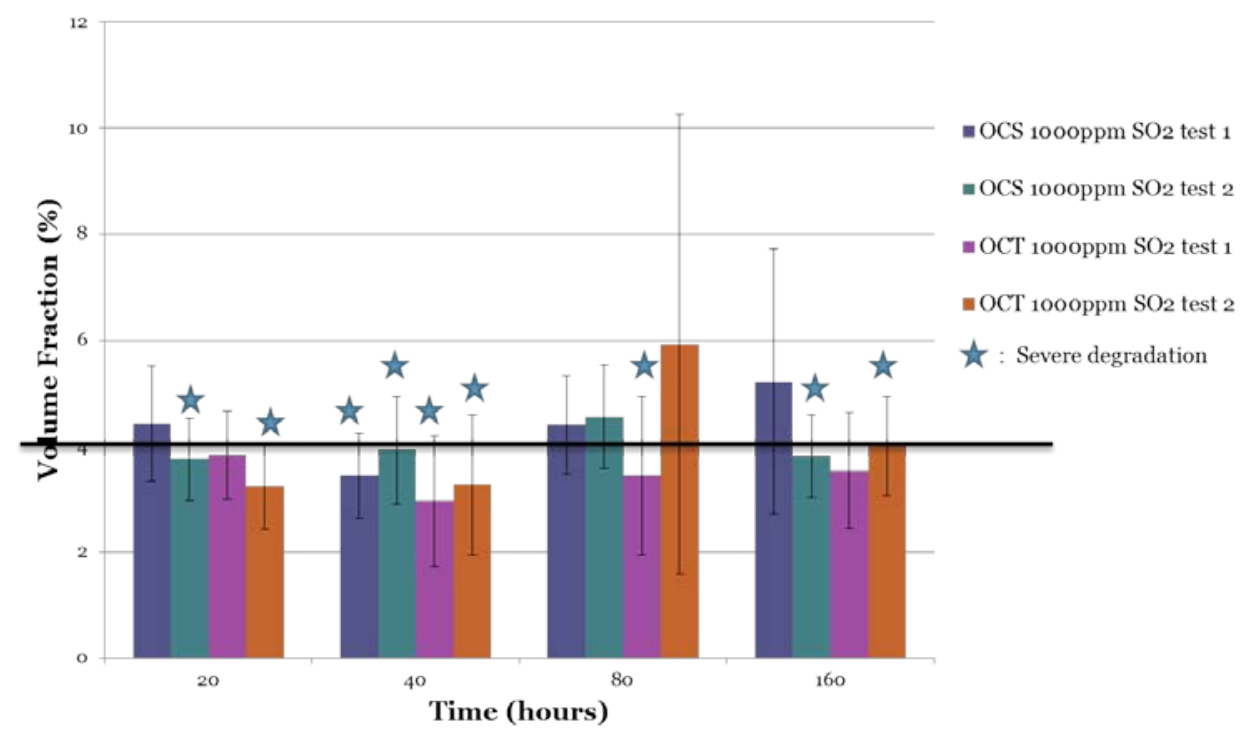

Figure 100: Calculated volume fraction of Laves Phase and MC in tested specimens

There was a slight correlation between the amount of Laves phase and Nb-carbides in the specimen, and the amount of degradation. Specimens containing more of these phases seemed to have performed better. This is the opposite of what one would expect. When these phases meet the surface of the specimen, $\mathrm{Fe}$ and Nb-oxides are preferentially grown and they would be expected to be a source for the liquid salt to cause corrosion more rapidly. A volume fraction of about $4 \%$ appears to be the cutoff value for marking severe corrosion. Those specimens with higher volume fractions performed well, while those with lower volume fractions did worse. There were some exceptions to this, and so it is inconclusive whether this is the cause of the 
variability. Figures 101 and 102 show the calculated phase fractions of the OCS and OCT alloys with temperature.[87] At the temperature tested $\left(700^{\circ} \mathrm{C}\right)$, there should be minimal Laves phase and carbides and significant amounts of gamma prime and $\mathrm{NiAl}$ as well as sigma phase. This is not as observed however, at least at SEM level imaging. The alloys were solution heat treated near $1200^{\circ} \mathrm{C}$, and they are very slow to reach their equilibrium low-temperature microstructure. The microstructure seen is similar to what would be expected near $1100-1200^{\circ} \mathrm{C}$. Each of the previously described tests in the M1 and SCM deposits was conducted in the as-processed condition, and not at the equilibrium temperature microstructure. They are therefore a study on the fireside corrosion resistance of the austenite phase only, which still provides useful information. The effect of the amount of Laves phase and $\mathrm{NbC}$ in the specimens as well as a slowly changing microstructure was examined more closely and will be discussed in more detail in the subsequent section. 
$\mathrm{Ni}-3.0 \mathrm{Al}-14.0 \mathrm{Cr}-45.44 \mathrm{Fe}-3.0 \mathrm{Nb}-0.15 \mathrm{Si}-2.0 \mathrm{Ti}-0.3 \mathrm{Zr}-0.01 \mathrm{~B}-0.1 \mathrm{C}$ wt(\%)

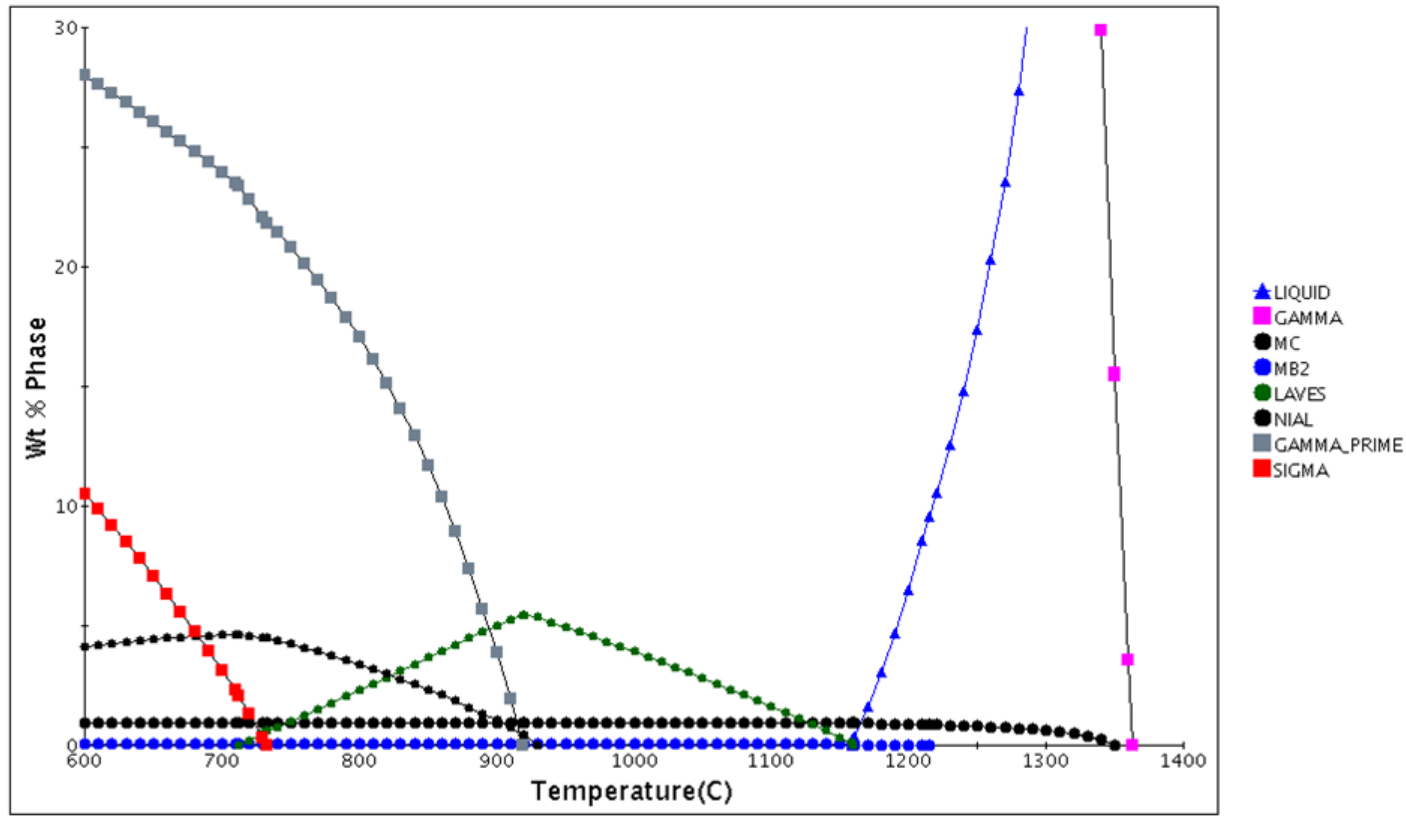

Figure 101: Predicted phases of OCS as a function of temperature [87]

$\mathrm{Ni}-3.0 \mathrm{Al}-14.0 \mathrm{Cr}-42.44 \mathrm{Fe}-3.0 \mathrm{Nb}-0.15 \mathrm{Si}-2.0 \mathrm{Ti}-0.3 \mathrm{Zr}-0.01 \mathrm{~B}-0.1 \mathrm{C}$ wt(\%)

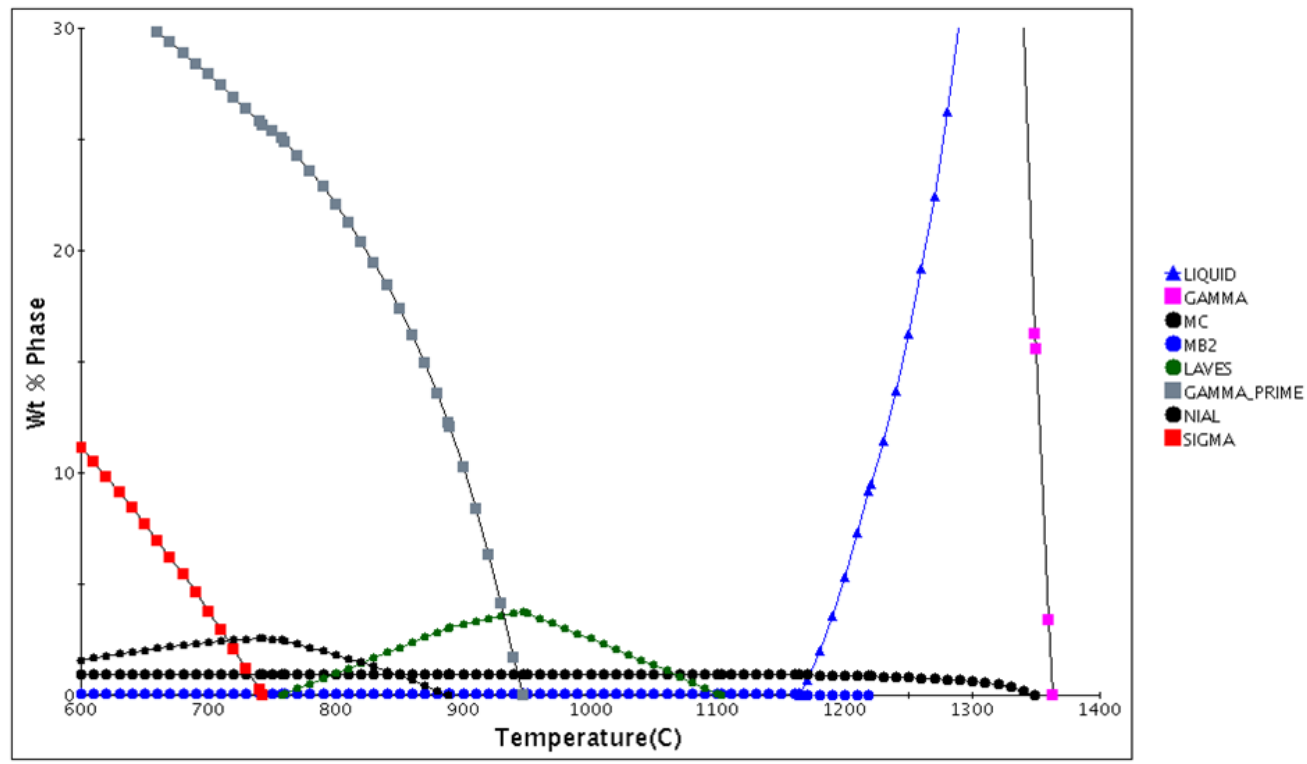

Figure 102: Predicted phases of OCT as a function of temperature [87] 


\subsubsection{Effect of Slowly Changing Microstructure}

The effect of the amount of Laves Phase and NbC phases in the OCT and OCS alloys and the slowly changing microstructure on the oxidation and corrosion resistance was studied. The volume fraction of Laves phase and NbC in OCS and OCT was calculated before and after exposure at $700^{\circ} \mathrm{C}$ in the SCM for 160 hours in $\mathrm{O}_{2}+1000 \mathrm{ppm} \mathrm{SO}_{2}$. The results are shown in Table 12.

Table 12: Volume Fraction (\%) of Laves Phase and NbC in OCS and OCT specimens before and after exposure in the SCM for 160 hours in $02+1000 \mathrm{ppm} \mathrm{SO}_{2}$

\begin{tabular}{|c|c|c|}
\hline & OCS & OCT \\
\hline Before Exposure & 4.24676 & 3.80952 \\
\hline After Exposure & 4.41368 & 4.05216 \\
\hline
\end{tabular}

The amount of these phases increased for both alloys after exposure. This is not surprising as the plots in Figures 101 and 102 show that the amount Laves phase should increase and then decrease as it gets closer to the equilibrium microstructure at $700^{\circ} \mathrm{C}$. The microstructures must be at the point in the change in which the amount of these phases increases, as they are very slowly changing into their equilibrium lower temperature microstructures. It should also be noted that neither of these specimens was severely degraded, and both ended up having a greater than $4 \%$ volume fraction of Laves phase and NbC. Larger amounts of NbC may mean less $\mathrm{Cr}$ is tied-up into carbides, allowing more chromium to be present in the austenite matrix and provide more availability to form a protective oxide scale. Larger amounts of Laves phase, $(\mathrm{Fe}, \mathrm{Ni})_{2} \mathrm{Nb}$, means 
there is less $\mathrm{Nb}$ in the austenite matrix, creating locally more $\mathrm{Cr}$ available to form a protective scale. It is also possible that these two alloys are just borderline alloys for protection under these conditions.

The effect of the slowly changing microstructure was examined in more detail. Specimens of OC8, OCS, and OCT were vacuum encapsulated in quartz tubes with argon and aged for 2350 hours at $700^{\circ} \mathrm{C}$. An example of the resulting microstructures of OCS or OCT (they are very similar alloys) are shown in Figure 103 compared with the un-aged as received microstructure. The microstructure was examined using the SEM and Laves Phase, NbC, and $\mathrm{NiAl}$ were detected. If the aged specimens were at the equilibrium $700^{\circ} \mathrm{C}$ microstructure, then according to Figures 101 and 102, sigma phase should also be present. The aged specimens were electrolytically etched with 1.5 volts in a $10 \%$ aqueous $\mathrm{KOH}$ solution, which highlights the sigma phase when present. No sigma phase was present in the aged OCS and OCT specimens. Comparison with the plot with the predicted phases in Figures 101 and 102, with no sigma phase and still a good amount of Laves phase present, indicates the OCS and OCT aged specimens are still not at their $700^{\circ} \mathrm{C}$ equilibrium microstructures and are most likely at the microstructure predicted around $800-900^{\circ} \mathrm{C}$. This shows how slowly equilibrium is reached for these alloys. This suggests that the change in microstructure may not be the cause of the variability in the short-term corrosion tests and that theses alloys are just borderline for protection. Even after 2350 hours, the alloys are not in their equilibrium microstructure. 
As Processed

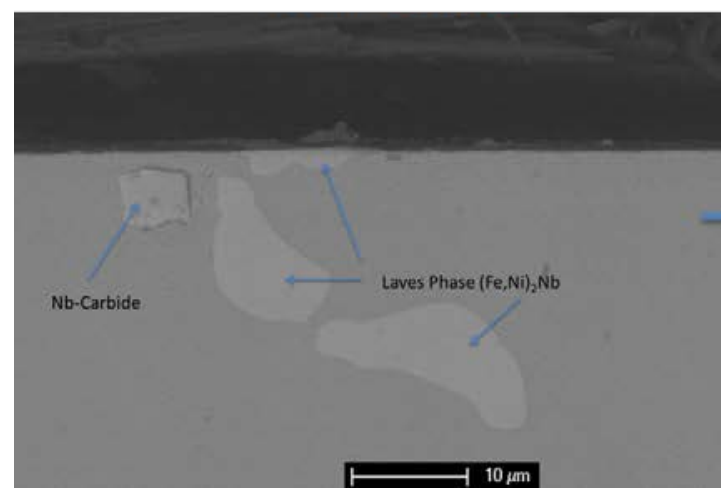

Aged at $700^{\circ} \mathrm{C}$ for 2350 hours

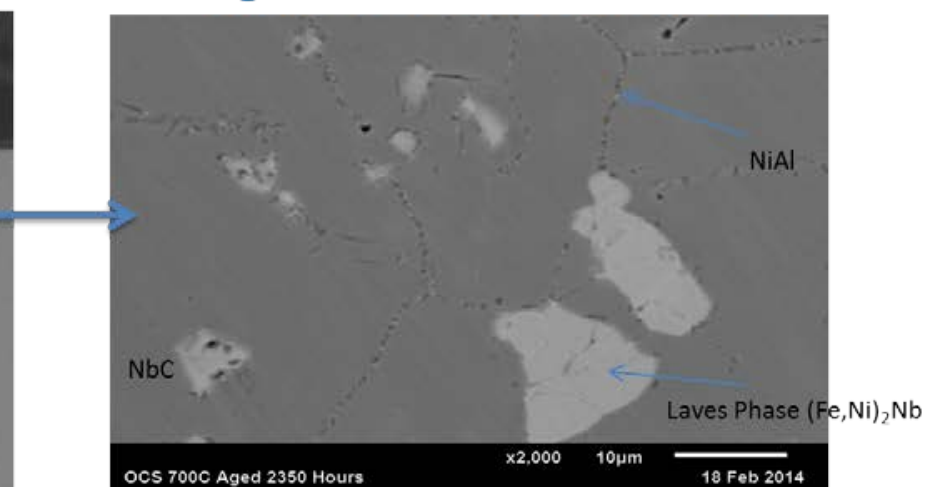

Figure 103: Microstructure of OCS as processed and aged at $700^{\circ} \mathrm{C}$ for 2350 hours

The aged OCS and OCT specimens were then exposed at $700^{\circ} \mathrm{C}$ in the SCM for 160 hours in $\mathrm{O}_{2}$ $+1000 \mathrm{ppm} \mathrm{SO}$. The results are presented in Figures 104 and 105 . The specimens were not severely degraded. In the non-deposit zone, thin protective oxide scales grew. The Laves phase or NbC preferentially oxidized to form Fe- or Nb-rich oxides where they reached the surface. In the thin deposit zone, there were some areas where thicker iron oxides scales grew over top of small pits rich in $\mathrm{Cr}, \mathrm{S}$, and $\mathrm{O}$ with some internal sulfidation at the base. These areas were small and the extent of the corrosion was not very severe. In the thick deposit zone, some thicker iron oxide scales grew, but there was no significant corrosion. 


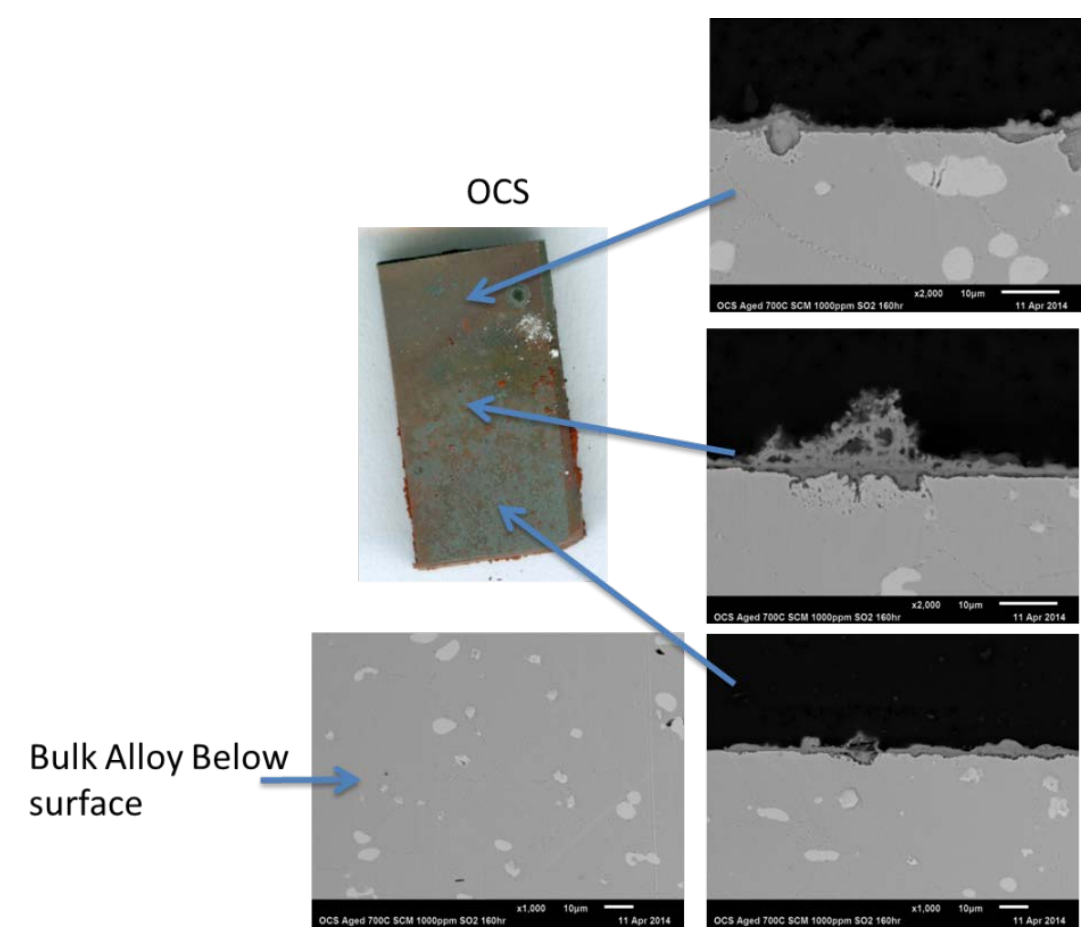

Figure 104: OCS Aged 2350 hours at $700^{\circ} \mathrm{C}$ then exposed at $700^{\circ} \mathrm{C}$ with the SCM powder deposit in $\mathrm{O}_{2}+$ $1000 \mathrm{ppm} \mathrm{SO}_{2}$ for 160 hours

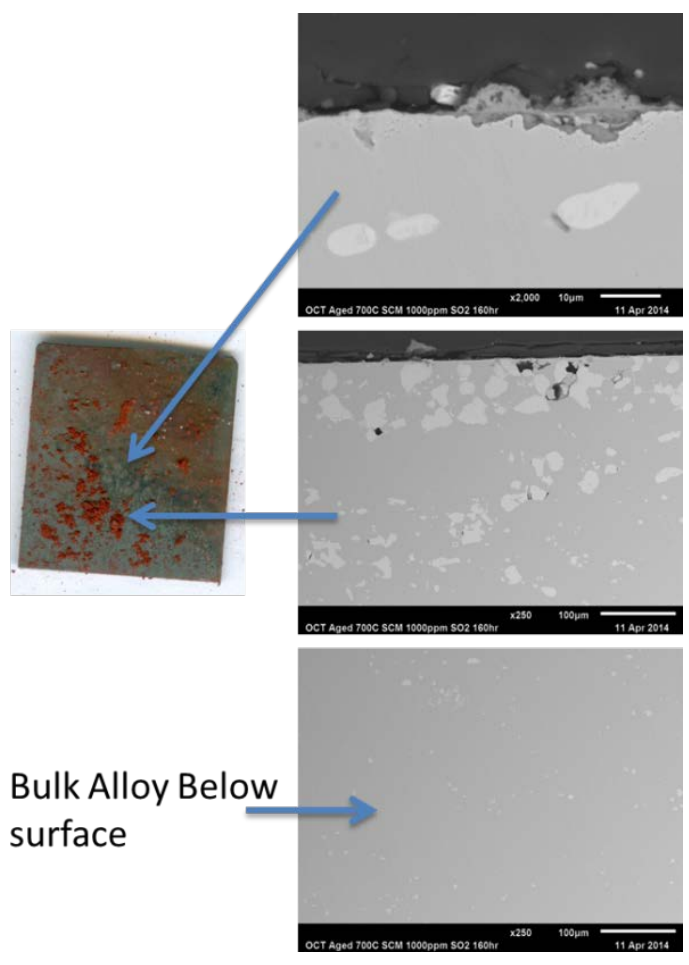

Figure 105: OCT Aged 2350 hours at $700^{\circ} \mathrm{C}$ then exposed at $700^{\circ} \mathrm{C}$ with the SCM powder deposit in $\mathrm{O}_{2}+$ $1000 \mathrm{ppm} \mathrm{SO}_{2}$ for 160 hours 
The amount of Laves phase and NbC was noticeably increased in the aged specimens compared to the as processed microstructure. This is as predicted by the diagrams in Figures 101 and 102 as the alloys reach their lower temperature equilibrium microstructure. There was also a buildup of the Nb-rich phases towards the surface of the specimens. This can be seen in the crosssectional images in Figure 105. The migration of $\mathrm{Nb}$-rich $\mathrm{Ni}_{3} \mathrm{Nb}$ towards the surface and an enrichment below the oxide scale in Alloy 625 exposed in steam atmospheres at temperatures of 700-800 ${ }^{\circ} \mathrm{C}$ was also seen by Garcia et al.[88] They described the enrichment beneath the surface as due to a Cr depletion below the surface from continuously forming a protective $\mathrm{Cr}_{2} \mathrm{O}_{3}$ scale, which also causes a $\mathrm{Nb}$ depletion in the subscale zone, since $\mathrm{Nb}$ activity decreases with $\mathrm{Cr}$ content. Because of the decreasing $\mathrm{Cr}$ content near the surface, $\mathrm{Nb}$ exhibits uphill diffusion towards the Cr-depleted zone, which causes an enrichment of $\mathrm{NiNb}_{3}$. A similar effect was also seen for the migration and enrichment of Laves phase at the oxide/metal interface in ferritic steels in steam atmospheres at $800^{\circ} \mathrm{C}$.[89] The enrichment of the Laves phase was once again due to a decreasing $\mathrm{Cr}$ content in forming a continuous oxide scale and subsequent decreasing $\mathrm{Nb}$ activity in this region, which leads to $\mathrm{Nb}$ migration to the areas of lowest $\mathrm{Cr}$ content. This is likely what is occurring with the AFA alloys in this study. As time increases Cr is depleted in the matrix to form a protective oxide scale, and the amount of Laves phase increases. The Nbrich Laves phase then migrates to the oxide metal interface where the Cr content is depleted. The effects in the Ni-based alloy are more severe than would occur in a ferritic or austenitic steel due to a greater effect of the Cr content on Nb activity.[89] There were not significant amounts of degradation with the aged OCS and OCT specimens, and the large build-up of Laves phase and $\mathrm{NbC}$ at the surface as well as the correlation seen previously between higher volume 
fractions of these phases increasing corrosion resistance indicates that these phases are effecting the corrosion mechanism in some way. It could possibly be that with a larger amount of $\mathrm{Nb}$ tied up in these phases, there is less in the austenite matrix, producing a locally increased amount of chromium in the matrix available to form the protective oxide scale. The alloys are likely border-line for protection and slightly more chromium in the matrix is giving it sufficient protection.

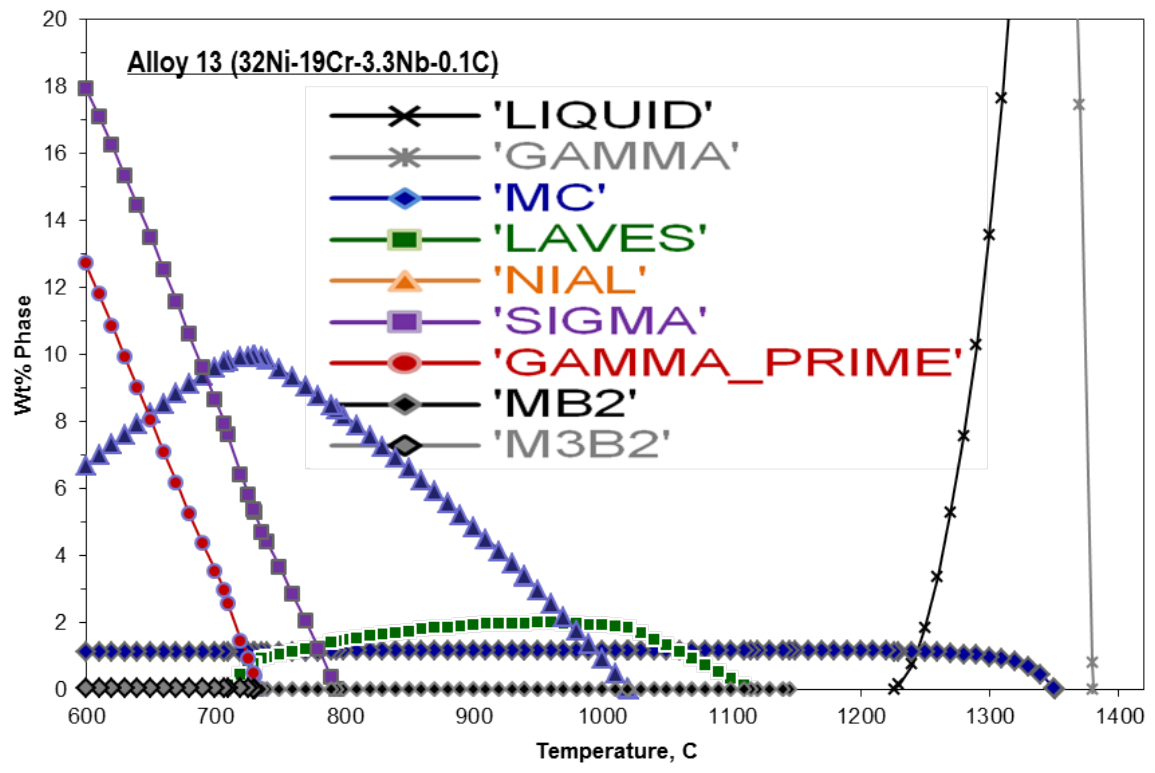

Figure 106: Predicted phases of OC8 as a function of temperature [87] 


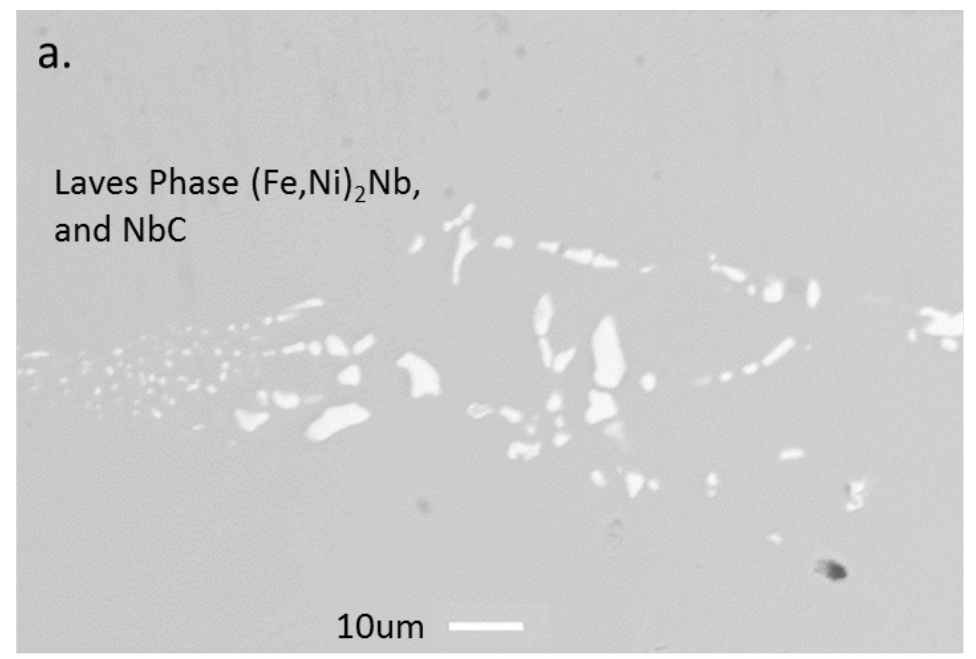

Figure 107: Microstructure of OC8 as processed

The OC8 alloy displayed excellent corrosion resistance in the SCM deposit. It is a promising alloy for high temperature applications. However at long durations, thermodynamic studies show that it will form brittle sigma phase. Thermodynamic calculations show the predicted phases with temperature in Figure 106. The as-processed microstructure is shown in Figure 107 and contains Laves phase, $(\mathrm{Fe}, \mathrm{Ni})_{2} \mathrm{Nb}$, and $\mathrm{NbC}$. Once again, this is indicative of that what would be predicted at a temperature around $1100^{\circ} \mathrm{C}$, where the alloy was heat treated. The corrosion resistance of the alloy was excellent with the SCM in its as-processed form, but the microstructure after it has slowly changed to its equilibrium lower temperature microstructure affects its long term corrosion resistance. An SEM image of the microstructure of the OC8 specimen after it has been aged at $700^{\circ} \mathrm{C}$ for 2350 hours is shown in Figure 108. It contains some Laves Phase, $\mathrm{NbC}$, and $\mathrm{NiAl}$ at the grain boundaries. 


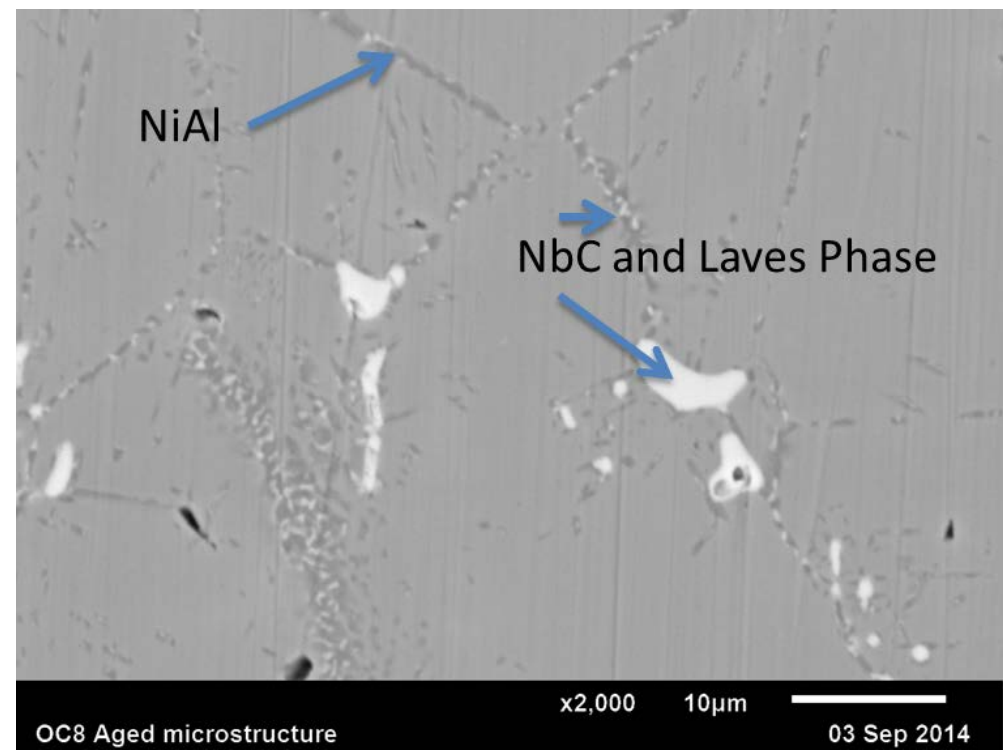

Figure 108: OC8 aged 2350 hours microstructure

The aged specimen was etched in the same manner as the other aged alloys and a small amount of sigma phase was detected at the grain boundaries. This can be seen in Figure 109. The microstructure is that which would be predicted at a temperature around $750-800^{\circ} \mathrm{C}$, which is a similar rate to how fast the OCS and OCT microstructures changed. 


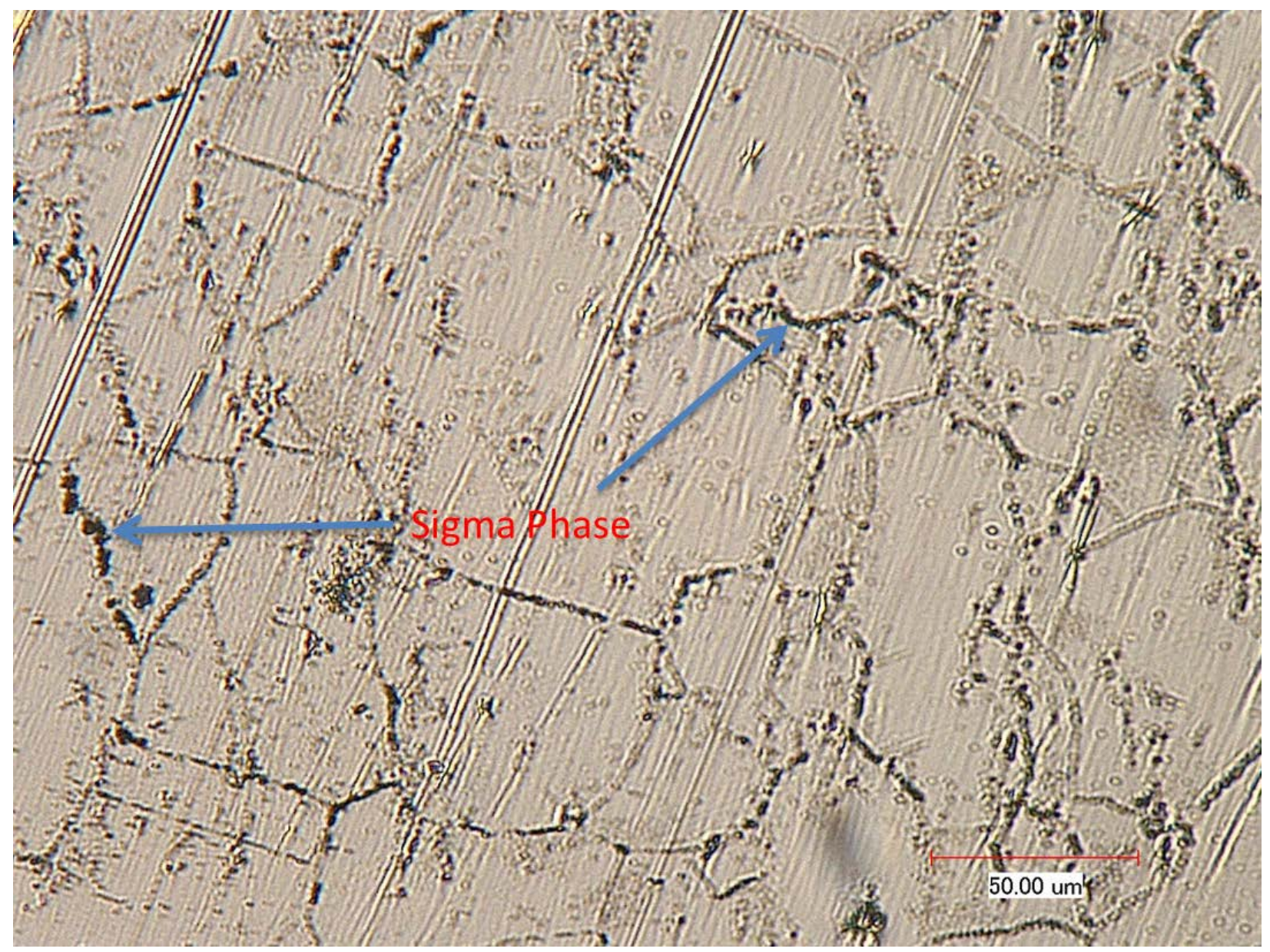

Figure 109: Etched microstructure of $\mathrm{OC} 8$ aged 2350 hours at $700^{\circ} \mathrm{C}$ displaying sigma phase formation at the grain boundaries 


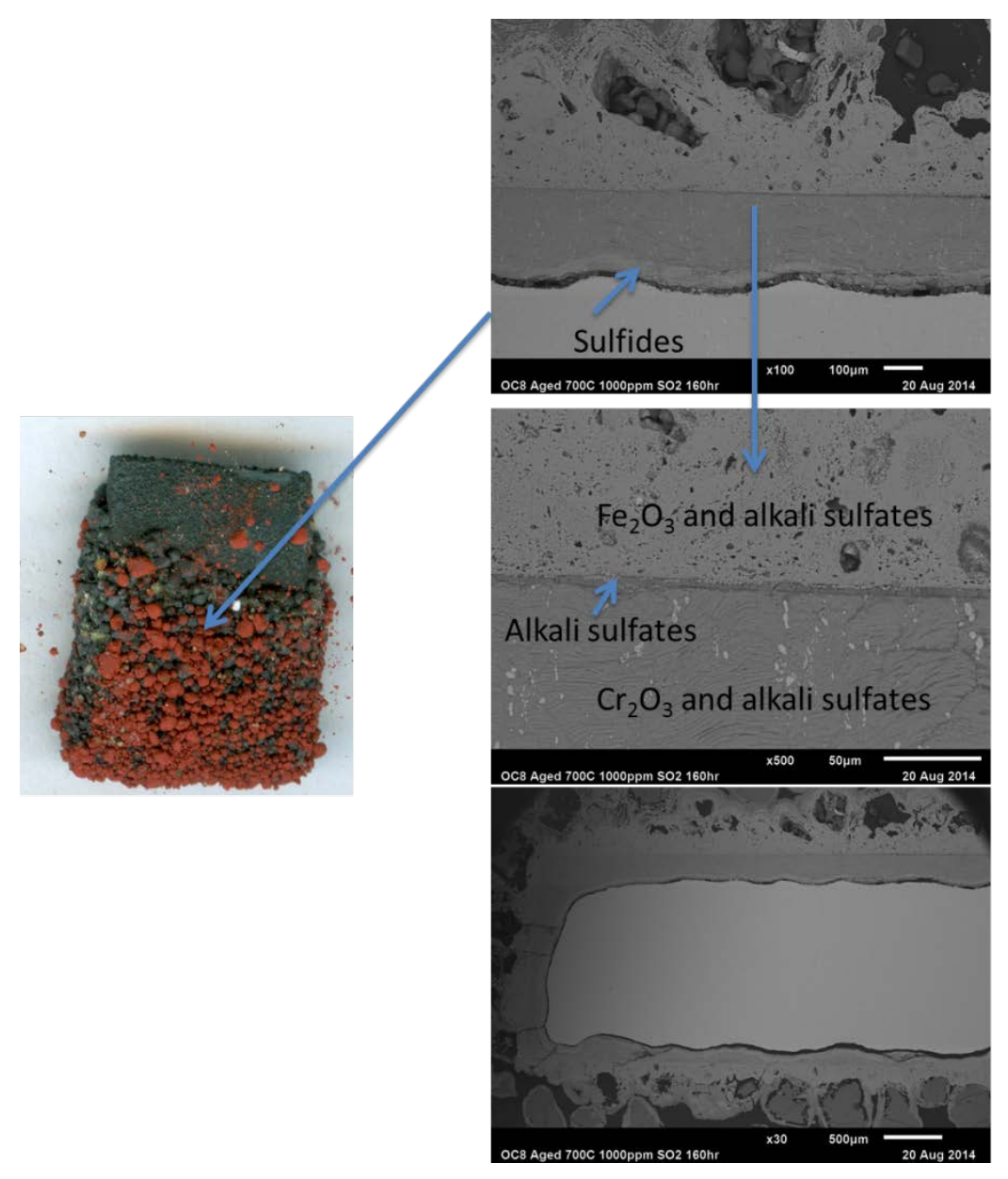

Figure 110: OC8 aged 2350 hours at $700^{\circ} \mathrm{C}$ exposed at $700^{\circ} \mathrm{C}$ with the SCM powder deposit in $\mathrm{O}_{2}+1000 \mathrm{ppm}$ $\mathrm{SO}_{2}$ for 160 hours

The aged OC8 specimen was then exposed at $700^{\circ} \mathrm{C}$ with the SCM powder deposit in $\mathrm{O}_{2}$ $+1000 \mathrm{ppm} \mathrm{SO}_{2}$ for 160 hours. The results are shown in Figure 110. The corrosion products are similar to what was described in previous sections. The specimen was severely corroded and it is evident that there is a large amount of metal loss (average $=99.96 u m$ ). This is in stark contrast with the results of the as-processed specimen shown in Figure 89 (average $=0$ metal loss). The changed microstructure has significantly reduced the corrosion resistance of this alloy, making it useless for long durations. The big change in the microstructure is the 
appearance of sigma phase. Sigma phase is a sluggishly forming, brittle intermetallic phase. It is not only undesirable for its brittle nature, but also it's characteristic to take chromium away from the austenite matrix. The formation of sigma phase in the aged OC8 is taking chromium away from the austenite matrix, so there is less available to form a protective oxide scale on the surface. The change in $\mathrm{Cr}$ composition and $\mathrm{Cr}$ activity for OC8 with temperature was calculated with help from Yuki Yammamoto and Mike Brady at Oak Ridge National Laboratory. The results are shown in Figure 111 and Table 13.

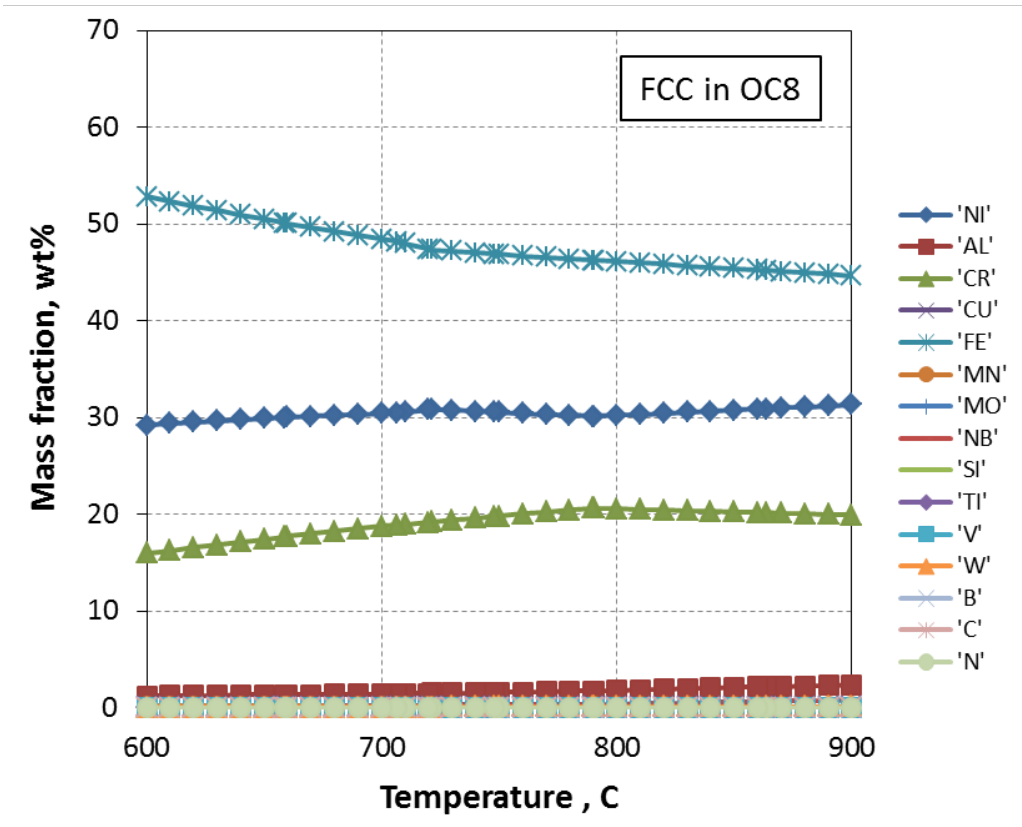

Figure 111: OC8 composition change with temperature [87] 
Table 13: OC8 Cr content and $\mathrm{Cr}$ activity change with temperature [87]

\begin{tabular}{|c|c|c|}
\hline Temperature $\left({ }^{\circ} \mathrm{C}\right)$ & Cr Content (wt.\%) & Cr Activity \\
\hline 900 & 19.9117 & 0.645936 \\
\hline 890 & 19.98499 & 0.655001 \\
\hline 880 & 20.05749 & 0.66435 \\
\hline 870 & 20.12919 & 0.673996 \\
\hline 863.63699 & 20.17439 & 0.680293 \\
\hline 860 & 20.2 & 0.683944 \\
\hline 850 & 20.26987 & 0.694206 \\
\hline 840 & 20.33897 & 0.704808 \\
\hline 830 & 20.40726 & 0.715766 \\
\hline 820 & 20.47475 & 0.727096 \\
\hline 810 & 20.54143 & 0.738816 \\
\hline 800 & 20.60727 & 0.750944 \\
\hline 790.45132 & 20.66936 & 0.762925 \\
\hline 790 & 20.6601 & 0.763106 \\
\hline 780 & 20.4538 & 0.767184 \\
\hline 770 & 20.24568 & 0.771402 \\
\hline 760 & 20.03579 & 0.775764 \\
\hline 750 & 19.82416 & 0.780278 \\
\hline 748.10129 & 19.78378 & 0.781152 \\
\hline 740 & 19.61312 & 0.785042 \\
\hline 730 & 19.40024 & 0.789958 \\
\hline 721.33475 & 19.21378 & 0.794324 \\
\hline 720 & 19.18936 & 0.794815 \\
\hline 710 & 18.99445 & 0.797922 \\
\hline 706.71382 & 18.92571 & 0.7987 \\
\hline 700 & 18.76569 & 0.801434 \\
\hline
\end{tabular}

The Cr content in the austenite matrix does not significantly decrease when the microstructure changes from its as processed microstructure down to its equilibrium lower temperature. The aged OC8 alloy had a microstructure that was characteristic of that at a temperature around 750$800^{\circ} \mathrm{C}$. At these temperatures, the austenite matrix should have sufficient amounts of Cr to remain protective (19.82-20.6 wt. \%). The sigma phase is taking Cr from the alloy, but not an amount that would cause the amount of corrosion that occurred and the large change from the 
corrosion resistance in its as-processed state. The change in Cr activity is more marked. There is an increase in the Cr activity in the austenite matrix as the microstructure changes, which may be affecting the decrease in corrosion resistance. The fact that the sigma phase forms at the grain boundaries is likely more important. The grain boundaries would be expected to be high in chromium, as they provide rapid-diffusion paths for protective Cr to reach the corrosion front. Sigma phase forming at the grain boundaries ties up this chromium, preventing faster diffusion to the corrosion front and locally reducing the amount of $\mathrm{Cr}$ available for protection.

Specimens of OC8, OCS, and OCT exposed to creep tests for longer durations were then examined. The OC8 specimens were from a 7000 hour creep test at $650^{\circ} \mathrm{C}$ provided by Oak Ridge National Laboratory (ORNL). The microstructure of the specimens after 7000 hours at this temperature is shown in Figure 112 compared with the as processed microstructure. The calculated predicted phases were presented in Figure 106. [87]
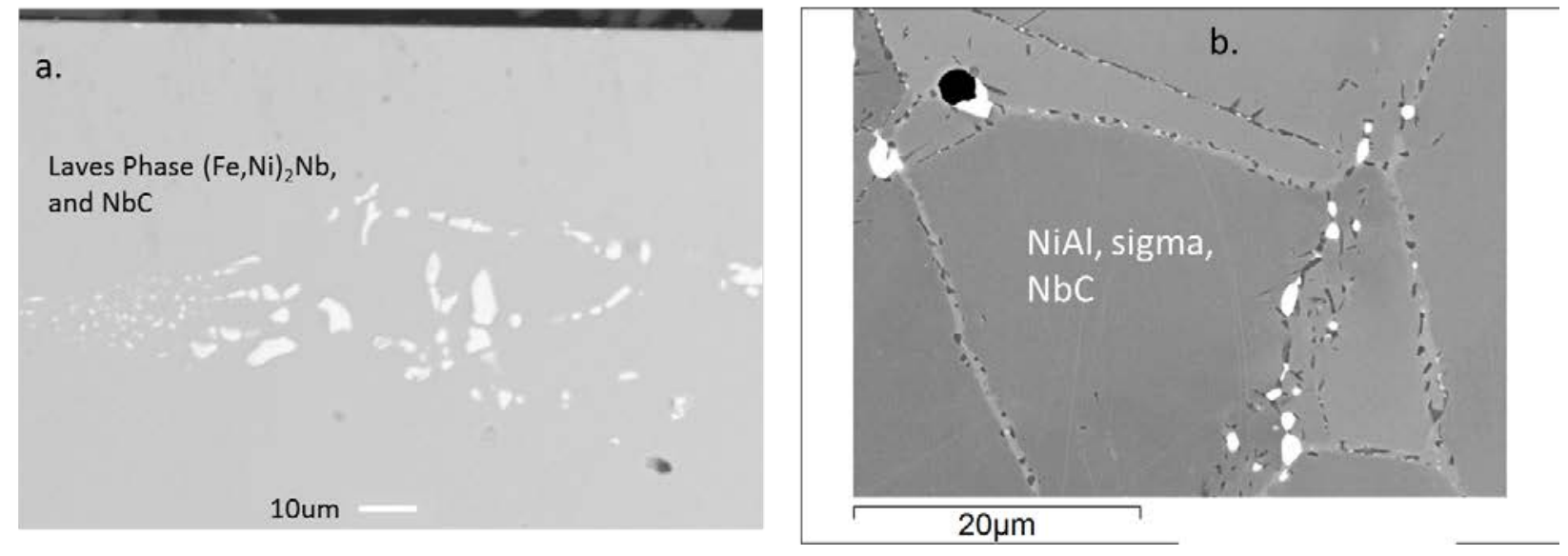

Figure 112: OC8 as-processed microstructure (a.) compared with 7000 hour creep at $650^{\circ} \mathrm{C}$ specimen microstructure (b.)

The as processed microstructure is representative of the predicted phases at $1100-1200^{\circ} \mathrm{C}$, the temperature at which the alloy was processed. Laves phase and NbC are evident. The 7000 hour 
creep specimen at $650^{\circ} \mathrm{C}$ is more representative of the microstructure predicted at that temperature. Significant amounts of sigma phase, $\mathrm{NbC}$, and NiAl were detected with help from Forschungzentrum Juelich in Juelich, Germany. This can be seen in Figure 113. After 7000 hours, the microstructures are finally in their equilibrium low temperature state.
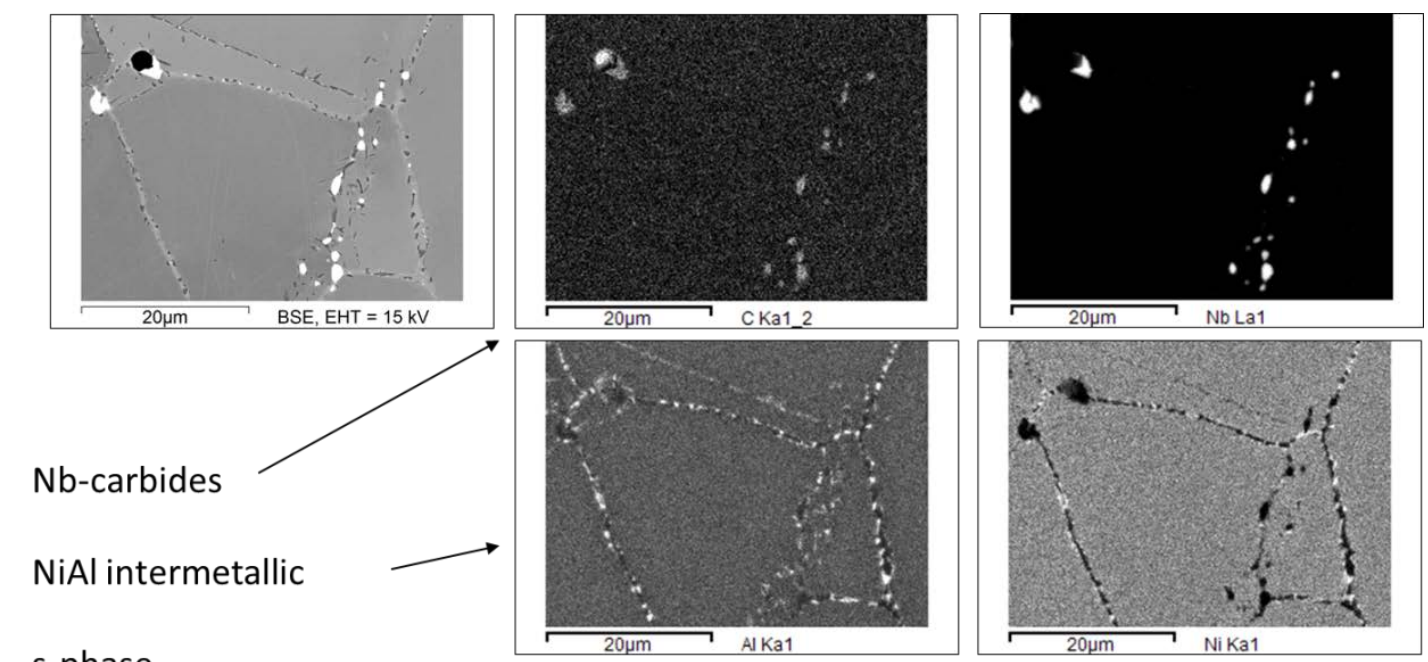

s-phase
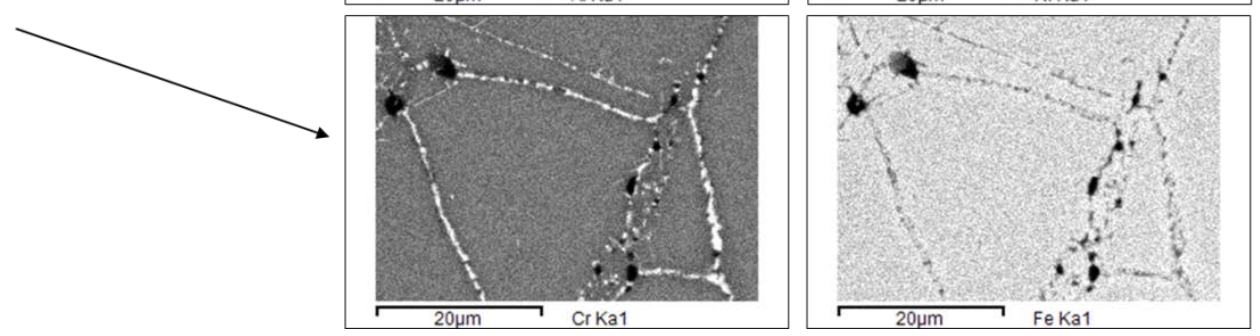

Figure 113: Phase maps of OC8 7000 hour creep specimen at $650^{\circ} \mathrm{C}$ 


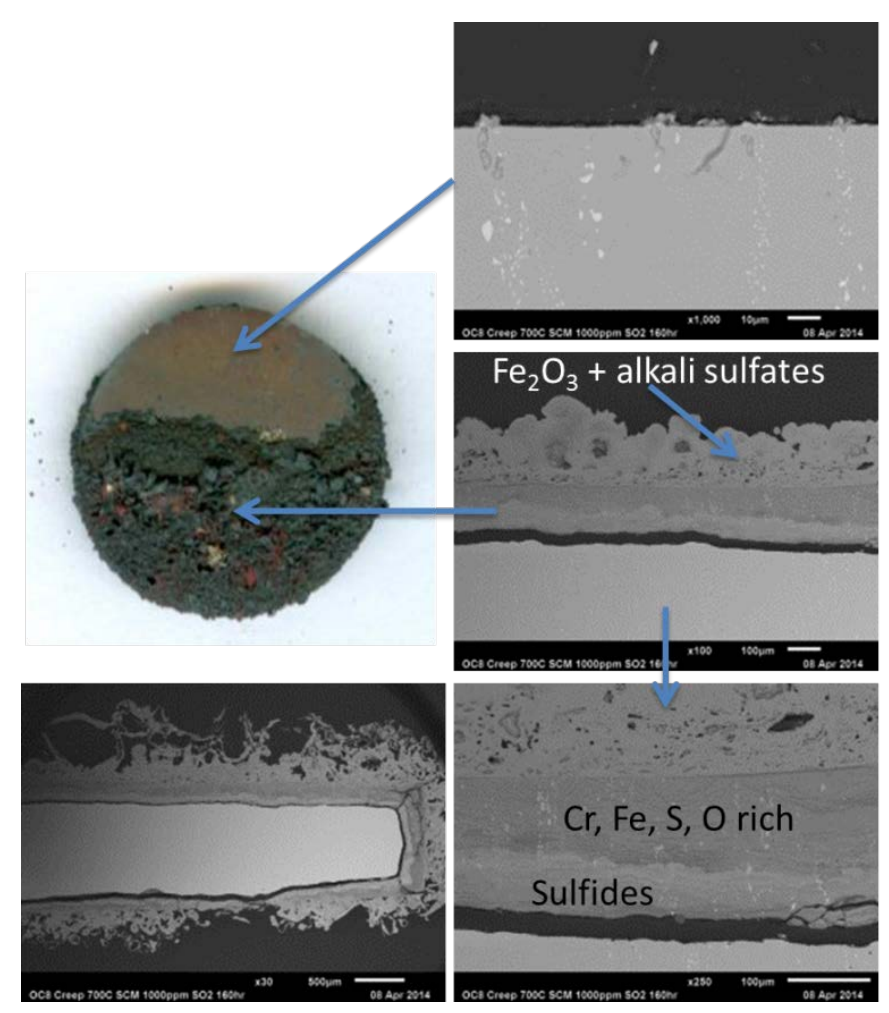

Figure 114: $0 C 87000$ hour creep specimens exposed at $700^{\circ} \mathrm{C}$ with the $\mathrm{SCM}$ in $\mathrm{O}_{2}+1000 \mathrm{ppm} \mathrm{SO}_{2}$ for 160 hours

These specimens were then exposed at $700^{\circ} \mathrm{C}$ with the SCM in $\mathrm{O}_{2}+1000 \mathrm{ppm} \mathrm{SO}_{2}$ for 160 hours. The results are shown in Figure 114. The amount of corrosion and metal loss was significant (average $=139.05 \mathrm{um}$ ), and similar to that seen with the aged specimen discussed previously. The amount of metal loss was greater with the creep specimen than with the aged specimen, indicating that as more sigma phase has formed, the corrosion resistance has decreased. The sigma phase that has formed at the grain boundaries has locally decreased the amount of chromium there. The grain boundaries act as diffusion paths for chromium to reach the surface, and this is prevented by the formation of sigma phase. 
As more sigma phase is formed, there is less chromium available to reach the surface. The sigma phase depletes the beneficial effects of chromium, and therefore decreases the fireside corrosion resistance of this alloy.

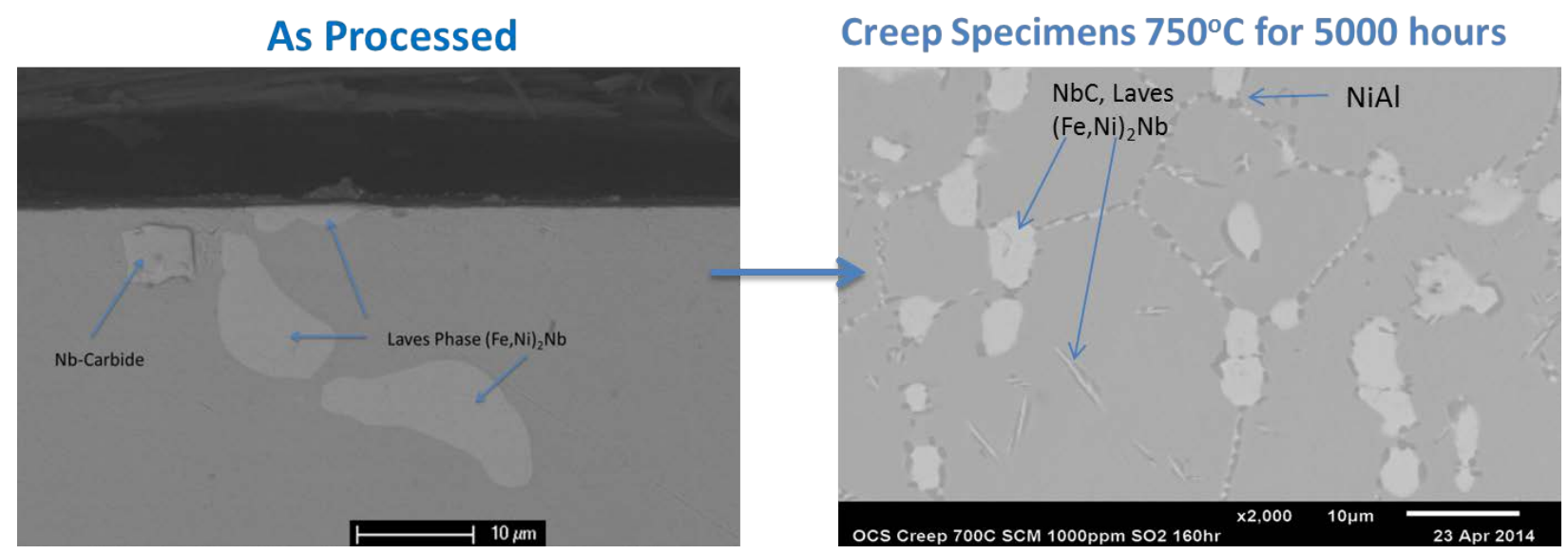

Figure 115: As-processed and OCS 5000 hour creep specimen microstructures

OCS and OCT creep specimens were also provided by ORNL. The OCS specimens were from a 5000 hour creep test and the OCT specimens were from a 5500 hour creep test $750^{\circ} \mathrm{C}$. The microstructure of OCS and OCT was examined in the SEM and is compared with the asprocessed microstructure in Figure 115. The creep specimen has noticable increases in NbC and Laves phase as well as $\mathrm{NiAl}$, characteristic of the microstructure that would be predicted at $750^{\circ} \mathrm{C}$. The specimens were etched in order to examine if sigma phase had formed, and the results did not show that any was produced. The predicted phases for these alloys from Figures 96 and 97 confirm that at $750^{\circ} \mathrm{C}$ sigma phase would not be expected to form. These specimens were also exposed at $700^{\circ} \mathrm{C}$ with the $\mathrm{SCM}$ in $\mathrm{O}_{2}+1000 \mathrm{ppm} \mathrm{SO}_{2}$ for 160 hours. The results are shown in Figure 116. 

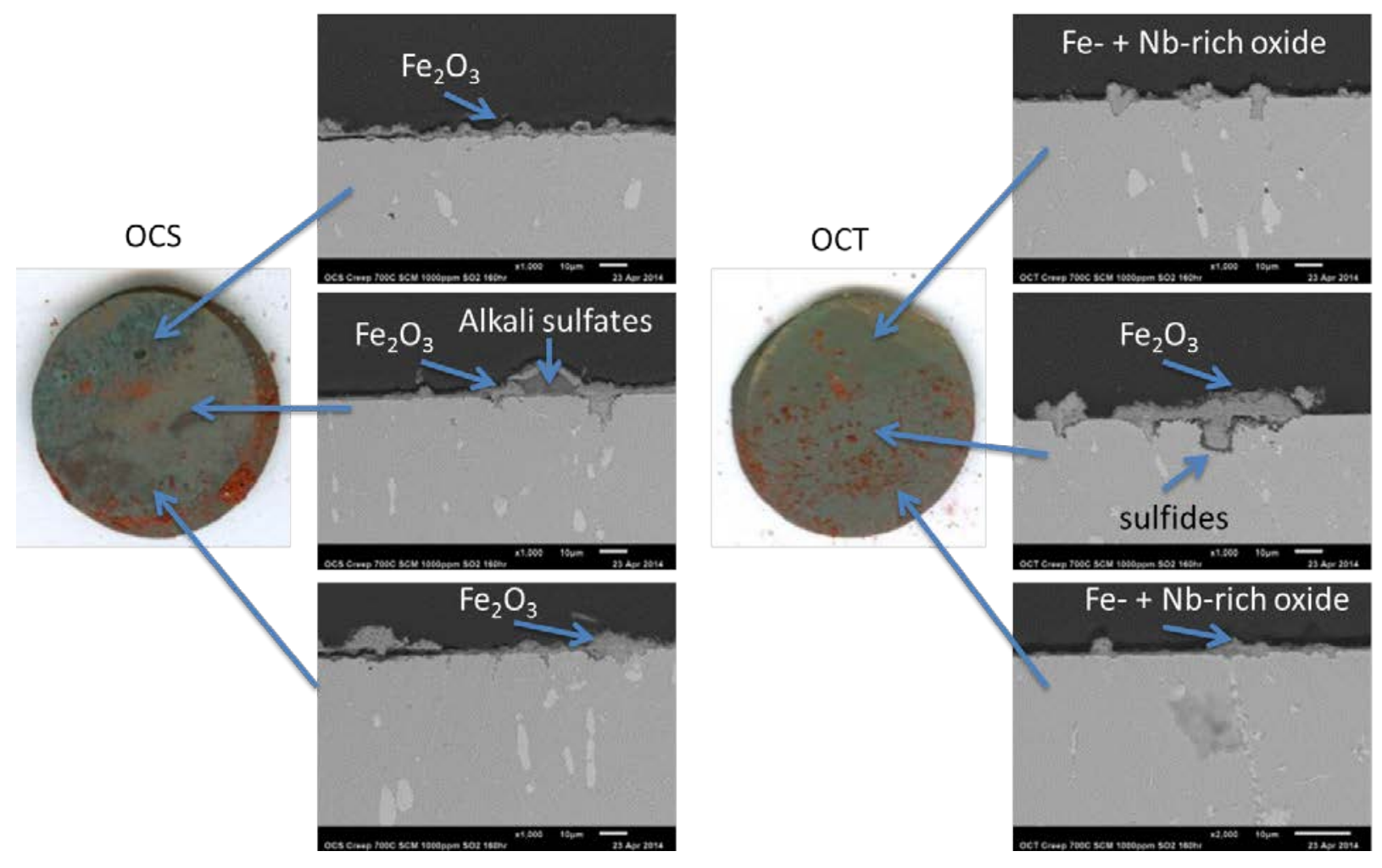

Figure 116: OCS 5000 hour and OCT 5500 hour creep specimens exposed at $700^{\circ} \mathrm{C}$ with the SCM powder deposit in $\mathrm{O}_{2}+1000 \mathrm{ppm} \mathrm{SO}_{2}$ for $160 \mathrm{hr}$

There was not a significant amount of degradation. There were some areas where thick oxides grew on the surface and some internal pits, but they were small. Where the $\mathrm{NbC}$ and Laves phases met the surface Fe- and Nb-rich oxides grew. The fact that these specimens were not seriously degraded and that they did not have any sigma phase formation supports the previous results with the OC8 alloy, that sigma phase formation at the grain boundaries decreases the corrosion resistance of the alloy. The specimens likely also performed well due to a noticeable increase in the amount $\mathrm{NbC}$ and Laves phase in the specimen and near the surface, which was explained previously.

In summary, in their as-processed state with the SCM, OC4 suffered severe spallation and was not protective, while OC8, which contains a higher $\mathrm{Cr}$ content remained protective. 
This alloy is promising, but at longer durations, undesirable sigma phase has been shown to form. The OCS and OCT alloys showed a large amount of variability in the results. These alloys are likely borderline alloys for protection. Specimens with higher volume fractions of Laves phase and $\mathrm{NbC}$ seemed to perform better. Larger amounts of $\mathrm{NbC}$ may mean less $\mathrm{Cr}$ is tied-up into carbides, allowing more chromium to be in the austenite matrix and provide more available to form a protective oxide scale. Larger amounts of Laves phase, $(\mathrm{Fe}, \mathrm{Ni})_{2} \mathrm{Nb}$, means there is less $\mathrm{Nb}$ in the austenite matrix, creating locally more $\mathrm{Cr}$ available to form a protective scale. In the M1 deposit, each of the alloys was severely degraded, even the OC8 alloy which performed well with the SCM. The corrosion was independent of alloy composition. The corrosion mechanism is the same for these alloys as the corrosion mechanism for the Cr-forming alloys, but there is the addition of $\mathrm{Al}$ to the internal corrosion pits and at the base forming sulfides. The solubility curve for alumina is similar to that for chromia, so synergistic fluxing should still occur in a similar manner. There was no variability in the OCS and OCT results with the M1 deposit. The AFA alloys are really sluggish to reach their equilibrium microstructure at the temperature tested. Specimens of OC8, OCS, and OCT were aged at $700^{\circ} \mathrm{C}$ for 2350 hours and then retested in the SCM. The OCS and OCT specimens were not degraded. The microstructures were still not at the equilibrium $700^{\circ} \mathrm{C}$ microstructure as significant amounts of Laves phase and $\mathrm{NbC}$ as well as NiAl could be seen, and no sigma phase was found, which could be reasons for the corrosion protection. The OC8 alloy was severely degraded as some sigma phase had formed at the grain boundaries. The grain boundaries would be expected to be high in chromium, as they provide rapid-diffusion paths for protective $\mathrm{Cr}$ to reach the corrosion front. Sigma phase forming at the grain boundaries ties up this chromium, preventing faster diffusion to the corrosion front and locally reducing the amount of $\mathrm{Cr}$ available for protection. The OC8, 
OCS, and OCT alloys were also subjected to longer duration creep tests (5000-7000 hours) and then retested in the SCM. The OC8 alloy contained significant amounts of sigma phase and was severely degraded, likely due to the sigma formation at the grain boundaries. The OCS and OCT alloys were once again not degraded, but at the temperature the creep tests were performed, sigma phase would still not be expected to form, further confirming that sigma phase formation in AFA alloys after longer durations (once they reach their low temperature equilibrium microstructure) reduces corrosion resistance.

\subsection{TEMPERATURE EFFECT}

It was mentioned in the Background sections that the corrosion rate for superheater tubes follows a bell-shaped curve as a function of temperature and the maximum of this curve falls in the temperature range of $650-750^{\circ} \mathrm{C}$. A $(\mathrm{Na}, \mathrm{K})_{2} \mathrm{SO}_{4}-\mathrm{Fe}_{2}\left(\mathrm{SO}_{4}\right)_{3}$ solution becomes molten in this temperature range and corrosion occurs via the mechanism described previously. The maximum amount of corrosion should occur at the highest temperature in which sufficient amounts of $\mathrm{SO}_{3}$ are in the gas to form the liquid salt. The $\mathrm{SO}_{3}$ and $\mathrm{SO}_{2}$ curves in Figure 4, if combined, would make a bell-shaped curve representing this. Other researchers have studied the maximum temperature in the bell-shaped curve with varying test conditions. Reid[15] found that the maximum was at $650^{\circ} \mathrm{C}$, while Natasan[19] using synthetic deposits containing varying amounts of $\mathrm{Al}_{2} \mathrm{O}_{3}, \mathrm{SiO}_{2}, \mathrm{Fe}_{2} \mathrm{O}_{3}, \mathrm{Na}_{2} \mathrm{SO}_{4}, \mathrm{NaCl}$, and $\mathrm{K}_{2} \mathrm{SO}_{4}$ in air plus $1 \% \mathrm{SO}_{2}$ found that it was at $725^{\circ} \mathrm{C}$. The maximum temperature of the bell-shaped curve can be influenced by many factors such as alloy composition, deposit composition, and gas atmosphere. Syed et al.[2,57] found that the maximum corrosion rate was at $650^{\circ} \mathrm{C}$ for air-firing and $700^{\circ} \mathrm{C}$ for oxy-firing, and that oxy-firing 
shifted the maximum in the curve to higher temperatures. The deposit composition may also affect this maximum temperature, with $\mathrm{CaO}$ or $\mathrm{SiO}_{2}$ pushing the maximum temperature higher as well due to the formation of higher melting compounds in the deposit. The exact maximum corrosion rate temperature is therefore highly dependent on the atmosphere and the variables mentioned. These variables were studied in more detail and will be described in the subsequent sections.

The maximum in the curve was first determined using base conditions of the SCM powder in $\mathrm{O}_{2}+1000 \mathrm{ppm} \mathrm{SO}_{2}$ for 160 hours. Tests were conducted at $650^{\circ} \mathrm{C}, 700^{\circ} \mathrm{C}$, and $750^{\circ} \mathrm{C}$ on the spinel and chromia-forming $\mathrm{T} 92$ and $\mathrm{FeNiCr}$ alloys under these conditions. The macroscopic results are shown in Figure 117. The largest amount of corrosion appears at $700^{\circ} \mathrm{C}$. Cross-sections of the specimens were examined in the SEM, and the corrosion products were the same as described in the Mechanism Study sections. Weight change and metal loss values were used to characterize the corrosion rate for the alloys at each temperature. The results are presented in the plots in Figure 118. 


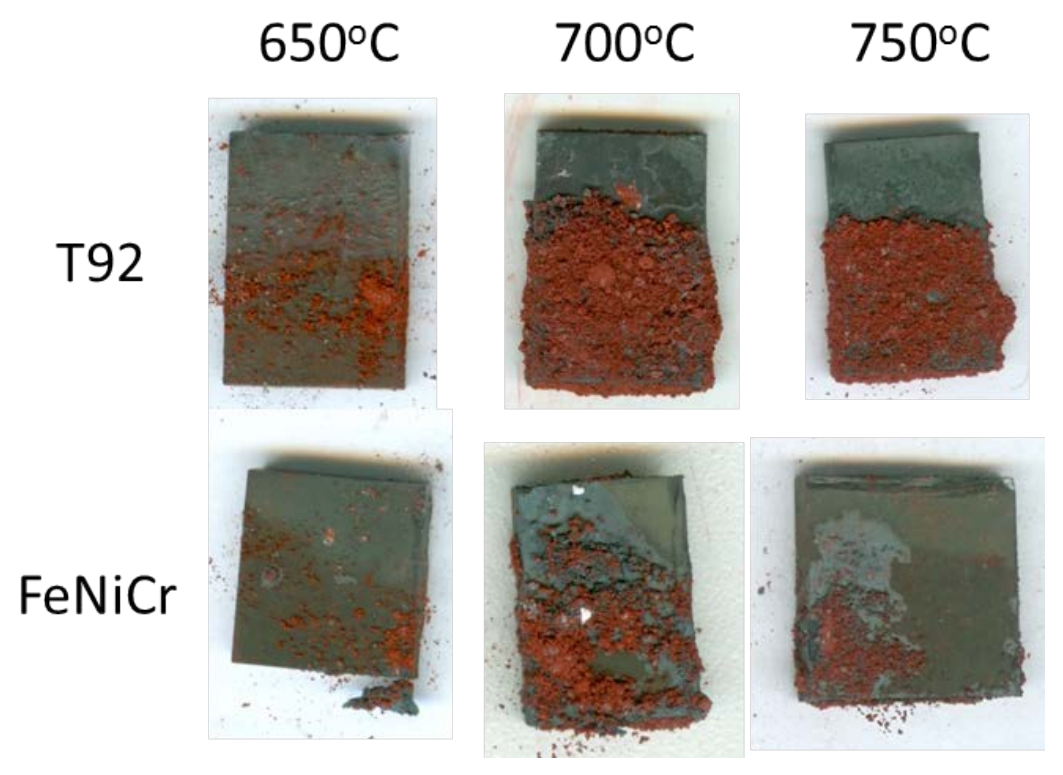

Figure 117: Macroscopic images of T92 and FeNiCr exposed at $650^{\circ} \mathrm{C}, 700^{\circ} \mathrm{C}$, and $750^{\circ} \mathrm{C}$ with the $\mathrm{SCM}$ powder in $\mathrm{O}_{2}+1000$ ppm $\mathrm{SO}_{2}$ for 160 hours
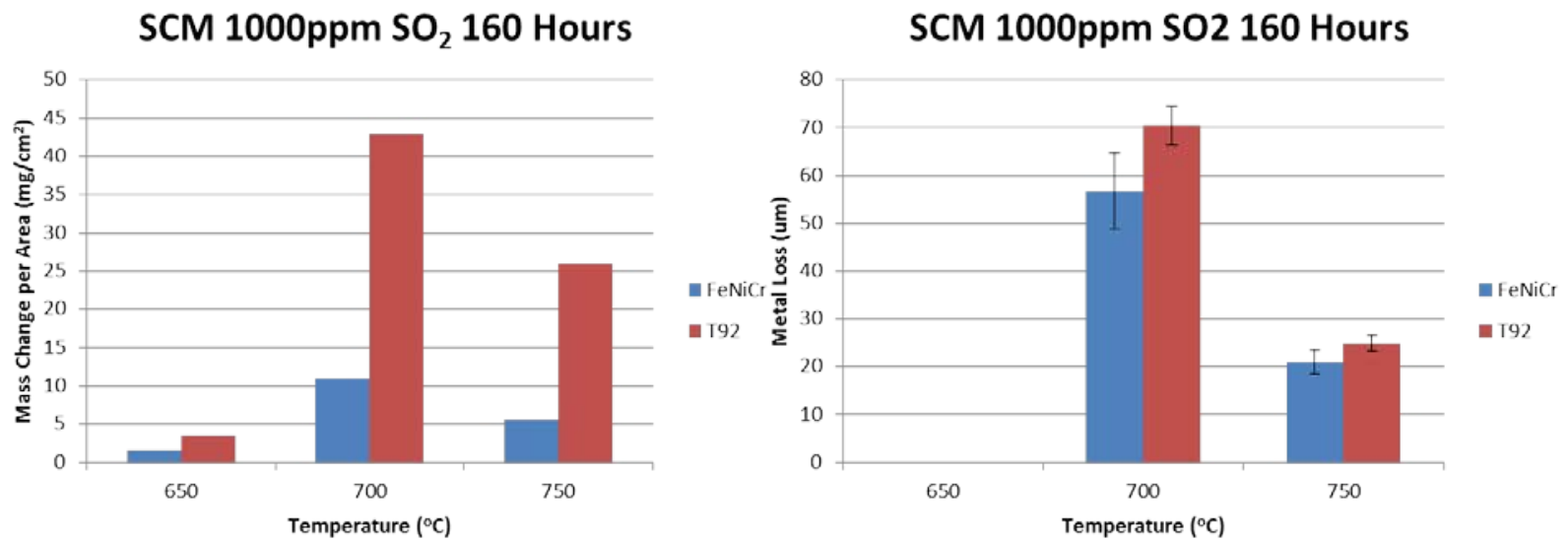

Figure 118: Weight change and metal loss plots of T92 and FeNiCr exposed at $650^{\circ} \mathrm{C}, 700^{\circ} \mathrm{C}$, and $750^{\circ} \mathrm{C}$ with the SCM powder in $\mathrm{O}_{2}+1000 \mathrm{ppm} \mathrm{SO}_{2}$ for 160 hours

The weight change and metal loss plots match well with the macroscopic images. The largest amount of degradation occurs at $700^{\circ} \mathrm{C}$, and it appears to follow a bell-shaped curve. There was more degradation at $750^{\circ} \mathrm{C}$ than $650^{\circ} \mathrm{C}$, as there was essentially no corrosion of the alloys when 
tested at $650^{\circ} \mathrm{C}$. This can again be related to the $\mathrm{K}_{2} \mathrm{SO}_{4}-\mathrm{Fe}_{2}\left(\mathrm{SO}_{4}\right)_{3}$ phase diagram. At $650^{\circ} \mathrm{C}$, the liquid solution will not form as rapidly as it would at higher temperatures, as more $\mathrm{Fe}_{2}\left(\mathrm{SO}_{4}\right)_{3}$ will be required to form the liquid. The degradation may be lower at $750^{\circ} \mathrm{C}$ due to many factors. As the temperature increases, the equilibrium amount of $\mathrm{SO}_{3}$ in the gas decreases, and therefore there is less available to form the liquid melt. As the temperature increases, the amount of transient oxides will decrease as the protective oxide scales will grow more rapidly. There will be less $\mathrm{Fe}_{2} \mathrm{O}_{3}$ to react with $\mathrm{SO}_{3}$ in the gas atmosphere and form $\mathrm{Fe}_{2}\left(\mathrm{SO}_{4}\right)_{3}$. Also, as the temperature changes, the solubility curves will have shifted. With the shift, the synergistic fluxing rate will likely have decreased as the melt basicity will likely have moved to regions on the solubility curves where synergistic fluxing cannot occur at a maximum rate. The maximum synergistic fluxing rate may therefore be at $700^{\circ} \mathrm{C}$. This also indicates that there may be a bellshaped curve for Type II hot corrosion of alloys as well. These tests show that under these conditions, the temperature in the bell-shaped curve which produces the maximum amount of corrosion is $700^{\circ} \mathrm{C}$, and there is a rapid rise in corrosion from $650^{\circ} \mathrm{C}$ to $700^{\circ} \mathrm{C}$. This temperature is higher than that found by Reid[15] and Syed[2,57] and just slightly less than that found by Natasan[19]. Tests would need to be conducted at $725^{\circ} \mathrm{C}$ to confirm this. It should be noted that the exact test conditions were not the same between each of these groups. The results may be dependent on many experimental and atmospheric factors some of which will be studied and discussed in the subsequent sections. 


\subsubsection{Effect of Deposit Composition on the Maximum Temperature}

The deposit composition can have a large impact on the amount of corrosion that occurs, as was seen in the Deposit Composition Effect sections, but it also may affect the maximum temperature of the bell-shaped corrosion curve. The SCM deposit was used as a base deposit to compare the effect of oxide additions on the maximum temperature in the bell-shaped corrosion curve. T92 and FeNiCr were exposed with the SCM-A, SCM-C, and SCM-S powder deposits at $650^{\circ} \mathrm{C}$, $700^{\circ} \mathrm{C}$, and $750^{\circ} \mathrm{C}$ in $\mathrm{O}_{2}+1000 \mathrm{ppm} \mathrm{SO}$ for 160 hours. The results are shown in Figures 119 and 120 as weight change and metal loss values (for bars not seen in plot, weight change and metal loss was minimal).
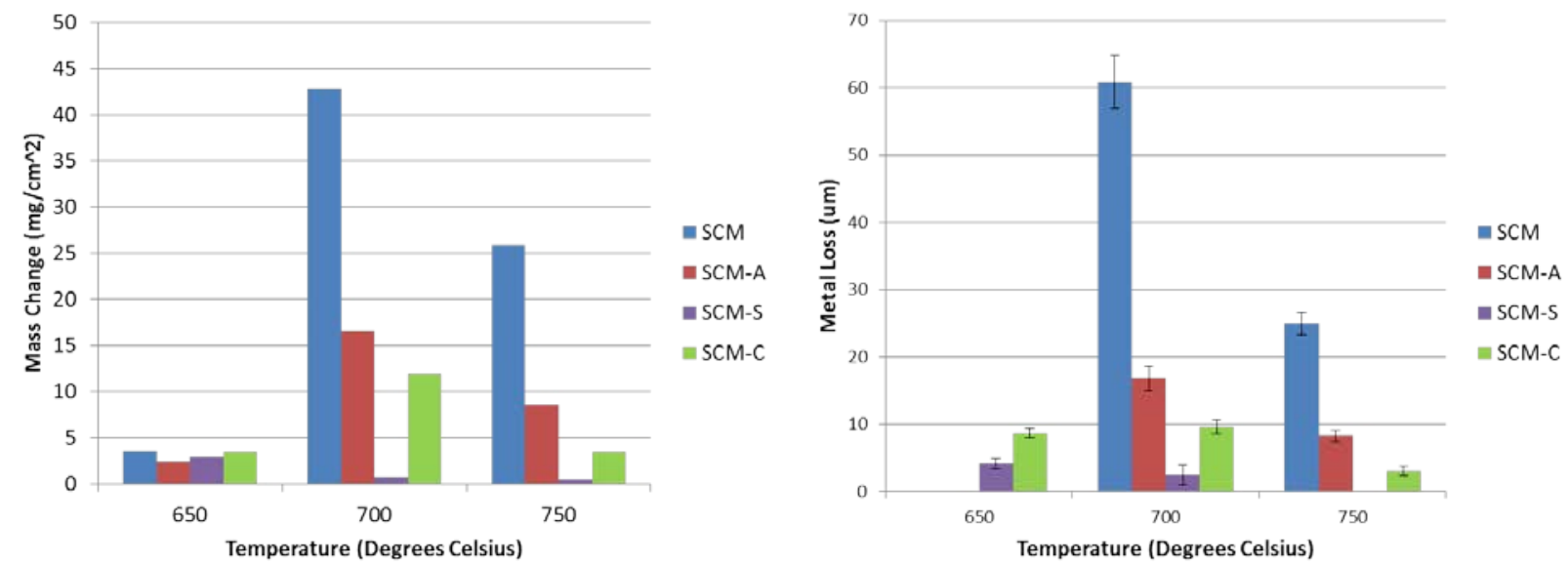

Figure 119: Mass Change and metal loss of T92 exposed at 650, 700, and $750^{\circ} \mathrm{C}$ with the SCM, SCM-A, SCM$\mathrm{S}$, and SCM-C powder deposits in $\mathrm{O}_{2}+1000 \mathrm{ppm} \mathrm{SO}_{2}$ for 160 hours 

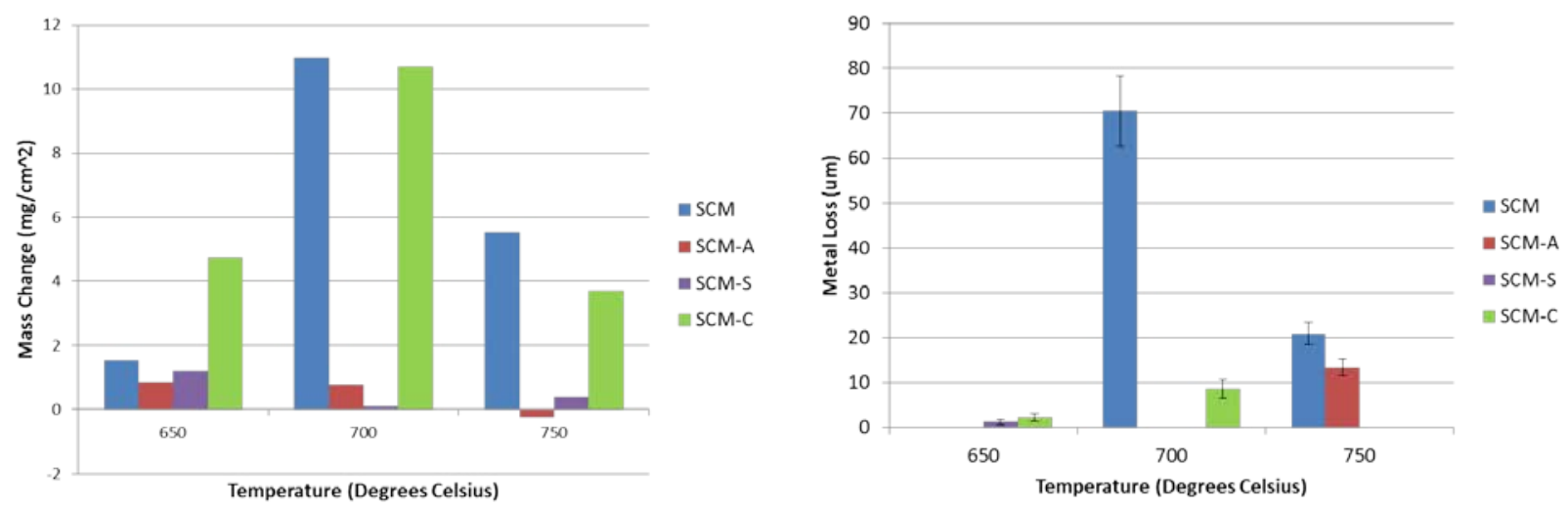

Figure 120: Mass Change and metal loss of FeNiCr exposed at 650,700 , and $750^{\circ} \mathrm{C}$ with the SCM, SCM-A, SCM-S, and SCM-C powder deposits in $\mathrm{O}_{2}+1000 \mathrm{ppm} \mathrm{SO} \mathrm{S}_{2}$ for 160 hours

The bell-shaped curve remains in the same position with a maximum around $700^{\circ} \mathrm{C}$. The oxide additions did not appear to shift it in any direction. There was less corrosion with these deposits than with the SCM at each temperature, as was the case with the tests in the Alloy Composition sections. Cross-sections were examined of the specimens and the corrosion products were also the same as described previously in the Deposit Composition Effect sections. The oxide additions change the melt basicity and shift further up or down the solubility curves given in Figure 24, so that the cycle between basic and acidic fluxing described earlier takes longer and synergistic fluxing is not occurring at a maximum rate. The additions of $\mathrm{SiO}_{2}$ or $\mathrm{CaO}$ to the deposit may also dilute the amount of alkali sulfates and $\mathrm{SO}_{3}$ able to form the liquid solution and cause corrosion. It was explained previously that when calcia is added to the deposit, it forms $\mathrm{K}_{2} \mathrm{Ca}_{2}\left(\mathrm{SO}_{4}\right)_{3}$, which has a melting point of $875^{\circ} \mathrm{C}$ and would not be molten or corrosive at the temperatures tested. When silica is added to the deposit, it will form $(\mathrm{K}, \mathrm{Na})_{2} \mathrm{Si}_{2} \mathrm{O}_{5}$, which has a melting point around $874^{\circ} \mathrm{C}$. If the boiler tubes were exposed at higher temperatures in the range of the melting points of these compounds, then the bell-shaped curve may shift toward that higher temperature, however in the temperature range of interest, it appears as though the deposit 
composition does not have a large effect on the maximum temperature in the bell-shaped corrosion curve. The amount of corrosion decreases with the oxide additions due to a change in melt basicity and a reduction in the synergistic fluxing rate, but the maximum amount of corrosion still occurs around $700^{\circ} \mathrm{C}$ and is due to the right amount of $\mathrm{SO}_{3}$ in the gas atmosphere and the solution becoming liquid at this temperature.

\subsubsection{Effect of Alloy Composition on the Maximum Temperature}

The alumina-forming austenitic alloys OC4 and OC8 developed by Oak Ridge National Laboratory were tested at $650^{\circ} \mathrm{C}, 700^{\circ} \mathrm{C}$, and $750^{\circ} \mathrm{C}$ in order to examine the effect of alloy composition on the maximum temperature in the bell-shaped corrosion curve. The AFA alloys were tested using the SCM at 650,700 , and $750^{\circ} \mathrm{C}$ in $\mathrm{O}_{2}+1000 \mathrm{ppm} \mathrm{SO}_{2}$ for 160 hours. Macroscopic images of the results at each temperature, for each of the alloys is presented in Figure 121 compared with the two chromia-forming alloys. 


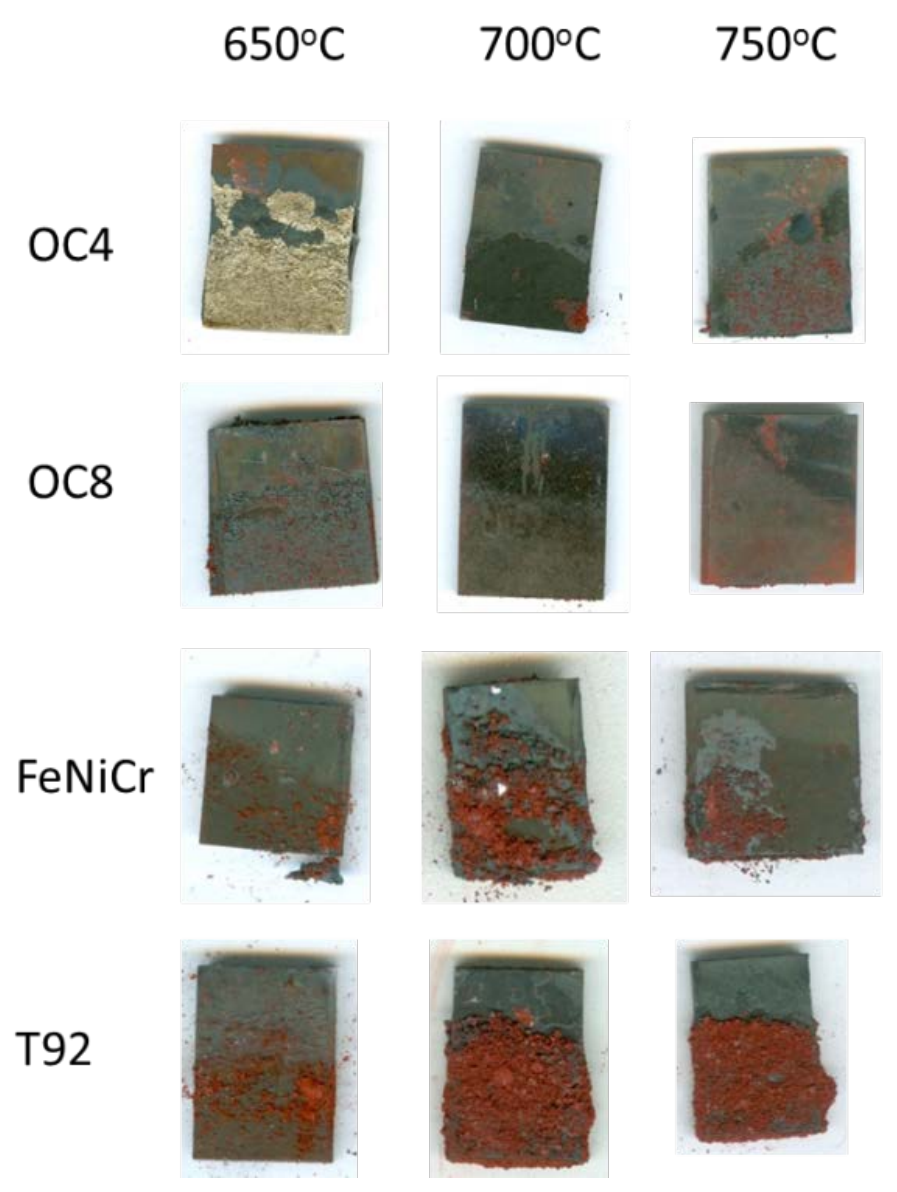

Figure 121: Macroscopic images of AFA alloys compared with Cr-forming alloys tested at various temperatures with the SCM powder in $\mathrm{O}_{2}+1000 \mathrm{ppm} \mathrm{SO}_{2}$ for 160 hours

The amount of degradation at each temperature was calculated by using weight change and metal loss plots. The results can be seen in Figures 122 and 123, compared with the results from the chromia-forming alloys T92 and FeNiCr. 
SCM 1000ppm SO 160 Hours

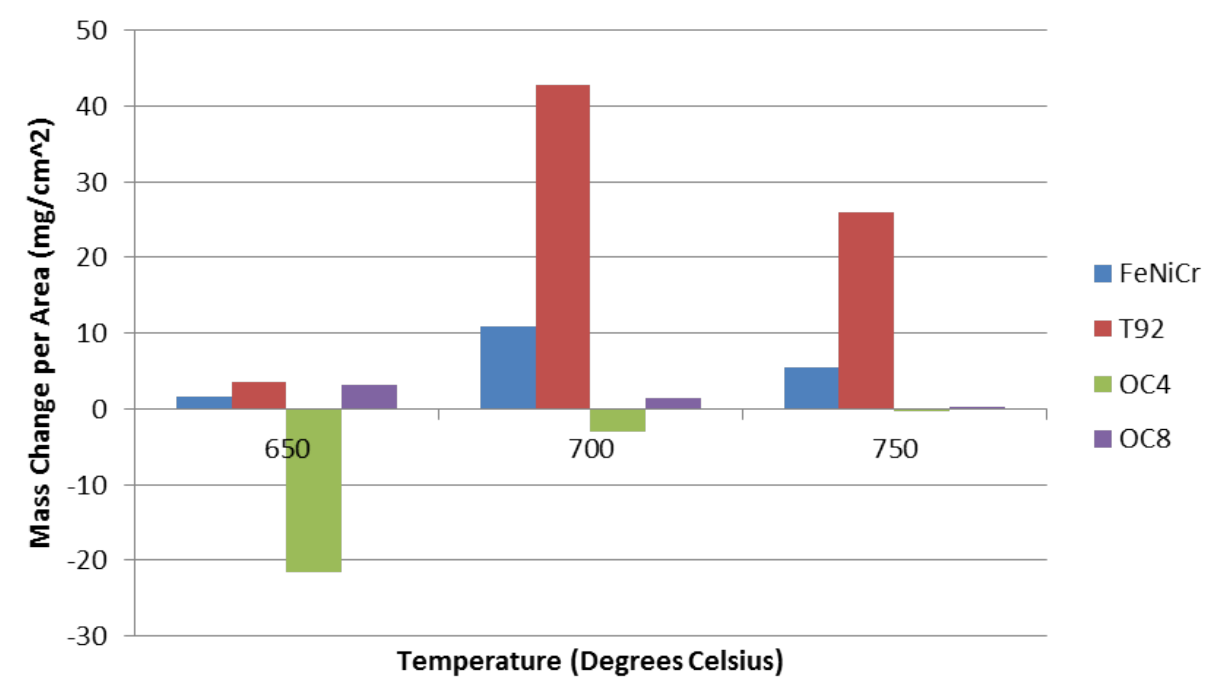

Figure 122: Mass Change of AFA alloys compared with Cr-forming alloys tested at various temperatures with the $\mathrm{SCM}$ powder in $\mathrm{O}_{2}+1000 \mathrm{ppm} \mathrm{SO}_{2}$ for 160 hours

SCM 1000ppm SO 160 Hours

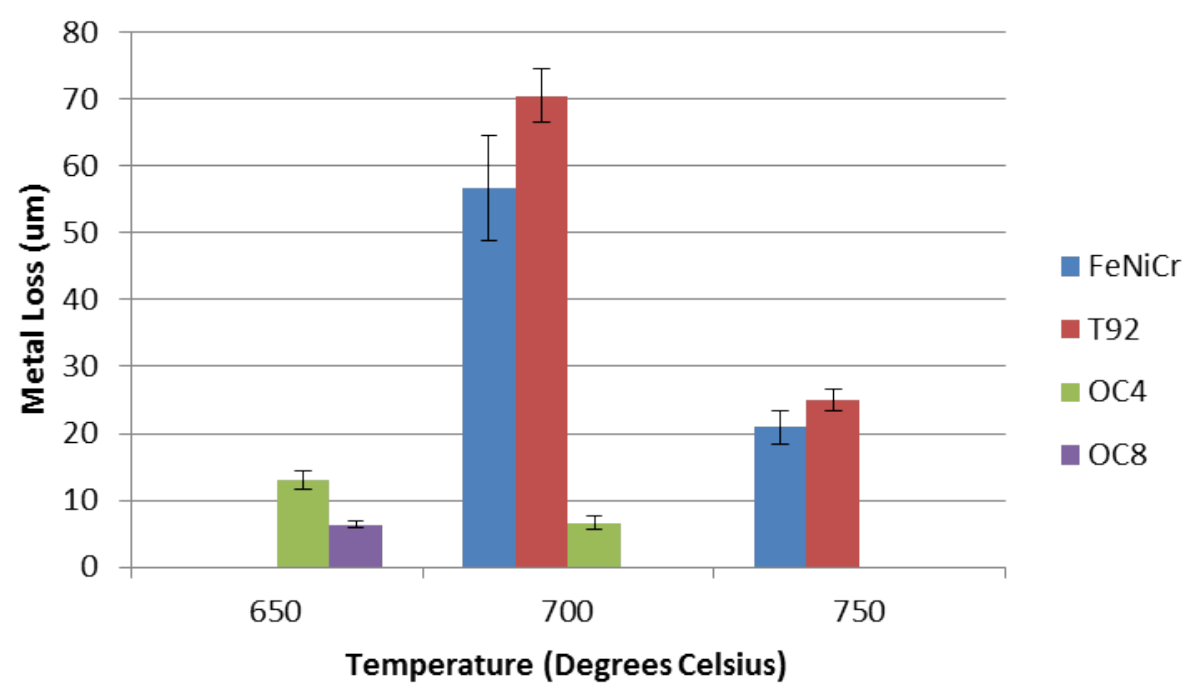

Figure 123: Metal loss of AFA alloys compared with Cr-forming alloys tested at various temperatures with the SCM powder in $\mathrm{O}_{2}+1000 \mathrm{ppm} \mathrm{SO}_{2}$ for 160 hours 


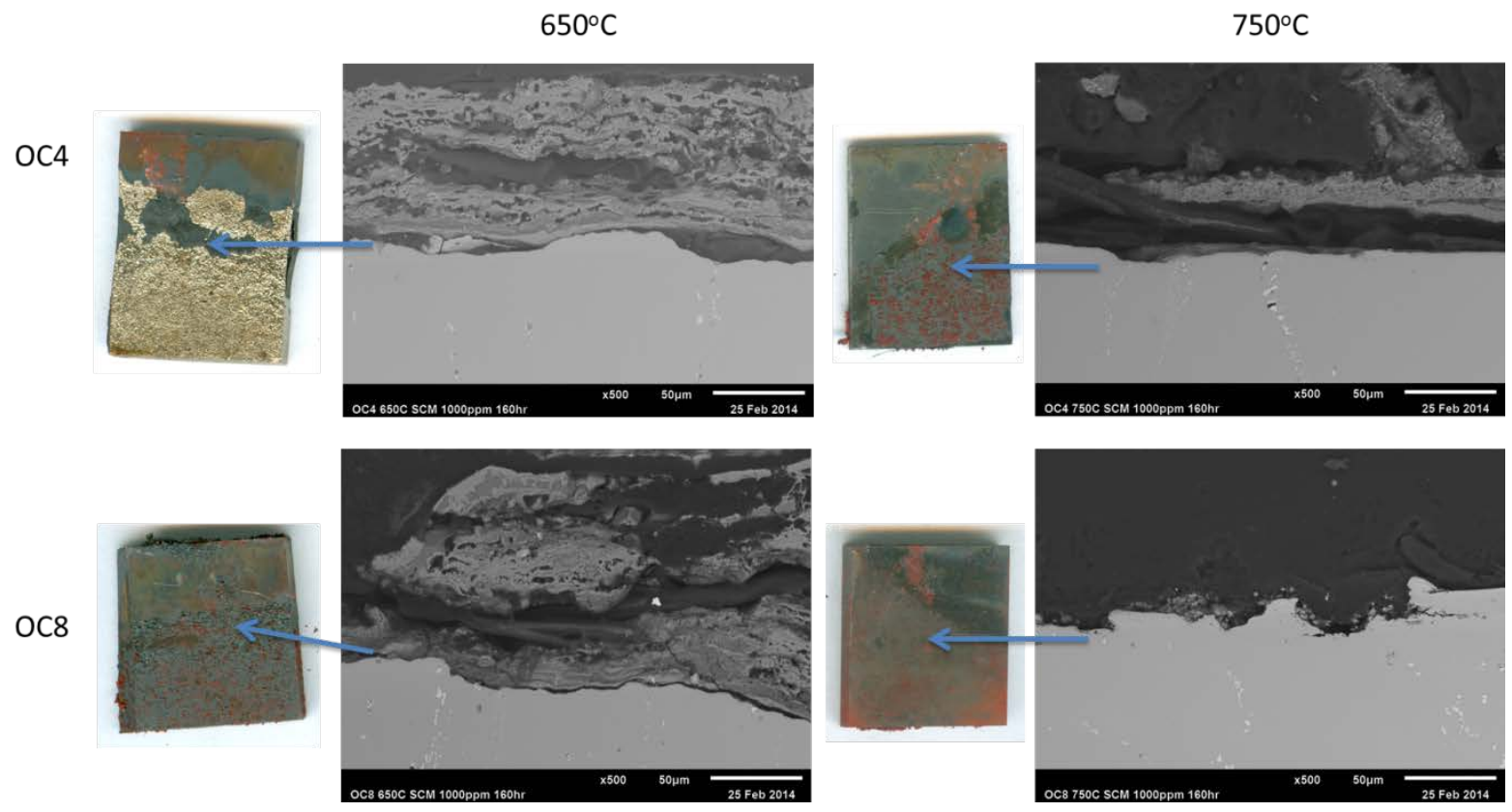

Figure 124: Cross-sectional microscopic images of $\mathrm{OC} 4$ and $0 \mathrm{OC} 8$ exposed at $650^{\circ} \mathrm{C}$ and $750^{\circ} \mathrm{C}$ with the SCM powder deposit in $\mathrm{O}_{2}+1000 \mathrm{ppm} \mathrm{SO}_{2}$ for 160 hours

Cross-sectional SEM images of the results are shown in Figure 124 . The results at $700^{\circ} \mathrm{C}$ were presented back in Figures 89 and 90, and can be used as a comparison. Where there was no spallation for the OC4 specimens and in areas where there was degradation of the OC8 specimens, the corrosion products contained iron rich oxide external scales mixed in with alkali sulfates. The largest amount of degradation occurred for the AFA alloys at $650^{\circ} \mathrm{C}$, which is lower than $700^{\circ} \mathrm{C}$ for the $\mathrm{Cr}$-forming alloys. The maximum amount of degradation at $650^{\circ} \mathrm{C}$ was less than the maximum amount for the Cr-forming alloys at $700^{\circ} \mathrm{C}$, but still a noticeable amount. The bell-shaped curve for the AFA alloys appears to have shifted to a lower temperature of $650^{\circ} \mathrm{C}$. The AFA alloys were tested in their as-processed state, so the microstructures have not changed to their equilibrium low-temperature state and are similar to that shown in Figure 92, containing some Laves phase and NbC but not a large amount. The temperatures and pressures 
needed for advanced ultra-supercritical oxy-combustion boilers are increasing, and if these alloys perform better at higher temperatures, then they might be promising alloys for these applications. The OC8 creep specimens discussed previously were severely degraded when exposed at $700^{\circ} \mathrm{C}$ with the SCM in $\mathrm{O}_{2}+1000 \mathrm{ppm} \mathrm{SO}_{2}$ for 160 hours due to the formation of sigma phase. Specimens were tested under the same conditions but at $750^{\circ} \mathrm{C}$ to see if the slight improvement at the higher temperature found in the as-processed state would have any effect on the corrosion resistance when the specimen is in its equilibrium microstructure. The results are presented in Figure 125. There was noticeably less corrosion at the higher temperature when compared to the $700^{\circ} \mathrm{C}$ results in Figure 110. There were areas of internal sulfidation and oxidation rich in $\mathrm{Cr}$, $\mathrm{Al}, \mathrm{S}$, and $\mathrm{O}$ with external Fe and $\mathrm{Nb}$-rich oxides on top, but the amount of degradation was not as severe as the results at $700^{\circ} \mathrm{C}$. When simply oxidized, the AFA alloys had a greater oxidation rate as the temperature increased from $650^{\circ} \mathrm{C}$ to $800^{\circ} \mathrm{C} .[48-49,90]$ However, the oxidation was still minimal compared to the degradation occurring with fireside corrosion. Fireside corrosion is much more severe than simple oxidation, and the bell-shaped curve that exists is shifted to lower temperatures for the AFA alloys. These alloys may be more promising as the temperatures and pressures in boilers increase. 


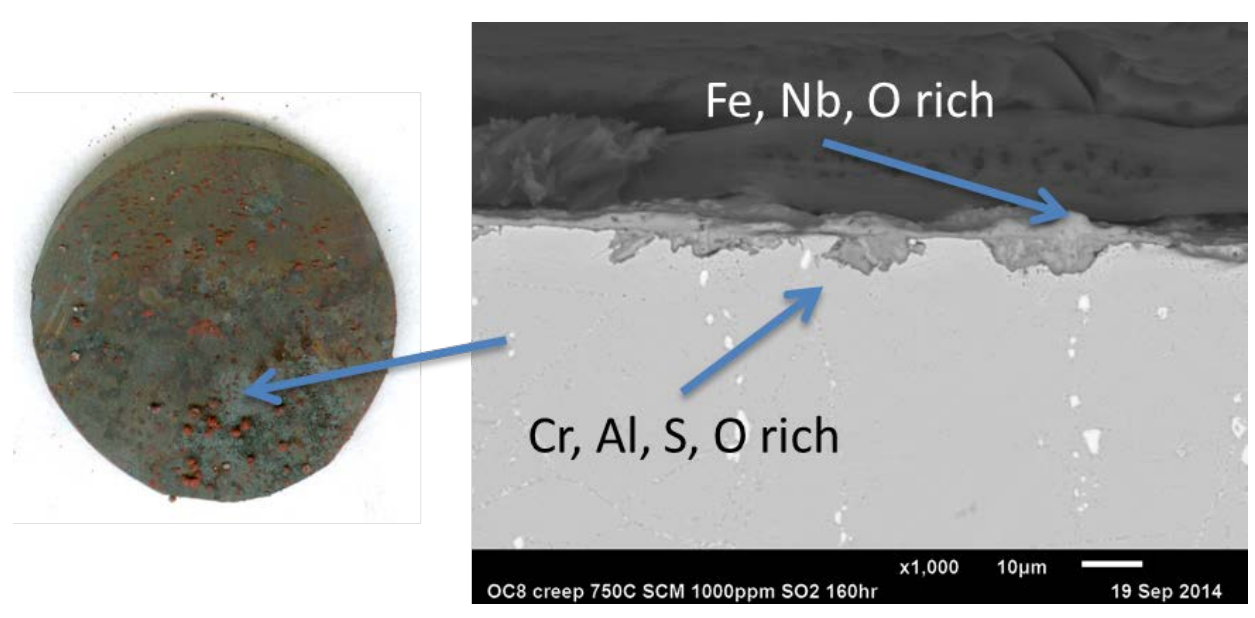

Figure 125: OC8 7000 hour creep specimen exposed at $750^{\circ} \mathrm{C}$ with the SCM powder deposit in $\mathrm{O}_{2}+1000 \mathrm{ppm}$ $\mathrm{SO}_{2}$ for 160 hours

\subsection{DEPOSIT THICKNESS EFFECT}

A liquid $(\mathrm{Na}, \mathrm{K})_{2} \mathrm{SO}_{4}-\mathrm{Fe}_{2}\left(\mathrm{SO}_{4}\right)_{3}$ solution was described as facilitating the corrosion that occurs on the tubes. $\mathrm{SO}_{3}$ migrates in through to the corrosion front through the liquid melt. The $\mathrm{SO}_{3}$ concentration in the molten sulfate is the equilibrium concentration at that temperature, and deposits of varying thickness will cause different $\mathrm{SO}_{3}$ concentrations at the metal surface, setting up a corrosion potential gradient. Thicker deposits will delay the $\mathrm{SO}_{3}$ from reaching the corrosion front, and therefore slowing down the corrosion rate. Because the tests in this study were conducted isothermally, the deposit thickness is likely affecting the corrosion rate due to a corrosion potential gradient with the $\mathrm{SO}_{3}$. The effect of deposit thickness was examined by using two deposition procedures. The powder-crucible method allows the examination of three deposit zones, while the slurry coating method allows for a more precise measurement of the effects of deposit thickness on the amount of corrosion. 


\subsubsection{Powder-Crucible Method}

The powder-crucible method allows for the examination of three deposit zones with each specimen. The specimens were placed into alumina crucibles with the deposit powder, so that half of the specimen was covered. This allows for the examination of a no-deposit zone, a thin deposit zone (where the powder first starts to cover the specimen), and a thick deposit zone (where the specimen is completely submerged in the powder at the base of the crucible). This is illustrated in the schematic presented in Figure 126.

\section{Deposit thickness effect}

- No deposit zone

- Thin Deposit zone

- Thick deposit zone

Figure 126: Schematic of the three deposit zones able to be analyzed when using the powder-crucible method (the red area denotes the region covered in the deposit)

It was mentioned in previous sections that the tests using this method showed that corrosion appears to initiate in the thin deposit zone and work its way down the specimen, to where eventually the thick deposit zone becomes corroded as well. An example of this is shown in Figure 127. The corrosion has clearly started and is the largest in the thin deposit zone. 


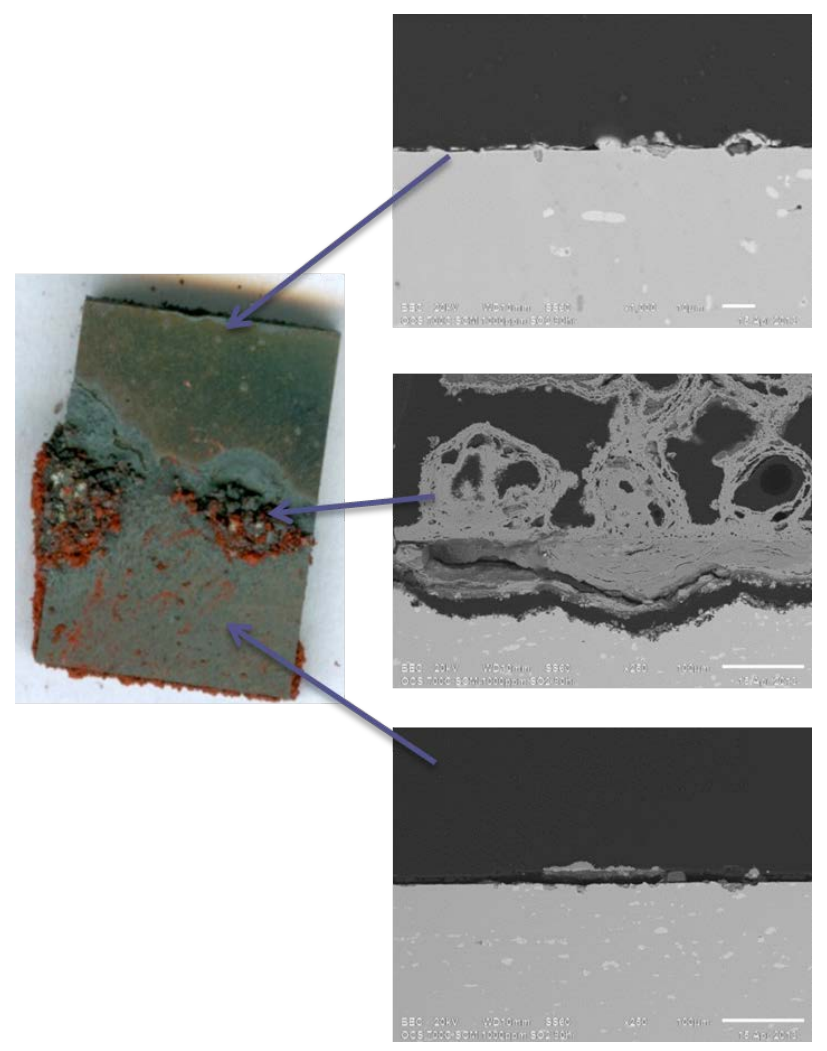

Figure 127: OCS exposed at $700^{\circ} \mathrm{C}$ with the SCM using the powder-crucible method in $\mathrm{O}_{2}+1000 \mathrm{ppm} \mathrm{SO}_{2}$ for 80 hours

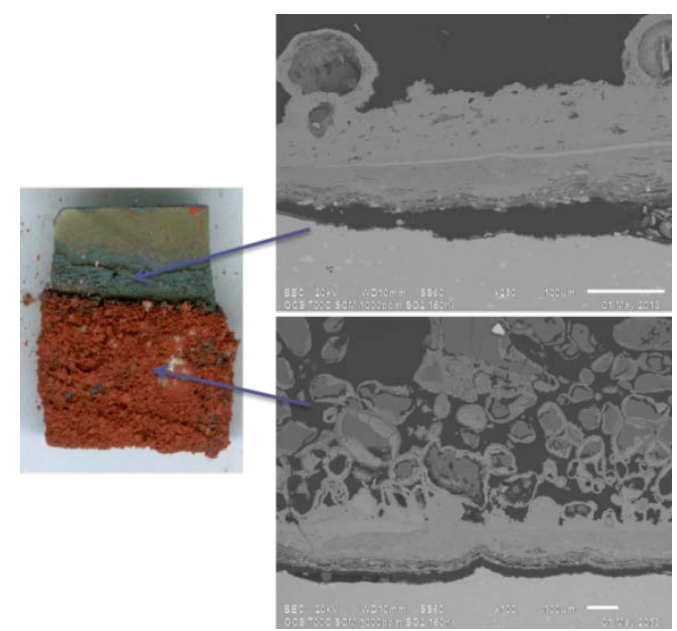

Figure 128: OCS exposed at $700^{\circ} \mathrm{C}$ with the SCM using the powder-crucible method in $\mathrm{O}_{2}+1000 \mathrm{ppm} \mathrm{SO}_{2}$ for 160 hours 
Figure 128 shows the same test but for a longer duration, and the entire deposit zone (thick and thin) is severely degraded, and there was even some pitting and corrosion in the non-deposit zone. Once the liquid deposit forms, it appears to migrate up the specimen into the non-deposit zone, where with further time they would produce corrosion as described in the mechanism sections. This is what is seen in Figure 128, as it appears as though liquid has traveled up into the non-deposit zone and started causing pitting and corrosion. This shows that the liquid precedes severe degradation. This was examined further by calculating the metal loss of specimens with respect to position on the specimen and time. The T92 and FeNiCr specimens tested at $700^{\circ} \mathrm{C}$ with the SCM powder deposit in $\mathrm{O}_{2}+1000 \mathrm{ppm} \mathrm{SO}_{2}$ were examined in this manner. The results are presented for T92 and FeNiCr in Figures 129 and 130 respectively.

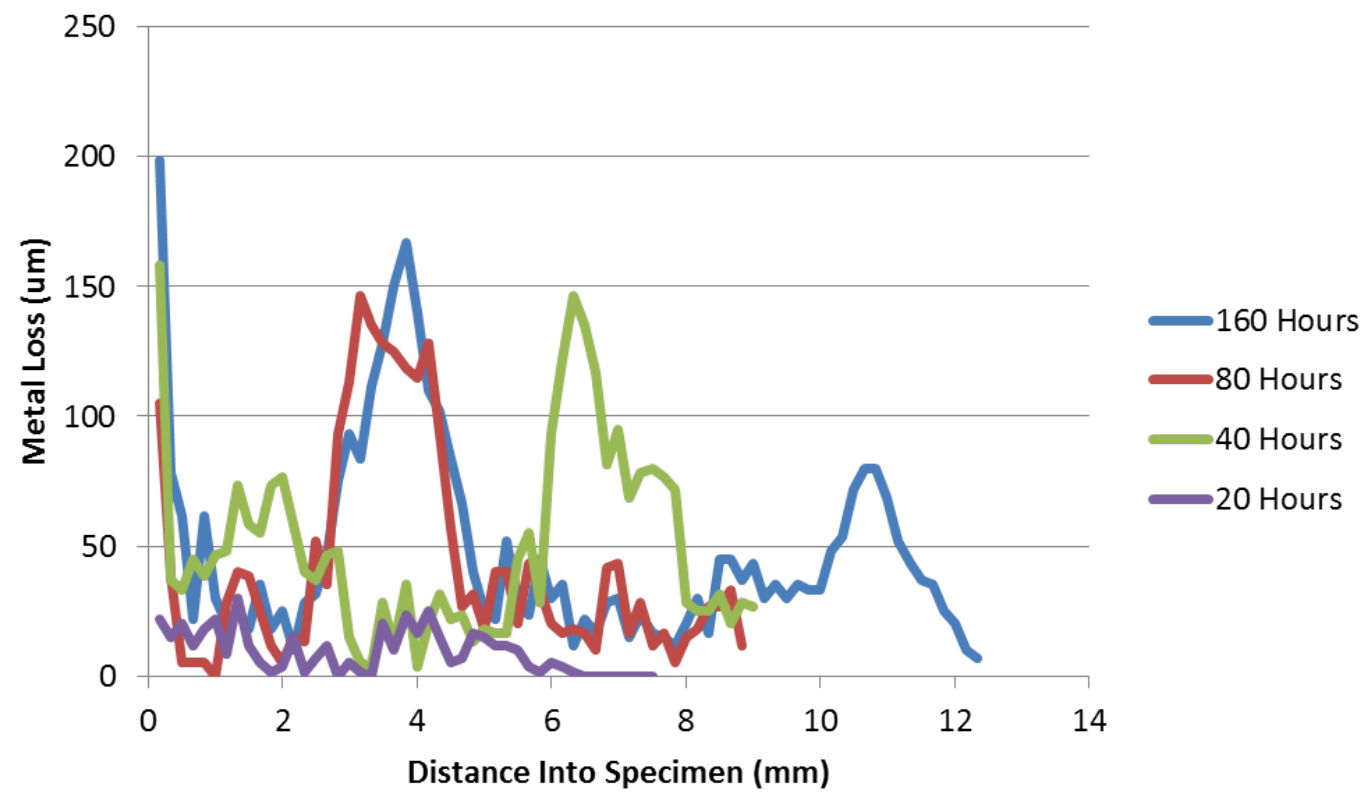

Figure 129: Metal loss with respect to position on the specimen of T92 exposed at $700^{\circ} \mathrm{C}$ with the SCM powder deposit in $\mathrm{O}_{2}+1000 \mathrm{ppm} \mathrm{SO}_{2}$. (Zero distance into specimen marks the position where the specimen is completely buried in the deposit) 


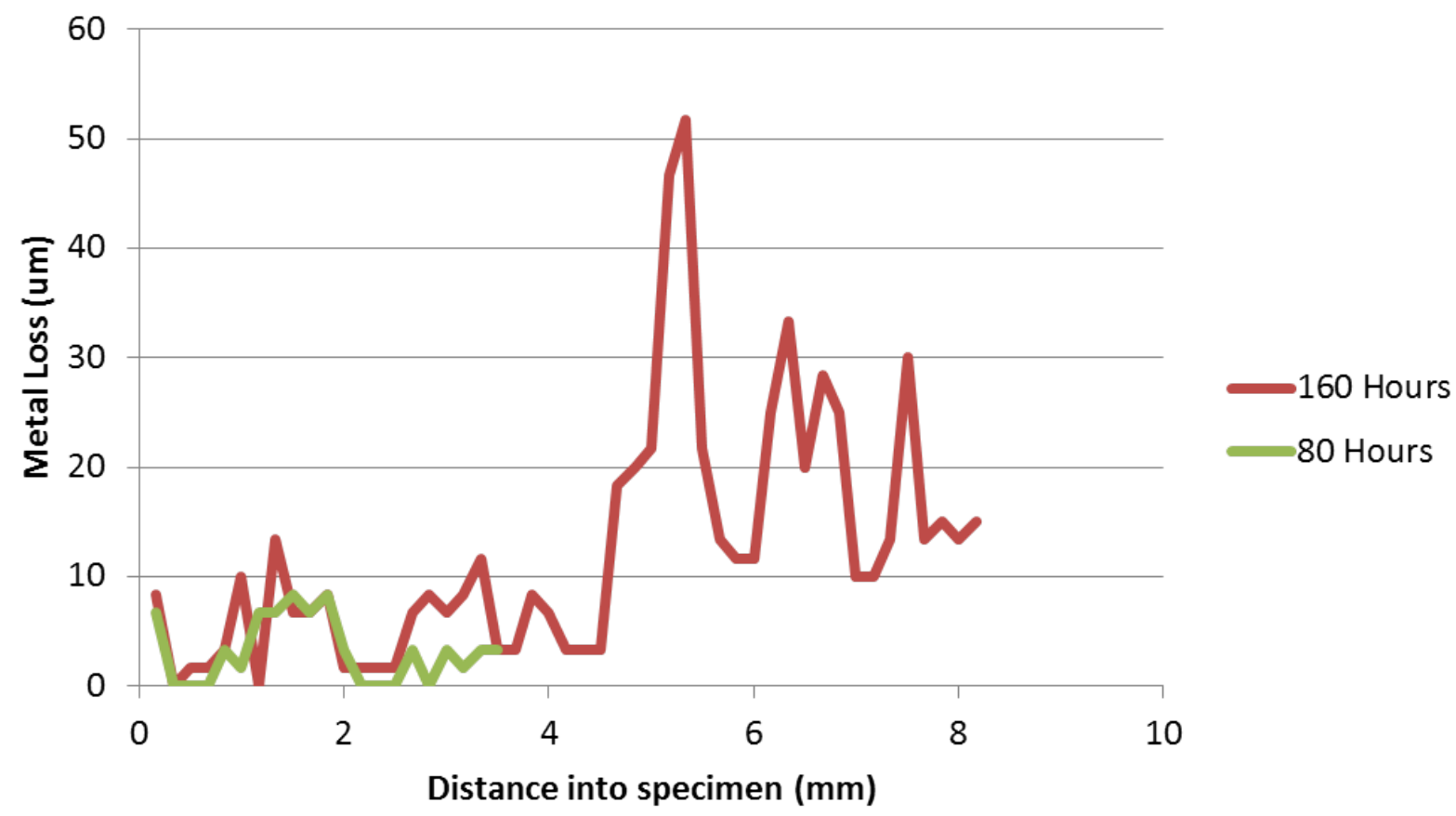

Figure 130: Metal loss with respect to position on the specimen of FeNiCr exposed at $700^{\circ} \mathrm{C}$ with the SCM powder deposit in $\mathrm{O}_{2}+1000 \mathrm{ppm} \mathrm{SO}_{2}$. (Zero distance into specimen marks the position where the specimen is completely buried in the deposit)

The results prove that the corrosion is being initiated in the thin deposit zone, and it migrating to the thicker deposit zone as time increases. For T92, there are some small areas of degradation throughout the deposit zone after 20 hours, but after 40 hours there is an increase in the amount of metal loss in the thin deposit area as there is a large peak in the metal loss plot in this area of the specimen. Then after 80 and 160 hours, this increase in metal loss moves down further into the thick deposit zone as the peak in metal loss shifts further down the specimen. Also after 160 hours, there is degradation further up the specimen displaying that the liquid is migrating up the specimen and causing corrosion. For the FeNiCr alloy, there was minimal to no degradation after 20-40 hours. After 80 hours there were some small areas of metal loss throughout the 
deposit zone, but still minor amounts of degradation. After 160 hours the metal loss peaks are highest in the position on the specimen where the deposit was the thinnest, further proving that the corrosion is being initiated in the thin deposit zone.

Corrosion occurs in boiler tubes where the deposit is the thinnest, due to a corrosion potential gradient from the $\mathrm{SO}_{3}$ migrating through the deposit. In this study, the corrosion most likely starts in the thin deposit zone, because that is the area that $\mathrm{SO}_{3}$ will have quickest access to the specimen and the deposit. The $\mathrm{SO}_{3}$ gas has to migrate through the powder, and it will have quickest access where the deposit first has contact with the specimen, where the deposit is thinnest. Here it can react with $\mathrm{Fe}_{2} \mathrm{O}_{3}$ and the alkali sulfates to form the liquid melt and cause corrosion. It takes the $\mathrm{SO}_{3}$ a longer time to migrate through the powder deposit where the specimen is completely submerged at the base of the crucible. Therefore, it takes longer for corrosion to initiate there. Once it has, the corrosion rate appears to be the same throughout the deposit zone.

\subsubsection{Slurry Method}

Turning the powder deposits into a slurry and coating the specimens allows for a more accurate measure of the effect of deposit thickness on the amount of corrosion. The SCM and M1 deposits were made into slurries for deposition using the process described in the Materials Preparation section. The powder deposit was mixed with deionized water to make the slurry. For the SCM and the deposits containing the M1 and SCM + oxide additions, the specimens were placed onto a hot plate, and the slurry was dropped onto the specimen with a dropper. The water evaporates away leaving the deposit of iron oxide and alkali sulfates remaining on the

specimen. For the M1 deposit, the specimens were heated with a heat gun, and then the slurry 
was sprayed on. Once again, the water evaporates away, leaving the alkali sulfates deposited on the surface. This was repeated until the desired amount of slurry was coated onto the specimens. The slurries were deposited onto specimens of $\mathrm{T} 92$ and FeNiCr in thicknesses of 3mg/ $\mathrm{cm}^{2}$, $10 \mathrm{mg} / \mathrm{cm}^{2}$, and $15 \mathrm{mg} / \mathrm{cm}^{2}$. Once deposited, the specimens were exposed at $700^{\circ} \mathrm{C}$ in $\mathrm{O}_{2}+$ $1000 \mathrm{ppm} \mathrm{SO}_{2}$ for 160 hours. The amount of degradation was measured by metal loss values plotted in Figure 131 compared with the results of the same test using the powder deposit.
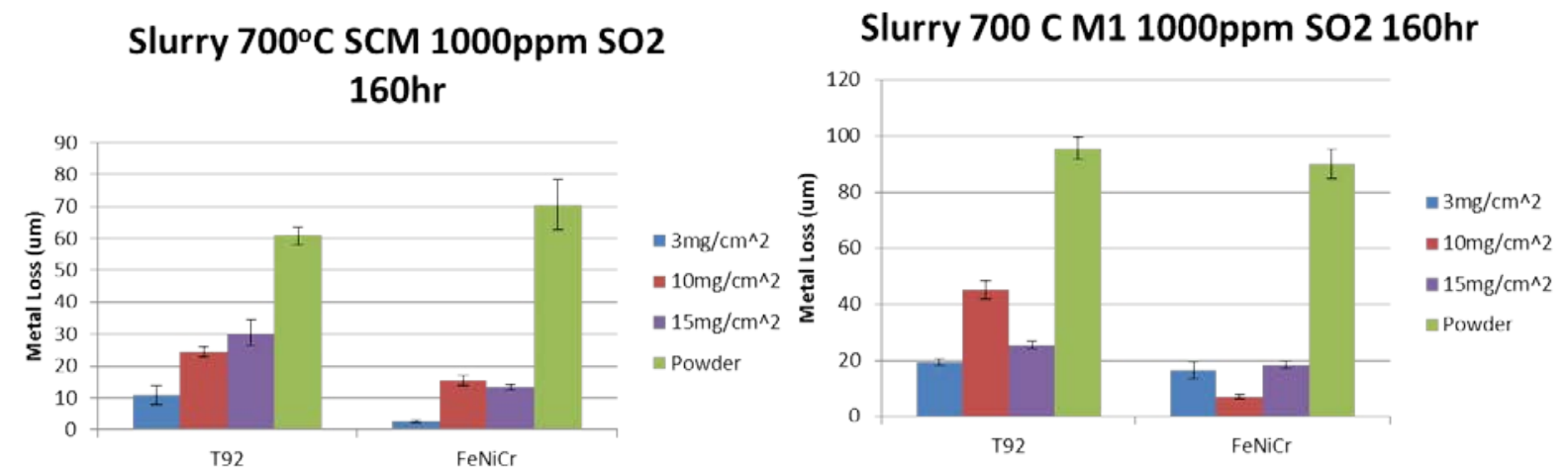

Figure 131: Metal loss of T92 and FeNiCr deposited with varying thicknesses of SCM and M1 slurries exposed at $700^{\circ} \mathrm{C}$ in $\mathrm{O}_{2}+1000 \mathrm{ppm} \mathrm{SO}$ for 160 hours compared with the powder deposit

The amount of corrosion generally increased as the deposit thickness increased. There are more alkali sulfates on the specimen as the deposit thickness increases. Similar results were seen by Kawahara and Kira[91] with the deposition of alkali sulfate deposits on steel alloys used in waste incineration plants. The amount of corrosion is significantly greater using the powder deposit than the slurries. The thin deposit zone suffered corrosion before the thick deposit zone in the powder tests due to the $\mathrm{SO}_{3}$ having easier access to the corrosion front, however as time goes on, the $\mathrm{SO}_{3}$ has access to the corrosion front in both zones and the amount of degradation increases due to a large amount of deposit covering the surface. The amount of degradation 
increases as the deposit thickness increases. This is evident with the results of the slurry tests. This is likely due to the fact that as the deposit thickness increases, the amount of alkali sulfates on the specimen increases. The powder deposit tests could be considered as having a much larger thickness of alkali sulfates available on the surface compared to the slurry tests, so the amount of degradation is much greater. Kawahara and Kira[91] found that submerging specimens in powder deposits was the best means of simulating fireside corrosion due to the corrosion intensity and the stability of the model ash.

The deposits described in the Deposit Composition Effect sections were also made into slurries and deposited on the surface of T92 and FeNiCr specimens in a similar manner as the M1 and SCM deposits. The specimens were coated with $10 \mathrm{mg} / \mathrm{cm}^{2}$ of each deposit. It is difficult to coat the specimen surface so that it is uniformly distributed with the deposit materials with the oxide additions to the deposit. The various oxides $\left(\mathrm{Al}_{2} \mathrm{O}_{3}, \mathrm{CaO}\right.$, and $\left.\mathrm{SiO}_{2}\right)$ are not very soluble in water, whereas the alkali sulfates are. When the slurry was deposited on the surface, the specimens were on a heat plate, which causes the water used in the slurry to evaporate leaving behind the alkali sulfates on the surface. The oxide additions are not water soluble, so they are mixed in with the water and it is difficult to get them evenly distributed on the specimen surface, but each of the deposits was distributed on the surface of the specimens as best as possible for this study. The coated specimens were exposed at $700^{\circ} \mathrm{C}$ in $\mathrm{O}_{2}+1000 \mathrm{ppm}^{\mathrm{SO}} \mathrm{O}_{2}$ for 160 hours. The amount of degradation was characterized by the metal loss and is shown in Figures 132 and 133. This can be compared to the metal loss results of the powder deposits reported in Figures 69 and 70. 


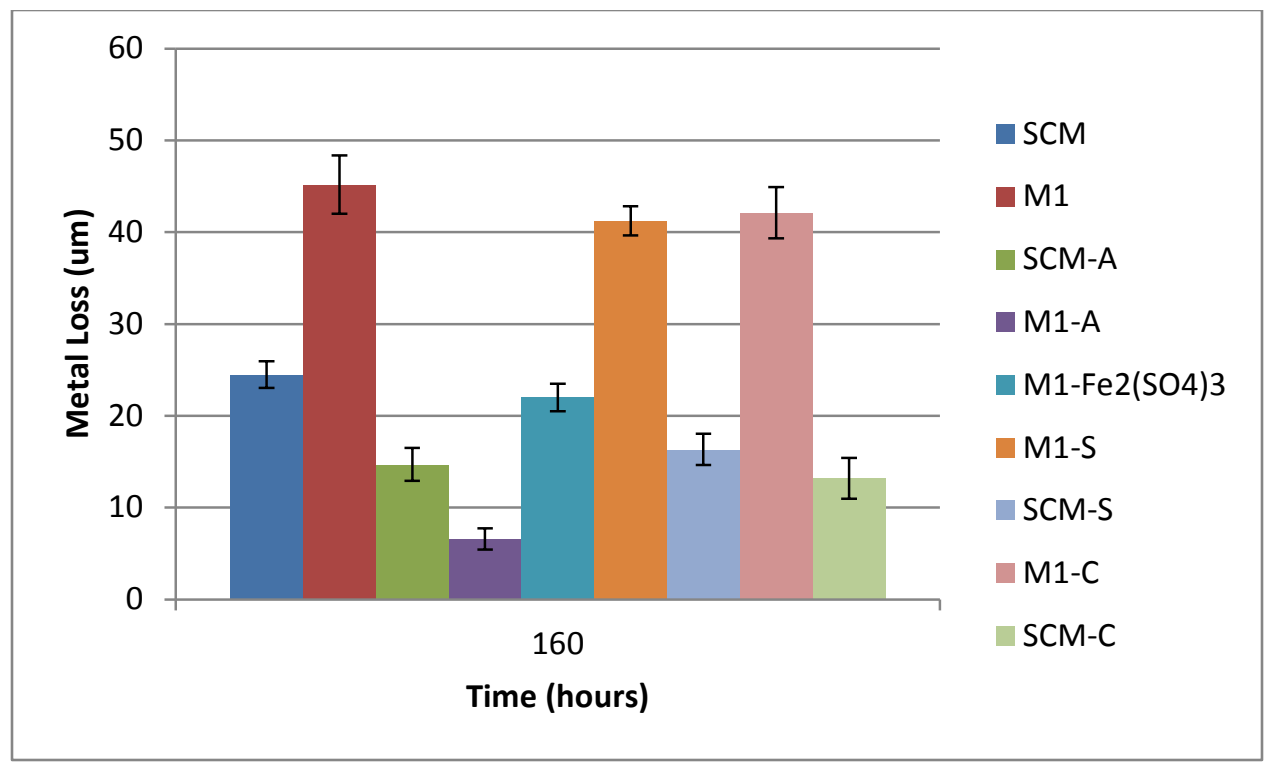

Figure 132: T92 coated with $10 \mathrm{mg} / \mathrm{cm}^{2}$ of various deposit slurries and exposed at $700^{\circ} \mathrm{C}$ in $\mathrm{O}_{2}+1000 \mathrm{ppm} \mathrm{SO}_{2}$ for 160 hours

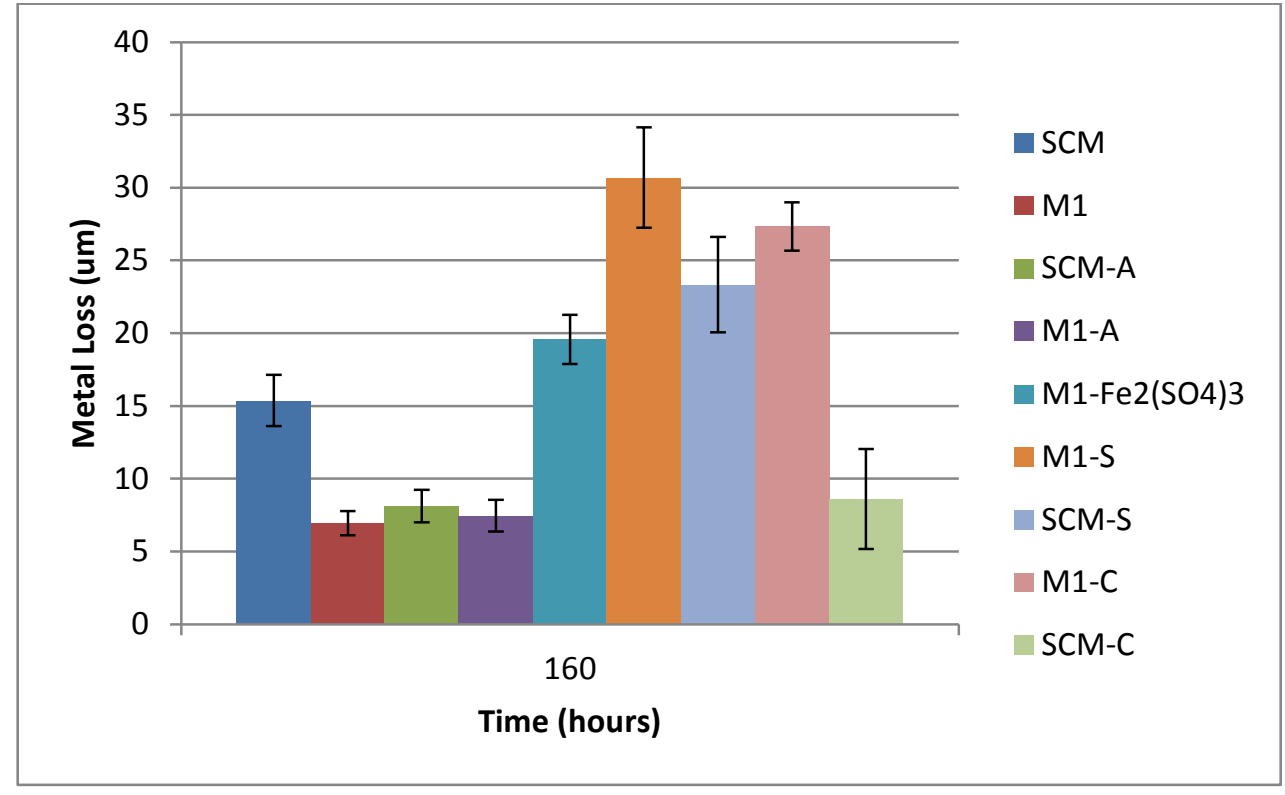

Figure 133: FeNiCr coated with $10 \mathrm{mg} / \mathrm{cm}^{2}$ of various deposit slurries and exposed at $700^{\circ} \mathrm{C}$ in $\mathrm{O}_{2}+1000 \mathrm{ppm}$ $\mathrm{SO}_{2}$ for 160 hours 
The amount of corrosion was generally greater with the powder deposits than with the slurry coatings, but there were some exceptions as the deposits containing silica and calcia performed just as poorly or worse than the powder deposits. The corrosion followed a similar trend with the oxide additions $\left(\mathrm{Fe}_{2} \mathrm{O}_{3}\right.$ and $\left.\mathrm{Al}_{2} \mathrm{O}_{3}\right)$ and their effect on the melt basicity/acidity and synergistic fluxing described in the Deposit Composition sections, however the silica and calcia containing deposits suffered more corrosion than the M1 and SCM deposits and definitely more than would be expected considering the fluxing mechanism described previously. It is unknown why these deposits (silica and calcia containing deposits) behaved this way when deposited with the slurry. The oxides may not have been distributed as evenly across the specimen, meaning that some areas would be more concentrated than others with alkali sulfates, and some areas concentrated with the oxide additions. Where the cross-section was taken and where each of the metal loss values were calculated, may have been in an area where the corrosion was the greatest and where the alkali sulfates were concentrated, creating the observed higher degradation results. 


\subsection{CONCLUSIONS}

The fireside corrosion propagation mechanism was examined by exposing the alloys T92 and a model austenitic Fe-12\%Ni-18\%Cr to short term fireside corrosion tests in gas atmospheres containing $\mathrm{O}_{2}+1000$ ppm $\mathrm{SO}_{2}$ with synthetic deposits containing the alkali sulfates $\mathrm{Na}_{2} \mathrm{SO}_{4}$ and $\mathrm{K}_{2} \mathrm{SO}_{4}$ with various oxide additions. The two deposits used for the mechanism study were M1, which is $\mathrm{Na}_{2} \mathrm{SO}_{4}$ and $\mathrm{K}_{2} \mathrm{SO}_{4}$ in an equimolar ratio, and the standard corrosion mix (SCM), which is $\mathrm{Na}_{2} \mathrm{SO}_{4}: \mathrm{K}_{2} \mathrm{SO}_{4}: \mathrm{Fe}_{2} \mathrm{O}_{3}$ in a $1.5: 1.5: 1.0$ molar ratio. The $\mathrm{M} 1$ deposit was significantly more corrosive than the SCM. Based on the results of these tests, the following conclusions can be made on the mechanisms of fireside corrosion:

- A liquid (K,Na) $)_{2} \mathrm{SO}_{4}-\mathrm{Fe}_{2}\left(\mathrm{SO}_{4}\right)_{3}$ solution is able to form, and alkali iron trisulfates are not needed for fireside corrosion to occur.

- The synergistic dissolution and fluxing of the protective oxides and base metal through the formed liquid melt is the fireside corrosion mechanism. This is similar to what was described by Rapp[57] for Type II hot corrosion.

- The liquid melt causes the dissolution of the protective chromium oxide scale by basic fluxing, which causes a local increase in $\mathrm{SO}_{3}$ and changes the melt so that it is under favorable conditions for acidic fluxing of $\mathrm{Fe}_{2} \mathrm{O}_{3}$, using up the created $\mathrm{SO}_{3}$. This is able to repeat and cause accelerated corrosion. 
- The addition of $\mathrm{Fe}_{2} \mathrm{O}_{3}$ to the alkali sulfates (SCM) changes the local melt basicity of the deposit so that synergistic fluxing does not occur at a maximum rate.

- Fireside corrosion can be considered a more complex form of Type II hot corrosion due to a more complex deposit.

The effects of other oxide additions $\left(\mathrm{Al}_{2} \mathrm{O}_{3}, \mathrm{CaO}\right.$, and $\left.\mathrm{SiO}_{2}\right)$ to the $\mathrm{M} 1$ and SCM deposits were studied in order to examine their effects on the described fireside corrosion mechanism. Each of these individual oxide additions decreased the amount of corrosion. The oxide additions each changed the local melt basicity.

- Alumina is a neutral oxide that can undergo basic or acidic fluxing when reacting with alkali sulfates. In this case, alumina is acting in a basic manner, increasing the local basicity of the melt and slowing the rate of synergistic fluxing.

- $\mathrm{CaO}$ is a highly basic oxide that significantly increases the melt basicity slowing down synergistic fluxing and reducing the amount of degradation.

- $\mathrm{SiO}_{2}$ is a highly acidic oxide and significantly increases the acidity of the melt so that the synergistic fluxing rate would be reduced. The solubility curve for $\mathrm{SiO}_{2}$ is a straight line and does not cross with $\mathrm{Fe}_{2} \mathrm{O}_{3}$ and $\mathrm{Cr}_{2} \mathrm{O}_{3}$, therefore synergistic fluxing is essentially nonexistent.

- Silica and calcia also are able to form higher melting compounds with the alkali sulfates in the deposit, reducing the amount available to form the liquid and cause corrosion.

The effect of the gas atmosphere on the amount of corrosion was also studied. Shi [20] found that around $10^{-4}$ atm of $\mathrm{SO}_{3}$ was needed at $700^{\circ} \mathrm{C}$ for the formation of a $\mathrm{K}_{2} \mathrm{SO}_{4}-\mathrm{Na}_{2} \mathrm{SO}_{4^{-}}$ $\mathrm{Fe}_{2}\left(\mathrm{SO}_{4}\right)_{3}$ deposit. Tests were conducted on $\mathrm{T} 92$ and $\mathrm{FeNiCr}$ at $700^{\circ} \mathrm{C}$ with the SCM in $\mathrm{O}_{2}+$ 
$100,500,1000$, and $2500 \mathrm{ppm} \mathrm{SO}_{2}$ in order to examine the effect of $\mathrm{SO}_{3}$ content on the amount of corrosion. From these tests, the following conclusions can be made:

- Except for the very high psoz gas atmospheres, the degradation is independent of psoz. The rates are therefore controlled by the conditions at the oxide/salt interface established by synergisitic fluxing. Higher $\mathrm{SO}_{3}$ partial pressures accelerate the attack by inducing higher local oxygen partial pressures at the base of the pit since oxygen is transported in the melt by pyrosulfate ions.

- The minimum amount of $\mathrm{SO}_{3}$ in the gas for corrosion to occur was found to be slightly less $\left(7.16 \times 10^{-5} \mathrm{~atm}\right)$, but close to the value of $10^{-4} \mathrm{~atm}$ found by Shi.[20]

Alumina-forming austenitic stainless steels were studied, as they are promising alloys for high temperature applications. Four different AFA alloys were used as part of this study. Their compositions are given in Table 8 . The alloys were tested at $700^{\circ} \mathrm{C}$ with the SCM and M1 deposits in $\mathrm{O}_{2}+1000 \mathrm{ppm} \mathrm{SO}_{2}$. In the SCM:

- OC4 suffered severe spallation and was not protective

- OC8, which contains a higher Cr content remained protective. This alloy is promising, but at longer durations, undesirable sigma phase has been shown to form.

- The OCS and OCT alloys showed a large amount of variability in the results. These alloys are likely borderline alloys for protection.

- Specimens with higher volume fractions of Laves phase and NbC seemed to perform better. Larger amounts of $\mathrm{NbC}$ may mean less $\mathrm{Cr}$ is tied-up into carbides, allowing more chromium to be in the austenite matrix and provide more available to form a protective oxide scale. Larger amounts of Laves phase, $(\mathrm{Fe}, \mathrm{Ni})_{2} \mathrm{Nb}$, means there is less $\mathrm{Nb}$ in the austenite matrix, creating locally more $\mathrm{Cr}$ available to form a protective scale. 
In the M1 deposit:

- Each of the alloys was severely degraded, even the OC8 alloy which performed well with the SCM. The corrosion was independent of alloy composition.

- There was no variability in the OCS and OCT results with the M1 deposit.

- The corrosion mechanism is the same for these alloys as the corrosion mechanism for the Cr-forming alloys, but there is the addition of $\mathrm{Al}$ to the internal corrosion pits and at the base forming sulfides. The solubility curve for alumina is similar to that for chromia, so synergistic fluxing should still occur in a similar manner.

The AFA alloys are really sluggish to reach their equilibrium microstructure at the temperature tested. Specimens of OC8, OCS and OCT were aged and long duration creep tests (5000-7000 hours) were conducted to examine the change in microstructure on the corrosion resistance. Specimens of OC8, OCS, and OCT were aged at $700^{\circ} \mathrm{C}$ for 2350 hours and then retested with the SCM in $\mathrm{O}_{2}+1000 \mathrm{ppm} \mathrm{SO}_{2}$ for 160 hours.

- The OCS and OCT specimens were not degraded.

- The microstructures were still not at the equilibrium $700^{\circ} \mathrm{C}$ microstructure as significant amounts of Laves phase and $\mathrm{NbC}$ as well as $\mathrm{NiAl}$ could be seen, and no sigma phase was found, which could be reasons for the corrosion protection.

- The OC8 alloy was severely degraded as some sigma phase had formed at the grain boundaries. Sigma phase forming at the grain boundaries ties up chromium, preventing faster diffusion to the corrosion front and locally reducing the amount of $\mathrm{Cr}$ available for protection. 
The OC8, OCS, and OCT alloys were also subjected to longer duration creep tests (50007000 hours) and then retested with the SCM in $\mathrm{O}_{2}+1000 \mathrm{ppm} \mathrm{SO}_{2}$ for 160 hours.

- The OC8 alloy contained significant amounts of sigma phase and was severely degraded, likely due to the sigma formation at the grain boundaries.

- The OCS and OCT alloys were once again not degraded, but at the temperature the creep tests were performed, sigma phase would still not be expected to form, further confirming that sigma phase formation in AFA alloys after longer durations (once they reach their low temperature equilibrium microstructure) reduces corrosion resistance.

The maximum amount of corrosion for fireside corrosion follows a bell-shaped curve that has a maximum at a temperature between $650-750^{\circ} \mathrm{C}$ where the salt deposit is expected to be molten. Tests were conducted with T92 and FeNiCr with the SCM in $\mathrm{O}_{2}+1000 \mathrm{ppm} \mathrm{SO}_{2}$ at 650 , 700 , and $750^{\circ} \mathrm{C}$ in order to determine the maximum in the bell-shaped curve under these simulated conditions.

- The maximum was found to be at $700^{\circ} \mathrm{C}$, and having a sharp increase in the amount of corrosion from $650^{\circ} \mathrm{C}$ to $700^{\circ} \mathrm{C}$.

- As temperature decreases, the liquid will not form as rapidly as it would at higher temperatures, as more $\mathrm{Fe}_{2}\left(\mathrm{SO}_{4}\right)_{3}$ will be required to form the liquid.

- As temperature increases, the equilibrium amount of $\mathrm{SO}_{3}$ in the gas decreases, and therefore there is less available to form the liquid melt. The amount of transient oxides will decrease as the protective oxide scales will grow more rapidly. There will be less $\mathrm{Fe}_{2} \mathrm{O}_{3}$ to react with $\mathrm{SO}_{3}$ in the gas atmosphere and form $\mathrm{Fe}_{2}\left(\mathrm{SO}_{4}\right)_{3}$. The solubility curves will have shifted as well. 
- The SCM-A, SCM-C, and SCM-S deposits were tested at the varying temperatures and the maximum was still found to be $700^{\circ} \mathrm{C}$. The oxide additions to the deposit did not shift the bell-shaped curve.

- The bell-shaped curve had shifted and the maximum amount of corrosion was at $650^{\circ} \mathrm{C}$ for the AFA alloys. These alloys performed better at higher temperatures.

The effect of deposit thickness was examined by using two deposition procedures. The powder-crucible method allows the examination of three deposit zones, while the slurry coating method allows for a more precise measurement of the effects of deposit thickness on the amount of corrosion.

- Corrosion was found to be at a maximum in the powder deposits where the deposit was the thinnest on the specimen.

- $\mathrm{SO}_{3}$ migrates through the deposit to the corrosion front, and there is greater aeration and it has quicker access where the deposit is the thinnest.

When the deposits were slurry coated onto the specimens:

- The amount of degradation increased as the amount of deposit increased, however the amount of corrosion was significantly less than when using the powder deposits.

- The powder deposits could be considered a very thick deposit on the surface, continuing the effect of increasing degradation with increasing deposit thickness.

Various oxide additions $\left(\mathrm{Al}_{2} \mathrm{O}_{3}, \mathrm{CaO}\right.$, and $\left.\mathrm{SiO}_{2}\right)$ were added to the $\mathrm{M} 1$ and SCM deposits and made into slurries. They were deposited on specimens so that $10 \mathrm{mg} / \mathrm{cm}^{2}$ was on the surface.

- The amount of corrosion was generally greater with the powder deposits than with the slurry coatings 
- The corrosion followed a similar trend with the oxide additions and their effect on the melt basicity/acidity and synergistic fluxing described in the Deposit Composition sections

- The silica and calcia containing deposits suffered as much or more as the powder deposits, more corrosion than the M1 and SCM deposits, and definitely more than would be expected considering the fluxing mechanism described previously. 


\section{APPENDIX}

\section{OXY-FUEL COMBUSTION ATMOSPHERE}

Oxy-fuel firing is carrying out the combustion in an environment consisting of recirculated flue gases containing primarily $\mathrm{CO}_{2}$, steam and pure oxygen instead of air in order to create a flue gas with minimal amounts of $\mathrm{N}_{2}$. With the reduced amounts of nitrogen, the products of the oxy-fuel combustion process have increased amounts of $\mathrm{CO}_{2}$, steam and corrosive gases, such as $\mathrm{SO}_{2}$ that can cause significant corrosion in superheater and reheater tubes when compared to air-fired combustion. The previous tests were conducted in atmospheres containing varying amounts of $\mathrm{SO}_{2}$ with a balance of oxygen. These will be compared to a more simulative oxy-combustion gas atmsophere. The results and discussion of these exposures are placed in the appendix section due to the fact that many variables are changed when compared to the $\mathrm{O}_{2}+\mathrm{SO}_{2}$ atmospheres used for the rest of the study. This will be explained in more detail in subsequent paragraphs. Tests were conducted on Fe-12\%Ni-18\%Cr and T92 with the SCM deposit for 20, 40, and 160 hours in a gas atmosphere typical of what might occur in a oxy-combustion coal-fired boiler, whose composition given in Table 10 is $60 \% \mathrm{CO}_{2}-25 \% \mathrm{H}_{2} \mathrm{O}-3 \% \mathrm{O}_{2}-0.5 \% \mathrm{SO}_{2}$. The equilibrium $\mathrm{SO}_{3}$ partial pressure $\left(1.51 \times 10^{-3}\right.$ atm $)$ is comparable to the tests completed in the $\mathrm{SO}_{2}$ 
concentration effect section in $\mathrm{O}_{2}+2500 \mathrm{ppm} \mathrm{SO}_{2}\left(1.79 \times 10^{-3} \mathrm{~atm}\right)$, and will allow for the study of the additions of $\mathrm{CO}_{2}$ and $\mathrm{H}_{2} \mathrm{O}$ in the atmosphere. The tests in the oxy-fuel atmosphere were conducted at the Forschungszentrum Juelich in Juelich, Germany.

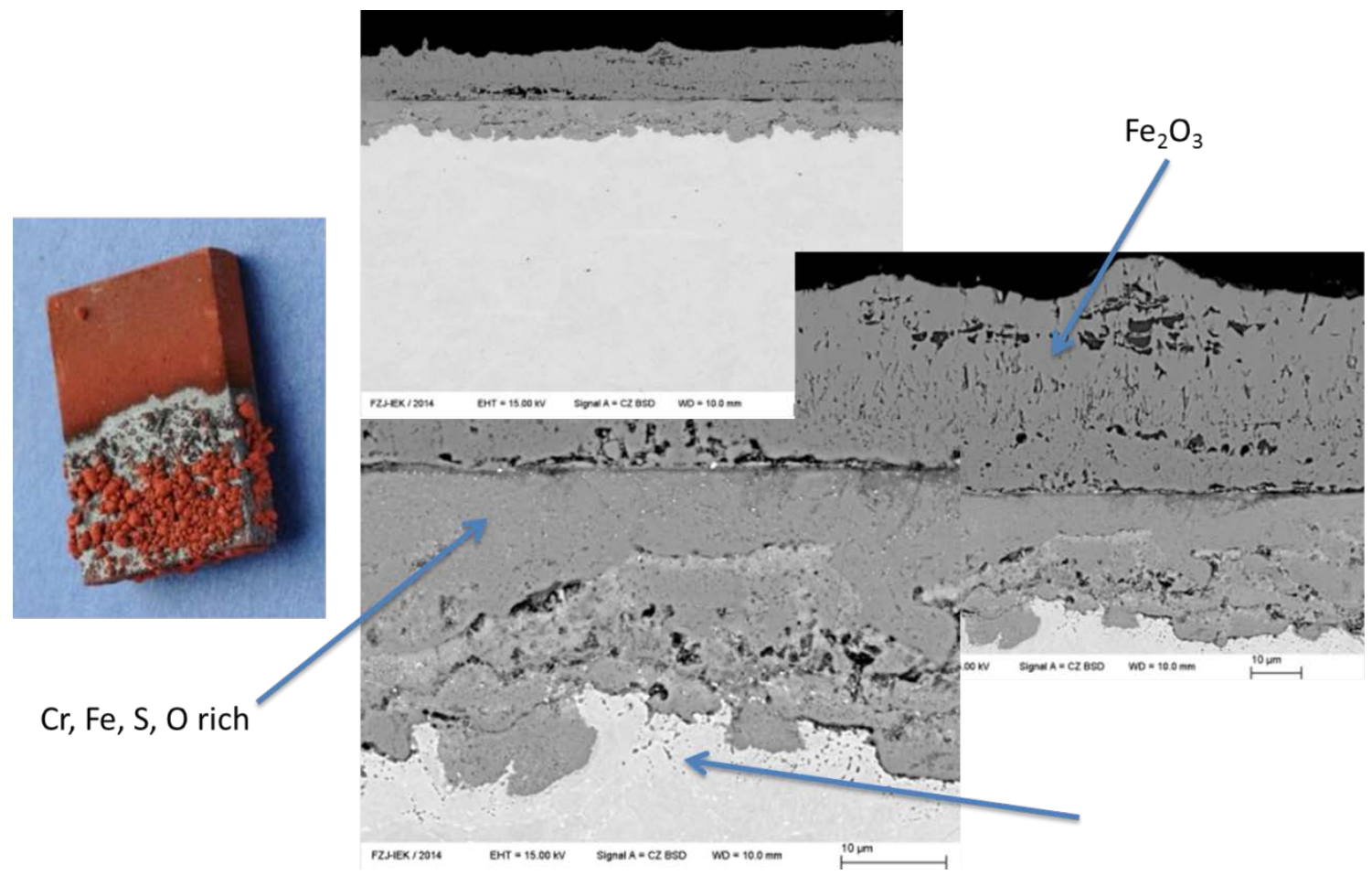

Figure 134: Macroscopic and microscopic images of T92 exposed at $700^{\circ} \mathrm{C}$ in the SCM powder deposit for 20 hours in $60 \% \mathrm{CO}_{2}-25 \% \mathrm{H}_{2} \mathrm{O}-3 \% \mathrm{O}_{2}-0.5 \% \mathrm{SO}_{2}$ 


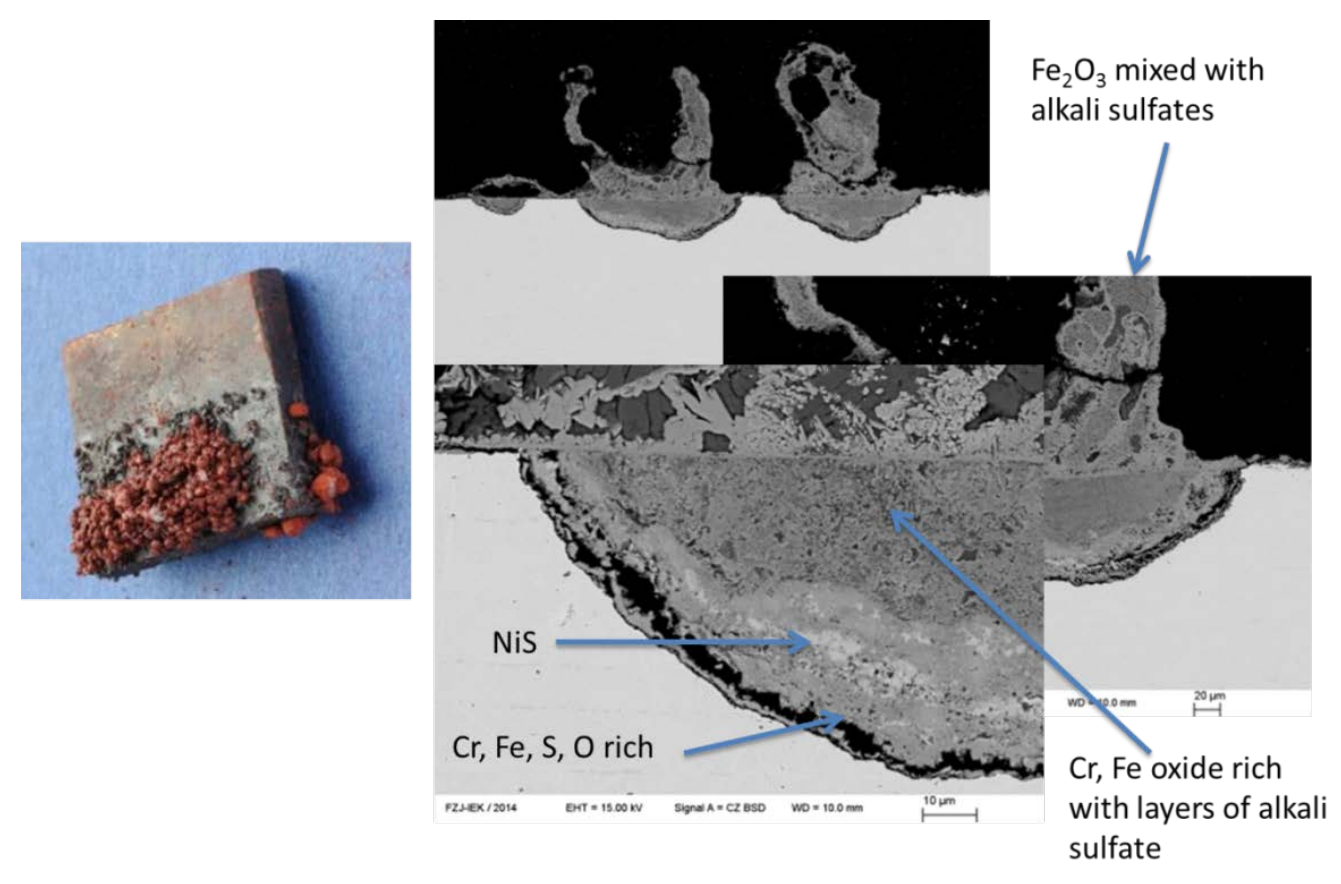

Figure 135: Macroscopic and microscopic images of FeNiCr exposed at $700^{\circ} \mathrm{C}$ in the $\mathrm{SCM}$ powder deposit for 20 hours in $60 \% \mathrm{CO}_{2}-25 \% \mathrm{H}_{2} \mathrm{O}-3 \% \mathrm{O}_{2}-0.5 \% \mathrm{SO}_{2}$

Macroscopic images as well as SEM microscopic cross-sectional images of the results for T92 and FeNiCr after 20 hours in the SCM can be seen in Figures 134 and 135. There was significant amount of pitting and degradation after just 20 hours for each of the alloys. The corrosion products were similar to what was seen in the gas atmosphere containing oxygen and $\mathrm{SO}_{2}$, with thick iron oxide scales forming over top of pits rich in $\mathrm{Cr}, \mathrm{S}$, and $\mathrm{O}$ with sulfides at the base. There did not appear to be any carburization or effect of the excess $\mathrm{CO}_{2}$. Macroscopic results of the specimens tested for 40 and 160 hours are shown in Figure 136. 

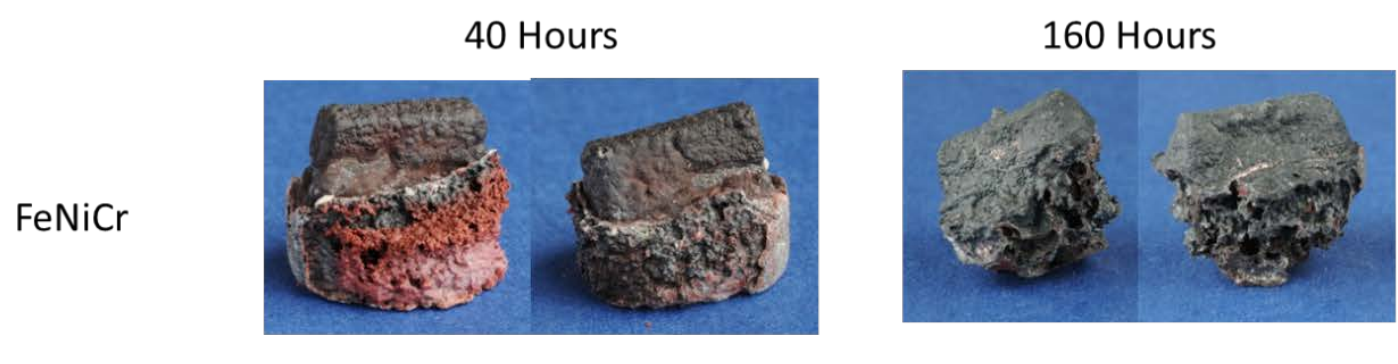

T92
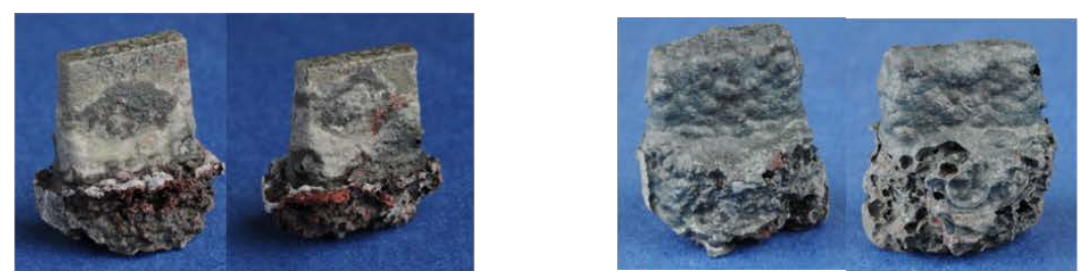

Figure 136: Macroscopic images of FeNiCr and T92 exposed at $700^{\circ} \mathrm{C}$ with the $\mathrm{SCM}$ in powder deposit for 40 and 160 hours in $60 \% \mathrm{CO}_{2}-25 \% \mathrm{H}_{2} \mathrm{O}-3 \% \mathrm{O}_{2}-0.5 \% \mathrm{SO}_{2}$

As time increases, the corrosion is catastrophic and the specimens are destroyed. The deposit is clearly forming a liquid and a significant amount of fluxing of the base metal is evident as thick, porous, non-protective oxide scales can be seen. After 160 hours the specimens had to be broken out of the crucibles as they were stuck as hardened pools of metal in the bottom. Microscopic images as well as metal loss data is not available for these tests right now. They are being completed in Juelich, Germany and will be included in future work for this project. 


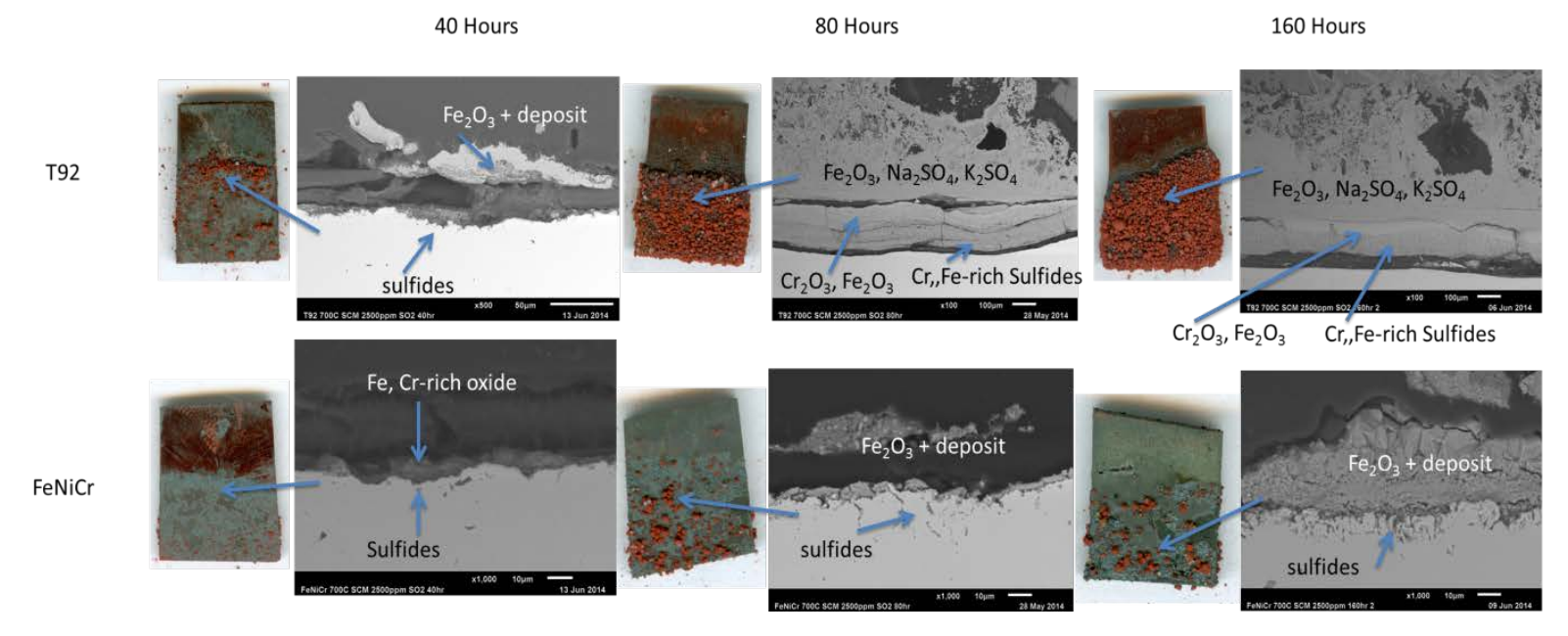

Figure 137: Macroscopic and microscopic images of T92 and FeNiCr exposed at $700^{\circ} \mathrm{C}$ with the SCM powder deposit in $\mathrm{O}_{2}+2500 \mathrm{ppm} \mathrm{SO} \mathrm{S}_{2}$ for 40,80 , and 160 hours

Figure 137 shows the results of the tests in $\mathrm{O}_{2}+2500 \mathrm{ppm} \mathrm{SO}_{2}$ for 40 , 80, and 160 hours. There is a similar equilibrium $\mathrm{SO}_{3}$ partial pressure with this gas atmosphere to the oxy-fuel atmosphere. There is a significant amount of degradation after 80-160 hours with the $\mathrm{O}_{2}+2500$ $\mathrm{SO}_{2}$ atmsophere, but it is not nearly as catastrophic as the oxy-fuel atmosphere after 40-160 hours. Even though metal loss and cross-sectional microscopic images are not available for all of the oxy-fuel tests, it is clearly evident that the amount of degradation is much more significant in the oxy-fuel atmosphere than in an atmosphere containing $\mathrm{SO}_{2}$ with a balance of oxygen. The oxy-fuel gas atmosphere changes many variables when compared to the tests in $\mathrm{O}_{2}+\mathrm{SO}_{2}$. The oxy-fuel gas has $\mathrm{CO}_{2}, \mathrm{H}_{2} \mathrm{O}$, a lower oxygen partial pressure, and a much higher pso2 and therefore higher $\mathrm{p}_{\mathrm{s} 2}$. Each of these may be responsible for the added corrosion. No carburization or effects from carbon were noticed. The addition of water vapor to the atmosphere may be increasing the corrosion. Water vapor added to oxygen containing atmospheres can significantly increase the amount of degradation with Cr-forming alloys as they help in producing volatile oxy-hydroxide $\left(\mathrm{CrO}_{2}(\mathrm{OH})_{2}\right)$ species which results in increased 
oxidation rates and material loss due to evaporation of the $\mathrm{Cr}_{2} \mathrm{O}_{3}$ scale. The disruption of a protective chromium oxide scale due to the formation of oxy-hydroxide species would cause the metal to quickly grow non-protective $\mathrm{Fe}_{2} \mathrm{O}_{3}$ scales which will form the liquid solution and produce rapid degradation. The higher $\mathrm{SO}_{2}$ partial pressures and therefor higher $\mathrm{S}_{2}$ partial pressures may mean that sulfidation/oxidation is being superposed on the effects of the deposit, however the magnitude of the difference in degradation is larger than expected if this were the case. When $\mathrm{SO}_{3}$ and $\mathrm{H}_{2} \mathrm{O}$ are placed into a gas, it can produce liquid $\mathrm{H}_{2} \mathrm{SO}_{4}$ when the temperature decreases. $\mathrm{H}_{2} \mathrm{SO}_{4}$ condensation on furnace components from the shutdown of the previous exposure may have been in contact with the specimens and deposit and could be causing the increased amount of degradation. It is unknown which of the many variables are causing the catastrophic degradation, and more work will need to be conducted to determine this. No comparison between oxy-firing and air-firing can be made, because no tests were completed in an air-fired gas atmosphere. Future work with air-fired tests would be beneficial to make this comparison.

The effect of the gas atmosphere may play a large role in the maximum temperature in the bell-shaped curve. The amount of degradation will increase as the amount of $\mathrm{SO}_{3}$ in the gas atmosphere increases. The amount of $\mathrm{SO}_{3}$ that can form is temperature dependent, with larger amounts able to be formed at lower temperatures. The maximum temperature in the curve will be the maximum temperature in which sufficient amounts of $\mathrm{SO}_{3}$ are able to form the liquid solution, which the minimum amount was found earlier to be close to $10^{-4} \mathrm{~atm}$. As the temperature decreases $\left(650^{\circ} \mathrm{C}\right)$, the amount of $\mathrm{SO}_{3}$ needed would decrease, and as the temperature increases $\left(700^{\circ} \mathrm{C}\right)$, then the amount of $\mathrm{SO}_{3}$ needed would increase. Assuming the amount of $\mathrm{SO}_{3}$ in the gas is sufficient at all of the temperatures, then the previous section showed 
that $700^{\circ} \mathrm{C}$ is the maximum in the corrosion curve. The maximum temperature has also been shown to be greater in oxy-combustion atmospheres compared to conventional air-fired atmospheres.[2,57] The was examined by exposing T92 and FeNiCr with the SCM powder deposit at $650^{\circ} \mathrm{C}, 700^{\circ} \mathrm{C}$, and $750^{\circ} \mathrm{C}$ in the oxy-combustion gas used previously and given in Table 10. This was also performed at the Forschungszentrum Juelich in Juelich, Germany, and the results of these tests were not available in time to be included in this thesis. The analysis would need to be done in future work for this project. 


\section{BIBLIOGRAPHY}

1. Stein-Brzozowska, G., Maier, J., Scheffknecht, G., Impact of Oxy-Fuel Combustion on the Corrosion Behavior of Advanced Austenitic Superheater Materials. Energy Procedia, 2011. 4: p. 2035-2042.

2. Syed, A.U., Simms, N.J., Oakey, J.E., Fireside Corrosion of Superheaters: Effects of air and oxy-firing of coal and biomass. Fuel 2012. 101: p. 62-73.

3. Stringer, J., Wright, I.G., Current Limitations of High-Temperatures Alloys in Practical Applications. Oxidation of Metals, 1995. 44: p. 265-308.

4. Gagliano, M.S., Hack, H., Stanko, G., Fireside Corrosion Resistance of Proposed USC Superheater and Reheater Materials: Laboratory and Field Test Results. Presented at the 33th International Technical Conference on Coal Utilization and Fuel Systems, 2008.

5. Brady, M.P., Magee, J., Yamamoto, Y., Helmick, D., and Wang, L., Co-Optimization of Alumina-Forming Austenitic Stainless Steel Composition Ranges for High-Temperature Creep and Oxidation/Corrosion Resistance. Manuscript to be submitted to Materials Science and Engineering A or Materials and Design.

6. Reid, W.T., Cohen, P. Trans. ASME, 1944. 66: p. 685.

7. $\quad$ Ely, F.G., Schueler, L.B., Furn. Perf. Factors Suppl. To Trans. ASME, 1944. 66: p. 23.

8. $\quad$ Bishop, R.J., J. Inst. Fuel, 1968. 41: p. 51-65.

9. Simms, N.J., Kilgallon, P.J., Oakey, J. E., Fireside Issues in Advanced Power Generation Systems. Energy Materials, 2007. 2: p. 154-160.

10. Otsuka, N., Effects of fuel impurities on fireside corrosion of boiler tubes in advanced power generating systems - a thermodynamic calculation of deposit chemistry. Corrosion Science, 2002. 44: p. 265-283.

11. Srivastava, S.C., Godiwalla, K.M., Banerjee, M.K., Fuel Ash Corrosion of Boiler and Superheater Tubes. Journal of Materials Science, 1997. 32: p. 835-849.

12. Yan, L., Gupta, R.P., Wall, T.F., A Mathematical Model of Ash Formation During Pulverized Coal Combustion. Fuel, 2002. 81: p. 337-344. 
13. Tomeczek, J., Palugniok, H., Kinetics of Mineral Matter Transformation During Coal Combustion. Fuel, 2002. 81: p. 1251-1258.

14. Nelson, H.W. et al., A Review of Available Information on Corrosion and Deposits in Coal- and Oil-Fired Boilers and Gas Turbines. ASME, 1959. p. 7-12.

15. Reid, W.T., External Corrosion and Deposits Boilers and Gas Turbines. 1971, New York: American Elsevier Publishing Company, Inc.

16. Gluskoter, H.J., Mineral Matter and Trace Elements in Coal. American Chemical Society, 1975.

17. Huffman, G.P. and Huggins, F.E., Reactions and Transformations of Coal Mineral Matter at Elevated Temperatures. U.S. Steel Corporation Technical Center, Monroeville, PA. The American Chemical Society, Vol. 188. No. 1155, 1984.

18 Smith, E.J.D., J. Inst. Fuel, 1956. 29: p. 253.

19. Natesan, K., Purohit, A., Rink, D.L., Fireside Corrosion of Alloys for Combustion Plants. Proc. 16th Annual Conference on Fossil Energy Materials, Baltimore, MD, April 22-24, 2002.

20. Hack, H., Stanko, G., Experimental Results for Fireside Corrosion Resistance of Advanced Materials in Ultra-Supercritical Coal-Fired Power Plants. Presented at the 32nd International Technical Conference on Coal Utilization \& Fuel Systems, 2007.

21. Goebel, J.A., Pettit, F.S., Goward, G.W., Mechanisms for the Hot Corrosion of NickelBase Alloys. Metallurgical Transactions, 1973. 4: p. 261-278.

22. Goebel, J.A., Pettit, F.S., $\mathrm{Na}_{2} \mathrm{SO}_{4}$-Induced Accelerated Oxidation (Hot Corrosion) of Nickel. Metallurgical Transactions, 1970. 1: p. 1943-1955.

23. Levy, A., Merryman, E.L., Reid, W.T., Mechanisms of Formation of Sulfur Oxides in Combustion. Environmental Science and Technology, 1970. 4: No. 8 p. 653-662.

24. Dooley, A., Whittingham, G., Trans. Faraday Soc., 1942. 42: p.354.

25. Levy, A., Merryman, E.L., Combus. Flame, 1965. 9: p. 229.

26. Harlow, W.F., Causes of High Dewpoint Temperatures in Boiler Flue Gases. Proceedings of the Institution of Mechanical Engineers, 1944. 151: p. 293.

27. Fleig, D. et. al, Measurement and Modeling of Sulfur Trioxide Formation in a Flow Reactor Under Post-Flame Conditions. Combustion and Flame, 2013. 160: p. 11421151.

28. $\quad$ Kung, S.C., Fireside Corrosion in Oxy and Air-Firing Combustion Environments. IEAGHG Oxy Combustion Workshop, January 26, 2011. 
29. Kung, S.C., Measurement of Corrosive Gaseous Species from Staged Coal Combustion. DOE 25 ${ }^{\text {th }}$ Annual Conference on Fossil Energy Materials, April 27, 2011.

30. Cain Jr., C., Nelson, W., Trans. ASME, J. Eng. Power, 1967. 83 Series A: p. 468.

31. Corey, R.C., Cross, B.J., Reid, W.T., Trans. ASME, 1945. 67: p. 289.

32. Levy, A., Merryman, E.L., Trans. ASME, J. Eng. Power, 1967. 89 Series A: p. 297.

33. Coats, A.W., Dear, D.J.A., Penfold, D., J. Inst. Fuel, 1968. 41: p. 129.

34. Blough, J.L., Fireside Corrosion Testing of Candidate Superheater Tube Alloys, Coatings, and Claddings - Phase II Field Testing. Foster Wheeler Topical Report for Oak Ridge national Laboratory, 1996.

35. Birks, N., Meier, G.H., Pettit, F.S., Introduction to the High Temperature Oxidation of Metals. 2 ed2006, New York: Cambridge University Press.

36. Burrows, B.W., Hills, G.J., J. Inst. Fuel, 1966. 39: p. 168.

37. MOZA, A.K., SHOJ, K. and AUSTIN, L.G., J. Inst. Fuel 53 (1980) 17

38. Cain Jr., C., Nelson, W., Trans. ASME, J. Eng. Power, 1961. 83 Series A: p. 468.

39. Luthra, K.L., High Temperature Hot Corrosion of Cobalt-Base Alloys: Part II. Reaction Mechansim. Metallurgical Transactions A, 1982. 13: p. 1853-1864.

40. Corey, R.C., Grabowski, H.A., Cross, B.J., Trans. ASME, 1949. 71: p. 951.

41. Shi, L., Zhang, Y., Shih, S., The Effect of $\mathrm{K}_{2} \mathrm{SO}_{4}$ Additive in $\mathrm{Na}_{2} \mathrm{SO}_{4}$ Deposits on Low Temperature Hot Corrosion of Iron-Aluminum Alloys. Oxidation of Metals, 1992. 33: p. 385-405.

42. Viswanathan, R., Henry, J.F., Tanzosh, J., Stanko, G., Shingledecker, J., Vitalis, B., Purgert, R., U.S. Program on Materials Technology for Ultra-Supercritical Coal Power Plants. Journal of Materials Engineering and Performance, 2005. 14: p. 281-292.

43. Chi, C., Yu, H., Xie, X., Advanced Austenitic Heat-Resistant Steels for UltraSupercritical (USC) Fossil Power Plants. Alloy Steel - Properties and Use. p. 171-200.

44. Yamamoto, Y. et al., Creep-Resistant $\mathrm{Al}_{2} \mathrm{O}_{3}$-Forming Austenitic Stainless Steels. Science, 2007. 316: p. 433.

45. Yamamoto, Y., Santella, M.L., Brady, M.P., Bei, H. and Maziasz, P.J., Effect of Alloying Additions on Phase Equilibria and Creep Resistance of Alumina-Forming Austenitic Stainless Steels. Metallurgical and Materials Transactions A, 2009. 40: p. 1868-1880. 
46. Brady, M.P., Yamamoto, Y., Santella, M.L., Maziasz, P.J., Pint, B.A., Liu, C.T., Lu, Z.P., and Bei, H., The Development of Alumina-Forming Austenitic Stainless Steels for High Temperature Structural Use. JOM, 2008. Vol. 60, 7: p. 12-18.

47. Yamamoto, Y., Brady, M.P., Lu, Z.P., Liu, C.T., Takeyama, M., Maziasz, P.J., and Pint, B.A., Alumina-Forming Austenitic Stainless Steels Strengthened by Laves Phase and MC Carbide Precipitates. Metallurgical and Materials Transactions A, 2007. 38: p.27372746.

48. Brady, M.P., Yamamoto, Y., Santella, M.L., Walker, L.R., Composition, Microstructure, and Water Vapor Effects on Internal/External Oxidation of Alumina-Forming Austenitic Stainless Steels. Oxidation of Metals, 2009. 72: p. 311-333.

49. Brady, M.P., Yamamoto, Y., Santella, M.L., and Pint, B.A., The Effects of Minor Alloy Additions and Oxidation Temperature on Protective Alumina Scale Formation in CreepResistant Austenitic Stainless Steels. Scripta Materialia, 2007. Vol. 57, 12: p. 11171120.

50. Yamamoto, Y., Takeyama, M., Lu, Z.P., Liu, C.T., Evan, N.D., Maziasz, P.J., and Brady, M.P., Alloying Effects on Creep and Oxidation Resistance of Austenitic Stainless Steel Alloys Employing Intermetallic Precipitates. Intermetallics, 2008. 16(3): p. 453-462.

51. Yamamoto, Y., Muralidharan, G., Brady, M.P., Recent Developments in Creep-Resistant, Alumina-Forming Austenitic Stainless Steels. Materials in Clean Power Systems VIII: Durability of Materials, in TMS 2013. San Antonio Texas March 3-7, 2013.

52. Brady, M.P., Magee, J.H., Yamamoto, Y., Maziasz, P.J., Santella, M.L., Pint, B.A., and Bei, H., Development and Exploratory Scale-Up of Alumina-Forming Austenitic (AFA) Stainless Steels. Proceedings of Stainless Steel World 2009 Conference \& Expo, Maastricht, The Netherlands, November 10-12, 2009, Stainless Steel World, The Netherlands, 2009.

53. Brady, M.P., Magee, J., Yamamoto, Y., Helmick, D., Wang, L., Co-optimization of wrought alumina-forming austenitic stainless steel composition ranges for hightemperature creep and oxidation/corrosion resistance. Materials Science and Engineering: A, Volume 590, 10 January 2014, Pages 101-115

54. Yamamoto, Y., Muralidharan, G., Brady, M.P.,. Scripta Materialia, 2013. 69 (11), p. 816819

55. Latham, E.P., Flatley, T., Morris, C.W., Corrosion Resistant Materials for Coal Conversion Systems. Applied Science Publishers. London, 1983. p. 137-158.

56. Natesan, K. and Zeng, Z., Coal Ash Effects in the Corrosion Performance of Structural Alloys in Simulated Oxy-Fuel Environments. 27 ${ }^{\text {th }}$ Annual Conference on Fossil Energy Materials, Pittsbugh, PA. June 18-20, 2013. 
57. Hussain, T., Syed, A.U., Simms, N.J., Trends in Fireside Corrosion Damage to Superheaters in Air and Oxy-Firing of Coal/Biomass. Fuel, 2013. 113: p. 787-797.

58. Kung, S.C., Comparison of Coal Ash Corrosion Corrosion Resistance of Alloys Exposed to Advanced Air-Coal and Oxy-Coal Combustion Environments. Babcock and Wilcox Power Generation Group. Presented to the $7^{\text {th }}$ International Conference on Advances in Material Technology for Fossil Power Plants, Waikoloa, HI. October 22-25 2013.

59. McCreath, C.G., Hot Corrosion Site Environment in Gas Turbines. Mater. Sci. and Technol., 1987. 3: p. 494-500.

60. Bornstein N.S., A., W.P., The Chemistry of Sulfidation Corrosion-Revisited. Mater. Sci. Forum, 1997. 127: p. 127-134.

61. Luthra, K.L., Low Temperature Hot Corrosion of Cobalt-Base Alloys: Part I. Morphology of the Reaction Product. Metallurgical Transactions A, 1982. 13: p. 18431852.

62. Giggins, C.S., Pettit, F.S., Hot Corrosion Degradation of Metals and Alloys - A Unified Theory, Scientific Report for Pratt and Whitney, 1979.

63. Deodeshmukh, V., Gleeson, B. Environmental and Compositional Effects on the Hot-Corrosion Behavior of Ni-Based Alloys and Coatings. Corrosion 2008.

New Orleans, LA: NACE International.

64. Inman, D., Wrench, N.S., Corrosion in Fused Salts. Brit. Corros. J., 1966, 1: p. 246-250.

65. Rapp, R.A., Chemistry and Electrochemistry of the Hot Corrosion of Metals. Corrosion, 1986. 42: p. 568-577.

66. Gupta, D.K., Rapp, R.A., The Solubilities of NiO, Co3O4, and Ternary Oxides in Fused Na2SO4 at $1200^{\circ}$ K. J. Electrochem. Soc., 1980. 127: p. 2194-2202.

67. Jose, P.D., Gupta, D.K., Rapp, R.A., The Solubility of $\alpha$-Al2O3 in Fused Na2SO4 at $1200^{\circ} \mathrm{K}$. J. Electrochem. Soc., 1985. 132: p. 735-737.

68. Shi, D.Z., Rapp, R.A. , The Solubility of SiO2 in Fused Na2SO4 at $900^{\circ} \mathrm{C}$. J. Electrochem. Soc., 1986. 133: p. 849-580.

69. Deanhardt, M.L., Stern, K.H., Solubility Products of Metal Oxides in Molten Salts by Coulometric Titration of Oxide Ion Through Zirconia Electrodes. J.

Electrochem. Soc., 1982. 128: p. 2577-2582.

70. Rapp, R.A., Ostuka, N., The Role of Chromium on the Hot Corrosion of Metals. ECS Transactions, 2009. 16(49): p. 271-282.

71. Zhang, Z.S., Solubilities of Cr2O3 in Fused Na2SO4 at 1200K. J. Electrochem. Soc., 1986. 133: p. 655-657. 
72. Zhang, Z.S., Rapp R.A., Solubility of $\alpha-F e 2 O 3$ in Fused Na2SO4 at 1200K. J. Electrochem. Soc., 1985. 132: p. 734-735.

73. Rapp, R.A., Goto, K.S., The Hot Corrosion of Metals by Molten Salts. The Second International Symposium on Molten Salts, 1981.

74. Goebel, J.A., Pettit, F.S., The Influence of Sulfides on the Oxidation Behavior of NickelBase Alloys. Metallurgical Transactions, 1970. 1: p. 3421-3429.

75. Luthra, K.L., Shores, D.A., Mechanism of Na2SO4 Induced Corrosion at $600^{\circ}$ $900^{\circ}$ C. J. Electrochem. Soc., 1980. 127: p. 2202-2210.

76. Wortman, D.J., Fryxell, R.E., Luthra, K.L., Bergman, P.A., Mechanism of LowTemperature Hot Corrosion: Burner Rig Studies. Thin Solid Films, 1979. 64: p. 281-288.

77. Barkalow, R.H., Goward, G.W., Microstructural Features of Low Temperature Hot Corrosion in Nickel and Cobalt Base MCrAlY Coating Alloys. R.A. Rapp, Editor 1983, National Society of Corrosion Engineers: Houston. p. 502-506.

78. Chiang, K.T., Pettit, F.S., Meier, G.H., Low Temperature Hot Corrosion. R.A. Rapp, Editor 1983, National Society of Corrosion Engineers: Houston. p. 519-530.

79. Jones, R.L., Cobalt Oxide- $\mathrm{SO}_{2} / \mathrm{SO}_{3}$ Reactions in Cobalt-Sodium Mixed Sulfate Formation and Low Temperature Hot Corrosion. R.A. Rapp, Editor 1983, National Society of Corrosion Engineers: Houston. p. 513-518.

80. Hwang, Y.S. and Rapp, R.A., Synergistic Dissolution of Oxides in Molten Sodium Sulfate. Journal of the Electrochemical Society vol. 137, No. 4. April, 1990.

81. Niles, W.D., Siegmund, C.W., The Mechanism of Corrosion by Fuel Impurities, Butterworths, London, 1963. p. 332-346.

82. Corrosion of metals and alloys-methods for metallographic examination of samples after exposure to high temperature corrosive environments. In: Draft ISO Standard. ISO/TC 156 NWI 5092005; 2006.

83. Rahmel, A. and Jaeger, W., Z. Anorg. Chem. 303, 90 (1960)

84. Leblanc, P.P., and Rapp, R.A., Solubilities of $\mathrm{Cr}_{2} \mathrm{O}_{3}$ and $\mathrm{SiO}_{2}$ in $\mathrm{Na}_{2} \mathrm{SO}_{4}-\mathrm{K}_{2} \mathrm{SO}_{4}$ $\mathrm{Fe}_{2}\left(\mathrm{SO}_{4}\right)_{3}$ at 963K. J. Electrochemical Soc., Vol. 140, No. 3, March 1993.

85. Andresen, R.E., J. Electrochem. Soc., 1979, vol. 126, pp. 328-34.

86. Jacobson, N.S., Sodium Sulfate: Deposition and Dissolution of Silica. Oxiation of Metals, 1989. vol. 31, No.1/2 pp. 91-103. 
87. Yamamoto, Y., Muralidharan, G., and Brady, M.P., Private Correspondence, May 2013.

88. Garcia-Fresnillo, L., Chyrkin, A., Boehme, C., Barnikel, J., Schmitz, and F., Quadakkers, W.J., Oxidation Behaviour and Microstructural Stability of Alloy 625 During Long-Term Exposure in Steam. J. of Materials Science, 2014. 49, pp. 6127-6142.

89. Asensio, C., Chyrkin, A., Niewolak, L., Konoval, V., Hattenforf, H., Kuhn, B., Singheiser, L., and Quadakkers, W.J., Subsurface Depletion and Enrichment Processes During Oxidation of a High-Chromium, Laves Phase Strengthened Ferritic Steel. Electrochemical and Solid State Letters, 14, pp. 17-20, 2011.

90. Yanar, N.M., Lutz, B.S., Brady, M.P., and Meier, G.H., The Effects of Water Vapor on the Oxidation Behavior of Alumina-Forming Austenitic Stainless Steels. Submitted to Oxidation of Metals.

91. Kawahara, Y. and Kira, M. Effect of Physical Properties of Molten Deposits on HighTemperature Corrosion of Alloys in a Waste Incinerator Environment. Corrosion Engineering, 46, pp. 13-26, 1997. 